The Theoretical Construction and Measurement of Writing Self-Efficacy

\author{
Kim M. Mitchell \\ A thesis submitted to the Faculty of Graduate Studies of \\ The University of Manitoba \\ In partial fulfillment of the requirements for the degree of \\ Doctor of Philosophy \\ College of Nursing, Rady Faculty of Health Sciences \\ University of Manitoba
}

Copyright (C) 2020 by Kim M. Mitchell 


\begin{abstract}
Background: Writing is a pedagogical strategy that facilitates critical thinking, identity development, and ways of knowing. Existing writing self-efficacy instruments have focused on assessing writing selfefficacy through examining mechanical and process features of writing, to the neglect of the situated context and its influence. Nurses in Baccalaureate programs benefit from writing to understand nursing concepts, discourses, and ways of being in a health care environment; however, nursing as a discipline continues to embrace outdated objectivist perspectives on writing that privilege surface textual products over how the writer grows from the process.
\end{abstract}

Purpose: The purpose of this thesis was to theoretically construct the concept of writing self-efficacy from a cognitive and socially constructed perspective and then measure writing self-efficacy from within the discipline of nursing. The initial phase required exploring the epistemological compatibility of selfefficacy theory and social constructionism. The culmination of this work was a multiphase multimethod project to develop and test the Situated Academic Writing Self-Efficacy Scale (SAWSES) based on Bandura’s self-efficacy theory and a model of socially constructed writing. A paper-based thesis is presented within which explores five areas of this project in depth: 1) Tracing how writing has been discussed in nursing education and identifying the domains of social and situated perspectives on writing that are applicable to nursing; 2) An exploration of the social turn in writing theory and its uptake in research and theory on writing self-efficacy; 3) A pragmatic discussion of the Delphi method for tool development research; 4) An analysis of interviews conducted with 20 nursing students about the influence of the context of nursing education on their writing self-efficacy; 5) The development and validation of the SAWSES.

Methods: The items were developed and revised through engagement with the literature. Four independent sample studies formed the tool editing and validation process. Tool editing occurred through two processes: 1) A Delphi panel consisting of 7 nursing and 8 writing scholars; 2) Cognitive interviews with 20 undergraduate students. Study validation required two sample recruitments. Study 1 
piloted a 20-item instrument with 255 nursing students. Exploratory factor analysis and a structural equation model for hypothesis testing were developed to test construct validity. Concurrent validity was assessed by comparing the new tool with established tools. To enhance generalizability, Study 2 tested the 3-factor structure established in Study 1 with an interdisciplinary sample of undergraduate $(\mathrm{N}=543)$ and graduate students $(\mathrm{N}=264)$ using multi-group confirmatory factor analysis.

Results: The Delphi and cognitive interview studies reduced the initial 41 items developed to 20 items. During the cognitive interviews, the students described a rigid writing environment that required them to “codeswitch” their identities and behaviours based on teacher preferences, as well as their own motivations and valuing of the writing. During Study 1, Exploratory factor analysis reduced the scale to 16 items and established scale structure as represented by three factors 1) Writing essentials (3 items); 2) Relational reflective (8 items), and; 3) Creative identity (5 items). Structural equation model procedures identified that writing apprehension and supportive environment were the strongest predictors of SAWSES. Study 2 confirmed the factor structure identified in Study 1 and detected no meaningful statistical differences in the response to items between the samples of interdisciplinary undergraduate and graduate students. Additional analysis and comparison between the three samples detected possible developmental features within the three factors.

Conclusions: Findings from these studies support reliability and validity for SAWSES. SAWSES will offer educators a validated tool to research student writing self-efficacy, stimulate student reflection on writing and significantly inform writing pedagogy. The three identified factors present a structure to the questionnaire which is developmental and has the potential to detect gaps in student self-assessed ability to master various facets of disciplinary writing: 1) writing essentials (synthesis, emotional control, language); 2) relationship building with writing facilitators (teachers, the writing of authors in their sources) and the self through reflection; and 3) explore gaps in student achievement of transformative writing (creativity, voice, and disciplinary identity), where confidence can help identify the most engaged writers. 


\section{Acknowledgements}

While only one name appears on the cover of this thesis, the work is never a solo effort. There are many who contribute to the journey, some by assignment and some who give their time selflessly and unsolicited. With much gratitude to my committee, Dr. Diana McMillan (advisor), Dr. Michelle Lobchuk (internal member), and Dr. Nathan Nickel (external member), I am grateful for many things but what I am most grateful for is your collective willingness to be open to (and sometimes put up with) my need to push boundaries.

Dr. Johnson Li from the Department of Psychology, who in many ways, is an honorary fourth committee member as he also acted as my external reviewer on the initial study proposal. Dr. Li introduced me to R and set me on a statistical journey I was not anticipating when I entered this program. He graciously and voluntarily offered to review Paper 5 in this thesis as the project concluded which was much needed assurance about my own boundary crossing of disciplines through use of psychological statistical methods.

To Dr. Roger Watson for acting as my external examiner and for his through and attentive read of my thesis. I am grateful for his recognition of the challenges of diving into multiple methodologies at the $\mathrm{PhD}$ level and his suggestions as to where to extend the evaluation of my new tool.

Dr. Rasheda Rabbani, statistical consultant in the Manitoba Centre for Nursing and Health Research (MCNHR), spent many hours helping me with my statistical needs, feeding me resources, and being my statistical auditor on the application of latent variable analysis. I also owe a debt to other MCNHR personnel, in particular, Diane Cepanic for her grant submission advice (x3), which earned me funding. James Plohman who patiently allowed me to “pop in” to ask many many many questions and for facilitating much of my study recruitment at the University of Manitoba. Sidrah Khawaja, undergraduate research assistant, who performed a couple of critical research duties and, most importantly, was my second check on the parallel form ruler measurements described in Paper 5.

My colleagues at Red River College in particular Dr. Catherine Baxter (now of Brandon University) and Patrick Griffith who chaired our nursing program during my tenure as a doctoral student. The accommodations I received in order to complete this journey in a timely fashion went above and beyond. My 
office mates, Dr. Deb Gural and Dr. Tom Harrigan, who also helped me ensure I was speaking “psychology” in ways that did the discipline theoretical justice. Meagan Chorney, MA, for taking the time to discuss my first draft of the items developed for this questionnaire. Dr. Pat Gregory who could relate to it all. Cindy Boughen, Joanna Simmons-Swinden, and Karla King who assisted with my recruitment at Red River College. And extra special thanks to my instructor family at RRC who stopped me in the hall and asked if I was finished yet. It’s your turn now.

Many thanks to the administrative assistants in many departments and nursing instructors at the University of Manitoba, Red River College, and Brandon University who helped with student recruitment and/or invited me into their classrooms to introduce my study to their students.

To my student participants. There are over 1000 that gave their time to share their views on writing. Special shout out to the 20 nursing students who sat and talked their way through the developing instrument without restraint during the cognitive interviews.

To my 15 Delphi panel experts who all agreed to be named in these acknowledgements and didn’t hold back in their feedback on my developing questionnaire:

Jo-Anne Andre, University of Calgary, Canada

Vasiliki Betihavas, University of Sydney, Australia

Bridget Blankely, University of Southampton, UK

Trevor Day, Royal Literary Fund, UK

Paul Glew, Western Sydney University, Australia

Caroline Havery University of Technology Sydney, Australia

Fiona Henderson, Victoria University, Australia

Diana Jefferies, Western Sydney University, Australia

Andrea Klien, Independent Scholar, Germany

Sabine Korin, University of Applied Sciences Hamburg, Germany

Lynne Kuhl, Viterbo University, USA

Linda McCloud-Bondoc, Athabasca University, Canada

Brenna Quinn, University of Massachusetts Lowell, USA

Coleen Toronto, Curry College, USA

Christina West, University of Manitoba, Canada

To the many other scholars who all played various roles doing very important things during this doctoral journey. In no particular order: Dr. Tina West who loves writing, Dr. Kendra Rieger who is entirely to blame for pushing me down the doctoral path, Dr. Alex Clark for his mentorship, my classmate Tara Horrill and so many other supportive College of Nursing grad students, Dr. Donna Martin, Associate Dean 
extraordinaire, Dr. Dawn Wiseman for reading and being a dose of reality once and a while, Dr. Isabella Ghement for R questions, Britt Amell for introducing me to the works of Yagelski (book) and Reither (paper), and many other Canadian Association for the Study of Discourse and Writing folk (aka "my people”). And thousands of Twitter followers who related, validated, or put me in my place but, overall, helped me keep my sanity on many occasions.

It would also be remiss of me not to acknowledge every writing teacher and mentor I've ever had across my life, especially my Grade 8 English teacher, Mr. Gervais Warren, who walked by my desk one day, picked up some cheesy teen novel I had sitting there and said something like: "You shouldn’t be reading these, you should be writing them.” The power of a teacher who believes in you is EVERYTHING.

There is only one group of people that suffer more than the student in doctoral studies and that is the doctoral student's family. Dave Bell, my partner in crime and the best proof-reader, massage-giver, and dinner cooker on the planet. No, these words are still not “made up.” My children Emma and Nolan McCormick who experienced their teen lives with a very distracted Mama and somehow emerged (mostly) unscarred - time will tell. My, at the time, 16-year-old daughter Emma hand drew the diagram of the model described in many places throughout this thesis. (Yes, I paid her). And my parents, George and Judy Mitchell, who never dreamed of a university education for themselves but didn't hesitate to support our dreams. My mother could have been a math genius and, as is typical for women of her generation, no one ever told her. My penchant for statistics pales in comparison.

Finally, I was fortunate to be the recipient of several awards and funding that supported both my advancement as a doctoral student and researcher and funded this research:

- $\quad$ Research Manitoba Doctoral Studentship 2017-2019 \$35,700

- Western and Northern Region Canadian Association of Schools of Nursing Graduate Student Research Grant 2019 \$2500

- College of Nursing Endowment Fund Graduate Student Research Grant 2019 \$5000

- Christine A. Tanner Award for Scholarly Writing. Best article. Journal of Nursing Education, "Constructing Writing Practices in Nursing” 2019 \$500USD

- Conference funding for two Qualitative Health Research conferences through the Deeper Dives Project (Quebec, 2017; Halifax, 2018)

- Being Chosen as the College of Nursing "Rising Star” with attendance at the Sigma Theta Tau International Conference in Melbourne Australia, 2018.

- $\quad$ Red River College BRAVO Award for Research Excellence, 2017 


\section{Dedication}

My family:

My partner in life, Dave Bell

My children, Emma and Nolan McCormick

My parents, George and Judy Mitchell

The writing has changed in your hands, and in a twinkling, from an expression of your notions to an epistemological tool. The new place interests you because it is not clear. You attend. In your humility, you lay down the words carefully, watching all the angles. Now the earlier writing looks soft and careless. Process is nothing; erase your tracks. The path is not the work. I hope your tracks

have grown over; I hope birds ate the crumbs; I hope you will toss it all and not look back.

Annie Dillard, The Writing Life 


\section{Table of Contents}

\section{Table of Contents}

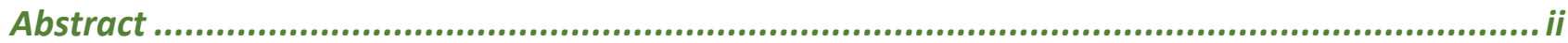

Acknowledgements ..................................................................................... iv

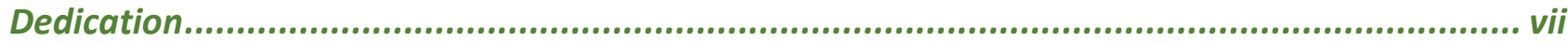

Table of Contents .............................................................................................. viii

Prologue - A Critical Reflection on Writing and Writing Self-Efficacy................................1

A Thorough Engagement With the Literature ............................................................................................

What do we Know from the Writing Self-Efficacy Literature? ..................................................................14

Considering Two Theoretical Premises for Writing Self-Efficacy......................................................20

Figure 1: A Visual of the Intertwined Socially Constructed Model of Writing .................................................23

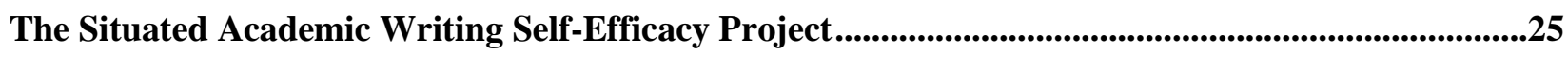

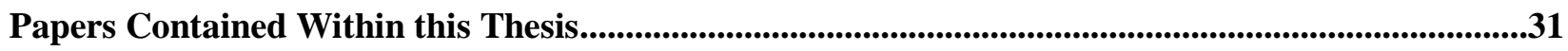

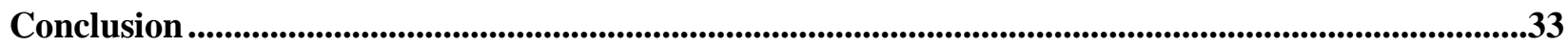

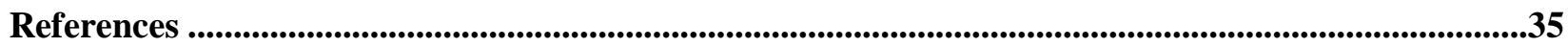

Paper 1: Constructing Writing Practices in Nursing ................................................... 48

Background ...........................................................................................................................................................51

Epistemological Shifts in Writing Research: Product, Process, and Social Movements.......................53

Nursing Discourse as a Barrier to the Construction of Writing...............................................................56

A Model for Writing...............................................................................................................................................................62

Table 1: The elements relevant to a social construction of writing in nursing ..................................................65

Figure 1: A socially constructed model of writing .......................................................................................66

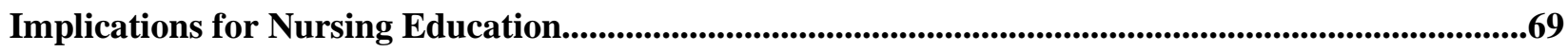

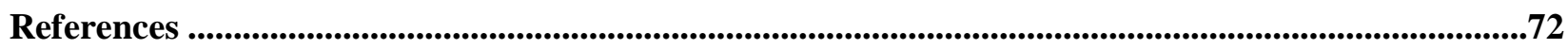

Interlude 1.............................................................................................. 80

Paper 2: Applying the 'Social Turn' in Writing Scholarship to Perspectives on Writing Self-Efficacy

Exploring Cognitive Perspectives on Writing .................................................................................................89

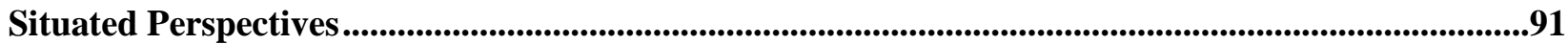

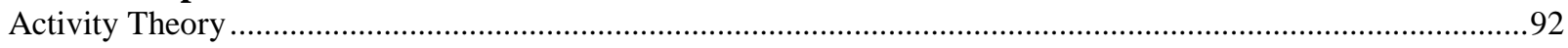

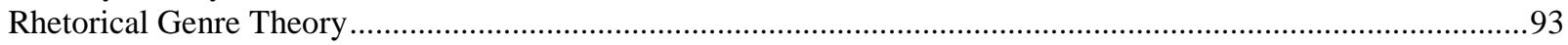

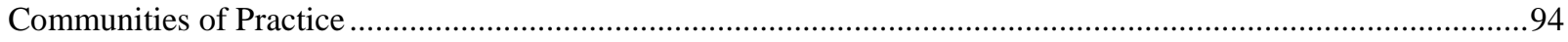

Negotiating a Synthesis of Social Cognitive and Socially Constructed Theoretical Perspectives ........96

References ....................................................................................................................................................................103

Interlude 2............................................................................................. 109 
Paper 3: Delphi Decision Making: Blending Qualitative and Quantitative Methods in Tool Development Research .............................................................................. 112

The "Ever-Adapting” Delphi Method .....................................................................................................................114

The Writing Self-Efficacy Delphi Method........................................................................................118

Figure 1: Visual Pathway for Delphi Decision-Making ...........................................................................119

Table 1: Success of Three Recruitment Strategies by Target Group.................................................................121

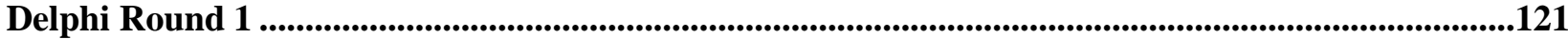

Table 2: Quantitative Results for 5 Case Study Items and Final Decision After Blending Qualitative Evidence

Delphi Round 2 ....................................................................................................................................................131

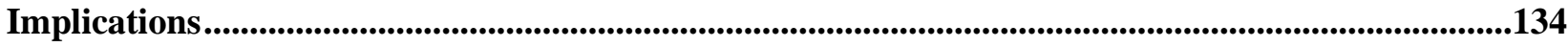

Table 3: Data Importation Example Carried Forward to Cognitive Interview Phase........................................139

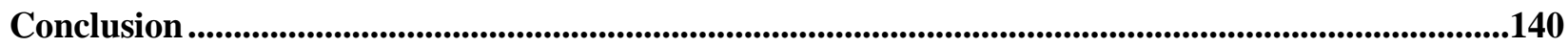

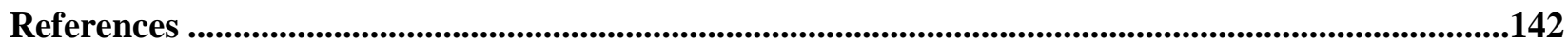

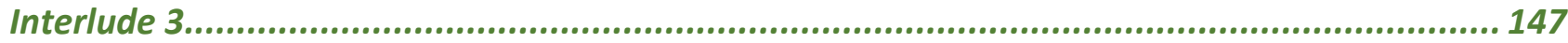

Paper 4: "Follow the Rubric is the Thing in Nursing": Navigating Systemic, Instructional, and Personal Influences on Writing Activities ............................................................... 152

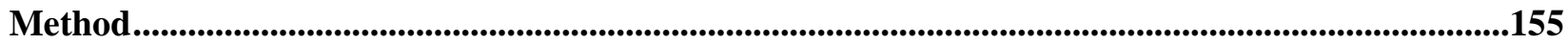

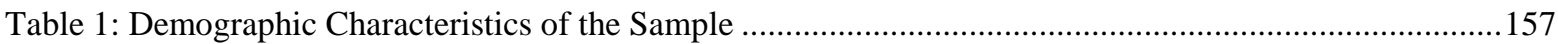

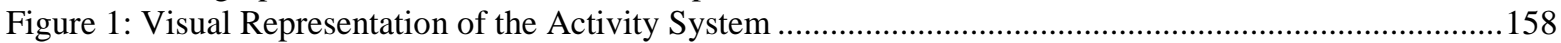

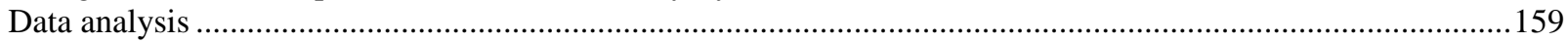

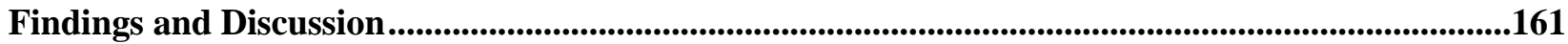

Table 2: Students by Participant Number and Demographic Characteristics..................................................162

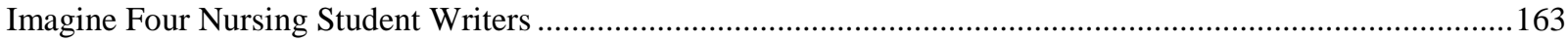

Codeswitching Within a Rigid Writing Context ............................................................................................165

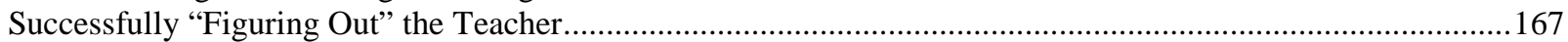

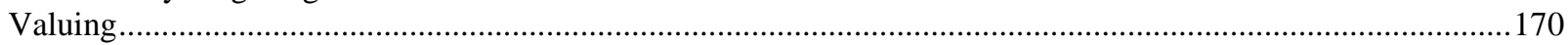

Study Limitations ...............................................................................................................................................................171

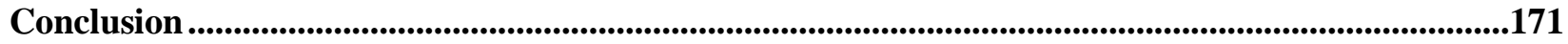

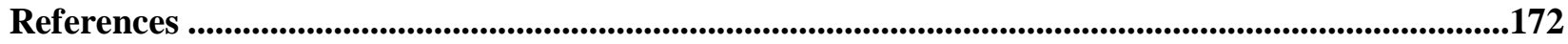

Interlude 4................................................................................................. 177

Paper 5: Development and Validation of the Situated Academic Writing Self-Efficacy Scale (SAWSES) ............................................................................................ 181

Current Measures of Writing Self-Efficacy ....................................................................................................185

Theoretical Premise of the Scale Development ..................................................................................................187

Methods and Results ...............................................................................................................................................189

Item Development and Revision...................................................................................................................190

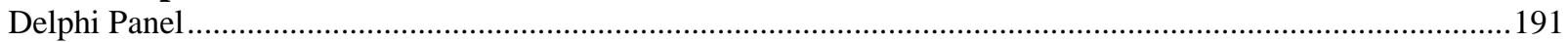

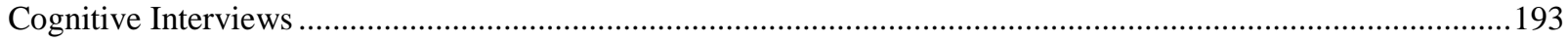

Study 1: Exploratory Factor Analysis and Hypothesis Testing ...............................................................195

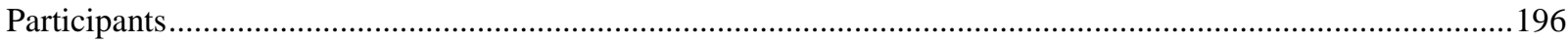


Table 1: Demographic Characteristics of the Samples for Study $1(\mathrm{~N}=234)$ and Study 2 Undergraduates $(\mathrm{N}=$

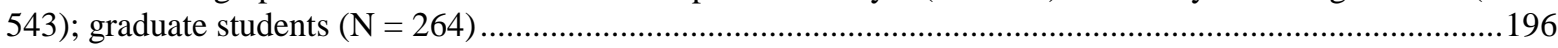

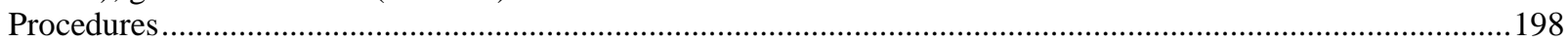

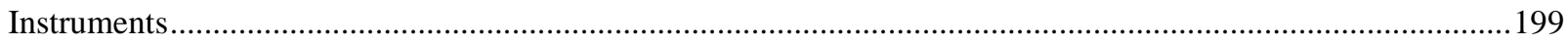

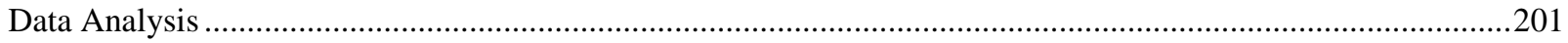

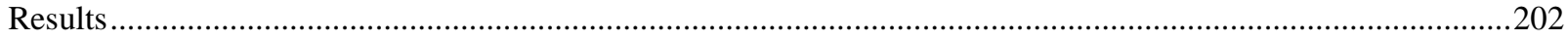

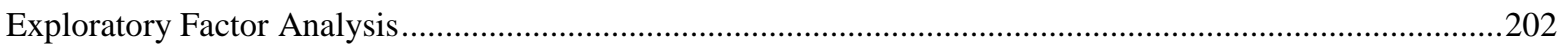

Figure 1: Scree Diagram for Exploratory Factor Analysis ..........................................................................202

Table 2: Four exploratory factor analysis models SAWSES Nursing student sample $(\mathrm{N}=255)$, with goodness

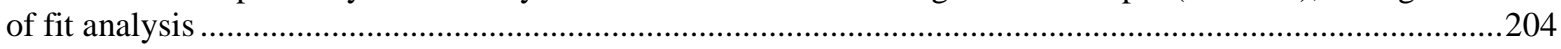

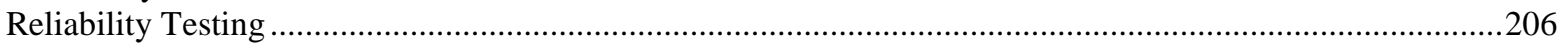

Table 3: Mean, Standard Deviations, and 95\% Confidence Intervals (CI) for Scale, Subscales, and Items on the

Situated Academic Writing Self-Efficacy Scale (SAWSES): Study 1 Nursing sample (N = 255); Study 2

Interdisciplinary Undergraduate Students ( $\mathrm{N}=543$ ); Interdisciplinary Graduate Students ( $=264)$ (Possible

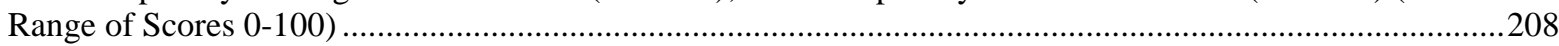

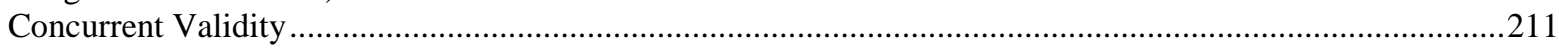

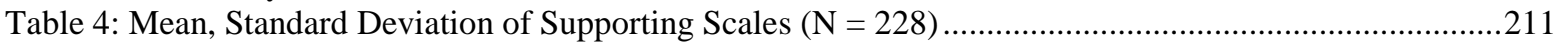

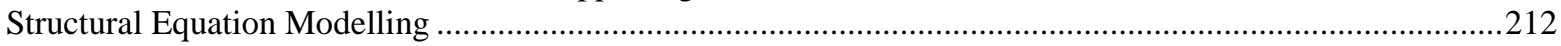

Table 5: Model Goodness of fit for three SEM models with MLR estimator $\mathrm{N}=228$....................................212

Figure 2: Hypothesized Structural Equation Model 1 in Nursing Student Sample ..........................................214

Figure 3: Hypothesized Model 2 with Modification Indices Considered in Nursing Student Sample...............215

Figure 4: Best Fit Model 3 Apprehension and Context-Support as Predictors and Modification Indices

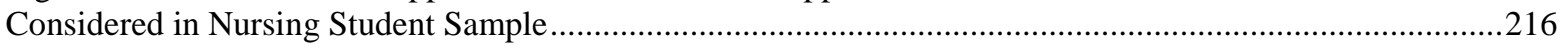

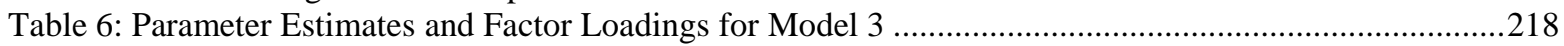

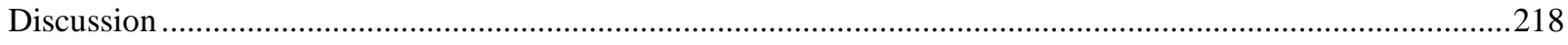

Study 2: Multigroup Confirmatory Factor Analysis..................................................................................219

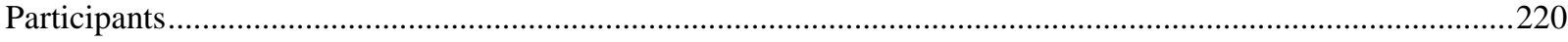

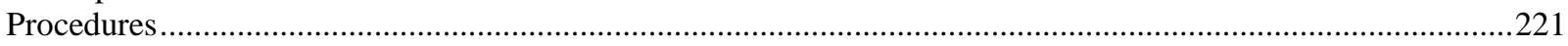

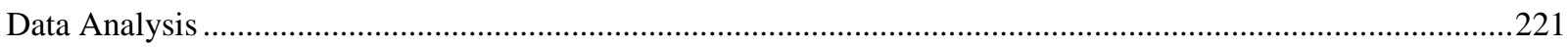

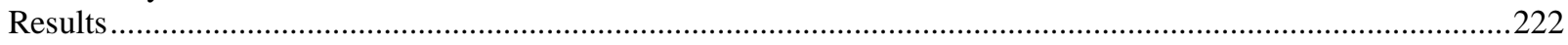

Table 7: Multigroup CFA Tests of Goodness of Fit and Measurement Invariance on SAWSES ....................223

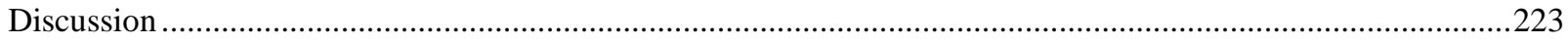

Exploring Differences Between Study 1 and Study 2 Samples ..................................................................224

Writing Attitude ................................................................................................................................................224

Table 8: Mean, Standard Deviation, and One-Way ANOVA Results for Self-Reported Writing Attitude and

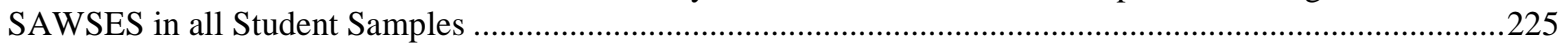

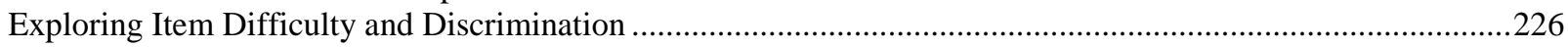

Table 9: Item Difficulty and Discrimination for all student groups ...........................................................226

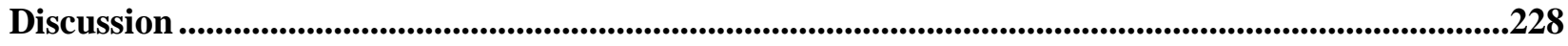

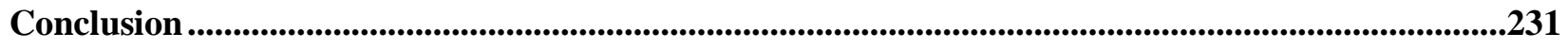

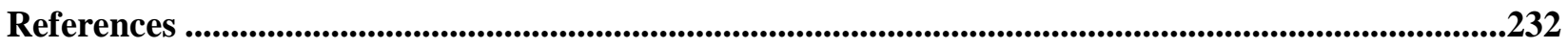

Epilogue - What's Next for Writing and Writing Self-Efficacy? ...................................... 242

Summary and Key Contributions from Each Included Paper.........................................................243

Table 1: Self-Efficacy Scale for Academic Writing - Final Items, Factor Structure, and Original Theoretical

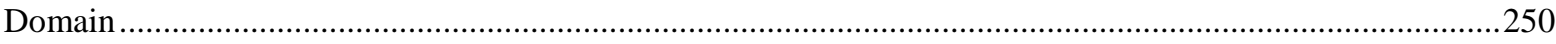

Implications for Pedagogy in Nursing Education and Beyond.............................................................254

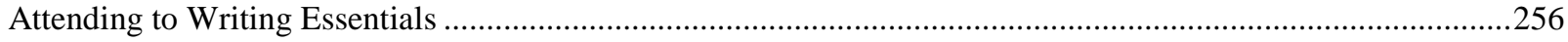

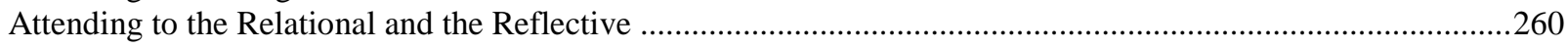

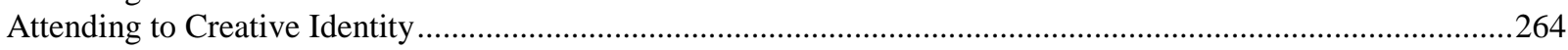

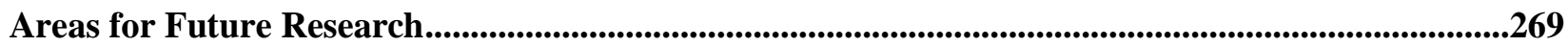

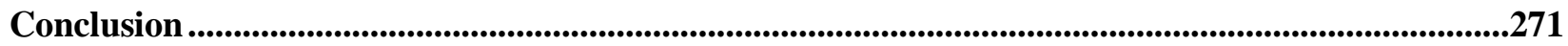


References

Appendix A - Situated Academic Writing Self-Efficacy Scale Evolution of Item Editing 279

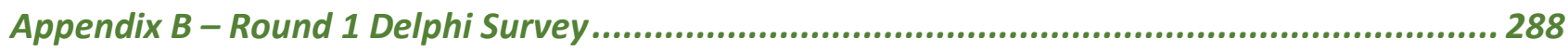

Appendix C - Email Invitation Script Delphi .......................................................... 293

Appendix D - Delphi Study Consent Form ................................................................ 295

Appendix E - Description of the Theoretical Perspective .................................................300

Appendix F-Example of Summary of the Results Round 1 ........................................... 302

Appendix G - Round 2 Delphi Survey............................................................... 307

Appendix H-Example of Summary of the Results Round 2 ........................................... 316

Appendix I - Informed Consent Cognitive Interviews ................................................ 321

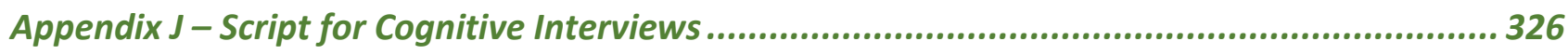

Appendix K - Prescripted Prompts for Cognitive Interviews.......................................... 328

Appendix L - Demographic Form Cognitive Interviews ................................................ 329

Appendix M - Invitation to Participants for the Cognitive Interview .................................. 331

Appendix N - Email Request to Nursing Programs for Cognitive Interviews .......................... 332

Appendix O - Recruitment Poster for Cognitive Interviews ........................................... 333

Appendix P - Nursing Survey and Questionnaires Including Demographic Items.................. 334

Appendix Q - Informed Consent for Nursing Survey ................................................... 346

Appendix R - Email Request to Nursing Programs for Nursing Survey................................ 350

Appendix S - Email Invitation to Faculty to Attend Classes to Conduct Nursing Survey............ 351

Appendix T - Email Invitation to Nursing Students to Request Participation ......................... 352

Appendix U - Reminder Email to Nursing Students to Complete Survey............................... 353

Appendix V - Script to Introduce Study During Nursing Classes........................................ 354

Appendix W - Interdisciplinary Survey Including Demographic Items ............................... 356

Appendix X - Informed Consent for Interdisciplinary Survey ....................................... 362

Appendix Y - Email Invitation to Participants for Interdisciplinary Survey........................... 365

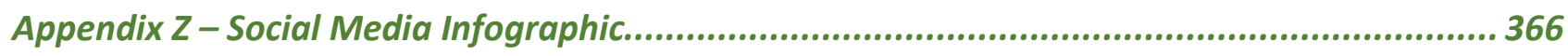




\section{Prologue - A Critical Reflection on Writing and Writing Self-Efficacy}

All writers have histories. This thesis is rooted in experiences that likely stretch back as far as my elementary school days, with small epiphanius moments scattered throughout time straight through to the past four years of intense immersion into writing theory and philosophy. It means, writing self-efficacy has been on my mind long before I knew about self-efficacy as a concept. As Bawarshi (2003) observed in Genre and the Invention of the Writer, a book title fitting for what I am about to do in this opening chapter, "beginnings take place in the midst of things” (p. 2). For you, the reader, this is the beginning; for I, the author, it is the midst. I write this opening chapter after the completion of the four independent sample research studies validating a new tool to measure writing self-efficacy and all manuscripts have been prepared. I know how the story ends - with a reliable and valid tool called the Situated Academic Writing Self-Efficacy Scale. I also know where the story came from and, for that, I wish I had taken better notes. When considering how thinking and learning evolve over time, notes would enhance my retrospective perceptions of how far I've come as a writer and a teacher of writing and contribute to understanding why the tool I developed takes its particular form. Bawarshi, when saying beginnings are "in the midst," refers to a philosophical notion put forth by Russian philosopher, Bakhtin (1981), who reminds us that all beginnings take place in response to previous beginnings. Bakhtin, who is one of the grandfathers of some of the theoretical premise that lies behind my work about to be presented - in particular rhetorical genre theory - also helped us understand that all writing is a dialogue of utterances, born from previous utterances.

Genre theorists such, as Bawarshi (2003), used Bakhtin’s philosophy of the dialogic to pronounce that all writing refers to previous writing, whether that be intentional or not. All present writing also refers to forthcoming writing. Clandinin and Connelly (2000), incorporating the ideas of John Dewy, echo Bakhtin's notion when they identified: 
The notion of experiences grow out of other experiences, and experiences lead to further experiences ... We learned to move back and forth between the personal and the social, simultaneously thinking about the past, present, and future, and to do so in everexpanding social milieus. (pp. 2-3)

Ivanič (1998) begins her seminal book on writing and identity, a book which was reconfigured from her own doctoral work, by saying:

Who am I as I write this book? I am not a neutral, objective scribe conveying the objective results of my research impersonally in my writing. I am bringing to it a variety of commitments based on my interests, values, and beliefs which are built up from my own history.... (p. 1)

Ivanič's work was imperative in my own conceptions of writing and identity in this thesis. When I think of the key moments across my writing life and my 18-year career as a nurse educator that brought me to my current understanding of what writing is and what writing does for transforming thinking and learning, I can track, in retrospect, the epiphanies that impacted my own practices in my own writing and teaching of writing. Therefore, as Ivanič did before me, I write myself into this chapter, “just as doctoral students do” (Kamler \& Thompson, 2006, p. xi). I present these epiphanies in eight vignettes - or Exhibits - of my thinking and confidence and as a description of how writers and writing teachers are invented.

\section{Exhibit 1 - Writing Teenage Angst}

“That young adult voice I cultivated behind closed doors and under bed covers in my teen years - a hybrid voice of old soul wisdom and immature arrogant misanthropist...” (Mitchell, 2019, p. 10)

I estimate, from 1984 to 1989, before I even set foot in the doors of a post-secondary institution, I had written over 1500 handwritten pages in Hilroy scribblers and other notebooks. 
This does not include any required writing I did at school. None of my school writing was near as important or as memorable to me as writing about my own life. The only thing I ever wanted to be when I grew up was a writer. But who makes money as a writer?

\section{Exhibit 2 - Literature is Romantic}

"I have dreamt in my life, dreams that have stayed with me ever after, and changed my ideas; they have gone through and through me, like wine through water, and altered the color of my mind. And this is one: I'm going to tell it - but take care not to smile at any part of it."

\section{— Emily Brontë, Wuthering Heights}

It's the summer of 1990. I'm a University of Manitoba student in the Faculty of Arts and I decide to take a summer course in Romantic Literature. The class is me and what seems like 15 other students who have already graduated and are working as teachers in the school system. I'm 19 years old with little life experience to relate to the themes of the complex novels I am reading. My only English lit course prior to this upper level course was introductory. I got a lot of B+’s in that class after being an A+ writer in high school. But here, with my writing in comparison to 20and 30-something year-old graduated teachers, I don’t measure up. I didn’t yet have the sophistication or the life experience to be able to be that insightful about literature. We write papers on Wordsworth and Wuthering Heights, and mine come out full of red corrections. I learned what passive voice was that summer because I, apparently, used a lot of passive voice.

\section{Exhibit 3 - New Discipline, New Writing}

"Within disciplines, writers speak to colleagues in recognizable discursive spaces in recognizably acceptable ways, shaping their actions to the presumed understandings and needs of their readers. Only in relation to these communities are meanings validated, and they only receive validation to the extent they are compatible with the understandings and practices of these communities.” (Hyland, 2004, p. xi) 
I have an arts degree in English literature and a minor in history. I have successfully written 28 academic papers in my previous degree. But an Arts degree is not going to get me out of the grocery store or off the pool deck. I need a career. It's now 1993. I'm in Introduction to Nursing and we have papers to write. One of them was an analysis of a journal of our choosing. I choose Nurse Practitioner. I'll be honest. I have no idea what a nurse is let alone a nurse practitioner. My first draft reads like a literary thematic analysis, because that's how I know how to write. We do a group discussion exercise in that class and I figure out, without anyone telling me, that I am writing the assignment all wrong. It has the wrong voice, the wrong words, the wrong structure. I rewrite it and get an A. There are barely any red marks on my paper and the feedback is glowing. Writing in nursing is going to be easy. Well, easier than English literature. I wrote or co-wrote 29 papers, presentation scripts, and client-based assignments in my nursing courses. I also wrote countless reflective journals. I'm pretty sure my current students come nowhere near this number in 2020.

\section{Exhibit 4 - Transition to Graduate Writing}

"We write to work out what we think. It's not that we do the research and then know. It's that we write our way to understanding through analysis. We put words on the page, try them out, see how they look and sound, and in the writing we see things we had no idea were there before we started writing.” (Kamler \& Thompson, 2006, p. 4)

It's the year 2000. I’m a master's student in nursing in a course called Science and Theory of Nursing. The concept analysis assignment is the hardest paper I've written to date. It held that honour for a very long time after. It may still hold that honour, not because there were no difficult papers that came later in my life, but because it was a new level of writing. I can say that, while at the same time being certain that a paper of that nature would be easy for me now. It is the first paper I write where I don't write it in chronological order. It is also the first paper I 
write that I type directly into the computer without handwriting first. My writing practices are changing.

I’ll eventually publish that concept analysis (McCormick, 2002). Fast forward 18 years, it has 243 citations according to Google scholar. It was the craziest review process, not during the review itself - which I have no memory of - but when it went back to the editor. The editor liked it but thought it was too wordy. She asked me to fix it. She gave a few examples. I didn’t know how to do what she was asking; I mean, this is how I write. This is what I sound like. My memory is that she de-worded it herself. My initial impressions of the paper after publication were that it no longer sounded like me. Now I can’t tell. I published six papers out of my nursing masters. I read those papers now and I have no memory of writing any of them. I have very few memories of writing my thesis. It's like a different person wrote them. The emotional connections I have to the words are gone, although I still think they were written by a good writer. But yet, somewhere in the depths of my thinking, all that writing I can no longer remember made a difference to the thousands of pages of writing that have come after. They live in my word choices, my ideas, and my identity.

\section{Exhibit 5 - All Writing is Creative Writing}

“Autobiographically, I could include additional details such as acknowledging I am female, or that my interest in writing voice arose out of my experiences writing a novel. This experience is my 'before and after' and is the lens through which I view my life. As a result, I have come to believe that writing has formed my identity and I no longer have a self unless I write...”

$$
\text { (Mitchell, 2017, p. 6) }
$$

Summer 2005. I've been teaching nursing at Red River College for 3 years. I have two small children ages 4 and 1.5. There’s something unsettled in my life. How did I get here? There are all these words and ideas screaming inside my head. A particular memory keeps coming to 
my consciousness. I always wanted to be a writer. I buy my first laptop. Every evening from the time the kids go to bed till all the words are out of me for the day, I write. I'm afraid if I take a night off, I'll quit and never finish. I'm not getting much sleep. I start drinking coffee. I've never been a coffee drinker. I feel my marriage slipping away from me. I write the first draft in 3 months. By some miracle I am accepted to a very competitive mentorship program with the Manitoba Writers Guild. The mentor who chooses me is a 50-something poet from Brandon. A man. He chooses me more for the impassioned personal statement I wrote in my application than the pages of my girly teen angst novel I submitted as my writing sample. I learn to work with my writing emotions, but they terrorize me in my dreams. I learn what that editor of the concept analysis paper meant about my wordiness and lack of efficiency. I learn to abhor overuse of to be verbs, adjectives, and adverbs. But most importantly, I learn there are similarities between academic and creative writing that exist in the emotional embodiment of words on the page.

\section{Exhibit 6 - APA $^{1}$ Does Not Equate to Writing}

"We propose that APA style is not just a collection of arbitrary stylistic conventions but also encapsulates the core values and epistemology of the discipline.” (Madigan et al., 1995, p. 428)

Also 2005. I'm on a committee at work with a team of faculty who feel we need to do something about our students' “terrible writing skills.” I’ve learned things being on the other side of the coin. All those self-beliefs I had that I was an average student who knew how to work the system, they were all wrong. Most students cut corners and don't edit and won't set foot in the library. Why won’t they set foot in the library? How can they write 10-page papers from websites and not a single peer reviewed journal? Faculty grade from rubrics in this program. No

\footnotetext{
${ }^{1}$ APA = American Psychological Association

${ }^{2}$ CNA = Canadian Nurses Association
} 
one ever graded me from a rubric in my nursing program. I get assigned to mark papers for other faculty and they have rubrics with things on them like, "Mentions CNA ${ }^{2}$ Code of Ethics in intro paragraph (1 mark).” What is this? Why are we grading such prescriptive micro-isms of content? One faculty member starts pulling every student's sources listed in their reference lists and finds that more than half the class has copied things word for word without acknowledgement. I wonder if I'm supposed to be pulling students' sources too. We have decided we have such a problem with plagiarism that our students need a workshop on APA. I get assigned to teach it. One early iteration of a plagiarism policy in our department requires students to revise their paraphrased passages in their paper and put in the citations they left out related to unacknowledged ideas they shared. It seemed like a good idea at the time, but I have countless memories of having conversations with students about uncited material in their papers where the students had nothing to cite. They had written those parts of their paper from their head without use of sources. I figure out quickly that our students don't need to be drilled about APA, they need to have an outlet to talk about writing. They need to learn how to find and use high quality source materials. They are stressed and emotional and fear being accused of plagiarism. With all this citation emphasis, they have trouble seeing the assignments they do as containing anything that comes from them. They need to know a version of writing that creates excitement for ideas and learning and feels non-threating. But this perspective is a difficult sell in writing belief systems that hinge on textual obsessions such as commas, italics, and a hanging indent done correctly.

Exhibit 7 - Only Take This Online Course if you Feel Confident as a Writer "Self-evaluation is not likely to be accurate when little frame of reference is present for the experience” (Mitchell, Harrigan, \& McMillan, 2017, p. 8) 
In 2010 we are granted our own Nursing Baccalaureate program. My not-for-credit workshop turns into a 1-credit hour course in the first year of the program. It has the workload of a 10-credit hour course. I teach writing in a lecture theatre to two groups of about 100 students each. This is not realistic. Some of these students have extensive writing backgrounds and others don't know where the indent button is on the computer. We do in-class writing exercises and students are stressed to tears. I move the in-class writing into discussion posts on LEARN. This is not teaching writing. This is a logistical nightmare. I dream about seminar courses with 30 students where we can have readings and discuss language. The same kind of courses I experienced taking creative writing. Writing courses are supposed to be about conversations. Instead, I turn one of my course sections into an online course. I allow students to self-select which section they want to be in. I advise our administration: “Tell them to select the online section only if they feel confident as writers.” The self-selected online students with supposedly confident writing skills get worse grades than the students in the classroom. What is up with that?

\section{Exhibit 8 - Writing Self-Efficacy, Research Self-Efficacy}

"Self-referent thought activates cognitive, motivational, and affective processes that govern the translation of knowledge and abilities into proficient action. In short, perceived self-efficacy is concerned not with the number of skills you have, but with what you believe you can do with what you have under a variety of circumstances.” (Bandura, 1997, p. 37)

January 2012. I've been out of the research game for a while, but I'm about start a research study to figure out if my scholarly writing course is helping improve writing selfefficacy. It is confession time. I have very few research mentors around me, so like with everything, I just figure it out as I go. I make a lot of mistakes. The study is thrown together on a whim and sent to ethics a little too late to start data collection for the first class. How did I 
choose self-efficacy? I am aware of the concept from study examples I use with students in my other class teaching research. I know it is sort of like confidence but sort of not. I cannot - at least at the time - define the difference. As what happens when you throw a study together last minute with no funding, I have not read the literature. I have designed a writing self-efficacy tool from finding the General Self-Efficacy Scale (Schwarzer \& Jerusalem, 1995) via Google. I didn’t know there were already existing writing self-efficacy tools out there. I convert general self-efficacy into a writing tool in about 30 minutes flat. That's how I remember it anyway. It's a good detail to the story - a thing of legends - because that early questionnaire via a stroke of luck or genius, has served me well in my writing self-efficacy studies with very credible reliability and validity. As with everything I’ve written here, because I didn't take good notes, all my memories are colored over with the shades of things that came later. I only dove into the writing self-efficacy literature sometime in 2013 or 2014, in preparation for writing a manuscript. I did everything backwards. I had no frame of reference for studying writing selfefficacy. I overinflated my own confidence.

\section{A Thorough Engagement With the Literature}

"Nursing has fallen behind in exploring writing as an acculturation mechanism for the discipline by perpetuating outdated and positivistic modes of writing and failing to progress the teaching of writing outside of the basic skills perspective.” (Mitchell, 2018, p. 400)

After that first writing self-efficacy study presented in Exhibit 8 (Mitchell, Harrigan, Stefansson, and Setlak, 2017), I conducted three other studies about writing self-efficacy before succumbing to the inevitable call of doctoral work: a repeat of the first study with a stronger design (Mitchell, Harrigan, \& McMillan, 2017), a follow up of the second cohort (Mitchell \& McMillan, 2018; Mitchell, McMillan, \& Rabbani, 2019), and an examination of all the existing tools about writing self-efficacy (Mitchell, Rieger, \& McMillan, 2017). I began this thesis with 
this retrospective, because no thesis is born in a vacuum. The above Exhibits, each serve their own purpose to illustrate my own coming to know about writing as an emotional, creative, identity forming, disciplinary activity. They act as an introduction to previous experiences and previous writings which, consciously or unconsciously served my decision-making throughout this doctoral experience with writing self-efficacy. Everything I read, all the ideas I was drawn to, every conclusion I made emerged from a previous experience. My experiences and perspectives about writing come from writing in multiple disciplines, my creative experiences, the journals I wrote as a teenager, and the insights I developed as a grader of writing as a nursing faculty member. As Ivanič (1998) did before me, in this prologue "I am doing explicitly here what is usually left implicit or, at best, relegated to the edges of the book itself” (p. 2). I fell into exploring writing self-efficacy more by accident than by design. Starting PhD studies in 2016 drew me into the philosophy of writing and much of this thesis is rooted in my own "Theoretical Constructions” of writing introduced to me in that body of literature.

I wrote two important papers that sparked the direction my thesis ultimately took during the doctoral course, Philosophy of Nursing Science, a seminar course lead by my advisor Dr. Diana McMillan. The first explored the concept of academic voice from two different epistemological perspectives. I chose to look at voice from a positivist (objectivist) perspective and a feminist socially constructed perspective (Mitchell, 2017). As someone who has spent most of my life understanding that writing comes from all around us - writers beg, borrow, and outright steal ideas from their personal environment to make meaning and create knowledge or, in the case of my fiction, tell stories - the idea of writing as a sterilized objective output was foreign to me. Yet, I can point to numerous experiences I've observed in my own academic life that confirmed that academic voice was subject to pressures of feigning objectivity - don't use 
first person, cite everything you say, and judge text quality by its surface characteristics, like grammar or sentence structure or how well the APA has been implemented.

And of course, most importantly, and an objectivist rule I am right now violating with deliberate intent: never, ever write yourself into your academic work. You don’t belong there. Your work is separate from you. It would be disingenuous of me, given everything I've preached and many of the things I've published, to write an introduction of my doctoral work that removes me from the experience. Academia seems to have a lot of discomfort with academics who break down the fourth wall - meaning turn to the audience and speak directly to them about our personal motivations behind our practices. In the academic voice paper (Mitchell, 2017), among other examples, I tell the story of Suzanne Fleischman, a scholar of French linguistics, who wrote about exploring academic voice (1998) and medical discourse (1999). This work was born out of her own medical diagnosis of myodysplastic syndrome, where she openly talks about her inability to get funding for her change in career focus, and the criticisms she faced for writing something so personal into her science. I would eventually write more about the value of selfinsertion in academic work, in particular in the form of storytelling used for knowledge translation (Mitchell, 2019). In that paper, I experimented with writing that merged the personal and the professional in the form of a personal narrative in the middle of a discussion of social media storytelling.

The second paper in our Philosophy course asked us to explore a controversy from a philosophical standpoint. I kept thinking about nursing's theory-practice gap - the ongoing conflict between our practice selves and our academic selves. Early papers written by nurses about writing talk about this conflict as relating to the shift of nursing education from the hospital to the university (Mulhull, 1997). Writing, the practice side laments, belongs to our academic selves, without much use to the bedside. Of course, writing doesn't belong only to 
academia. Writing belongs to everyone including practitioners. I remember in preparation for writing this paper word searching the PDFs of various documents that regulate nursing practice across Canada in search of mention of writing. None of the entry level competencies written in English from any Canadian province mention writing. The broader concept of communication is used most commonly. The College of Registered Nurses of Manitoba (2019) mentions writing as part of the overarching principles of nursing competency in connection to English language proficiency. The Canadian Association of Schools of Nursing (CASN, 2015) states in their National Nursing Education Framework, “The ability to compose a written academic argument” (p. 9) as one of the essential components of the guiding principle of Research, Methodologies, Critical Inquiry, and Evidence for Baccalaureate education. I feel it is very difficult to achieve buy in from faculty and nursing students of the value of writing to their practice if it is not explicit in our practice regulation documents.

One of the earliest papers (Allen et al., 1989) published in nursing education about writing got it right: "Writing skills are enhanced through the development of conceptual clarity. They can also be used to determine a student's level of conceptual maturity. At the same time, engaging in the writing process increases conceptual clarity” (p. 7). Because nothing at the time had been written about writing by nursing scholars, Allen et al. drew from literature published by composition experts, in particular with respect to the Writing to Learn paradigm which postulated that writing education was about far more than producing pristine textual outputs. Writing was also a mechanism for learning, knowing, dialogue, and stimulated critical thinking. Writing is reflective practice (Bolton, 2010). Reflective practice is purposeful rather than happenstance. It takes us out of our self-centered view of the world and forces consideration of the experiences of others in other contexts and life stages. Writing to learn inspired the writing across the curriculum movement in the United States, which paralleled the academic literacies 
movement in the United Kingdom (Russell et al., 2009), which are discussed in more depth in Paper 2.

In 1989, Allen et al. recognized there was something more to writing than transmissive communication and demonstration of, often regurgitated, factual knowledge gained, and yet, in the wider nursing community, there was little uptake of that knowledge. There were promising interludes, like Luthy et al.’s (2009) acknowledgement that writing was disciplinary, and nursing had its own language. Or one of my favorite papers (Ryan et al., 2014), which decried the objectivism of writing in nursing stemming from the disciplinary demand that we always acknowledge the ideas of those senior to us. Tradition seems to dictate that our own ideas are meaningless without citing someone else. There were disappointments too, like Johansen and Harding's (2013) qualitative study looking at the writing experiences of post-graduate nurses in a wound management course, which found writing to be a barrier to learning and not a fit for practice focused nurses. Or White and Lamson’s (2017) “educational innovation” paper which amounted to a workshop to drill grammar and APA.

Nearly 30 years after the publication of Allen et al. (1989) I wrote my own ode to writing in nursing (Mitchell, 2018), the second philosophy paper that eventually became "Constructing Writing Practices in Nursing” and is re-presented as Paper 1 in this thesis. I illustrate how nursing continues to be behind the curve in their investigations about writing, continuing to push for drilling of grammar in papers about writing pedagogy. That paper married the idea of nursing's anti-academic discourse, emerging from within the practice environment as the result of a theory-practice gap, with an idea suggested by a reviewer of our paper exploring item content within all the tools developed to measure writing self-efficacy (Mitchell, Rieger, \& McMillan, 2017). The reviewers suggested we might need a new theory of writing specific to nursing. The Mitchell, Rieger, and McMillan paper found very significant gaps in contextual 
aspects of writing that were being ignored in writing self-efficacy measurement. It made it clear that, at least in the post-secondary context, it was unlikely that any current measure of writing self-efficacy was capturing the complete experience of writing.

The theory that emerged from "Constructing Writing Practices” became very important to this thesis and the ultimate development of the Situated Academic Writing Self-Efficacy Scale (SAWSES). It is fair to say, that without having written that paper, SAWSES would have taken a very different direction. I will detail that theory later on in this chapter, where I will inevitably have to turn "more academic" in my presentation of my work. The other side-effect of writing the “Constructing Writing Practices in Nursing” paper was becoming more in tune with some of the troublesome issues I was observing within the writing self-efficacy literature itself. There was a heavy focus on assessing writing self-efficacy by having students self-assess writing based on their ability to use correct grammar (e.g. Shell et al., 1989) or successfully apply process elements of writing such as ability to correct errors or do research or take notes (e.g. MacArthur et al., 2016). There is far more to producing a work of writing than the visible parts of writing such as what appears on the page or whether the student has a specific strategy to organize a specific task of writing.

\section{What do we Know from the Writing Self-Efficacy Literature?}

Before I had extensively read the writing self-efficacy literature or fully understood my life-long hunch that writing changed from context to context, I defined writing self-efficacy like this: “Everything inherent in a writer's belief about their ability to write within a specific context” (Mitchell, Rieger, \& McMillan, 2017, p. 206). We had observed while analyzing the tools that the writing self-efficacy literature at the time, did not define writing self-efficacy separately from Bandura’s (1997) generic theory of self-efficacy: "Perceived self-efficacy refers to beliefs in one's capabilities to organize and execute the courses of action required to produce 
given attainments” (p. 3). Thus, writing self-efficacy, according to the literature was just selfefficacy, but with writing.

Post-secondary writing self-efficacy research has related the concept to various other cognitive and psychosocial variables. Some of the key social cognitive variables are as follows:

- Increased motivation (van Blankenstein et al., 2019; MacArthur et al., 2015; Prat-Sala \& Redford, 2012; Teng et al., 2017)

- Increased locus of control (Jones, 2008; McCarthy et al., 1985; Meier et al., 1984).

- $\quad$ Decreased writing anxiety (Martinez et al., 2011; Mitchell, Harrigan, \& McMillan, 2017;

Mitchell, Harrigan, Stefansson, \& Setlack, 2017; Mitchell \& McMillan, 2018; Mitchell, McMillan \& Rabanni, 2019; Stewart et al., 2015; Woodrow, 2011)

- $\quad$ Decreased writing apprehension (Goodman \& Cirka, 2009; Pajares \& Johnson, 1994;

Sanders-Reio et al., 2014; Vanhille et al., 2017).

- Reading ability (Blakeslee et al., 2018; Mitchell \& McMillan, 2018; Perin et al., 2017; PratSala \& Redford, 2012; Raedts et al., 2007; Shell et al., 1989)

One of the most prominent claims about writing self-efficacy is the idea that being in possession of self-efficacy is a more powerful predictor of performance than ability (Pajares \& Valiante, 2006). This claim is easy to imagine in a context of say for example, my other passion of bicycle racing, where the rider's skills at handling a bike, being strategic in taking advantages of openings against an opponent, and ability to keep the rubber on the pavement to avoid crashing, are all observable skills. These things take practice. You can be a strong rider and not have the skills in a bike race. You can have strong skills but if you don’t believe you can beat your rival, you may back off. Or, if you don't care if you beat your rival you may back off. There are very visible bike racing abilities with measurable effects. And best of all, you can transfer your skills from race to race. The context for the use of those skills, changes little. 
But what about writing? There are complexities in the act of writing that are difficult to capture in measurable effects. If we think about student writing and if we compare each writing assignment as being the parallel experience of the bike race, there are several confounding factors. First, I don't know too many undergraduate students that report practicing their writing skills for their academic assignments. They join the race without any comparable practice session. One might argue that note-taking or rough drafts might serve this purpose, but in most other skill-based activities, you practice between skill demonstrations in as many similar contexts as possible. Previous writing assignments and contexts are not necessarily comparable events, as those who have written about the lack of writing transfer observe (Brent, 2011). Genre theory tells us that different genres of writing require different rhetorical actions - and those actions have social purposes intended to maintain community norms (Miller, 1984). What about if you don't care about what you are writing? If you don't value the writing assignment, the quality of your output may not match your ability even if you believe yourself to be a strong writer. Or what if you face a very high stakes writing scenario, as graduate students do when writing a thesis, and academics do when seeking publication? Your imagined sense of external perceptions and the audience you face will have a significant impact on your self-beliefs about your ability to be successful, beyond how skilled you might appear on the surface.

This complexity in writing and the academic writing context in general, explains the numerous challenges that writing self-efficacy researchers have had predicting performance scores with writing self-efficacy measures. Researchers have only sometimes been able to predict writing performance and only when they overcontrol the writing environment. For example, using timed and untimed in class writing exercises (MacArthur et al., 2016; McCarthy et al., 1985; Maimon, 2002; Nicholas et al., 2005; Pajares \& Johnson, 1994; Perin et al., 2017; Quible, 1999; Rankin et al., 1993; Raedts et al., 2007; Raedts et al., 2017; Shell et al., 1989; Van 
der loo et al., 2016; Vanhille et al., 2017; Williams \& Takaku, 2011; Woody et al., 2003;

Zimmerman \& Kitsantas, 2002) or standardized testing (Jones, 2008; Teng et al., 2017;

Woodrow, 2011). Even then predicting performance with writing self-efficacy scores is rarely achieved. Neither in class writing assignments or standardized testing are representative of the kinds of writing that students are required to do and get graded on in academic programs. Is it meaningful to predict performance only when we tightly control the writing environment and contain it to highly structured writing? A secondary strategy is to ensure that the only aspects of writing performance assessed are those that most closely match the self-assessments on the writing self-efficacy tool - which means surface aspects of writing, such as grammar, syntax, word choice, formatting, and organization (Pajares \& Johnson, 1994; Quible, 1999). This is a key criticism of cognitive approaches to understanding student self-efficacy with writing - that the studies examine writing in contexts that look nothing like the actual contexts that students write for in post-secondary education (Greeno, 1998).

Broad assessments such as grade point average (GPA) or overall course letter grade have also been used (Jones, 2008; Martinez et al., 2011; Mitchell \& McMillan, 2018; Zimmerman \& Bandura, 1994) with low (but usually still statistically significant) correlations with writing selfefficacy. Assessment of writing self-efficacy within naturalistic writing environments such as using assignments associated with course content are also common (e.g. Lavelle, 2006; MacArthur et al., 2015; Miller et al., 2015; 2018; Mitchell, Harrigan, \& McMillan, 2017; Mitchell, Harrigan et al., 2017; Mitchell \& McMillan, 2018; Prat-Sala \& Redford, 2010; Rayner et al., 2016; Sanders-Rio et al., 2014) and rarely find that self-efficacy predicts performance. The relationship between writing self-efficacy and performance appears to be not as strong as originally hypothesized. Writing self-efficacy studies from the last 10 years have largely abandoned attempting to predict writing performance with writing self-efficacy scores (van 
Blankenstein et al., 2019; Blakeslee et al., 2018; Ekholm et al., 2015; Huerta et al., 2017;

Plakhotnik \& Rocco, 2016; Prat-Sala \& Redford, 2010; Stewart et al., 2015; Taniguchi et al., 2017; Van de Poel \& Gasiorek, 2012). The direct influence of writing self-efficacy on writing performance may be mediated by various contextual factors which have not yet been explored in writing self-efficacy research.

Writing self-efficacy will, of course, improve from the beginning to the end of a writing course (Blakeslee et al., 2018; Goodman \& Cirka, 2008; Jones, 2008; Miller et al., 2015; 2018; Mitchell, Harrigan, \& McMillan, 2017; Schmidt \& Alexander, 2012; Van de Poel \& Gasiorek, 2012; Woody et al., 2013). When you consider threats to internal validity, any attention given to a population will naturally cause improvement. But sometimes, writing self-efficacy does not improve pre to post writing intervention (Martinez et al., 2011). Student writing self-efficacy may not show meaningful improvement because it is common for post-secondary students to overinflate their self-reported writing self-efficacy, particularly in contexts when the population of study has no frame of reference for the degree of complexity of the writing they are about to face. This effect is particularly evident in students new to university level education. If students can only call up reflections of their writing experiences in high school, self-efficacy ratings in the post-secondary context, especially in first year, are unlikely to be accurate. These students do not yet know what they don’t know. Past successes may bear no relationship to a particular writing context as students move further in their education from high school to undergraduate to graduate writing. As different disciplines have been known to have different writing expectations, changing disciplines can also impact writing performance assessments (Lea \& Street, 1998) with consequences to writing self-efficacy, especially when the student has not yet recognized the acceptable writing conventions for that discipline or the particular genre motives associated with their written work. 
With expectations becoming more demanding and writing becoming more complex as one moves further along in their academic studies, it can feel to students like they make very few gains in their writing abilities. I began this prologue with a retrospective of key writing highlights from my academic and personal writing endeavors. At each phase of writing I felt like I was a great writer. I can look back at those old texts now and see how far I have come. But writing development is insidious. Some writing is more personal than other writing and putting it out in the world will have greater impacts on self-efficacy. This was particularly true when I wrote my novel, but it was also true when seeking to publish the social media storytelling paper (Mitchell, 2019) because I had taken risks with that work, breaking down the fourth wall, that are generally not well accepted in academic writing. Some aspects of writing are exclusively cognitive through the involvement of working memory. I wrote the first draft of this chapter without looking up a single supporting paper, citing where I could, only from memory. Flower and Hayes (1981) described the cognitive categories of planning, translating (composing) and reviewing (revising) where working memory played a role in all phases. These cognitive categories remain critical to the writing process and that Flower and Hayes's theory continues to be referred to in the writing literature nearly 40 years later, speaks to their continued relevance. Hayes (1996) later independently revised the theory in an attempt to better incorporate the social context, however, adds that he only went as far as he was capable, after all, he is a psychologist not a sociologist. He encouraged a parallel empirical research tradition about the social aspects of writing as if, somehow, a writer's process choices could be separated from their social context.

But what of the writing context - the situated nature of writing that also impacts writing self-efficacy? Explorations of the situated realities of writing are what inspired the series of papers contained within this thesis. My assessment of writing self-efficacy literature and the four 
research studies I had conducted prior to becoming a doctoral student were central to my approach to exploring writing when I entered the doctoral program. That experience merged in my thinking with the philosophical explorations about writing that emerged from my doctoral coursework (Mitchell, 2017; 2018; 2019). This meant, two theoretical frameworks were needed in developing a new measure of writing self-efficacy that considered both the cognitive aspects of writing self-efficacy, but also the situated social influences on writing. What follows is an exploration of the two theoretical frameworks and their philosophical premises

\section{Considering Two Theoretical Premises for Writing Self-Efficacy}

Measurement plays an important role in nursing in creating further understanding of nursing's ways of knowing. The act of defining a concept and developing items is a constructionist process but using those items as statistical measurement is a realist ontology assuming that reality can be defined and represented by a numerical score. Durepos et al., (2018) have proposed that measurement creates an intermediary reality they define as constructive realism. Through constructive realism, a cognitive construct, such as writing self-efficacy, can be re-conceptualized as a socially constructed concept and then developed into a measurable construct and produce a version of the truth that is an approximation of reality forming a bridge between positivist and constructionist epistemologies.

Bandura’s (1997; 2006) self-efficacy theory brings a necessary perspective to the assessment of writing self-efficacy by defining human agency and providing insight into how learners develop the foresight to initiate action plans, continue to move forward with their goals, self-regulate their behaviours in order to accomplish their goals, and understand how they selfreflect on the process. Students may have self-efficacy and ability, but still fail to accomplish a writing task because, perhaps, they don't value the task, they don't believe the actions they have been told to take to improve will have any effect on the outcome, or their sense of initial writing 
self-efficacy may have been inflated due to lack of similarity between their past writing experiences and the new unfamiliar writing genres and/or context. Therefore, even capable students can lack the motivation to perform, feel they have no control over their environment, or misread the complexity of their writing environment, any of which can affect the performance outcome (Bandura, 1991; 1993; 2006). When exploring self-efficacy from a writing perspective, Bandura’s four sources of self-efficacy are defined as follows:

1. Mastery: Mastery is defined by considering past experiences (success or failure) with writing, beliefs that writing success can be attributed to ability rather than luck, and perceptions of the value inherent in taking self-regulatory actions to improve their writing.

2. Vicarious experience: Involves self-comparisons with "like" others who act as models for writing success. In writing experiences, vicarious experiences might include reading another student's paper and forming beliefs about their own writing abilities based on whether they believe their own writing is better or worse than the model provided. The model helps the student writer self-assess if they are capable or incapable of producing a similar or better outcome.

3. Verbal persuasion: In writing environments, feedback from credible others would act to persuade the writer they are capable, have a chance for success, or have talent. The student must value the skills and knowledge of the feedback provider in order for their verbal persuasiveness to have any influence on their self-efficacy beliefs.

4. Emotional arousal: Includes both psychological and physiological responses to the writing experience. How well a student is able to control their emotional response to writing and continue to complete the task will affect their self-efficacy beliefs. High emotional arousal such as severe anxiety, apprehension, frustration, or fear is debilitating to writing 
performance and may lead to writing avoidance. Positive emotional arousals such as excitement, passion, or drive will facilitate writing.

Self-regulation must also be discussed in relation to self-efficacy theory (Bandura, 1991). A student's level of writing self-efficacy will influence whether that student sees any value in taking action to improve their writing ability. Self-regulation allows a student to visualize the prospective consequences of particular actions. Help seeking is a common self-regulatory action in writing. Seeking preliminary feedback in the midst of a writing task and using that feedback to set goals and plan their writing would be another self-regulatory action. Students with higher self-efficacy and self-regulatory abilities will seek out more difficult writing tasks and exert more effort in their writing assignments.

Self-efficacy theory conjures images of the writer visualizing their external state and making self-efficacy judgements as a result (Bandura, 1997; Greeno, 1998). However selfefficacy theory does not clearly define the external state. Socially constructed situated perspectives of writing are more effective for defining the context in which writing takes place. Writing occurs within communities. Those communities have their own shared genres and discourses, and mastery of those genres or discourses is how a person develops an identity as a full member of that community (Hyland, 2003; Russell, 1997; Wenger, 1998). How communities influence writing practices are defined in constructionist perspectives on writing. If communities and disciplines influence the kinds of goals students have in their writing, how they plan their writing, and how their writing is evaluated, then the characteristics of socially constructed writing communities and discourses will impact writing self-efficacy. A constructionist model of writing is not linear but rather functions as an assemblage of factors, "the folding of one text into another” (St. Pierre, 2014, p. 378) with the nurse’s writerly identity at the core and the context of writing acting as the container for the writing experience. Each element of the writing model (see 
Figure 1) is intertwined with the others and any of the constructionist domains of writing can be the focus of the writing process at any moment (see also Paper 1, Mitchell, 2018). In social constructionism, context is the binding factor. A person's identity, relationships, allowance for creativity, and emotions will all be contextually influenced. Reflective capacity is what intertwines the model together into a collective unit.

\section{Figure 1: A Visual of the Intertwined Socially Constructed Model of Writing}

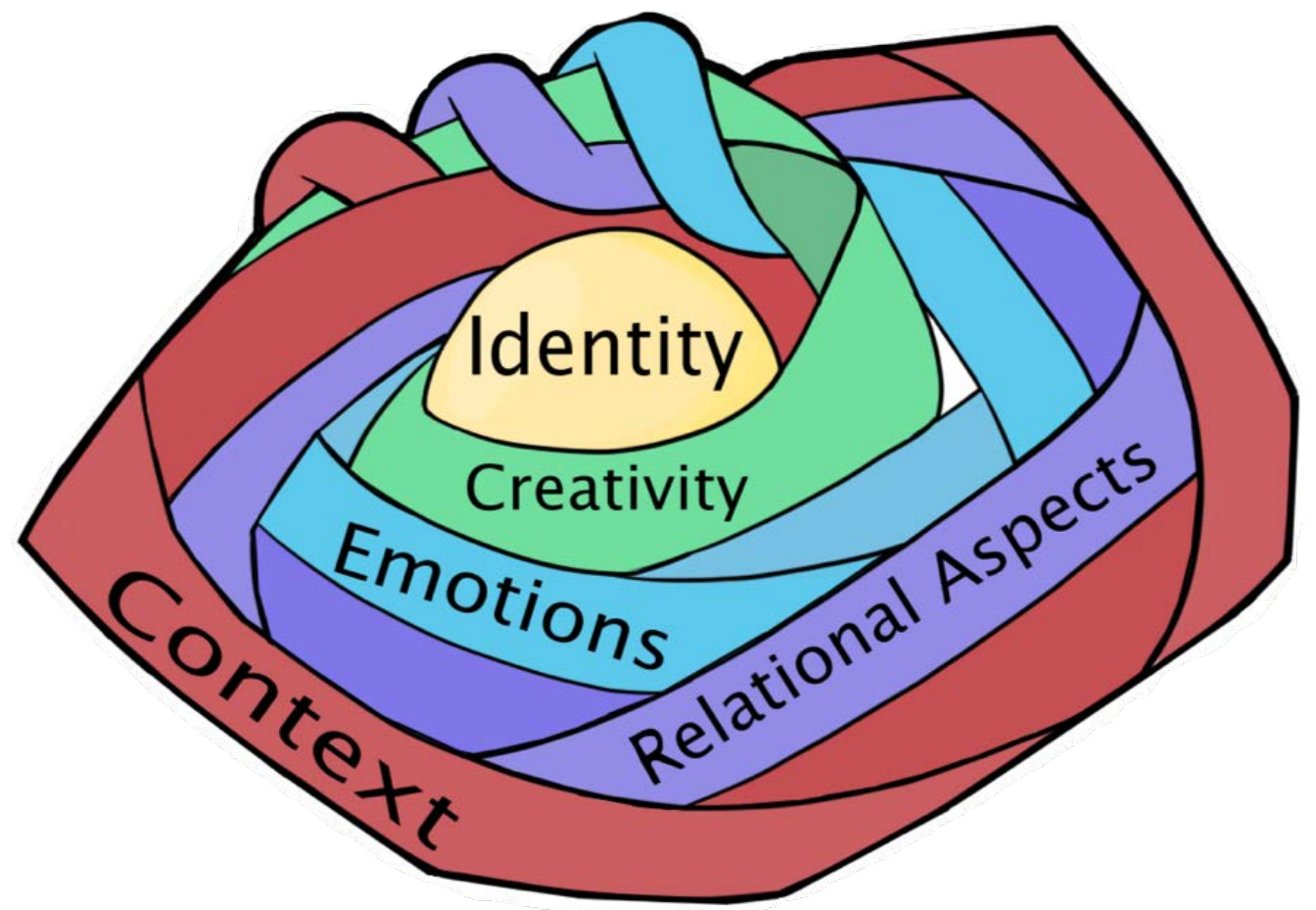

(Model drawing by Emma McCormick)

The components of the model are defined as follows:

1. Identity: Incorporates writing voice, the self as it appears within a written text, past experiences with writing and their influence on present writing, and degree of writing mastery. A writer's perceived identity in the discipline of nursing will also be relevant. Reflexivity facilitates the metacognition and intertwining required to activate the other components of the model as they relate to writing and nursing identity. A writer's self- 
efficacy will be negatively impacted when they do not identify with their discipline or its writing or when they feel their personal self and ideas are not valued in the writing process.

2. Creativity: Novelty and originality as defined by a discipline informs creativity. Idea generation, synthesis, ability to manipulate a genre, and interpretive abilities all require creativity. Creativity fuels passions and develops identity through a merger of the personal and the professional. A writer's self-efficacy will be impacted if they feel that they are not allowed to be creative or if their version of creativity is not shared by the faculty who assigns the writing.

3. Emotions: Writing emotions can be positive or negative, are subject to roller-coaster extremes, and will drive or inhibit the writing act. Emotions are present at all phases of writing from planning to feedback. Ability to control emotions, write in the face of difficulties, and an environment that validates or does not validate the normality of writing emotions will impact writing self-efficacy.

4. Relational Aspects: Writers form relationships with the sources they incorporate through citation, inspiration, or interpretation. Writers write for an imagined audience and that audience connects with their writing when a writer reveals themselves in their work. Students also form relationships with their teachers during pedagogical processes and feedback interactions. Ability to understand and relate to the sources read to inform their writing, position their own writing within a larger body of work, and connect with faculty during the writing process will all affect student writing self-efficacy.

5. Context: The writing context includes perceived difficulty of the writing task and writing evaluators, how they perceive the support they are receiving for their writing, the stakes involved in producing a well-received product, and the values and demands inherent in a disciplinary discourse. Writing self-efficacy will be impacted if students feel unsupported, 
devalue the assigned writing, or if they do not feel their actions in their writing context are likely to lead to success within the writing genre they need to produce.

While Paper 2 (Mitchell et al., 2019) in this thesis will elaborate on the theoretical combination of these two perspectives, a brief description of the process will follow. The proposed writing self-efficacy instrument was developed with items that fell into each of these five constructionist domains of writing. Self-efficacy theory blends into the constructionist perspective. Being masterful in writing the genres of the nursing discipline is a sign that the writer is developing an identity in the discipline. Vicarious experiences and verbal persuasion are relational aspects of writing as one defines how a writer views themselves in relation to their peers, and the other explores how feedback, perhaps from faculty or other community members, affects self-perceptions of writing. Finally, emotional arousal merges with the emotional knowing domain of the constructionist perspective. Together the theories provide a more complete view of the factors that influence nursing student writing self-efficacy and will inform measurement of the concept.

\section{The Situated Academic Writing Self-Efficacy Project}

The instrument development project was designed as a multimethod sequential design with the primary research question being, "What items will form the most reliable and valid measure of constructionist writing self-efficacy?” The project proceeded as follows:

1. Item development was completed in May 2018 prior to attendance at the Sigma Theta Tau Conference in Melbourne Australia where the intention was to pilot the items with conference attendees during a poster session (Mitchell et al., 2018). The 41 initially developed items and their evolution through all phases of the study can be viewed in Appendix A - Situated Academic Writing Self-Efficacy Scale Evolution of Item Editing. 
2. Following ethical approval, the initial developed items were piloted with an international Delphi panel of 8 writing scholars and 7 nursing scholars during May and June of 2019. The items were further edited and refined, and the item list was reduced to 25 items (Appendix A).

\section{Research Question:}

What items will an expert panel of nursing and writing scholars establish as most representative of the proposed constructionist framework for measuring writing self-efficacy?

\section{Relevant Appendix Documents for the Delphi Phase:}

Appendix B - Round 1 Delphi Survey

Appendix C - Email Invitation Script Delphi

Appendix D - Delphi Study Consent Form

Appendix E - Description of the Theoretical Perspective

Appendix F - Example of Summary of the Results Round 1

Appendix G - Round 2 Delphi Survey

Appendix $\mathbf{H}$ - Example of Summary of the Results Round 2

3. Twenty undergraduate nursing students were interviewed from two local nursing programs in July 2019. The items were further edited, and the item count was reduced to 20 items (see Appendix A). The students shared many rich reflections about their writing experiences in their nursing programs. These reflections underwent content analysis through the lens of Activity Theory to examine the nature of the contextual impacts on writing self-efficacy.

\section{Research Questions:}

To what degree will undergraduate nursing students be able to comprehend, retrieve associated memories, judge those memories as appropriate examples, and form a response to the proposed items on a writing self-efficacy instrument? 
What kind of writing experiences will undergraduate nursing students describe to support their writing self-efficacy experiences and ratings?

\section{Relevant Appendix Documents for the Cognitive Interview Phase:}

Appendix I - Informed Consent Cognitive Interviews

Appendix $\mathbf{J}$ - Script for Cognitive Interviews

Appendix K - Prescripted Prompts for Cognitive Interviews

Appendix L - Demographic Form for Cognitive Interviews

Appendix M - Invitation to Participants for the Cognitive Interviews

Appendix N - Email Request to Nursing Programs for Cognitive Interviews

Appendix $\mathbf{O}$ - Recruitment Poster for Cognitive Interviews

4. The final list of 20 items were piloted in an online survey with nursing students from September through December 2019. Tool validation was the main goal of this phase including the following forms of validity as outlined by Polit and Beck (2017).

- Criterion related validity - using concurrent validity procedures of comparing responses to two established writing self-efficacy instruments developed under different theoretical pretenses, with responses to the new situated tool.

- Discriminant validity - the Shell et al. (1989) tool was deliberately chosen to assess if the new tool would exhibit divergent properties from a scale that focused its selfefficacy assessments on grammar and mechanics for writing.

- Construct validity - through hypothesis testing procedures involving convergent validity assessment of the new tool with an established measure of writing apprehension. Hypothesized relationships between the new tool and professional nursing identity and writing context will also be included in the assessment. 
- Structural validity - to compare the structural dimensions of the new tool to the socially constructed model of writing through exploratory factor analysis.

The goals of this phase of the study were exploratory factor analysis to identify the factor structure of the questionnaire. Two existing writing self-efficacy measures were included to assess concurrent validity (Mitchell et al., 2017; Shell et al., 1989). A structural equation model was proposed to assess construct validity. Three constructs - nursing identity, context ratings, and writing apprehension - formed the structural equation model. The choice of variables emerged from previous writing self-efficacy literature as well as hypothesized relationships within the constructionist model of writing.

a. Constructionist writing perspectives emphasize the role writing plays in the development of an identity within a discipline (Russell, 1997; Mitchell, 2018). Incomplete development of disciplinary identity may lead to low self-efficacy when writing in the genres specific to that discipline. Having an identity in a discipline will also contribute to developing an emotional connection to the writing performed and an understanding of what might be considered academic writing creativity within that discipline. Identifying as a nurse, which will be assessed using the Professional Identity Scale (Adams et al., 2006), may affect how students connect with the writing they are assigned in their nursing program. Nursing identity may also contribute to predicting writing self-efficacy levels.

b. The inconsistent faculty support for writing reported by nursing students in qualitative studies may also define the context of writing in the nursing discipline (Blakeslee et al, 2018; Chaudoir et al., 2016; Whitehead, 2002). Thus, for this study, in developing a statistical model for hypothesis testing the construct validity of this questionnaire, ratings of writing context issues such as perceived supportiveness, 
value of the assignment to learning, and the stakes of the assignment to their desired grade in a course or program, are hypothesized as potential predictors of student writing self-efficacy.

c. Lastly, writing apprehension using Daly and Miller’s (1975) gold standard questionnaire has been firmly established as producing negative effects on writing self-efficacy levels in past research (Goodman \& Cirka, 2009; Pajares \& Johnson, 1994; Sanders-Rio et al,, 2014; Vanhille et al,, 2017). A negative relationship between a measure of writing apprehension and a new measure of writing selfefficacy should be theoretically predictive and support instrument validation.

\section{Research questions:}

What is the best fit factor structure in the latent variable analysis of the revised constructionist writing self-efficacy questionnaire (now called the Situated Academic Writing Self-Efficacy Scale - SAWSES)?

Do writing apprehension, nursing identity, and writing context ratings predict SAWSES scores?

\section{Relevant Appendix Documents for the Nursing Student Survey:}

Appendix P - Nursing Survey and Questionnaires including Demographic Items Appendix Q - Informed Consent for Nursing Survey

Appendix R - Email Request to Nursing Programs for Nursing Survey

Appendix S - Email Invitation for Faculty to Attend Classes to Conduct Nursing Survey Appendix T - Email Invitation to Nursing Students to Request Participation Appendix U - Reminder Email to Nursing Students to Complete Survey Appendix V - Script to Introduce Study During Nursing Classes

5. To improve the generalizability of the developing scale, a fifth phase of the study was developed to confirm the factor structure identified with the nursing student sample with an 
interdisciplinary sample of undergraduate and graduate students. Students were sampled via social media and through administrative offices at three local institutions from December 2019 to March 2020. Multigroup confirmatory factor analysis procedures were the main method associated with this phase of the study. Additional validation procedures were included in this phase including:

- Structural validity - Confirmatory factor analysis was required to identify if the factor structure identified in the nursing sample would be confirmed in an interdisciplinary sample of undergraduate and graduate students.

- Discriminative validity - the responses of interdisciplinary undergraduate and graduate students when compared to nursing student responses allowed for identification of the potential for the new tool to discriminatively differentiate between nurse writers and interdisciplinary undergraduate and graduate writers.

- External validity - confirmation of factor structure in an interdisciplinary sample would add confidence that the scale may be used effectively in all post-secondary and post-graduate student populations and is broadly generalizable.

\section{Research questions:}

Does the factor structure for SAWSES, initially identified in the nursing student population, confirm in interdisciplinary undergraduate and graduate student samples?

Do undergraduate and graduate students exhibit response differences to the SAWSES scale when item ratings are examined through multigroup confirmatory factor analysis measurement invariance testing and item response analysis procedures (difficulty and discrimination)?

\section{Relevant Appendix Documents:}

Appendix W - Interdisciplinary Survey Including Demographic Items

Appendix X-Informed Consent for Interdisciplinary Survey 
Appendix Y - Email Invitation to Participants for Interdisciplinary Survey

Appendix Z - Social Media Infographic

\section{Papers Contained Within this Thesis}

Five papers were developed and written based on the theoretical premise of the project and the findings of the studies conducted to validate the Situated Academic Writing SelfEfficacy Scale.

\section{Paper 1: Constructing Writing Practices in Nursing}

This paper examined the epistemological context of writing in nursing education. It proposes that nursing has not adopted more current socially constructed perspectives in their writing practices or their teaching of writing and instead continues to perpetuate writing perspectives that are objectivist and product focused. The paper synthesized the literature on socially constructed writing to define identity, creativity, emotions, relational aspects, and writing context as the core facets of disciplinary writing. The model proposed is intertwined through reflexive processes. These five domains of socially constructed writing ultimately structured the item development for the Situated Academic Writing Self-Efficacy Scale.

\section{Paper 2: Applying the 'Social Turn' in Writing Scholarship to Perspectives on Writing Self-Efficacy}

Because the instrument development project proposed to merge Bandura’s self-efficacy theory (a cognitive theory) with socially situated perspectives on writing (a socially constructed theory), it was necessary to explore if the two theoretical perspectives were epistemologically compatible. Paper 3: Delphi Decision Making: Blending Qualitative and Quantitative Methods in Tool Development Research

Although use of a Delphi panel is mentioned as a common strategy in instrument development and validation, most literature discussing Delphi methods, limited their discussions to policy or 
clinical guideline contexts. This paper was written as pragmatic guidance for new and seasoned researchers who wish to use Delphi methods for item decision making in an instrument development project.

\section{Paper 4: “Follow the Rubric is the Thing in Nursing”: Navigating Systemic, Instructional, and Personal Influences on Writing Activities}

The cognitive interviews with the nursing students elicited many vivid descriptions of their writing experiences in their nursing programs. The paper explores the journeys of four students, created as composites from the 20 student participants, and their response to the nursing writing context. The fictitious students are characterized as grade hungry, determined self-preservers, risk adverse, and seeking belonging. The central feature emerging from this analysis, is guided by Activity Theory (Kain \& Wardle, 2005), focused on the tremendous energy students exert while trying to figure out their teachers. The systemic influences of a rigid writing context forced many students to have to "codeswitch" their writing styles through adjustment of their student identities, personas, and behaviours while attempting to meet writing expectations in their courses.

\section{Paper 5: Development and Validation of the Situated Academic Writing Self-Efficacy Scale} (SAWSES)

This multi-study manuscript describes the outcome of the five instrument development phases completed for this project. The research details the methods and findings for the item development and revision phases (item development, Delphi, and cognitive interviews) and then details the findings for the nursing sample (Study 1) and the interdisciplinary student samples (Study 2). 


\section{Conclusion}

“This experience has made us think about a culture at the university where writing is pushed to the periphery, where the priority is given to the course content, and where students are not expected to communicate clearly in a written form. Students write poorly not only because an individual instructor did not give them guidance, but also because that instructor has never been asked, taught, or required to provide such guidance and might be incapable of providing useful feedback... We think that unless we change the culture of how we think about writing in the university, student writing will not improve” (Plakhotnik \& Rocco, 2016, p. 166).

This thesis was built upon several assumptions and anticipated contributions:

1. That the writing environment in nursing education has not advanced beyond thinking of writing by its superficial textual features and that many faculty expect students come to nursing courses ready prepared to write without being provided with additional assignmentor genre-specific instruction.

2. That a paradigm shift in how writing is viewed and taught in nursing education at the postsecondary level is required to improve student writing and help students see the value of that writing to their clinical practice.

3. That socially constructed situated perspectives on writing, which are largely absent from social cognitive perspectives on writing, could provide valuable insights to the measurement of writing self-efficacy.

4. That measuring writing self-efficacy with consideration for socially constructed and situated perspectives on writing hold the potential to provide better guidance in disciplinary contexts for intervening in student writing difficulties. 
5. Methodologically, psychosocial measurement tools are most rigourously assessed in multiphased, multi-method research studies, that consider the functioning of the instrument in a variety of populations. 


\section{References}

Adams, K., Hean, S., Sturgis, P., \& Macleod Clark, J. (2006). Investigating the factors influencing professional identity of first-year health and social care students. Learning in Health and Social Care, 5(2), 55-68. https://doi.org/10.1111/j.1473-6861.2006.00119.x

Allen, D. G., Bowers, B., \& Diekelmann, N. (1989). Writing to learn: A reconceptualization of thinking and writing in the nursing curriculum. Journal of Nursing Education, 28(1), 611.

Bakhtin, M. (1981). Discourse in the novel (C. Emersion \& M. Holquist, Trans.). In M. Holquist (Ed.), The dialogic imagination (pp. 259-422). University of Texas Press.

Bandura, A. (1991). Social cognitive theory of self-regulation. Organizational Behavior and Human Decision Processes, 50, 248-287. https://doi.org/10.1016/0749-5978(91)90022-L

Bandura, A. (1993). Perceived self-efficacy in cognitive development and functioning. Educational Psychologist, 28(2), 117-148. https://doi.org/10.1207/s15326985Awp2802_3

Bandura, A. (1997). Self-efficacy: The exercise of control. W. H Freeman.

Bandura, A. (2006). Toward a psychology of human agency. Perspectives on Psychological Science, 1(2), 164-180. https://doi.org/10.1111/j.1745-6916.2006.00011.x

Bawarshi, A. S. (2003). Genre and the invention of the writer: Reconsidering the place of invention in composition. Utah State University Press

Blakeslee, A., Hines, S., Primeau, S., McBain, A., Versluis, J., \& McCaffery, R. (2018). Reading and writing in nursing education. Journal of Nursing Education and Practice, 8(6), 5665. https://doi.org/10.5430/jnep.v8n6p56

Bolton, G. (2010). Reflective practice: Writing and professional development ( $3^{\text {rd }}$ ed.). Sage. 
Brent, D. (2011). Transfer, transformation, and rhetorical knowledge: Insights from transfer theory. Journal of Business and Technical Communication, 25(4), 396-420. https://doi.org/10.1177/1050651911410951

Brontë, E. (n.d.). Wuthering heights quotes. https://www.goodreads.com/work/quotes/1565818wuthering-heights

Canadian Association of Schools of Nursing. (2015). National nursing education framework: Baccalaureate. https://www.casn.ca/wp-content/uploads/2014/12/FINAL-BACCFramwork-FINAL-SB-Jan-2016.pdf

Chaudoir, S., Lasiuk, G., \& Trepanier, K. (2016). Writing assignments: A relatively emotional experience of learning to write in one baccalaureate nursing program. Quality Advancement in Nursing Education, 2(2), 1-21. https://qaneafi.casn.ca/journal/vol2/iss2/3/

Clandinin, D. J., \& Connelly, F. M. (2000). Narrative inquiry: Experience and story in qualitative research. Jossey-Bass.

College of Registered Nurses of Manitoba. (2019). Entry level competencies (ELCs) for the practice of registered nurses. https://www.crnm.mb.ca/uploads/document/document_file_92.pdf

Daly, J. A., Miller, M. D. (1975). The empirical development of an instrument to measure writing apprehension. Research in the Teaching of English, 9(3), 242-249. https://www.jstor.org/stable/40170632

Durepos, P., Orr, E., Ploeg, J., \& Kaasalainen, S. (2018). The value of measurement for development of nursing knowledge: Underlying philosophy, contributions and critiques. Journal of Advanced Nursing, 74(10), 2290-2300. https://doi.org/10.1111/jan.13778 
Ekholm, E., Zumbrunn, S., \& Conklin, S. (2015). The relation of college student self-efficacy toward writing and writing self-regulation aptitude: Writing feedback perceptions as a mediating variable. Teaching in Higher Education, 20(2), 197-207. https://doi.org/10.1080/13562517.2014.974026

Fleischman, S. (1998). Gender, the personal, and the voice of scholarship: A viewpoint. Signs: Journal of Women in Culture and Society, 23(4), 975-1016. https://www.jstor.org/stable/3175200

Fleischman, S. (1999). I am..., I have..., I suffer from...: A linguist reflects on the language of illness and disease. Journal of Medical Humanities, 20(1), 3-32. https://doi.org/10.1023/A:1022918132461

Flower, L., \& Hayes, J. R. (1981). A cognitive process theory of writing. College Composition and Communication, 32(4), 365-387. https://doi.org/10.2307/356600

Goodman, S. B., \& Cirka, C. C. (2009). Efficacy and anxiety: An examination of writing attitudes in a first-year seminar. Journal on Excellence in College Teaching, 20(3), 5-28.

Greeno, J. G. (1998). The situativity of knowing, learning, and research. American Psychologist, 53(1), 5-26. https://doi.org/10.1037/0003-066X.53.1.5

Hayes, J. R. (1996). A new framework for understanding cognition and affect in writing. In C. M. Levy \& S. Ransdell (Eds.). The science of writing: Theories, methods, individual differences and applications (pp. 1-27). Lawrence Erbaum Associates.

Huerta, M., Goodson, P., Beigi, M., \& Chlup, D. (2017). Graduate students as academic writers: Writing anxiety, self-efficacy and emotional intelligence. Higher Education Research \& Development, 36(4), 716-729. https://doi.org/10.1080/07294360.2016.1238881

Hyland, K. (2003). Genre-based pedagogies: A social response to process. Journal of Second Language Writing, 12(2003), 17-29. https://doi.org/10.1016/S1060-3743(02)00124-8 
Hyland, K. (2004). Disciplinary discourses: Social interactions in academic writing. University of Michigan Press.

Ivanič, R. (1998). Writing and identity: The discoursal construction of identity in academic writing. John Benjamins Publishing.

Johansen, E., \& Harding, T. (2013). ‘So I forgot to use 1.5 line spacing! It doesn’t make me a bad nurse!' The attitudes to and experiences of a group of Norwegian postgraduate nurses to academic writing. Nurse Education in Practice, 13, 366-370. https://doi.org/10.1016/j.nepr.2012.10.001

Jones, E. (2008). Predicting performance in first-semester college basic writers: Revisiting the role of self-beliefs. Contemporary Educational Psychology, 33, 209-238. https://doi.org/10.1016/j.cedpsych.2006.11.001

Kain, D., \& Wardle, E. (2005). Building context: Using activity theory to teach about genre in multi-major professional communication courses. Technical Communication Quarterly, 14(2), 113-139. https://doi.org/10.1207/s15427625tcq1402__1

Kamler, B., \& Thompson, P. (2006). Helping doctoral students write: Pedagogies for supervision. Routledge, Taylor \& Francis.

Lavelle, E. (2006). Teachers’ self-efficacy for writing. Electronic Journal of Research in Educational Psychology, 4(1), 73-84.

Lea, M. R., \& Street, B. V. (1998). Student writing in higher education: An academic literacies approach. Studies in Higher Education, 23(2), 157-172, https://doi.org/10.1080/03075079812331380364

Luthy, K. E., Peterson, N. E., Lassetter, J. H., \& Callister, L. C. (2009). Successfully incorporating writing across the curriculum with advanced writing in nursing. Journal of Nursing Education, 48(1), 54- 59. https://doi.org/10.3928/01484834-20090101-07 
MacArthur, C. A., Philippakos, Z. A., \& Graham, S. (2016). A multicomponent measure of writing motivation with basic college writers. Learning Disability Quarterly, 39, 31-43. https://doi.org/10.1177/0731948715583115

MacArthur, C. A., Philippakos, Z. A., \& Ianetta, M. (2015). Self-regulated strategy instruction in college developmental writing. Journal of Educational Psychology, 107(3), 855-867. https://doi.org/10.1037/edu0000011

Madigan, R., Johnson, S., \& Linton, P. (1995). The language of psychology: APA style as epistemology. American Psychologist, 50, 428-436. https://doi.org/10.1037/0003-

\section{$\underline{066 X .50 .6 .428}$}

Maimon, L. (2002). The relationship between self-efficacy and the functions of writing. Journal of College Reading and Learning, 33(1), 32-45. https://doi.org/10.1080/10790195.2002/10850135

Martinez, C. T., Kock, N., \& Cass, J. (2011). Pain and pleasure in short essay writing: Factors predicting university students’ writing anxiety and writing self-efficacy. Journal of Adolescent \& Adult Literacy, 54, 351-360. https://doi.org/10.1598/JAAL.54.5.5

McCarthy, P., Meier, S., \& Rinderer, R. (1985). Self-efficacy and writing: A different view of self-evaluation. College Composition and Communication, 36(4), 465-471.

McCormick, K. M. (2002). A concept analysis of uncertainty in illness. Journal of Nursing Scholarship, 34(2), 127-131. https://doi.org/10.1111/j.1547-5069.2002.00127.x

Meier, S., McCarthy, P. R., \& Schmeck, R. R. (1984). Validity of self-efficacy as a predictor of writing performance. Cognitive Therapy and Research, 8(2), 107-120. https://doi.org/10.2307/357865

Miller, C. (1984). Genre as social action. Quarterly Journal of Speech, 70, 151-167. https://doi.org/10.1080/00335638409383686 
Miller, L. C., Russell, C. L., Cheng, A. L., \& Skarbek, A. J. (2015). Evaluating undergraduate nursing students' self-efficacy and competence in writing: Effects of a writing intensive intervention. Nurse Education in Practice, 15(3), 174-180.

https://doi.org/10.1016/j.nepr.2014.12.002

Miller, L. C., Russell, C. L., Cheng, A-L., \& Zembles, S. (2018). Testing the efficacy of a scaffolded writing intervention with online degree-completion nursing students: A quasiexperimental design. Nurse Education in Practice. 32, 115-121. https://dx.doi.org/10.1016/j.nepr.2018.06.011

Mitchell, K.M. (2017). Academic voice: On feminism, presence, and objectivity in writing. Nursing Inquiry, 24(4), 12200. https://doi.org/10.1111/nin.12200

Mitchell, K. M. (2018). Constructing writing practices in nursing. Journal of Nursing Education, 57(7), 399-407. https://doi.org/10.3928/01484834-20180618-04

Mitchell, K. M. (2019). Social media storytelling: Using blogs and Twitter to create a community of practice for writing scholarship. Canadian Journal for Studies in Discourse and Writing/Rédactologie, 29, 1-23. https://doi.org/10.31468/cjsdwr.726

Mitchell, K. M., Harrigan, T., McMillan, D. E. (2017). Writing self-efficacy in nursing students: The influence of a discipline-specific writing environment. Nursing Open, 1-11. https://doi.org/10.1002/nop2.90

Mitchell, K. M., Harrigan, T., Stefansson, T., \& Setlack, H. (2017). Exploring self-efficacy and anxiety in first-year nursing students enrolled in a discipline-specific scholarly writing course. Quality Advancement in Nursing Education, 3(1), 4. https://doi.org/10.17483/2368-6669.1084 
Mitchell, K. M., \& McMillan, D. E. (2018). A curriculum-wide assessment of writing selfefficacy in a baccalaureate nursing program. Nurse Education Today, 70, 20-27. https://doi.org/10.1016/j.nedt.2018.08.003

Mitchell, K. M., McMillan, D. E., Lobchuk, M., \& Nickel, N. (2018). Psychometric Testing of a New Instrument to Measure Writing Self-Efficacy: A Proposed Mixed-Methods Delphi Study. International Nursing Research Congress - Sigma Theta Tau - Melbourne, Australia. https://sigma.nursingrepository.org/handle/10755/624591

Mitchell, K. M., McMillan, D. M., \& Rabbani, R. (2019). An exploration of writing self-efficacy and writing self-regulatory behaviours in undergraduate writing. Canadian Journal for the Scholarship of Teaching and Learning,10(2), Article 8. https://ojs.lib.uwo.ca/index.php/cjsotl_rcacea/article/view/8175

Mitchell, K. M., Rieger, K. L., \& McMillan, D. E. (2017). A template analysis of writing selfefficacy measures. Journal of Nursing Measurement, 25(2), 205-223. https://doi.org/10.1891/1061-3749.25.2.205

Mulhall, A. (1997). Nursing research: Our world not theirs? Journal of Advanced Nursing, 25, 969-967. https://doi.org/10.1046/j.1365-2648.1997.1997025969.x

Nicholas, K. R., Menchetti, B. M., Nettles, S. M. (2005). An exploratory investigation of structured writing strategy training for African-American college students with learning disabilities. Journal of College Reading and Learning, 36(1), 37-59. https://doi.org/10.1080/10790195.2005.10850179

Pajares, F., \& Johnson, M. J. (1994). Confidence and competence in writing: The role of selfefficacy, outcome expectancy, and apprehension. Research in the Teaching of English, 28(3), 313-331. http://www.jstor.org/stable/40171341 
Pajares, F., \& Valiante, G. (2006). Self-efficacy beliefs and motivation in writing development. In C. A. MacArthur, S. Graham, \& J. Fitzgerald (Eds.), Handbook of writing research (pp. 158-170). Guilford Press.

Perin, D., Lauterbach, M., Raufman, J., \& Kalamkarian, H. S. (2017). Text-based writing of lowskilled postsecondary students: Relation to comprehension, self-efficacy and teacher judgments. Reading and Writing, 30, 887-915. https://doi.org/10.1007/s11145-016-9706$\underline{0}$

Plakhotnik, M. S., \& Rocco, T. S. (2016). Increasing writing self-efficacy of adult learners: Different approaches, different results. Adult Learning, 27(4), 160-167. http://doi.10.1177/1045159515611879

Polit, D. F., \& Beck, C. T. (2017). Nursing research: Generating and assessing evidence for nursing practice $\left(10^{\text {th }}\right.$ ed.). Wolters Kluwer.

Prat-Sala, M., \& Redford, P. (2010). The interplay between motivation, self-efficacy, and approaches to studying. British Journal of Educational Psychology, 80, 283-305. https://doi.org/10.1348/000709909X480563

Prat-Sala, M., \& Redford, P. (2012). Writing essays: Does self-efficacy matter? The relationship between self-efficacy in reading and in writing and undergraduate students’ performance in essay writing. Educational Psychology, 32, 9-20. https://doi.org/10.1080/01443410.2011.621411

Quible, Z. K. (1999). Writing self-efficacy and writing apprehension: Do they affect the performance of students in written business communication? Journal of Business and Training Education, 8, 55-75.

Raedts, M., Van Steendam, E., De Grez, L., Hendrickx, J., 7 Masui, C. (2017). The effects of different types of video modelling on undergraduate students' motivation and learning in 
an academic writing course. Journal of Writing Research, 8(3), 399-435. https://doi.org.10.17239/jowr-2017.08.03.01

Raedts, M., Rijlaarsdam, G., van Waes, L., \& Daems, F. (2007). Observational learning through video-based models: Impact on students’ accuracy of self-efficacy beliefs, task knowledge and writing performances. In G. Rijlaarsdam (Series Ed.) and P. Boscolo \& S. Hidi (Volume Eds.), Studies in Writing: Vol, 19. Writing and Motivation (pp. 219-238). Elsevier.

Rankin, J. L., Bruning, R. H., Timme, V. L.., \& Katkanant, C. (1993). Is writing affected by spelling performance and beliefs about spelling? Applied Cognitive Psychology, 7, 155169. https://doi.org/10.1002/acp.2350070207

Rayner, G., Papakonstantinou, T., \& Gleadow, R. (2016). Comparing the self-efficacy and writing related abilities of native and non-native English-speaking students. Cogent Education, 3, 1179164. https://doi.org/10.1080/2331186X.2016. 1179164

Russell, D. R. (1997). Rethinking genre in school and society: An activity theory analysis. Written Communication, 14(4), 504-554. https://doi.org/10.1177/0741088397014004004

Ryan, M. M., Walker, M., Scaia, M., \& Smith, V. (2013). (un)Disciplining the nurse writer: Doctoral nursing students’ perspectives on writing capacity. Nursing Inquiry, 21(4), 294300. https://doi.org/10.1111/nin.12045

Sanders-Reio, J., Alexander, P. A., Reio, T. G., \& Newmann, I. (2014). Do students’ beliefs about writing relate to their writing self-efficacy, apprehension, and performance? Learning and Instruction, 33, 1-11. https://doi.org/10.1016/j.learninstruc.2014.02.001

Schmidt, K. M., \& Alexander, J. E. (2012). The empirical development of an instrument to measure writerly self-efficacy in writing centers. Journal of Writing Assessment, 5(1), 62. http://www.journalofwritingassessment.org/article.php?article=62 
Schwarzer, R., \& Jerusalem, M. (1995). General self-efficacy scale. In J. Weinman, S. Wright, \& M. Johnston (Eds.), Measures in health psychology - A user's portfolio: Causal and control beliefs (pp. 35-37). NFER-Nelson.

Shell, D. F., Murphy, C. C., \& Bruning, R. H. (1989). Self-efficacy and outcome expectancy mechanisms in reading and writing achievement. Journal of Educational Psychology, 81(1), 91-100. https://doi.org/10.1037/0022-0663.81.1.91

Stewart, G., Seifert, T. A., \& Rolheiser, C. (2015). Anxiety and self-efficacy’s relationship with undergraduate students’ perceptions of the use of metacognitive writing strategies. The Canadian Journal for the Scholarship of Teaching and Learning, 6(1), 4. https://doi.org/10.5206/cjsotl-rcacea.2015.1.4

St. Pierre, E.A. (2014). An always already absent collaboration. Cultural Studies-Critical Methodologies, 14, 374-379. https://doi:10.1177/1532708614530309

Taniguchi, S. T., Bennion, J., Duerden, M. D., Widmer, M. A., \& Ricks, M. (2017). Self-efficacy of risk taking in outdoor recreation as a predictor of the self-efficacy of risk taking in essay writing. Journal of Outdoor Recreation, Education, and Leadership, 9(4), 425-438. https://doi.org/10.18666/JOREL-2017-V9-14-8653

Teng, L. S., Peigian, P. S., \& Xu, L. (2017). Conceptualizing writing self-efficacy in English as a foreign language contexts: Scale validation through structural equation modeling. TESOL Quarterly. https://doi.org/10.1002/tesq.432

van Blankenstein, F. M., Saab, N., van der Rijst. R. M., Danel, M. S., Bakker-van den Berg, A. S., \& van den Broek, P. W. (2018). How do self-efficacy beliefs for academic writing and collaboration and intrisnic motivation for academic writing and research develop during an undergraduate research project? Educational Studies, 45(2), 209-225. https://doi.org. 10.1080/03055698.2018.1446326 
Van de Poel, K., \& Gasiorek, J. (2012). Effects of an efficacy-focused approach to academic writing on students' perceptions of themselves as writers. Journal of English for Academic Purposes, 11, 294-303. https://doi.org/10.1016/j.jeap.2012.07.003

Vanhille, J., Gregory, B., \& Corser, G. (2017). The effects of mood on writing apprehension, writing self-efficacy, and writing performance. Psi Chi Journal of Psychological Research, 22(3), 220-230. http://doi.org/10.24839/2325-7342.JN22.3.220

Wenger, E. (1998) Communities of practice: learning, meaning, and identity. Cambridge University Press.

White, B. J., \& Lamson, K. S. (2017). The evolution of a writing program. Journal of Nursing Education, 56(7), 443-446. https://doi.org/10.3928/01484834-20170619-11

Whitehead, D. (2002). The academic writing experiences of a group of student nurses: A phenomenological study. Journal of Advanced Nursing, 38(5), 498-506. http://doi.org/10.1046/j.1365-2648.2002.02211.x

Williams, J. D., \& Takaku, S. (2011). Help seeking, self-efficacy and writing performance among college students. Journal of Writing Research, 3, 1-18. https://doi.org/10.17239/jowr-2011.03.01.1

Woodrow, L. (2011). College English writing affect: Self-efficacy and anxiety. System, 39, 510522. https://doi.org/10.1016/j.system.2011.10.017

Woody, J. D., Zeleny, M. G., D’Souza, H. J., Harder, J., Reiser, J., \& Szto, P. (2014). Student progress in a social work writing course: Self-efficacy, course objectives and skills. Journal of Social Work Education, 50, 507-524. https://doi.org/10.1080/10437797.2014.917895 
Zimmerman, B. J., \& Bandura, A. (1994). Impact of self-regulatory influences on writing course attainment. American Educational Research Journal, 31, 845-862. https://doi.org/10.2307/1163397

Zimmerman, B. J., \& Kitsantas, A. (2002). Acquiring writing revision and self-regulatory skill through observation and emulation. Journal of Educational Psychology, 94(4), 660-668. https://doi.org/10.1037//0022-0663.94.4.660 
If you expect to succeed as a writer, rudeness should be the second-to-least of your concerns.

The least of all should be polite society and what it expects. If you intend to write as truthfully as you can, your days as a member of polite society are numbered, anyway.

Stephen King, On Writing 


\title{
Paper 1: Constructing Writing Practices in Nursing
}

\author{
Abstract \\ Background: While the quality of student writing is often lamented by faculty, writing \\ instruction is an area of nursing education that has received little attention. Nursing programs \\ rarely teach writing from a disciplinary perspective and promoting the drilling of basic-skills, \\ such as grammar, has failed to engage student writers. \\ Method: A critical examination of the history of writing research, the nursing academic context, \\ and the epistemology of writing as meaning making will provide the rationale behind a need for \\ a new perspective on nurses’ writing. \\ Results: A model to support socially constructed writing is proposed which explores the writer's \\ identity, relational aspects of writing, creative and emotional knowing, and the writing context. \\ Conclusion: This paper continues the conversation about re-visioning and enhancing the value of \\ writing within the nursing profession. The knowledge created while writing can contribute to \\ stimulating thinking, decision-making in practice, and identity formation of nurses.

\section{Author Contributions and Notes About this Paper} \\ As described in the Prologue, this paper was foundational to the item development for the \\ Situated Academic Writing Self-Efficacy Scale. Its origin was an assignment in the nursing \\ doctoral course Philosophy of Nursing Science, a seminar course facilitated by Dr. Diana \\ McMillan. It was published as a solo authored paper in the Journal of Nursing Education in July \\ 2018. In 2019, this paper was awarded the Christine A. Tanner scholarly writing award for best \\ paper in the journal for the 2018-2019 publishing year (June 1 to May 31) \\ (https://www.healio.com/nursing/journals/jne/christine-tanner-writing-award)
}


The paper can be referenced as:

Mitchell, K. M. (2018). Constructing writing practices in nursing. Journal of Nursing Education, 57(7), 399-407. https://doi.org/10.3928/01484834-20180618-04

\section{Copyright}

From the publisher's webpage as of June 3, 2020, the author's accepted version of the paper can be included in thesis, dissertations or grant applications when the thesis is open access. https://www.healio.com/footer/legal/permissions\#excerpt Additional copyright approval was sought to include the figure that appears in the publication in other areas of this this thesis (e.g. the Prologue). 


\section{Constructing Writing Practices in Nursing}

Academic writing instruction, and best practices for the induction of students in any discipline as thinkers and writers, is subject to two approach debates. Writing can be taught as a generic skill focusing on grammar and syntax and structural basics, presumably transferable to all contexts, or it can be taught within a disciplinary context that introduces students to the genre, tacit knowledge, values, relationality, and identity forming processes inherent in an academic discipline (Elton, 2010). Rarely are the two schools combined. One criticism of the skills-based model is that it is deficit focused rather than strength-based and assumes all student writing is deficient and in need of remediation (Allen et al., 1989; Elton, 2010; Lea \& Street, 1998; Lillis \& Turner, 2001; Nightingale, 1988).

The discipline of nursing acknowledges that the majority of writing instruction is situated within English departments or conducted by generic writing experts (Andre \& Graves, 2013; Diehl, 2007; Luthy et al., 2009), which ensures that nursing’s disciplinary values, discourses, and conventions will not be nurtured in the instructional process of learning to write. Disciplinary discourse perspectives of writing recognize that writers situate the language choices they make, their stance, and their knowledge within the tacit social context of their discipline (Hyland, 2004). Generic instruction, however, assumes the writing act is objective, formulistic, and is positivist in nature (Gimenez, 2012; Mitchell, 2017; Webb, 1992) - a stance Ryan et al., (2013) refers to as "insular," and which is also incongruent with the nursing value of relationality. Positivism as applied to academic writing assumes that it is possible for the author to separate themselves from their past experience, emotional response to the content, and the context in which the writing takes place. Positivists see writing as a mechanical and linear, thus measurable through quantitative methods (St. Pierre, 2014). The author is expected to remain invisible in the 
work (Mitchell, 2017). Passive voice, avoidance of first person, and a disengaged narrative are considered features of positivist writing (Tierney, 2002).

In the international nursing literature, periodic calls have been made for nurses to change the way they write and teach writing. While nursing's current preference for objectivist writing has taken us from a burgeoning scholarly discipline to an established research discipline, Fairbairn and Carson (2002) argue that nurses need to be able to write in a manner that tells the stories of nursing. Those stories occur primarily in practice and writing that is jargon filled, obscure, and speaks only to audiences of researchers will not have reach beyond the walls of academia. The goal of writing should be to create meaning and knowing. Writing that has meaning to practitioners, students, and the public requires considering factors including: disciplinary and writing context (Allen et al., 1989; Dieklemann \& Ironside, 1998; Gimenez; Webb, 1992), creativity (Diehl, 2007; Rolfe, 1997), emotional responses (Chaudior et al., 2016; Parboteeah \& Anwar, 2009), audience needs (Rolfe, 1997; Ryan et al., 2013), reflexivity (Mullhall, 1997; Ryan et al., 2013), and writer identity and voice (Mitchell, 2017; Ryan et al., 2013; Webb, 1992). These are only a sampling of citations from nurse writers who have previously connected the values of nursing to the writing process, although interdisciplinary authors looking at writing's social constructs present similar factors (see for example Flower, 1994; Game \& Metcalfe, 1996; Ivanič, 1998; Nightingale, 1988; Richardson \& St. Pierre, 2005).

\section{Background}

The inspiration for this current paper was established during a project I conducted with colleagues (Mitchell et al., 2017), examining the items on existing writing self-efficacy questionnaires used in published research. This project was initiated as a preliminary step to the development of a writing self-efficacy questionnaire which considers the socially constructed elements of writing. A template analysis method was used to categorize and theme the individual 
items on 11 published writing self-efficacy measures. Bandura’s (1977; 1997) self-efficacy theory and a cognitive process theory of writing by Flower and Hayes (1981) were used to identify a priori themes for the classification of the items. During the review process, one anonymous reviewer questioned, "Do these frameworks make this emerging, revised measure nursing discipline-specific or will another nursing writing framework (yet to be determined) need to be added to the analysis?” The paper that follows, which will examine writing from the stance of social constructionism, responds to this question of need for a model of writing amenable to the nursing discipline.

To provide additional background congruent with a social constructionist perspective which states that a writer's reality cannot be separated from the context of writing, or the past experiences and identity of the writer (Andrews, 2012), it will be relevant to understand that I am a registered nurse who has focused much of my nursing career in academia with interest toward exploring the writing experiences of undergraduate nursing students. Thus, much of my perspective on writing has developed over 15 years from working with and listening to the writing fears, frustrations, and elations as experienced by my cohorts of students. Only 6\% of Canadian nursing programs offer a discipline-specific writing course (Andre \& Graves, 2013). I was the course developer for one of those courses. The details of the instructional activities offered in that course are reported in Mitchell, Harrigan, et al. (2017).

The focus of this paper will be to provide the rationale behind a need for a new perspective on nurses' writing. It discusses writing as a process that is not only socially constructed, but which also establishes the identity of the writer within a discipline. A writer does more than make text, in this perspective; a writer makes meaning (Flower, 1994). The position taken is that nursing has fallen behind in exploring writing as an acculturation mechanism for the discipline by perpetuating outdated and positivistic modes of writing and 
failing to progress the teaching of writing outside of the basic skills perspective. Through an examination of the history of writing research, the nursing academic context, and the epistemology of writing as meaning making, a model of writing for the nursing discipline will be presented.

\section{Epistemological Shifts in Writing Research: Product, Process, and Social Movements}

An introduction to the trajectory of theoretical thinking on writing and its movement from product to process to social constructionism is relevant. The 1970s is thought to be the decade that marks the beginnings of empirical writing research (Nystrand, 2006). Early writing research assessed writing by its product or text, a perspective that has positivist undertones as it focuses on what is objective and measurable (Nightingale, 1988). In product perspectives, the author and text are separate entities and the author is invisible and thought to not exist in the product. Product assessments decode writing for its grammar, syntax, and structure- the surface elements of writing - which are limiting to our understanding of the complexities inherent in the act of composing written work (Elton, 2010; Mitchell, 2017).

The dangers inherent in the product prospective of writing are most evident when exploring the literature discussing perspectives on writing assessment. Writing scholars examining the effect of product-focused assessment recognize the limits of focusing on grammar alone to assess writing. Evaluating requires a balance between giving some corrective guidance for learning and not overly focusing on mechanical aspects as to ignore ideas expressed. Analyzing examples from undergraduate student papers and their associated evaluator comments, Lillis and Turner (2001) demonstrate how vague grading comments such as "faulty grammar" or "faulty punctuation” left students unable to identify the errors in their writing. Indicating deficit without correction leaves the impression that these conventions are common sense, easily transferable from context to context due to past learning and should not need to be 
taught. Diekelmann and Ironside’s (1998) doctoral student participants lamented the technical requirements attached to their candidacy exams and their struggles to fulfill them. Evaluators would use rulers to assess margin width and were inflexible on page requirements. These doctoral students learned to write quickly and to let their advisors tear their work apart in an earlier draft because no matter how polished the writing was it would always be returned with heavy criticism.

Focus on these surface characteristics of writing is a deficit perspective. When student writing is viewed from this deficit perspective, which neglects examining the writing process, creativity, emotions, and student identity, students' knee-jerk reaction is to devalue the importance of writing. They then develop resistance to accepting the value of developing a practice of writing to help them integrate knowledge from their discipline into their identity and practice (Hathaway, 2015) or, as Dieklemann and Ironside (1998) observed in their doctoral nursing student sample, it leads to disengagement.

With the recognition that writing product assessments were limiting, cognitive processing models began emerging in the late 1970s with the most widely discussed process model developed by Flower and Hayes (1981) and then later revised by Hayes (1996). The composing process, rather than the text or the writer, becomes the focus (St. Pierre, 2014). Process models recognize that writing is recursive, not linear, and that product and process are “deeply intertwined.” The product, thus, cannot be separated from its producer (Richardson \& St. Pierre, 2005).Writing processes are diverse and theoretical discussions of them are broad enough in scope that it is accepted that no two academics would model, or teach, the same writing process (Elton, 2010).

While the writing as a process movement broadened scholars' understanding of the complexities of writing, their primary weakness was the tendency to decontextualizing the writer 
from their cultural and social environment. They ultimately depict the writer as "an isolated individual struggling to express personal meanings” (Hyland, 2003, p. 18). Ivanič (1998) illustrated the difference between the process and social views of writing identity. While both consider the writer's identity to be a crucial factor in the product, the social view recognizes that the writer is also re-inventing themselves within the text while attempting to build a relationship with the reader in the process. The writer creates or visualizes a version of the reader and integrates that imagined reader's needs into their word choices and depth of description. When a reader reads the text, they then invent a version of the writer. Both mechanisms influence the meaning imparted and the understanding created in relation to the content being presented.

Process models focused on the "how" questions about writing to the neglect of the "why" (Hyland, 2003). The evolution of writing theory in the 1980s and 1990s has since evolved into a perspective congruent with a social constructionist epistemology. Social constructionism views knowledge and truth as created by the mind, not discovered (Andrews, 2012). Reality then is constructed by individuals through community experience, and through conversations and relationship building with others (Ward et al., 2015). A constructivist approach to writing acknowledges that there is an alternative story present behind the language used in text even when that text is describing empirical research (Ivanič, 1998; Mulhall, 1997). That reality may be presented to the reader selectively and strategically. Product and process models are grounded in the belief that writing, and concurrently reading, are undertaken only for purposes of communicating. Social models recognize that the acts of reading and writing require that two (or more) individuals, remote in time and space, make a connection with one another. Meaning is generated in a complex negotiation between readers and writers where each bring their socially constructed perspectives, identities, and past experiences to the creation of the text and the interpretation of that text (Flower, 1994; Game \& Metcalfe, 1994; Ivanič, 1998; Nystrand, 2006; 
Rolfe, 1997; Straw, 1990). Beginning from a premise of social constructivist thinking implies that any model of writing proposed should consider the influence of contextual factors, identity, and development of the reader-writer relationship on the writing process.

Writing is a social act that takes place within interpretive communities (Bruffee, 1986) or discourse communities (Gosden, 1995) and those communities socially construct reality, thought, text, knowledge, facts, and selves (Bruffee, 1986). The extension of this knowledge is that writing assignments will teach students to develop their identity within a discourse community. This immersion into a community is not without struggle as numerous unwritten rules exist as to how to be successful within that discourse community and little is known about how novice writers in these environments come to know and apply these rules as they are generally not explicitly taught (Gosden, 1995). Nursing as a discourse community has a much discussed gap in priorities between theory, education, and practice which has resulted in an antiacademic discourse where nurses in practice view the requirements of academia as hegemonic and unrelated to “good” nursing (Laiho \& Ruoholinna, 2013). This gap has created problems for the nursing discipline with respect to their ability to connect the value of writing to professional nursing practice.

\section{Nursing Discourse as a Barrier to the Construction of Writing}

An analysis of the nursing education literature suggests that nursing continues to take a skills-based product focus to writing instruction. In Canada, most writing instruction in nursing programs occurs through generic writing courses or English literature courses or a combination of both. In $48 \%$ of programs no writing instruction is required (Andre \& Graves, 2013). The failure of the generic “one size fits all” approaches to writing instruction is often evidenced by student descriptions of their difficulties attempting to transfer their writing knowledge from one discipline to another (Chaudoir et al., 2016; Lea \& Street, 1998). Different disciplines often have 
different rhetorical styles, which in simplest terms means different conventions for forming an argument. The school of literary scholarship known as rhetorical genre theory, analyzes texts by their familiar repetitive structures (Paré, 2014). It recognizes that writing in a particular discipline serves a social purpose. Nursing rarely uses words such as genre or rhetoric or transfer when theorizing about disciplinary writing issues yet we have a genre and we have a rhetoric of our own. Some of that rhetoric comes from the traditions of biomedicine and objectivist epistemology, as described earlier. Some of it may come from our widespread adoption of American Psychological Association Style. Nursing is a citation heavy discipline. We are more comfortable with writing that pays homage to more senior published experts in the field rather than allowing our own voice to be privileged (Ryan et al., 2013), in contrast, for example, to history or literary studies (Madigan et al., 1995).

Discipline members often know what particular texts, for example, an academic paper, are supposed to sound like. Disciplinary expectations are tacit and socially constructed. We can read papers from nursing, medicine, psychology, history, and literature and know there is something different in the structure or approach of each but perhaps not be able to articulate what that difference is, except maybe by surface elements. Experts in a discipline can recognize when their discourse has been handled successfully and within "the rules.” Novices to a discipline, on the other hand, can only draw from their past writing experience to accomplish a writing task. If that writing fails to fit the expectations of the disciplinary expert, it will be criticized and downgraded. It may even appear to the disciplinary expert to be poor writing in need of remediation. Because it is often difficult to put into words what is wrong with a piece of writing when the problem is a matter of unusual phrasings or word choices that do not fit the "typical" for a discipline, it might simply be labeled as unclear, colloquial, or grammatically incorrect. What is actually a social acculturation problem, is then mislabeled as a problem with the product. 
Students have learned to write prior to entering nursing but it may not be the kind of writing that fits nursing's discourse preferences. Students need ongoing instruction and mentorship in order to transfer their writing skills from a familiar writing task, or genre, to an unfamiliar writing genre and be successful (Tierney, 2002). But this thinking needs to expand beyond disciplinary transfer to exploring the expectations of individual instructors and courses. Each assignment presents new metacognitive demands and has its own instructional needs (Slomp, 2012). Yet educators often expect students, without guidance, to be able to adequately address the requirements in any course assignment simply because they have received generic writing instruction. In nursing, most educators are not writing experts, so a gap exists between what nursing needs in terms of writing instruction and what they have been able to provide due to lack of skill in those faculty assigning the writing (Troxler et al., 2011). An issue unique to the nursing literature is acknowledgement of the reluctance among nursing instructors to assign writing assignments for reasons including: the time-consuming nature of grading (Luthy et al., 2009), the "unwelcome challenge” (Mandleco et al., 2012), or that instructors may doubt their own writing capacity and therefore may be reluctant to assign and grade student writing assignments (Whitehead, 2002). Each of these instructional issues, contributes to students’ lack of value in their writing assignments.

The nursing literature often reports that student writing problems are described as being limited to the mechanics of writing (Diekelmann \& Ironside, 1998; Mandleco et al., 2012; Troxler et al., 2011; White \& Lamson, 2017). Strategies to improve student writing are described in two systematic reviews on the topic (Oermann et al., 2014; Troxler et al., 2011). These reviews summarize interventions which range from quick fix grammar and APA tutorials to the more time consuming (and more effective) strategies involving scaffolded leveling of 
assignments or submission of multiple drafts for feedback. Strategies gathered in these reviews were program specific and the majority were not evaluated using research evidence.

To provide two recent specific examples of writing assessments targeting grammatical and structural focused interventions, Mandeleco et al. used quantitative methods to assess student writing pre- and post-writing workshop with content including, “punctuation, grammar, professional voice, plagiarism, clarity of expression, and paragraph and sentence coherence and unity” (p. 5) using a tool which assessed "basic elements” (verbs, pronouns, punctuation, capitalization and sentence faults). They observed improvement on only half the grammatical items assessed based on the workshops but degree of overall improvement of writing was only assessed anecdotally, where reports from faculty identified that student writing “improved.” White and Lamson (2017) described a teaching innovation in the form of a voluntary workshop which targeted, “issues with writing mechanics, composition, using current evidence, and formatting of citations and references” (p. 444) and provided students with a checklist for revisions which focused on APA formatting issues and directed students to page numbers in the APA Manual. The workshops were poorly attended, reminiscent of Hathaway's (2015) warnings that writing instruction framed as addressing deficiency will encounter resistance from students. Neglecting to recognize students’ previous learning, devaluing how much of a students' identity is inserted into their writing, neglecting interpretative factors such as how to understand the meaning of complex research studies and academic papers, and eliminating creative opportunities to inspire thinking and knowledge are ineffective ways to stimulate student "buy in” for the importance of writing in nursing.

Applicability of writing in a clinical practice discipline has also been discussed. Whitehead's (2002) student participants questioned the applicability of writing to clinical practice. Cottingham's (2005) discussion of the need for writing in nursing is scathing, with an 
arguable element of satire, as he is clearly a skilled writer himself. At his worst he accuses nursing academics (who he describes as “ethically timid” and “underperforming intellectually”) of de-emphasizing bed creases and denture care in favor of dithering over which line to indent on a reference list. At his best, he observes, quite correctly, that there is no evidence-base to claim a connection between good essay writing and good nursing. But Cottingham's argument is based on the view that student writing requires remediation as it is perpetually grammatically inept, which reduces student writing to products, without consideration for the process and identity building that develops through the act of writing. Given the preponderance of discussions of the benefits of academic writing on thinking and knowledge creation as I have cited throughout this paper, I am tempted to ask the question, “Does it matter that objective evidence is lacking to establish if good writing leads to good nursing?” But given how nursing academia has aligned itself with a positivist view of science and the need for objective evidence, it very much matters indeed.

Academic knowledge is, from the perspective of practitioners, hegemonic and therefore elitist (Mulhall, 1997). Laiho and Ruoholinna (2013) state that new university graduates of nursing eventually adopt the anti-academic discourse as a way of fitting in to the practice environment. Having spent the majority of my career in nursing education teaching academic writing and research to nurses, I can confirm that some students' disdain for these subjects begins much earlier than during their immersion into the culture of practice. These courses are difficult, and demanding, and the sense of succeeding at the material lacks the instant gratification and glory present in the ability to start an IV or insert a foley catheter. Some see courses of this nature as a waste of their time. Their devaluing of course material shows up on course evaluations in statements reflecting their opinion that writing and research have nothing to do with nursing. 
The benefits of the discipline specific approach to writing which are critical to the nursing discipline are well documented. Writing can cultivate a professional identity where student writing at all levels (undergraduate, masters, doctoral) facilitates students’ ability to find their fit within the discipline and helps them identify their passion for areas of nursing practice (Chaudoir et al., 2016; Rolfe, 1997; Ryan et al., 2013). Writing plays a role in academic socialization providing opportunities for students’ development as scholars and thinkers, aiming to be transformative through providing students with opportunities to not just think about the knowledge they have within their discipline in a holistic fashion but also talk about that knowledge as well (Hathaway, 2015; Lea \& Street, 1998). Integration of sources through synthesis and reflection on practice, can stimulate critical thinking (Allen et al., 1989; Chaudoir et al., 2016; Springer \& Clinton, 2015) and facilitate the development of competencies in nursing assessment and practice and communicating them to the broader nursing community (Chaudoir et al.). Writing instruction that considers many audiences and recognizes the importance of the relationship between faculty and student in the writing process can contribute to developing relationships within the classroom (Chaudoir et al., 2016), with readers or with patients (Ryan et al., 2013). Yet these benefits reflect the values of nurses in academia and contrast dramatically with the views of some nurses in practice and some nursing students who see writing as having no value to their day-to-day work (Cottingham, 2005; Whitehead, 2002).

Disciplinary factors, such as argument styles, citation expectations, use of nursing specific language and word choice, play a role in writing (Hyland, 2004; Ryan et al., 2013) and students are often graded by disciplinary preferences and knowledge requirements before those preferences are taught. Students learn what is required of them by trial and error and the frustration of attending to a wide variety of preferences among faculty contributes to their disillusionment with writing (Chaudoir et al., 2016; McCune, 2004). Students who receive 
feedback that is limited to grammar and mechanical errors and ignores their content, ideas, and the creative elements of their writing, feel as if their identity has been attacked or disregarded. In this perspective, students see their essays as extensions of their selves and feedback that ignores the personal aspects of writing leads to student detachment from their writing and they develop difficulty defining themselves as writers (Torres \& Anguiano, 2016). Consequently, students see themselves as facing these frustrations alone and without support. They do not realize that these personal disruptions are normal and are present in all writers at all stages of their careers (Antoniou \& Moriarty, 2008).

Nursing needs to re-think the critical aspects of the way we write and present knowledge. Defining writing by its mechanical and structural aspects is like defining nursing by its tasks. If writing is a social construction in the creation of knowledge, then a disciplinary focus on writing competencies in students and nurse writers broadly needs to be discussed and integrated into professional curriculums. If continuing to preserve a product model in writing instruction and grading is leading to disengagement, then acknowledging the social aspects of writing may help make the value and need for writing visible.

\section{A Model for Writing}

The remainder of this paper will be dedicated to discussing the constructs and attributes that should be considered as contributing to the writing act, writing pedagogy, and in providing writing feedback. The model can be applied in a scaffolded manner from undergraduate, masters, doctoral, and professional writing contexts. The model was developed based on characteristics and values present in a socially constructed epistemology.

The development of the model emerged through a lifelong journey with writing and a personal and professional engagement with the interdisciplinary writing literature. Like most academics, I have had no formal academic writing training, however, I have taken creative 
writing courses. My post-secondary initiation with academic writing occurred in the literature and history departments in my pre-nursing undergraduate degree. My writing skills were honed through creative and fiction writing which means I've always recognized the aspects of academic writing that are creative in nature - the bringing together of diverse and seemingly contradictory ideas and the interpretive synthesis required to have an innovative take on a concept or research approach. The emotional extremes, and the connection between writing and identity, are similar in the creative and academic writing experiences. Many theoretical passions begin haphazardly. Mine began when I stumbled upon, in an unrelated literature search, two academic papers linking academic writing and creative writing (Antoniou \& Moriairty, 2008; McVey, 2008). Thus, due to my personal writing experiences and my reading on creative writing, creativity as a component of this model was an apriori assumption in this model development.

I began exploring the writing literature in depth while prepping to write research manuscripts. Two previous papers had a strong influence on the development of this model and its philosophical perspective. Researching the definitions of the writing terms associated with Flower and Hayes’s (1981) cognitive processing model of writing and the search for appropriate labels for the other writing constructs that were themed from the writing self-efficacy questionnaires (see Mitchell et al., 2017) prompted another theoretical journey exploring the nature of academic voice (Mitchell, 2017). A discussion within the self-efficacy instrument analysis team about what defined writing voice - did it, or did it not, include argument prompted a deeper exploration of that concept. The research for those two papers led me down many rabbit holes, the most significant of which, to this paper, introduced me to Ivanič’s (1998) work in writing and identity and Hyland's (2003; 2004) work in disciplinary discourse, the latter of which alerted me to the contextual, disciplinary nature of writing. 
Exploring the problem inherent in viewing student writing from a deficit perspective caused me to stumble on nursing's anti-academic discourse as an explanation for the problem I was living in my professional world where I sensed a deep devaluing of writing and its importance to the nursing profession and nursing education. When I was asked as part of my doctoral studies to explore a philosophical issue in my research area which was controversial, this devaluing and anti-academic discourse was an obvious starting point. Pairing that antiacademic discourse with the question proposed by the reviewer for the writing self-efficacy instrument analysis (quoted earlier) sent me down the path of exploring the theoretical attributes of constructionist writing and its relational, contextual, identity forming, emotional and creative attributes. Therefore, it wasn't one literature search which informed this paper, but several. Using the "one stop search" platform at my institution to capture multiple databases, I focused on literature examining writing voice, writing identity, writing in nursing, disciplinary discourse, nursing discourse, discourse analysis and nursing, writing theory, writing as a way of knowing, writing as a method of inquiry, and writing and social construction. Writing as a concept is not well indexed in most databases (including the nursing database CINAHL) so searching for the stem writ* in the titles of papers proved useful. The most valuable literature was found through citation tracing and examining the reference lists of key papers. These papers were read, cataloged, and thematically analyzed. The thematic analysis identified the five key attributes present in the model and their defining characteristics. Additional reading prompted by other doctoral projects and the review process for this manuscript prompted an exploration of the nature of hermeneutic philosophy and its contribution to literary critique and defining readerwriter relationships. Genre theory, communities of practice, narrative inquiry, and storytelling were other areas of interest. This literature, in combination with some thought provoking 
questions from two astute blind reviewers, have enriched my theoretical perspective and enhanced the revision process for this paper.

Table 1: The elements relevant to a social construction of writing in nursing

\begin{tabular}{|c|c|c|c|}
\hline Construct & Attributes & $\begin{array}{c}\text { Select nursing } \\
\text { sources }\end{array}$ & $\begin{array}{c}\text { Select } \\
\text { interdisciplinary } \\
\text { sources } \\
\end{array}$ \\
\hline $\begin{array}{l}\text { Nurse } \\
\text { Writers' } \\
\text { Identity }\end{array}$ & $\begin{array}{l}\text { - Writing voice } \\
\text { - Cannot be separated from the } \\
\text { writers' cultural, gendered, and } \\
\text { professional identity } \\
\text { - Informed by past experiences with } \\
\text { writing, self-beliefs, and self- } \\
\text { regulatory capabilities } \\
\text { - } \quad \text { Present in standpoint and argument } \\
\text { - } \text { Causes internal conflicts within the } \\
\text { Integration of the model requires } \\
\text { reflexivity within the individual }\end{array}$ & $\begin{array}{l}\text { Mitchell (2017) } \\
\text { Mulhall (1997) } \\
\text { Ryan et al. } \\
\text { (2013) } \\
\text { Webb (1992) }\end{array}$ & $\begin{array}{l}\text { Ivanič (1998) } \\
\text { Nightingale } \\
\text { (1988) }\end{array}$ \\
\hline $\begin{array}{l}\text { Relational } \\
\text { aspects }\end{array}$ & $\begin{array}{l}\text { - Knowledge of the audience for the } \\
\text { work } \\
\text { - Interpretation of integrated texts } \\
\text { that were read and analyzed }\end{array}$ & $\begin{array}{l}\text { Rolfe (1997) } \\
\text { Ryan et al. } \\
\text { (2013) }\end{array}$ & $\begin{array}{l}\text { Flower (1994) } \\
\text { Ivanič (1998) } \\
\text { Straw (1990) }\end{array}$ \\
\hline $\begin{array}{l}\text { Emotional } \\
\text { Knowing }\end{array}$ & $\begin{array}{ll}\text { - } & \text { May be perceived positively or } \\
\text { - } & \text { negatively } \\
\text { - } & \text { Drives or inhibits writing } \\
\text { - } & \text { Present in all phases of writing } \\
& \text { from planning to feedback } \\
\end{array}$ & $\begin{array}{l}\text { Chaudoir et al. } \\
\text { (2016) } \\
\text { Parboteeah \& } \\
\text { Anwar (2009) }\end{array}$ & $\begin{array}{l}\text { Game \& } \\
\text { Metcalfe (1996) } \\
\text { McLeod (1987) } \\
\text { Richardson \& St. } \\
\text { Pierre (2005) }\end{array}$ \\
\hline $\begin{array}{l}\text { Creative } \\
\text { Knowing }\end{array}$ & $\begin{array}{l}\text { - } \quad \text { Novelty and originality as defined } \\
\text { by a particular social group } \\
\text { - } \quad \text { Required in the writing acts of } \\
\text { - } \text { synthesis and interpretation } \\
\text { - } \quad \text { Gives form to ideas } \\
\text { - } \quad \text { Informs identity development } \\
\end{array}$ & $\begin{array}{l}\text { Diehl (2007) } \\
\text { Rolfe (1997) }\end{array}$ & $\begin{array}{l}\text { Kelly (2016) } \\
\text { Richardson \& St. } \\
\text { Pierre (2005) }\end{array}$ \\
\hline $\begin{array}{l}\text { Writing } \\
\text { Context }\end{array}$ & $\begin{array}{ll}\text { - } & \text { The nursing discipline } \\
\text { - } & \text { Nursing values } \\
\text { - } & \text { Nursing cultural and professional } \\
\text { issues } \\
\text { - } & \text { Discourse requirements } \\
\text { - } & \text { Attributes of the writing task } \\
\text { (perceived difficulty and task type) }\end{array}$ & $\begin{array}{l}\text { Allen et al. } \\
\text { (1989) } \\
\text { Gimenez (2012) }\end{array}$ & $\begin{array}{l}\text { Hyland (2003) } \\
\text { Hyland (2004) }\end{array}$ \\
\hline
\end{tabular}


Table 1 provides a summary of the attributes of writing from this perspective along with suggested nursing and interdisciplinary references. This model cannot be viewed as linear, nor can it be applied as a stepwise process. Writing using this model becomes, in the words of St. Pierre (2014), an “assemblage,” a symbiosis, "the folding of one text into another” (p. 378).

While the nurse's writerly identity is at the core of this model, each of the constructs could be the focus of writing at any point in the process. The constructs presented act together and influence one another in an intertwined fashion. For example, the nurse writer cannot separate herself from her personal history, gender, culture, or past experience, as a writer and as a discipline member. The nurse writer may also define her identity through her ability (or not) to be creative or show emotions, or by identifying (or not) as “a writer.” See the Figure for a visual representation of this model.

Figure 1: A socially constructed model of writing

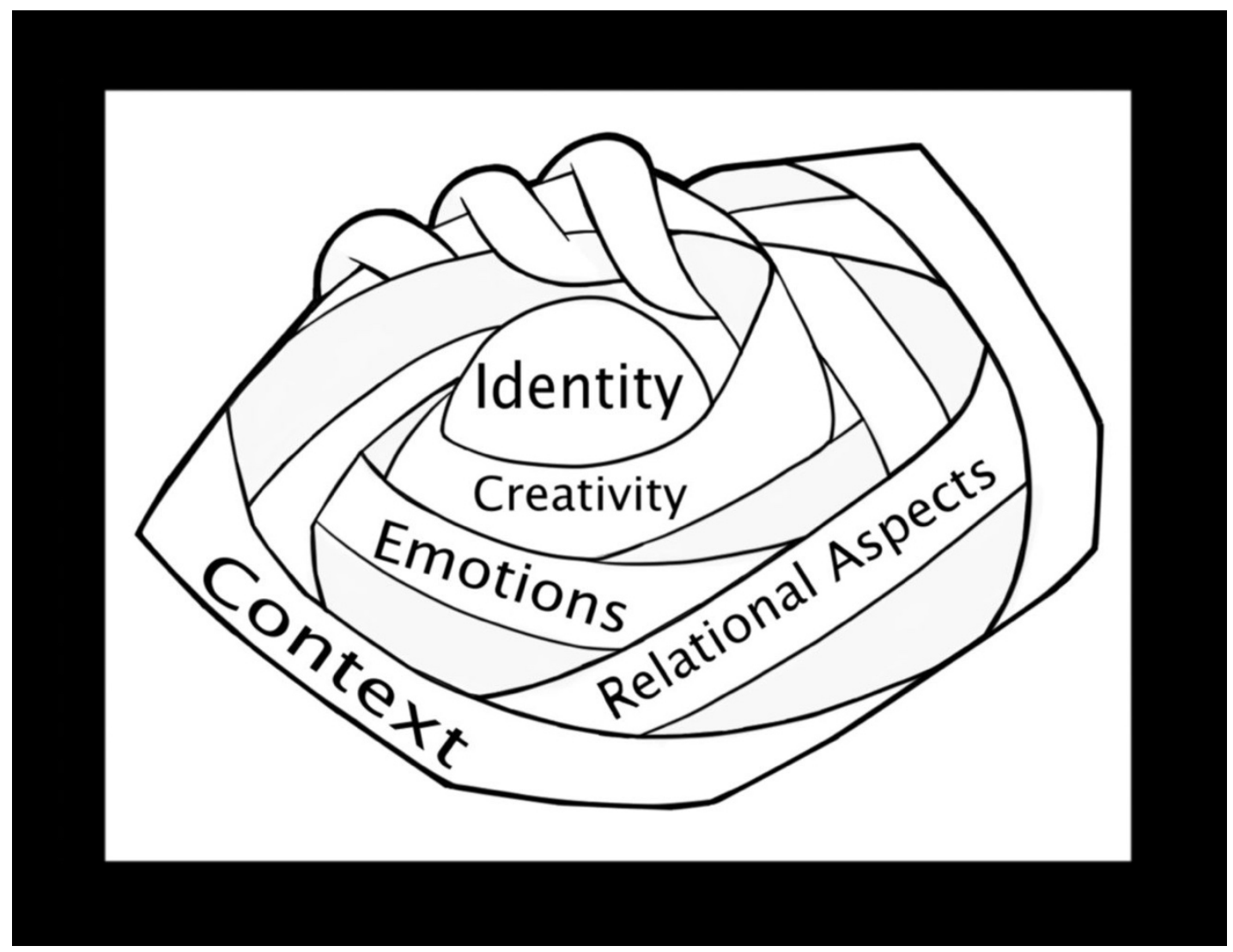




\section{Nurse Writer Identity}

Writing requires we "plumb the deep well of the unconscious” (Flower, 1994, p. 41). Whether deliberately presented or concealed, the writer is present in the work at all junctions in the form of writing voice (Mitchell, 2017). Knowledge cannot be created without a knower and all knowledge eventually is integrated into the writer's identity as self-knowledge (Nightingale, 1988). Ivanič (1998) identifies that we construct ourselves as individuals by positioning ourselves with respect to our standpoint and argument. Flower describes how the act of constructing writing can create a site of conflict when the writer is caught between writing conventions, or discourses, she knows how to handle and those she does not. Many other similar conflicts within the self occur in the writing process that function to bind identity to the other components of the model. Conflicts of self-belief, between emotional extremes, and negotiating self-regulatory capabilities in light of competing distractions are also relevant to forming an identity as a nurse writer. Finally, participating in reflexivity and reflective writing activities is essential to successful integration of identity within writing. Reflexivity also facilitates the integration of the writer's identity with the other components of the model.

\section{Relational Aspects of Writing}

Relationality represents the interplay between the nurse writer and all the ways a newly created text refers to other texts in any way through citation, inspiration, or interpretation (Ivanič, 1998). In addition, the author must build a relationship with a remote audience. That relationship constructs a negotiated meaning of text between a reader and writer (Flower, 1994). A constructivist perspective recognizes that a writer generates meaning when writing, then through interpretive processes, a reader generates another layer of meaning when reading (Straw, 1990). A nurse writer must be able to anticipate the needs of a reader and recognize and accept that those readers are creating their own interpretation of the work written. Also relevant to the 
relationality of writing is the ability to interpret the demands and expectations of teachers, instructors, and professors who assign writing, or journal editors (and peer reviewers) who are the gatekeepers to the sharing of knowledge in the profession. Relationship building in writing moves the nurse writer's work from an individual quest for knowledge to a broader conversation. Building relationships through writing can connect a writer to their community, alienate them, subject them to critique, or may go by unnoticed and be completely ignored (Olthouse, 2013).

\section{Emotional Knowing}

The perception of the emotions associated with writing can be positive or negative and that perception will drive or inhibit the act of writing. Emotions are present in all stages of the writing process from the anticipation of the project, to the act of writing, to receiving a response to one's writing from a target audience in the form of feedback or critique (McLeod, 1987; Richardson \& St. Pierre, 2005). It is not normal to talk about writing as an emotionless task or, when it contributes to knowledge, to leave those emotions out of the text. To do so implies the writing would be disingenuous.

\section{Creative Knowing}

Creativity has multiple meanings and interpretations but consistently requires originality and novelty to be present in the final product as defined by a particular social group (Kelly, 2016). Rolfe (1997) identifies the aspects of academic writing that involve creativity as synthesis, interpretiveness, and knowledge generation. While it may seem that creativity and the analytic requirements of academic writing are antagonists, seeing the inseparability of the two modes is a paradigm shift needed in academic writing (Antoniou \& Moriarty, 2008; Richardson \& St. Pierre, 2005). Academic writers, like designers, create for a specific purpose and a specific audience and their creativity lies in the ability to give form to an idea (Kelly, 2016). Archibald and Clark's (2018) discussion of how art can inform the research process is relevant. Creativity 
from an artist's perspective can tie the components of this model together through shaping identity, teaching emotional control, drawing from wide influences, and the necessity for prolonged engagement. Examining art and its processes warns us how hegemonic control can squash creativity. Creativity enables passion and passionate writing is both sensual and emotional, or in Game and Metcalfe’s (1996) words: writing is “the place of dreaming” (p. 94).

\section{Writing Context}

As Flower (1994) states: “Writers’ purposes are always bounded purposes hemmed in by innumerable constraints, unrecognized givens, and shared desires” (p. 45). The context of writing is the "why" of writing. Context is present in terms of discourse, disciplinary preferences, and cultural conditions (Game \& Metcalfe, 1996; Hyland, 2004; Ivanič, 1998). The task at hand and the purpose of that writing task also provides context through the nature of the writing assignment, its perceived difficulty and demands of possible assessor(s), as well as the stakes involved in the writing process. The requirements of different genres of texts (e.g. academic papers, reflections, or care plans) and the nurse writer's understanding of how to manage that type of text will also influence the writing context (Hyland, 2003; 2004). In nursing the writing context is constrained by the values of writing communicated by the discipline in the form of a theory practice gap and an anti-academic discourse as presented earlier in this paper.

\section{Implications for Nursing Education}

I began this paper by reflecting on how the inspiration for this work was born out of parallel work exploring writing self-efficacy instruments and their items. Pajares and Valiante (2006) eloquently outline the connection between writing self-efficacy and the vision presented: Writing is not only a process of making meaning but also an activity through which individuals engage in self-understanding ... After all, it is through introspection and selfreflection that meaning is constructed. The assumption that self-knowledge is 
inextricably connected to human competencies is now so taken for granted, that it is a central tenant of most modern theories and views of human cognition, motivation, and behavior. (p. 158)

While, writing in nursing may not, in most programs, currently be taught from a socially constructed perspective, each attribute of the model presented is already a concern to nurses and writers. Inevitably, this means writing self-efficacy could be altered by intervening in any component of the presented model. The model has the potential to not only influence writing practices of nurses, nursing students, and nursing academics but also writing pedagogies, with the recognition that scaffolding of all aspects of the model will be required from undergraduate to graduate to professional writing. The role of writing in education and in practice as well as the pedagogical approaches that should be used to address the instruction of writing for each component of the model require further explication through qualitative, quantitative and mixed method research. Undergraduate writing needs to recognize the past experiences of the students entering programs, incorporate discipline-specific instruction, and avoid assuming teaching mechanical basics will act as a quick fix for students' writing problems. Writing instruction must be present in every course that includes a writing assignment. At the graduate level, the focus should be on voice and identity as a scholar and researcher and writing for knowledge translation.

As nursing scholars Diekelmann and Ironside observed in 1998, "the practices of scholarship, reading, writing, thinking and dialogue are inseparable and belong together” (p. 1347). While the model is not novel by its components, as these elements of writing are well described in other disciplines, it is novel within the community of nursing. Each facet of the model demands further exploration from a nursing perspective, including how the knowledge 
building present in the act of writing contributes to knowledge applied in clinical practice, thus the model should not be considered an endpoint in this discussion, but rather a beginning.

This paper is intended to continue the conversation about re-visioning and enhancing the value of writing within the nursing profession. In order for writing to have meaning, it must be a process that allows individual writers to feel they are able to integrate their personal identity into the act of making knowledge. Positivistic, anti-identity, and deficit-based writing perspectives that emphasize surface elements of writing are constraints on nursing's ability to create research and knowledge that not only is relevant, but must feel relevant to practitioners and students. Nursing scholars who write about writing have asked, “For whom do [we] write?” (Ryan et al., 2013, p. 295). Currently, nurse academics write primarily for other academics. Viewing writing as a social activity, may give nurses’ permission to write for broader audiences and, thus, diminish the power of the hegemonic elitism practitioners and students observe in academic writing processes. Nurses in practice and nurse academics share a common goal - improving the lives of patients - and our writing should reflect that. 


\section{References}

Allen, D. G., Bowers, B., \& Diekelmann, N. (1989). Writing to learn: A reconceptualization of thinking and writing in the nursing curriculum. Journal of Nursing Education, 28(1), 611.

Andre, J. D., \& Graves, R. (2013). Writing requirements across nursing programs in Canada. Journal of Nursing Education, 52(2), 91-97. https://doi.org/10.3928/0148483420130114-02

Andrews, T. (2012). What is social constructionism? Grounded Theory Review, 1(11). http://groundedtheoryreview.com/2012/06/01/what-is-social-constructionism/

Antoniou, M., \& Moriairty, J. (2008). What can academic writers learn from creative writers? Developing guidance and support for lecturers in higher education. Teaching in Higher Education, 13(2), 157-167. https://doi.org/10.1080/13562510801923229

Archibald, M., \& Clark, A. M. (2018). Five lessons from art for better research. Journal of Advanced Nursing, 74(1), 8-10. https://doi.org/10.1111/jan.13195

Bandura, A. (1977). Self-efficacy: Toward a unifying theory of behaviour change. Psychological Review, 84(2), 191-215. https://doi.org/10.1016/0146-6402(78)90002-4

Bandura, A. (1997). Self-efficacy: The exercise of control. W. H Freeman.

Bruffee, K. A. (1986). Social construction, language, and the authority of knowledge: A bibliographical essay. College English, 48(8), 773-790. https://doi.org/10.2307/376723

Chaudoir, S., Lasiuk, G., \& Trepanier, K. (2016). Writing assignments: A relatively emotional experience of learning to write in one baccalaureate nursing program. Quality Advancement in Nursing Education, 2(2), 1-21. https://qaneafi.casn.ca/journal/vol2/iss2/3/

Cottingham, C. (2005). Essay wha? Nursing New Zealand, 11(8), 25. 
Diehl, S. H. (2007). Developing students' writing skills: An early intervention approach. Nurse Educator, 32(5), 202-206. https://doi.org/10.1097/01.NNE.0000289377.06384.00

Diekelmann, N., \& Ironside, P. M. (1998). Preserving writing in doctoral education: Exploring the concernful practices of schooling learning teaching. Journal of Advanced Nursing, 28(6), 1347-1355. https://doi.org/10.1046/j.1365-2648.1998.00819.x

Elton, L. (2010). Academic writing and tacit knowledge. Teaching in Higher Education, 15(2), 151-160. https://doi.org/10.1080/13562511003619979

Fairbairn, G., \& Carson, A. (2002). Writing about nursing research: A storytelling approach. Nurse Researcher, 10(1), 7-14. https://doi.org/10.7748/nr2002.10.10.1.7.c5875

Flower, L. (1994). The construction of negotiated meaning: A social cognitive theory of writing. Southern Illinois University Press

Flower, L., \& Hayes, J. R. (1981). A cognitive process theory of writing. College Composition and Communication, 32(4), 365-387. https://doi.org/10.2307/356600

Game, A., \& Metcalfe, A. (1996). Passionate sociology. Sage.

Gimenez, J. (2012). Disciplinary epistemologies, generic attributes and undergraduate academic writing in nursing and midwifery. Higher Education, 63, 401-419. https://doi.org/10.1007/s10734-011-9447-6

Gosden, H. (1995). Success in research article writing and revision: A social-constructionist perspective. English for Specific Purposes, 14(1), 37-57. https://doi.org/10.1016/0889$\underline{4906(94) 00022-6}$

Hathaway, J. (2015). Developing that voice: Locating academic writing tuition in the mainstream of higher education. Teaching in Higher Education, 20(5), 506-517. https://doi.org/10.1080/13562517.2015.1026891 
Hayes, J. R. (1996). A new framework for understanding cognition and affect in writing. In C. M. Levy \& S. Ransdell (Eds.). The science of writing: Theories, methods, individual differences and applications (pp. 1-27). Lawrence Erbaum Associates.

Hyland, K. (2003). Genre-based pedagogies: A social response to process. Journal of Second Language Writing, 12(2003), 17-29. https://doi.org/10.1016/S1060-3743(02)00124-8

Hyland, K. (2004). Disciplinary discourses: Social interactions in academic writing. University of Michigan Press

Ivanič, R. (1998). Writing and identity: The discoursal construction of identity in academic writing. John Benjamins Publishing.

Kelly, R. (2016). Creative development: Transforming education through design thinking, innovation, and invention. Brush Education.

Laiho, A., \& Ruoholinna, T. (2013). The relationship between practitioners and academics: Antiacademic discourse voiced by Finnish nurses. Journal of Vocational Education and Training, 65(3), 333-350. https://doi.org/10.1080/13636820.2013.819561

Lea, M. R., \& Street, B. V. (1998). Student writing in higher education: An academic literacies approach. Studies in Higher Education, 23(2), 157-172, https://doi.org/10.1080/03075079812331380364

Lillis, T., \& Turner, J. (2001). Student writing in higher education: Contemporary confusion, traditional concerns. Teaching in Higher Education, 6(1), 57-68. https://doi.org/10.1080/13562510020029608

Luthy, K. E., Peterson, N. E., Lassetter, J. H., \& Callister, L. C. (2009). Successfully incorporating writing across the curriculum with advanced writing in nursing. Journal of Nursing Education, 48(1), 54- 59. https://doi.org/10.3928/01484834-20090101-07 
Madigan, R., Johnson, S., \& Linton, P. (1995). The language of psychology: APA style as epistemology. American Psychologist, 50, 428-436. https://doi.org/10.1037/0003$\underline{066 X .50 .6 .428}$

Mandleco, B. L., Bohn, C., Callister, L. C., Lassetter, J., \& Carlton, T. (2012). Integrating advance writing content into a scholarly inquiry in nursing course. International Journal of Nursing Education Scholarship, 9(1), 4. https://doi.org/10.1515/1548-923X.2213

McCune, V. (2004). Development of first-year students’ conceptions of essay writing. Higher Education, 47, 257-282. https://www.jstor.org/stable/4151545

McLeod, S. (1987). Some thoughts about feelings: The affective domain and the writing process. College Composition and Communication, 38(4), 426-435. https://doi.org/10.2307/357635

McVey, D. (2008). Why all writing is creative writing. Innovations in Education and Teaching International, 45(3), 289-294. https://doi.org/10.1080/1470329082176204

Mitchell, K. M. (2017). Academic voice: On feminism, presence, and objectivity in writing. Nursing Inquiry. https://doi.org/10.1111/nin.12200

Mitchell, K. M., Harrigan, T., Stefansson, T., \& Setlack, H. (2017). Exploring self-efficacy and anxiety in first-year nursing students enrolled in a discipline-specific scholarly writing course. Quality Advancement in Nursing Education, 3(1), 4. https://doi.org/10.17483/2368-6669.1084

Mitchell, K. M., Rieger, K. L., \& McMillan, D. E. (2017). A template analysis of writing selfefficacy measures. Journal of Nursing Measurement, 25(2), 205-223. https://doi.org/10.1891/1061-3749.25.2.205

Mulhall, A. (1997). Nursing research: Our world not theirs? Journal of Advanced Nursing, 25, 969-967. https://doi.org/10.1046/j.1365-2648.1997.1997025969.x 
Nightingale, P. (1988). Understanding processes and problems in student writing. Studies in Higher Education, 13(3), 263-283. https://doi.org/10.1080/03075078812331377720

Nystrand, M. (2006). The social and historical context for writing research. In C. A. MacArthur, S. Graham, \& J. Fitzgerald (Eds.). Handbook of writing research (pp. 11-27). Guilford Press.

Oermann, M. H., Leonardelli, A. K., Turner, K. M., Hawks, S. J., Derouin, A. L., \& Hueckel, R. M. (2014). Systematic review of educational programs and strategies for developing students’ and nurses’ writing skills. Journal of Nursing Education, 54(1), 28- 34. https://doi.org/10.3928/01484834-20141224-01

Olthouse, J. M. (2013). MFA writers’ relationships with writing. Journal of Advanced Academics, 24(4), 259-274. https://doi.org/10.1177/1932202X13507972

Pajares, F., \& Valiante, G. (2006). Self-efficacy beliefs and motivation in writing development. In C.A. MacArthur, S. Graham, \& J. Fitzgerald (Eds.). Handbook of writing research (pp. 158-170). Guilford Press.

Parboteeah, S., \& Anwar, M. (2009). Thematic analysis of written assignment feedback: Implications for nurse education. Nurse Education Today, 29, 753-757. https://doi.org/10.1016/j.nedt.2009.02.017

Paré, A. (2014). Rhetorical genre theory and academic literacy. Journal of Academic Language and Learning, 8(1), A83-A94.

Pittam, G., Elander, J., Lusher, J., Fox, P., \& Payne, N. (2009). Student beliefs and attitudes about authorial identity in academic writing. Studies in Higher Education, 34(2), 153170. https://doi.org/10.1080/03075070802528270 
Read, B., Francis, B., \& Robson, J. (2001). 'Playing safe’: Undergraduate essay writing and the presentation of the student 'voice’. British Journal of Sociology of Education, 22(3), 387399. https://doi.org/10.1080/01425690120067999

Richardson, L., \& St. Pierre, E. A. (2005). Writing: A method of inquiry. In N. K. Denzin \& Y. S. Lincoln (Eds.). The Sage handbook of qualitative research (3rd. ed., pp. 959-978). Sage.

Rolfe, G. (1997). Writing ourselves: Creating knowledge in a postmodern world. Nurse Education Today, 17, 442-448. https://doi.org/10.1016/S0260-6917(97)80004-4

Ryan, M. M., Walker, M., Scaia, M., \& Smith, V. (2013). (un)Disciplining the nurse writer: Doctoral nursing students’ perspective on writing capacity. Nursing Inquiry, 21(4), 294300. https://doi.org/10.1111/nin.12045

Slomp, D. H. (2012). Challenges in assessing the development of writing ability: Theories, constructs and methods. Assessing Writing, 17(2012), 81-91. https://doi.org/10.1016/j.asw.2012.02.001

Springer, R. A., \& Clinton, M. E. (2015). Doing Foucault: Inquiring into nursing knowledge with Foucauldian discourse analysis. Nursing Philosophy, 16, 87-97. https://doi.org/10.1111/nup.12079

St. Pierre, E. A. (2014). An always already absent collaboration. Cultural Studies - Critical Methodologies, 14(4), 374-379. https://doi.org/10.1177/1532708614530309

Straw, S. B. (1990). Challenging communication: Readers reading for actualization. In D. Bogdan \& S. B. Straw (Eds.), Beyond communication: Reading comprehension and criticism (pp. 67-89). Boynton/Cook.

Tierney, W. G. (2002). Get real: Representing reality. International Journal of Qualitative Studies in Education, 15(4), 385-398. https://doi.org/10.1080/09518390210145444 
Torres, J. T., \& Anguiano, C. J. (2016). Interpreting feedback: A discourse analysis of teacher feedback and student identity. Practitioner Research in Higher Education, 10(2), 2-11.

Troxler, H., Vann, J. C. J., \& Oermann, M. H. (2011). How baccalaureate nursing programs teach writing. Nursing Forum, 46(4), 280-288. https://doi.org/10.1111/j.17446198.2011.00242.x

Ward, K., Hoare, K. J., \& Gott, M. (2015). Evolving from a positivist to constructionist epistemology while using grounded theory: Reflections of a novice researcher. Journal of Research in Nursing, 20(6), 449-462. https://doi.org/10.1177/1744987115597731

Webb, C. (1992). The use of first person in academic writing: Objectivity, language, and gatekeeping. Journal of Advanced Nursing, 17, 747-752. https://doi.org/10.1111/j.13652648.1992.tb01974.x

White, B. J., \& Lamson, K. S. (2017). The evolution of a writing program. Journal of Nursing Education, 56(7), 443-446. https://doi.org/10.3928/01484834-20170619-11

Whitehead, D. (2002). The academic writing experiences of a group of student nurses: A phenomenological study. Journal of Advanced Nursing, 38(5), 498-506. http://doi.org/10.1046/j.1365-2648.2002.02211.x 
The good news is that some days, it feels like you just have to keep getting out of your own way so that whatever it is that wants to be written can use you to write it. It's a little like when you have something difficult to discuss with someone, and as you go to do it, you hope and pray that the right words will come if only you show up and make a stab at it.

Anne Lamott, Bird by Bird 


\section{Interlude 1}

Doctoral candidacy can be a gruelling process. In my readings in preparations for writing “Constructing Writing Practices in Nursing,” (Paper 1; Mitchell, 2018), I had come across mentions of rhetorical genre theory, activity theory, and communities of practice. It always struck me that they seemed like the same theory. Simultaneously, I was secretly concerned that Bandura's theory of self-efficacy was epistemologically incompatible with the socially constructed perspective on writing and if I didn't spend some time figuring that out, someone smarter than me would take me to task about it. In order to successfully develop a measurement instrument which incorporated both perspectives, I needed to establish that I wasn't attempting to cross-pollinate two theories that genetically lacked compatibility.

I suggested these two problems to my committee when I was facing candidacy exams for the fall of 2018. In fact, these questions were so important to my forthcoming work, I spent most of my study time from April through August 2018, preparing to address them both. When exam day came, I found myself faced with a question that asked me to take two to three theories and address how they could help assess writing self-efficacy. I found a sneaky way to answer the question, explore my concern about theoretical compatibility, and discuss five theories instead of just two. I merged rhetorical genre theory, activity theory, and communities of practice into “situated perspectives” and I paired Bandura’s (1997) self-efficacy theory and Flower and Hayes’s (1981) cognitive process theory of writing under cognitive theories.

The paper presented is a much-abbreviated version of that candidacy exam paper - a little over half of its original length. The editing process was a brutal exercise in how to kill a lot of precious words. My edits were inspired by a call for papers in the Journal of Learning Development in Higher Education which asked authors to reflect upon the 20-year anniversary of the publication of Lea and Street's (1998) seminal paper on academic literacies and what 
uptake of academic literacies had occurred in the intervening time. Academic literacies aren’t really a theory, but rather a movement that explores how the teaching of writing occurs within disciplinary contexts, all of which have their own tacit rules, and are influenced by power structures within the institution. I was familiar with the Lea and Street paper and had cited it in “Constructing Writing Practices.” It was yet another socially constructed approach to viewing writing. I emailed the editor and asked if my paper, which focused on exploring how assessments of writing self-efficacy had not moved toward the "social turn” apparent in writing theory, would be a good fit for the call. He thought it would be.

The phrase "social turn” was inspired by the title of a paper I discovered (Bauer \& Theado, 2014) after I had achieved candidacy, exploring the uptake of socially constructed principles into writing pedagogy. The investigation looked exclusively at published papers over a span of years in the Journal of College Reading and Learning. Special note must also be made of the day I was randomly killing time exploring the scope and aims of various journals for their fit for my work and by happenstance stumbled on an entire issue of Educational Psychologist that discussed the need for a merger of situative and cognitive perspectives. Despite rigourous literature searching to prepare for my candidacy exam, it had never occurred to me to alter the term situated into situative in my search. It gave me hope that my idea of merging socially constructed situated perspectives with Bandura's cognitive theory was not misguided or fanciful. Paper 2 is the outcome of that merger. And - spoiler alert - rhetorical genre theory, activity theory, and communities of practice are not the same theory.

\section{Author Contributions}

The paper was published in November 2019 in the Journal of Learning Development in Higher Education. I, the student (Kim Mitchell) conceived the question developed within the manuscript, conducted the literature search, and wrote and edited the manuscript. Dr. McMillan 
and Dr. Lobchuk contributed to the conception of the question presented in the manuscript and provided critical feedback which informed the editing of the manuscript.

\section{References}

Bandura, A. (1997). Self-efficacy: The exercise of control. W. H Freeman.

Bauer, L., \& Theado, C. (2014). Examining the social turn in postsecondary literacy research and instruction: A retrospective view of JCRL scholarship. 2005-2013. Journal of College Reading and Learning, 45(1), 67-84. https://doi.org/10.1080/10790195.2014.950869

Flower, L., \& Hayes, J. (1981). A cognitive process theory of writing. College Composition and Communication, 32(4), 365-387. https://doi.org/10.2307/356600

Lea, M. R., \& Street, B. V. (1998). Student writing in higher education: An academic literacies approach. Studies in Higher Education, 23(2), 157-172, http://doi.org/10.1080/03075079812331380364

Mitchell, K. M. (2018). Constructing writing practices in nursing. Journal of Nursing Education, 57(7), 399-407. https://doi.org/10.3928/01484834-20180618-04

This paper can be referenced as:

Mitchell, K.M., McMillan, D.E., \& Lobchuk, M.M. (2019). Applying the “social turn” in writing scholarship to perspectives on writing self-efficacy. Journal of Learning Development in Higher Education,15(2019). http://journal.aldinhe.ac.uk/index.php/jldhe/article/view/512/pdf

\section{Copyright}

From the publisher webpage as of June 3, 2020

(https://journal.aldinhe.ac.uk/index.php/jldhe/about/submissions): Authors who publish with this journal agree to the following terms: 
1. Authors retain copyright and grant the journal right of first publication with the work simultaneously licensed under a Creative Commons Attribution License that allows others to share the work with an acknowledgement of the work's authorship and initial publication in this journal.

2. Authors are able to enter into separate, additional contractual arrangements for the nonexclusive distribution of the journal's published version of the work (e.g., post it to an institutional repository or publish it in a book), with an acknowledgement of its initial publication in this journal.

3. Authors are permitted and encouraged to post their work online (e.g., in institutional repositories or on their website) prior to and during the submission process, as it can lead to productive exchanges, as well as earlier and greater citation of published work (See The Effect of Open Access). 


\title{
Paper 2: Applying the 'Social Turn' in Writing Scholarship to Perspectives on Writing Self-Efficacy
}

\begin{abstract}
The aim of this paper is to explore the fit between the cognitive concept of writing selfefficacy and a socially constructed epistemology of writing. Socially constructed perspectives on writing emphasize context and community and include academic literacies, rhetorical genre theory, and the writing across the curriculum movement. These perspectives have been prominent in theoretical discussions of writing since the 1980s. This paper argues that the measurement of writing self-efficacy has continued to prioritize assessing writing self-efficacy as ability to successfully accomplish superficial writing product and process features, while the social context of writing and its resultant impacts on the identity forming, relational, emotional and creative impacts on writing self-efficacy have been largely ignored. The historical context of paradigmatic shifts in writing theory will be discussed with a lens toward proposing a synthesis of three constructionist situated perspectives - activity theory, rhetorical genre theory, and communities of practice - and how these situated perspectives may inform a more complete view of how writing self-efficacy should be assessed and measured. How practitioners may consider the merger of these theories in writing pedagogy will be introduced to inspire future research.
\end{abstract}




\section{Applying the 'Social Turn’ in Writing Scholarship to Perspectives on Writing Self-Efficacy}

In the evolution of writing epistemologies, writing research, which at its origins explored and prioritized writing text as products, evolved to exploring cognitive processes and, more currently, social processes. This evolution is typical of many research movements undergoing paradigm shifts attempting to distance themselves from their epistemologically objectivist origins. Nystrand (2006), in his review, situated the root of the historical context for writing research in the cognitive revolution of the 1960s. In the 1970s, media reports highlighted what was pronounced to be a generalized decline in writing ability in society. A “literacy crisis” was declared, which placed a spotlight on grammatical correctness, the product elements of writing, thought to be markers of education and social class. It was cognitive process theorists, in particular the work of Flower and Hayes (1981) by defining and describing the recursive processes of planning, composing, and revising, that triggered the recognition that a person sat behind the text produced and that person should be considered in research efforts. Limitations to the cognitive movement quickly became apparent resulting in a push toward perspectives where the writer could be viewed as more than "an isolated individual struggling to express personal meanings” (Hyland, 2003, p. 18).

Writers and writing scholars knew product and cognitive process movements were presenting an incomplete perspective of the complex craft of writing. Cognitive process models failed to explore how language functions in human interaction because they said nothing about how meanings were socially constructed or how forces outside the individual guided motives, built relationships, and influenced writing (Hyland, 2003). There are several defining moments in the shift from objectivist (product) perspectives on writing to constructionist (social) perspectives: the development of the writing across the curriculum movement in the US in the 1970s (Russell et al., 2009); the evolution of genre theory from a movement that looked 
exclusively at textual features and conventions to a perspective of social action (Miller, 1984); and the academic literacies perspective in the UK which mirrored the North American movements (Lea and Street, 1998) - to name a few. Social movements focused on describing how writing was socially situated in communities where products and processes would shapeshift from context to context. Collectively, they evolved in response to the recognition that there was no single recipe to develop writing in post-secondary student populations.

Nystrand's (2006) description of the evolution of writing research from product, to process, to social process, mirrored Lea and Street's (1998) seminal discussion of academic literacies, which evolved through three, non-mutually exclusive phases. First, Lea and Street highlighted study skills (or product focused) approaches, where writing errors were viewed as “a kind of pathology” (p. 159). Study skills perspectives were followed by the academic socialization perspective which acknowledged the disciplinary factors in written communication; Russell et al. (2009) related academic socialization to understanding the genres specific to the discipline. Academic socialization, in parallel to the social cognitive movement in psychology, acknowledged writing contexts without addressing their influence. Lea and Street's third movement, academic literacies, recognized the problem of writing transfer between settings and disciplines. When the gatekeepers of good writing (academic faculty) failed to recognize how the tacit nature of their disciplinary considerations and the power relations formed during writing evaluation influenced writing, the consequence was a disruption to student identity.

Several authors have noted difficulty in translating the ‘social turn’ in writing into pedagogical practices. Russell et al. (2009) observed how academic literacies have made a stronger contribution to research and theory than to pedagogy. Bauer and Theado (2014) conducted an analysis of articles published in the Journal of College Reading and Learning from 2005-2013 exploring the “social turn” in post-secondary literacy research and instruction and 
concluded that, despite the social turn in writing theory, a parallel social turn in writing pedagogy had not emerged. Perry (2012) also observed a weakness of social perspectives in their inability to inform writing pedagogy and suggested that cognitive and social perspectives on writing did not need to be mutually exclusive. Perry’s suggestion mirrors Reither’s (1985) observation: "we need to know more than we now know, not only about cognitive processes during composing, but also about processes involved in coming to know generally” (p 623).

One of the more popular cognitive concepts explored in writing contexts is writing selfefficacy (Bandura, 1997; Pajares and Valiante, 2006). Self-efficacy, a well-studied motivational concept driving human agency, has been established as a critical factor affecting career choices, course choices, academic progression, persistence in the face of difficulty, and individual performance. The growing importance of the assessment of writing self-efficacy in postsecondary students is evident in the increase in studies measuring the construct since it first appeared in the literature in a measurable format with the seminal work of Meier et al. (1984). In an in-progress systematic review (unpublished data), the lead author has identified 88 papers measuring writing self-efficacy in post-secondary students published since 1984. Of these, 64 have been published since 2011, and 33 of those since 2016. The educational importance of writing self-efficacy cannot be underestimated as strong self-efficacy is required to keep students striving to improve their writing and advance in their disciplines and future professions. However, numerous contextual and social factors threaten to disrupt (or with pedagogical influence, facilitate) the writing experience and these factors have been largely neglected in writing self-efficacy research and measurement.

Literature exploring social cognitive perspectives such as writing self-efficacy and socially constructed views of writing appear to operate in silos, where these bodies of literature rarely merge, cite each other, or learn from each other’s conclusions. A 2015 special issue of 
Educational Psychologist aimed to start a conversation about the potential for merging the two perspectives by exploring how “situative perspectives” could enhance educational psychology research by recognizing that individual goals were situated within the collective goals apparent in the individual's social context or system (Turner and Nolen, 2015). The social movement, for example, could enlighten writing self-efficacy researchers on the contextual factors which limit self-efficacy development. Social cognitive perspectives have a more articulated integration of the role of emotions as they affect writing self-efficacy and performance.

An added complexity is the use of the word "social” in both movements. The social in “social cognitive” refers to the mere existence of social influences on learning but still emphasizes the individual in that social context. The word social in "socially constructed" takes a deeper look at the nuances and intersections of the social context which drive perceptions of experience where the individual cannot be isolated from the social environment in which they operate. The field of writing self-efficacy research, as Camfield (2016) noted in her qualitative exploration of the concept, "has not yet reached a sophisticated and nuanced understanding of the reciprocal and socially situated nature of the development of writing self-efficacy” (p 3). Similarly, in a review we conducted exploring writing self-efficacy measurement instruments validated in post-secondary contexts (Mitchell et al., 2017), we identified that measures purporting to assess writing self-efficacy focus on grammar and sentence level concerns, or concrete writing tasks such as planning or revision, and concluded that writing context, disciplinary discourse issues, and creativity allowances in writing were gaps in current measurement of the concept. Thus, while most other theoretical perspectives on writing have seen that epistemological "social turn” from the limited product and process views, writing selfefficacy measurement has not followed suit. Could issues of learning the language of a discipline, power relations within communities, understanding audience, identity and creativity 
development, and feeling of ownership of the writing - all complex writing issues identified within that "social turn” - also impact writing self-efficacy?

Our goal in this paper, therefore, is to explore the "social turn" in writing scholarship as it may apply to writing self-efficacy. The paper will attempt to answer the question: Is there epistemological congruence between a socially constructed epistemology and the measurement of writing self-efficacy, which may allow for the merger of the social perspectives on writing and the social cognitive perspectives on writing self-efficacy? The paper will present a synthesis of Bandura’s self-efficacy theory (Bandura, 1997) with three social theories that we will refer to collectively as "situated perspectives" in the "complimentary yet distinct” (Artemeva, 2008, p. 162) triad of socially constructed theories which include activity theory, rhetorical genre theory, and communities of practice.

\section{Exploring Cognitive Perspectives on Writing}

Bandura’s (1997) seminal theory was one of the first to acknowledge that an emotional response to tasks could affect learning. Self-efficacy theory proposed that self-judgement of ability and mastery of tasks could be influenced through interactions that went beyond individual ability and perceptions developed through past experiences. Social and relational factors such as feedback received from significant others (e.g. academic evaluators) through social persuasion, and self-comparisons with peers through modeling and vicarious experiences, could also have an effect on self-efficacy development. Self-efficacy theory is embedded within Bandura’s social cognitive theory which is concerned with the effects of cognitive processes on the acquisition and regulation of behaviour. Indeed, his perspective of social learning was one of the first to consider that there was a person making conscious decisions in social performance situations and that behaviour could not simply be reduced to neuronal conditioning (Bandura, 2006). Bandura’s theoretical perspective can be epistemologically situated as constructivism with origins tracing 
back to Vygotsky. Social constructivism and social constructionism (e.g. Berger and Luckman, 1966), while often incorrectly used interchangeably, differ in that constructivism focuses on the individual knower, while constructionism places that individual in a social context where knowing is negotiated among members of a community (Raskin, 2002). Much of the research conducted exploring writing self-efficacy explores the writing experience as the plight of an individual. Viewing writing self-efficacy as developing through processes of individualism defy what students report about their writing experiences in interview studies where self-efficacy is developed through sense of community (Camfield, 2016).

Researchers have primarily explored writing self-efficacy as a measurable construct in quantitative research; however, research has not been able to consistently connect writing selfefficacy, as a measured variable, to writing performance outcomes. Inconsistent findings may be a function of a mismatch between the existing product- and process-focused writing self-efficacy measures that neglect to consider community influences on writing self-efficacy development, and a written work evaluated for the research study which would have been produced amidst complex, situated social relationships. Some writing self-efficacy research, in an effort to maximize perceived objectivity of writing assessment, has advocated use of standardized testing or timed writing as writing performance activities, both of which are unrealistic stand-ins to the kind of writing demanded from students at the post-secondary level. This means that writing self-efficacy researchers often conduct context-free experiments that draw conclusions demonstrating the researchers expect the real world to behave similarly (Greeno, 1998).

Socially constructed perspectives accept the complexity in the writing context (Nolen et al., 2015). In previous work, the first author (Mitchell, 2018) outlined the broad attributes of socially constructed writing. These attributes are: identity formation as a writer within a discipline; creativity associated with ideas and novelty of approach; emotions which can both 
drive and disrupt writing at all stages from planning to feedback; relational aspects which include the dialogic and intertextual relations built with readers and texts, as well as relationships formed with teachers, peers, and institutions developed during the writing process; and specific attributes unique to the context of writing which explore the demands that communities place on writers as they approach their craft. All five aspects of socially constructed writing are tied together through reflective capacity to enrich the writing experience and contribute to growth in selfunderstanding and metacognition. Thus, because, as Greeno (1998; 2015) notes, the cognitive and the social research perspectives have developed in isolation from one another; perspectives that unite the two movements are needed to provide the greatest understanding. This paper proposes that a merging of social cognitive and socially constructed perspectives is necessary for an advancement of writing scholarship. The next sections will introduce the situated perspectives, and then present a synthesis of these perspectives with writing self-efficacy theory.

\section{Situated Perspectives}

The situated perspectives to be explored here include cultural-historical activity theory (or activity theory), rhetorical genre theory (RGT), and situated learning within communities of practice (CoP). What these perspectives contribute to the understanding of writing self-efficacy is that they, to varying degrees, emphasize the role of community, including the institutional influences on a community, in any writing experience, and function to examine how context influences writing motives. Respectively, they have complementary purposes: activity theory focuses on activity or pedagogy as well as how communities regulate activities, RGT focuses on motivated, persuasive text production and interpretation, and CoP focuses on community interaction and its influence on development of expertise. All three theories emerged from Russian psychological and philosophical thought. The work of psychologist Lev Vygotsky (1986), who also has cognitive psychology origins, inspired, through various intermediaries, our 
current versions of activity theory and CoP, and Mikhail Bakhtin (1981;1986), Russian philosopher and social theorist, writing on dialogism and speech genres, inspired RGT. Rarely are these theories presented in isolation; typically, activity theory is presented in conjunction with RGT (e.g. Russell, 1995; 1997; Bawarshi, 2003). Other authors have attempted to merge the three theories into a synthesis (e.g. Artemeva, 2008; Brent, 2011). CoP, in particular the works of theory originators Lave and Wenger (1991) or Wenger (1998), are cited in nearly every article about RGT or activity theory. Brief descriptions of each of these theories will follow.

\section{Activity Theory}

Originating with the work of Vygotsky, expanded upon by one of his students Aleksei Leont’ev, and developed into its current form by Engeström (2001), “activity” is depicted visually as a triangle with many internal triangles for focused examination of intersecting players in a writing classroom (the 'activity') (see e.g. Kain and Wardle, 2005). Activity theory is the most structured of the three situated perspectives and functions as follows: the subjects of study may be students and teachers, the object might be the pedagogical process of an essay requiring critical thinking that the students are assigned to write, with the outcome being a successfully implemented essay. The tools students access might include pens, paper, computers, library resources, the internet, and their knowledge of course content and disciplinary discourse. The students will use these materials to achieve particular goals for their essay writing. Influencing these goals are rules, including assignment guidelines written by the teacher, conventions of grammar and style-guide implementation, but also larger system rules encompassing the power relations in writing, such as those set for academic probation and progression in a program. The community includes the classroom environment and relationships, the larger academic community of the institution of higher learning they attend, and disciplinary preferences for writing. Lastly, the division of labour for accomplishing the task includes anyone that may be 
involved in influencing their writing process: peers, tutors, family, and instructional support and grading activities.

The strength of activity theory for researchers is its ability to analyze contexts and power relations to diagnose areas of conflicts and barriers existing within the subjects, the tools they work with, other community members, or intersecting communities, each of which have their own motives (Russell, 1997). Activity theory is a relational theory that can inform pedagogical and policy processes affecting the activity system within intersecting communities. Effects on writing self-efficacy can emerge through any interaction in the activity system.

\section{Rhetorical Genre Theory}

The study of rhetoric and genre traditionally focused on the surface characteristics of texts in order to classify those texts based on forms of discourse, audiences targeted, modes of thinking, or rhetorical situations (Miller, 1984). Miller’s seminal paper took rhetorical genre theory (RGT) in new directions by framing genre as social action and articulating that all written genres have a motive and that motive is to (paradoxically) simultaneously evolve and maintain community norms, values, epistemology, ontology, ideology, and power relations (Berkenkotter and Huckin, 1993; Bawarshi, 2003; Paré, 2014). Genres dictate the form a writer uses and the acceptable discourse within that form, while at the same time writers are the inventors of that genre and can challenge the norms within the genre; the reciprocal relationship between the boundaries of a genre and the writer's motives within a genre is a relationship known as situated cognition (Bawarshi, 2003). Genres control writers’ rhetorical moves, and writers control the presentation of genres. Genres continually evolve as they interact with other related genres or with previous texts written in the same genre (through the Bakhtinian concept of intertextuality). An ongoing conversation (dialogism) develops based on a rhetorical exigence, defined as an urgent objective need, goal, or motive (Artemeva, 2004; Paré, 2014). 
Genres belong to particular communities and, as a result, can only be mastered by insiders to that specific community (Artemeva, 2004) through understanding of that community's tacit discourse. The use of language in combination with exploring motives for writing to an audience, and the fact that no two writers will bear the same motives even when writing in the same genre in the same community, has led genre theorists to refer to genre as “stabilized-for-no” (Schryer, 1993). Genres are continually shapeshifting to fit community needs (Devitt, 2000; Bawarshi, 2003) and change because the space and time the genre occupies has changed the motives (exigencies) of the community (Artemeva, 2004).

The strengths of RGT for writing self-efficacy assessment are its focus on ability to write consistently in a discourse for a genre, the recognition that novices will not instantly be able to manage the genres of their discipline, and the emphasis on interpretive acts of reading and writing and how all texts are responding to previous texts. If a writer has a goal for social action within their writing (e.g. to get a job or receive a grant), that writer must have enough selfefficacy to believe their writing abilities are strong enough to be successful at that social action. Genres will vary over time, between disciplines, and in how they define the relationship between reader and writer. Consequences will result from failing to execute a genre in the manner expected by the gatekeepers to a discipline (Russell, 1997). Paré (2014) notes that to challenge the norms of a genre, the writer likely needs to have power within a community. Novice writers will question the success of their application of a genre, and any risk-taking modifications attempted within, which may produce reciprocal effects on writing self-efficacy.

\section{Communities of Practice}

Initially developed by Lave and Wenger (1991) the first iteration of CoP introduced the concepts of situated learning, defined as learning while participating in a practice environment, and legitimate peripheral participation, which explores how novices observe and then trial-and- 
error the discourses and practices of a community and emerge as full participants. The strength of the CoP model is its ability to help researchers come to understand how novices to a community (newcomers, to use Lave and Wenger's term), become experts (old timers) thus CoP is more amenable to examining how writing contributes to identity development and sense of belonging within a discipline, rather than how writers come to identify as writers.

Wenger’s (1998) description of the concept of negotiated meaning among participants in a community is reminiscent of the reciprocal way genres and contexts mutually interact with one another in the RGT notion of situated cognition. Members of communities simultaneously use genre and rhetoric to manipulate and negotiate meaning, while at the same time being hemmed in by their context (Berkenkotter and Huckin, 1993; Wenger, 1998; Devitt, 1993; 2000). Negotiating meaning creates conflicts when boundary crossing occurs between communities - as Lea and Street (1998) observed when describing the student who received two diverse evaluations on two papers written for two disciplines using similar rhetorical strategies. Boundary crossing when learning to write in new genres can have an impact on writing selfefficacy. The primary tool we use to immerse ourselves into a new community is language (Bruffee, 1986). How language (and writing) practices brought in from other CoPs affect the CoP under examination, through changing how meanings are negotiated and how identities are developed, are how transformation and change take place. Transfer of writing ability, only tenuously possible as best, has a large impact on writing self-efficacy in particular in CoP transition zones such as from discipline to discipline, high school to first-year, undergraduate to graduate work, and university to workplace writing (Russell, 1997). 


\section{Negotiating a Synthesis of Social Cognitive and Socially Constructed Theoretical Perspectives}

The brief description of the three situated perspectives (activity theory, rhetorical genre theory, and communities of practice) serves as an introduction to how these perspectives can be merged to create a new perspective of writing self-efficacy. Cognitive theories are lacking in the ability to contribute to our understanding of the complex contextual issues that influence student development of identity, genre knowledge, and practice-based competence through writing. Constructionist theories are lacking in concrete solutions about what to do when facing the blank page with nothing but a prompt or a vague idea to guide the writing. They also lack in solutions for teaching complex aspects of writing such as voice or disciplinary discourse, which they acknowledge are tacit and rarely taught (Lea and Street, 1998; Mitchell, 2018). Cognitive theories continue to frame writing as an individual act (Greeno, 2015). Cognitive theories hypothesize that people create mental representations of external future states and make selfefficacy judgements as a result (Bandura, 1997; Greeno, 1998). Process theories of writing suggest steps for tackling a writing task - steps that are critical for novice writers to find a starting point for their writing. But the reflective requirements to assess if an action is having a positive effect on ability and, therefore, an impact on writing self-efficacy, is a bridge that is supplied by constructionist thinking (Bruffee, 1986). Constructionist theories can also ask critical questions about components of process writing, such as: Where do our goals come from? What ideas are valued? How do we know what needs revising in our writing? (Devitt, 1993). If social cognitive and social constructionist theories are blended together through an "interweaving” of individual self-efficacy processes and the structures of the context of the writing (Turner and Nolen, 2015), how will they intersect with one another and develop a more complete picture of writing self-efficacy to guide research and pedagogy? 
Self-efficacy theory explores the factors that drive motivation to write, to improve upon writing, and to persist in educational programs. Cognitive process models can be used to guide students through concrete planning, composing, and revising activities of writing. Constructionist perspectives fill the gaping holes in these theoretical perspectives because they attend to the context of writing, creativity allowances, and the relationships formed in the writing process. The components that structure constructionist writing (Mitchell, 2018) defined earlier, included identity, creativity, emotions, relational aspects, and context, with identity at the core of the model. Next, we use the components of this model to tie the theoretical perspectives together. The five domains of the model are tightly wound together through reflexive thought and that reflexive thought must be guided consciously by educators who assign writing in their classrooms.

Developing an identity in an activity system or CoP is marked by understanding the discourse of that system. Learner identities shape motivation and because identities are situated, motivations are also situated (Nolen et al., 2015). In beginner writers to a discipline, identity conflicts will abound and these conflicts are a result of boundary crossing from one CoP or activity system (context) to another (e.g. high school to university). Students need to recreate their identities when they begin to appropriate the genres of the new system (Russell, 1997). Incomplete development of an identity in a system will likely lead to low self-efficacy when writing within that system. Having self-efficacy to write in an activity system may be a marker of identity development.

If identity can be successfully appropriated through writing, emotional investment in the community will result in creative and passionate management of the genres of that community. Emotional response cannot be separated from cognition as Bandura’s inclusion of emotional arousal in self-efficacy theory attests. This emotional investment, as Phelps (2014) conjectures, 
may be enhanced through the boundary crossing that occurs between the professional activity systems and the personal activity systems. As Russell et al. (2009) observe, use of personal or non-academic genres can contribute to development of an intellectual stance for writing in the discourse of a discipline.

Developing an identity is also an antecedent to developing expertise in a community, activity system, or context (Wenger, 1998). Developing mastery, a source of self-efficacy, in a particular activity system cannot happen by only focusing on the mastery of writing process components - although providing suggestions to novice students on how to manage writing processes must also be considered. Writing processes will differ in every community, and every writing genre, and these must be taught by members of the community (Hyland, 2003). Identity development, expertise, mastery of a discipline’s genres are all connected experiences. Genres, although they appear to some students as rigid rule-based busy-work in classroom environments, can be modified, but it requires the mastery of that genre and an identity in a discipline to see the flexible capabilities of the genre and develop creativity within it (Artemeva, 2008; Paré, 2014).

Thus, mastery of a genre allows for creativity where the apparent rules of the system can be altered and genres mixed-and-matched. Breaking the rules of a genre and its discourse within a discipline is particularly challenging for novices where attempts to change a genre are often viewed as errors rather than innovations (Devitt, 2000). Student writing of essays in classrooms is its own genre. Certainly, the genres that exist in the relationality of the classroom are most rigid for undergraduates, which is a factor that should be brought to awareness simply for its resultant impacts on pedagogy. Students quickly realize that conformity to the genre is expected and this realization will have impacts on writing self-efficacy in the creative domain. The rules of genre are also rigid for doctoral students where tensions in the doctoral activity system are 
constantly in motion between the perceived rigidity of genre and the expectations of making an original contribution (Paré, 2014).

Writing functions best through dialogic interactions within a community, and intertextual relations in reading literature that inspires ideas. Hence, why the relational aspects of writing are emphasized in constructionist perspectives (Mitchell, 2018), but are absent or tokenized in cognitive process perspectives which conjure images of "the struggling writer alone in a loft, seeking inspiration” (Paré, 2014, p. A-90). As Paré (2014) says, when we look at relationships in writing, "the rhetorical situation suddenly becomes quite crowded” (p. A-89). Readers reconstruct texts for their own use based on their own needs, transforming information for their own time and space, which may take ideas to a place the original writer may never have intended. However, writers often doubt their ability to engage in such interpretation or believe that the rules constrain them from transforming knowledge in this way. Ultimately, these fears can have compounding effects on the lived experience of writing-self-efficacy.

Bandura (1997) acknowledges relationality in self-efficacy theory through sources such as vicarious experiences, including modelling and self-comparisons with others, and social persuasions, such as feedback. But self-efficacy theory’s vision of feedback is transmissional and unidirectional. Constructionist perspectives suggest that feedback needs to be iterative and dialogic in order to be effective. Self-efficacy is fostered by developing ties with peers and instructors in the writing process. During the early stages of entry into a discipline students are left with no choice but to appropriate tools of writing processes from other activity systems, may that be high school or other academic disciplines, and these choices, previously successful, may lead to failure in the current context (Lea and Street, 1998; Russell, 1997) with resulting impacts on writing self-efficacy. 
Exploring constructionist models of writing and how they intersect with writing selfefficacy has potential to contribute much to our understanding of persistent problems in writing scholarship such as: 1) transfer of knowledge from theory to practice (Miller, 1984); 2) understanding related issues of writing transfer, such as why students seem to need to re-learn how to write with every new assignment or why they struggle with the writing requirements of their profession as newcomers to the workplace (Miller, 1984; Russell, 1997; Lea and Street, 1998; Artemeva, 2004; Brent, 2011); 3) how teaching writing in a generic introductory format to students as they enter programs is failing to introduce them to the disciplinary discourses (Russell, 1995; Mitchell, 2018); and 4) how power relationships between students and faculty affect writing self-efficacy (Lea and Street, 1998).

The above synthesis provokes thoughts of four pedagogical implications that fit with situated perspectives and merge with social cognitive perspectives on writing self-efficacy.

1. If, as Russell et al. (2009) state, using personal genres of writing can influence identity development in a discipline, thought must be given to developing assignments that incorporate or springboard from personal experience. Allowing the personal within academic writing means relinquishing the belief that academic writing is objective writing with an invisible author. Flexibility in instructional expectations for student genres of writing build writing self-efficacy.

2. Defining what it means to be creative within an academic assignment is valuable to beginning writers. It could mean that what we picture as the pinnacle of academic writing the essay or literature review - is not the only way to establishing knowing. Most students will not go on to write literature reviews in their professional careers. Alternative forms of writing dispersed across a curriculum, such as digital storytelling, creative non-fiction, or 
podcast scripting, might be just as effective for learning to write in the discourse of a discipline.

3. While it is known that iterative feedback is the most effective for improving writing, what prevents its academia-wide implementation in undergraduate classrooms is the timeconsuming, labour intensive, nature of using multiple feedback rounds and drafts. Exploration of effective and efficient peer feedback processes and other relational feedback mechanisms can build self-efficacy and community identity and are necessary to make this form of writing pedagogy standard practice.

4. Students only confidently know how to use the writing processes of the last assignment they successfully wrote. Scaffolding is a Vygotskian constructionist pedagogy but involves actively teaching the cognitive processes of writing in planning, composition, and revision as they apply to a specific assignment. Processes differ in small tacit ways between courses, assignments, and the genres students are asked to write. The complexity of these processes increase as students progress to more senior years in their academic program and cross boundaries into graduate school. These process differences are not obvious or intuitive for all students.

While attempting to measure a concept is objectivist science, measurement tools are built from a theoretical standpoint on the concept being assessed. A socially constructed theory or standpoint may influence item development on quantitative measures. This paper was developed within the context of the doctoral work of the first author within the discipline of nursing education. Previous work on writing self-efficacy which identified a gap in measurement of the concept (Mitchell et al., 2017) led to an exploration of socially constructed and situated perspectives on writing (Mitchell, 2018). This past work triggered the question of whether there might be an epistemological incompatibility between Bandura's self-efficacy theory and socially 
constructed theories on writing, a question which inspired this paper. This work will culminate in the development of a measure of writing self-efficacy that considers self-efficacy theory and socially constructed perspectives on writing.

Writing is an identity-building initiation into a profession which has profound impacts on personal efficacy in a writing context. As Russell (1995) suggests, a discipline must be acutely aware of what defines good writing in their activity system in order to influence pedagogy. The exploration presented in this paper describes how socially constructed and social cognitive perspectives on writing can intersect and inform researchers and theorists hoping to understand writing experience as lived by students. Educators must see the value of what students bring to their writing from other communities of practice or their personal activity system (Camfield, 2016). Both constructionist and cognitive perspectives are needed to best inform pedagogy for writing. That both perspectives originate in some fashion from Vygotskian philosophy adds credence to their possible compatibility. Context is critical to the planning and implementation of writing pedagogy and socially constructed perspectives can provide the tools that educators and researchers need to assess their writing contexts. 


\section{References}

Artemeva, N. (2004). Key concepts in rhetorical genre studies: An overview. Technostyle, 20(1), 3-38. https://doi.org/10.31468/cjsdwr.524

Artemeva, N. (2008). Toward a unified social theory of genre learning. Journal of Business and Technical Communications, 22(2), 160-185. https://doi.org/10.1177/1050651907311925

Bakhtin, M. (1981). Discourse in the novel (C. Emersion \& M. Holquist, Trans.). In M. Holquist (Ed.), The dialogic imagination (pp. 259-422). University of Texas Press.

Bakhtin, M. (1986). The problem of speech genres (V. W. McGee, Trans.). C. Emerson \& M Holquist (Eds.), Speech genres and other late essays (pp. 60-102). University of Texas Press.

Bandura, A. (1997). Self-efficacy: The exercise of control. W. H Freeman.

Bandura, A. (2006). Toward a psychology of human agency. Perspectives on Psychological Science, 1(2), 164-180. https://doi.org/10.1111/j.1745-6916.2006.00011.x

Bauer, L., \& Theado, C. (2014). Examining the social turn in postsecondary literacy research and instruction: A retrospective view of JCRL scholarship. 2005-2013. Journal of College Reading and Learning, 45(1), 67-84. https://doi.org/10.1080/10790195.2014.950869

Bawarshi, A. (2003). Genre and the invention of the writer: Reconsidering the place of invention in composition. Utah State University Press.

Berger, P. L., \& Luckmann, T. (1966). The social construction of reality: A treatise in the sociology of knowledge. Anchor Books.

Berkenkotter, C., \& Huckin, T. (1993). Rethinking genre from a sociocognitive perspective. Written Communication, 10(4), 475-509. https://doi.org/10.1177/0741088393010004001 
Brent, D. (2011). Transfer, transformation, and rhetorical knowledge: Insights from transfer theory. Journal of Business and Technical Communication, 25(4), 396-420. https://doi.org/10.1177/1050651911410951

Bruffee, K. (1986). Social construction, language, and the authority of knowledge: A bibliographical essay. College English, 48(8), 773-790. https://doi.org/10.2307/376723

Camfield, E. (2016). Mediated-efficacy: Hope for helpless writers. Journal of Developmental Education, 39(3), 2-11. https://escholarship.org/uc/item/89f1r469

Devitt, A. (1993). Generalizing about genre: New conceptions of an old concept. College Composition and Communication, 44(4), 573-586. https://doi.org/10.2307/358391

Devitt, A. (2000). Integrating rhetorical and literary theories of genre. College English, 62(6), 696-718.

Engeström, Y. (2001). Expansive learning at work: Toward an activity theoretical reconceptualization. Journal of Education and Work, 14(1), 33-156.

Flower, L., \& Hayes, J. (1981). A cognitive process theory of writing. College Composition and Communication, 32(4), 365-387. https://doi.org/10.2307/356600

Greeno, J. G. (1998). The situativity of knowing, learning, and research. American Psychologist, 53(1), 5-26. https://doi.org/10.1037/0003-066X.53.1.5

Greeno, J. G. (2015). Commentary: Some prospects for connecting concepts and methods of individual cognition and situativity. Educational Psychologist, 50(3), 248-251. https://doi.org/10.1080/00461520.2015.1077708

Hyland, K. (2003). Genre-based pedagogies: A social response to process. Journal of Second Language Writing, 12(2003), 17-29. https://doi.org/10.1016/S1060-3743(02)00124-8 
Kain, D., \& Wardle, E. (2005). Building context: Using activity theory to teach about genre in multi-major professional communication courses. Technical Communication Quarterly, 14(2), 113-139. https://doi.org/10.1207/s15427625tcq1402_1

Lave, J., \&Wenger, E. (1991). Situated learning: Legitimate peripheral participation. Cambridge University Press.

Lea, M. R., \& Street, B. V. (1998). Student writing in higher education: An academic literacies approach. Studies in Higher Education, 23(2), 157-172, http://doi.org/10.1080/03075079812331380364

Lea, M., \& Street, B. (2006). The “academic literacies” model: Theory and applications. Theory into Practice, 45(4), 368-377. https://doi.org/10.1207/s15430421tip4504_11

Meier, S., McCarthy, P. R., \& Schmeck, R. R. (1984). Validity of self-efficacy as a predictor of writing performance. Cognitive Therapy and Research, 8(2), 107-120. http://doi.org/10.2307/357865

Miller, C. (1984). Genre as social action. Quarterly Journal of Speech, 70, 151-167. https://doi.org/10.1080/00335638409383686

Mitchell, K. M. (2018). Constructing writing practices in nursing. Journal of Nursing Education, 57(7), 399-407. https://doi.org/10.3928/01484834-20180618-04

Mitchell, K. M., Rieger, K. L., \& McMillan, D. E. (2017). A template analysis of writing selfefficacy measures. Journal of Nursing Measurement, 25(2), 205-223. http://doi.org/10.1891/1061-3749.25.2.205

Nolen, S. B., Horn, I. S., \& Ward, C. J. (2015). Situating motivation. Educational Psychologist, 50(3), 234-247. https://doi.org/10.1080/00461520.2015.1075399 
Nystrand, M. (2006). The social and historical context for writing research. In C. A. MacArthur, S. Graham, \& J. Fitzgerald (Eds.), Handbook of writing research (pp. 11-27). Guilford Press.

Pajares, F., \& Valiante, G. (2006). Self-efficacy beliefs and motivation in writing development. In C. A. MacArthur, S. Graham, \& J. Fitzgerald (Eds.), Handbook of writing research (pp. 158-170). Guilford Press.

Paré, A. (2014). Rhetorical genre theory and academic literacy. Journal of Academic Language and Learning, 8(1), A83-A94.

Perry, K. (2012). What is literacy? - A critical overview of sociocultural perspectives. Journal of Language and Literacy Education, 8(1), 50-71. http://jolle.coe.uga.edu/wpcontent/uploads/2012/06/What-is-Literacy_KPerry.pdf

Phelps, L. (2014). The historical formation of academic identities: Rhetoric and composition, discourse and writing. Canadian Journal for Studies in Discourse and Writing, 25(1), 325. https://doi.org/10.31468/cjsdwr.37

Raskin, J. (2002). Constructivism in psychology: Personal construct psychology, radical constructivism, and social constructionism. American Communication Journal, 5(3), 117.

Reither, J. A. (1985). Writing and knowing: Toward redefining the writing process. College English, 47(6), 620-628. https://doi.org/ 10.2307/377164

Russell, D. (1995). Activity theory and its implications for writing instruction. In J. Petraglia (Ed.), Reconceiving writing, rethinking writing instruction (pp. 51-78). Erlbaum.

Russell, D. R. (1997). Rethinking genre in school and society: An activity theory analysis. Written Communication, 14(4), 504-554. https://doi.org/10.1177/0741088397014004004 
Russell, D., Lea, M., Parker, J., Street, B., \& Donahue T. (2009). Exploring notions of genre in academic literacies and writing across the curriculum: Approaches across countries and contexts. In C. Bazerman et al. (Eds.), Genre in a changing world: Perspectives on writing (pp. 459-491). WAC Clearinghouse.

Schryer, C. F. (1993). Records as genre. Written Communication, 10(2), 200-234. https://doi.org/10.1177/0741088393010002003

Turner, J. C., \& Nolen, S. B. (2015). Introduction: The relevance of the situative perspective in educational psychology. Educational Psychologist, 50(3), 167-172. https://doi.org/10.1080/00461520.2015.1075404

Vygotsky, L. (1986). Thought and language (A. Kozulin Ed. \&Trans.). The MIT Press.

Wenger, E. (1998). Communities of practice: Learning, meaning, and identity. Cambridge University Press. 
Tom always told us, "Write about the moment after which everything is different."

Our lives are saved by such ridiculous moments. Language isn't any help. Especially the words part.

Chuck Palahniuk, Consider This 


\section{Interlude 2}

I was fortunate that I had the opportunity to apply for a Research Manitoba doctoral student fellowship in early 2017 while I was still in the first year of my doctoral studies. I was even more fortunate to be awarded that fellowship especially given the fact that a year later, with a new Conservative government in power, the doctoral fellowships at Research Manitoba for students not studying cancer or child health were unfortunately ended. The financial side of the studentship notwithstanding, the application process forced me to plan my doctoral research very early in my program. Very little of what I planned in that application changed.

One of the major activities I undertook during the preparation of that grant application was to establish a method for the Delphi panel I used in this research. The Delphi method was mentioned in every research and tool development textbook I read in preparation for that grant application, but they gave no details on how to conduct one. When I got into the literature discussing the Delphi method, none of the method papers addressed Delphi use in tool development contexts. I gleaned information from the policy and clinical guideline Delphi’s and patchworked together a method from published tool development studies.

The essence of what you read in this thesis is what I proposed in that grant with one main exception. I had intended to include students in my original Delphi. The change happened because I discovered cognitive interviews and I decided that having conversations with students about writing would be more meaningful to this research. Delphi panels also tend to focus on theoretical and conceptual applicability of items and other researchers have observed that the intended target population for the questionnaire, despite instructions, tend to rate items low if they aren't relevant to them personally while ignoring or not understanding the meaning behind conceptual relevance. I wanted to really examine the theoretical relevance of these items at this 
phase of the research. The students would be a much more powerful voice in the cognitive interviews.

It wasn’t until I started to conduct my Delphi study that I realized the degree to which I was fumbling around using instinct and my genuine nerdy love of data as I made decisions to analyse the responses provided to me by my panel members. This experience, in conjunction with the lack of literature that focused on the Delphi in an instrument development context, presented a significant gap in my doctoral work. I knew I had to write the paper that follows which explores my Delphi method and details my analysis decision-making. The decisionmaking I describe within the paper came as a result of having a very engaged panel of scholars who were more than willing to reflect on their own writing and teaching practices to assess the 41-items I presented to them.

Most importantly, my panel members did not hesitate to call me out on my assumptions, which proved to be things like, "all engaged writers daydream about their writing at odd times and places during the day” - as I do. As it turns out, they don't. Many writers, especially student writers, don't reflect about their writing at all until they are sitting and staring at the computer monitor revising. Nor do all writers engage with their emotions in a way that shows up in their writing or their rhetorical choices. My other main assumption was about the nature of creativity, and originality, and how can any writer accurately assess their capability to engage a reader with their words? Being able to acknowledge these assumptions directly contributed to many of the item deletions that happened during the Delphi study.

This Delphi paper is a methods paper rather than a research paper although there are many overlaps with the genre of the research study. The goal was to provide the research community with a pragmatic description of how to "play” with Delphi data. The paper is also a 
nice adjunct to Paper 5 as it provides details of my chosen Delphi methods that are not as detailed in that writing.

\section{Author Contributions}

I (Kim Mitchell), the student, conceived and proposed the idea of for the paper. I developed the methods described within and conducted the data collection and analysis. I sent regular emails to the remaining author team reporting on my processes and findings which the team approved. My advisor Dr. McMillian was instrumental in the initial development of the Delphi processes I had originally proposed in the Research Manitoba application for funding. Dr. McMillan, Dr. Lobchuk, and Dr. Nickel, all approved the methods and provided much substantive feedback which informed the editing and refinement of the ideas you will read in the paper that follows. 


\title{
Paper 3: Delphi Decision Making: Blending Qualitative and Quantitative Methods in Tool Development Research
}

\begin{abstract}
The end goal of instrument development studies sits within an ontology of constructive realism, an intermediary ontology between the representative constructed items and objectivist goals of measurement. Delphi methods become a part of that constructed realism through gathering expert opinions about the construct under investigation. Despite its popularity, little pragmatic guidance exists for researchers using the method in instrument development studies, and unlike clinical guideline or policy Delphi studies, the Delphi in instrument development is rarely the endpoint of the questionnaire. Authors of instrument development studies rarely describe the strategies used to decide when to keep, edit, or delete items when merging both quantitative and qualitative assessments of the developing items. This paper describes multimethod decision-making strategies as they were implemented during the Delphi phase of the Situated Academic Writing Self-Efficacy Scale validation project. Five case-study items are presented to highlight the strategies used to blend the qualitative and quantitative data provided by the Delphi experts. Data was blended by first categorizing the quantitative data as having strong evidence for inclusion, deletion, or neutrality. Qualitative data was integrated by contemplating panelist's individual and collective opinions about an item's value and wording, as well as stream-of-consciousness reflections from panelists about the nature of writing selfefficacy. This paper contributes to the literature by describing, through use of specific examples, how qualitative and quantitative data can be effectively integrated in order to make decisions in multimethod instrument development research and should be useful for all beginning and seasoned researchers attempting tool development.
\end{abstract}




\section{Delphi Decision Making: Blending Qualitative and Quantitative Methods in Tool Development Research}

The Delphi method is an established method of gathering expert opinions from a panel of relevant stakeholders to a research question. While the method itself varies based on the objective of the research, some key characteristics define the process including: anonymity of Delphi participants to each other but not necessarily the researcher; iteration over various rounds of presented materials and surveys in order for the researcher to facilitate progress on the development and refinement of ideas; controlled feedback provided to members between rounds based on researcher analysis; and statistical aggregation of the group response (Skulmoski et al., 2007). The nuances of the method have been debated including whether it most correctly belongs in the qualitative or quantitative paradigm of research (Keeney et al., 2011; Tapio et al., 2011). Those debates include observations that very few Delphi researchers report methodological or philosophical underpinnings beyond interpretivism (Guzys et al., 2015).

Multimethod Delphi studies are sequential in structure. The first round may be exclusively qualitative with the objective of brainstorming ideas for policy development, practice guidelines, forecasting trends, or developing conceptual frameworks (Keeney et al., 2001; McKenna, 1994; Tapio et al., 2011). Between rounds the researcher collates the suggested statements and presents them in subsequent rounds for rating of relevance or agreement. A key variation in instrument development Delphi studies is the choice to present the experts with predeveloped tool items based on literature reviews and an a priori framework (Hawkins et al., 2014; Rodrigues et al., 2017). A second common modification is to provide an opportunity for the expert to give qualitative comments after each pre-developed item for purposes of making editing suggestions, assessing item interpretation, or providing rationale for the conceptual importance (Eberman \& Cleary, 2011; O’Rourke et al., 2018). These alterations convert the 
Delphi process from an exploratory sequential to a convergent mixed design (Creswell \& Creswell, 2018). In convergent designs, analysis of expert responses is more integrative and can develop better support for outcomes, well-supported decisions, and consider different realities (Bazeley, 2018).

There is less guidance in the literature to inform questionnaire development Delphi processes using convergent methods. Books such as Keeney et al., (2011) focus on policy and clinical guideline Delphi processes rather than instrument development Delphi panels. While policy development processes can inform instrument development, most of the guidance specific to the needs of instrument development Delphi methods must be gleaned from individual research reports - a context where journal word counts may preclude in-depth descriptions of blended analytical processes. Because a pragmatic description of Delphi methods specific to instrument development appeared lacking in the literature, the goal of this paper is to fill that gap. The discussion includes specific examples from a Delphi project designed to refine the items for the Situated Academic Writing Self-Efficacy Scale, the nuances of strategies for analysis employed in a multimethod instrument development Delphi study.

\section{The "Ever-Adapting” Delphi Method}

The Delphi method is constantly modified, which some authors contend poses a threat to its credibility. Keeney et al. (2001) labeled the Delphi “ever-adapting.” In a systematic review of Delphi method usage and reporting within studies exploring healthcare quality indicators (Bouledid et al., 2011), the researchers describe the lack of universal requirements as a state of “confusion, disagreement, and uncertainty” (Introduction, para. 5). Viewing the Delphi as unstable and its many variations as a negative trait is an objectivist philosophical stance. McKenna (1994) observed that the Delphi may be more aligned with being an art than a science. Hasson and Keeney (2011), however, embrace the combination of quantitative and qualitative as 
a natural component of Delphi being a positivist and naturalist juxtaposition. Overtime, a shift in perspective has become apparent in the Delphi literature that acknowledges the constant modification of the method as a strength. Okoli and Pawlowski (2004) state Delphi methods invoke the true spirt of the term bricolage - or the use of whatever resources one has to meet the objective of the task that one faces.

Despite the mix of qualitative and quantitative methods, it must not be forgotten that the end goal of instrument development is to produce a finalized questionnaire that can best capture the reality of participants. That reality is always present as items undergo revision and refinement as they would in a Delphi process. The act of defining a concept and developing items is a qualitative process but using those items as statistical measurement is a realist ontology assuming that reality can be defined and represented by a numerical score. Durepos et al. (2018) have proposed that measurement creates an intermediary reality they define as constructive realism. Through constructive realism, a concept can be developed into a measurable construct and produce a version of the truth that is an approximation of reality, forming a bridge between positivist and constructionist epistemologies.

The subjective judgements of Delphi panel members are part of that constructive realism ontology. The opinions of the panel are valuable when precise analytical techniques are not sufficient for understanding a problem (Skulmoski et al., 2007). Delphi panels can include both experts and members of the target population, which means diverse perspectives can influence decisions; however, some authors observe that target populations tend to rate items based on personal relevance rather than theoretical relevance, which could lead to premature editing or elimination (Thomas, 2011).

Tool development research is subject to its own variations. The strongest instrument development projects triangulate numerous strategies in order to establish if the questionnaire is 
conceptually appropriate, understood by the population of interest, and gathers useful and accurate information. One of the criticisms of purely quantitative approaches to tool development is the ability to design a questionnaire that achieves appropriate statistical indicators of effectiveness, while the questionnaire remains theoretically or conceptually incomplete (Onwuegbuzie et al., 2010). While most instrument development studies report consulting experts on the appropriateness of the instrument to its context of use, the methods for doing so vary from superficial "face validity" approaches where the instrument is shown to experts and given approval (often with little or minimal suggestions for edits), to rigourous and time consuming multi-phased instrument development projects which involve multi-round Delphi consultations with numerous stakeholders combined with cognitive interviewing with the target audience for the questionnaire.

The stages of tool development should be iterative and move back and forth between stakeholder groups. Wickwar et al.’s (2013) adaptation of the Methotrexate in Rheumatoid Arthritis Knowledge Questionnaire for parents of children used a sequential process of consulting with experts. A panel of physicians and nurse practitioners first reviewed the questionnaire, followed by a panel of researchers, followed by cognitive interviews with parents, and then back to the research panel for final refinement. Rodrigues et al. (2017) developed a questionnaire to measure facilitators, barriers, and preferences to exercise in people with osteoporosis and used both quantitative and qualitative methods across their eight rounds of questionnaire revisions. They began with a pre-developed questionnaire based on a literature review and experience with the population, consulted with an advisory committee, conducted a Delphi panel, used patient cognitive interviews, a graduate student focus group, and followed-up with a second round of patient cognitive interviews. 
The triangulated and iterative approaches to instrument development often mean that the Delphi is one phase and one perspective within the overall tool development process. In instrument development studies, unlike the policy or clinical guideline studies, the Delphi endpoint is rarely a finalized questionnaire. Therefore, Delphi analysis processes must always consider the goals of phases to come when decisions are made about items. As the Delphi developed for the validation of the Situated Academic Writing Self-Efficacy Scale was a part of a multiphase study, an overview of the planned project is important for understanding some of the decision-making choices made through the Delphi phase:

1. Instrument development was a part of the first author's doctoral work and addressed a gap in current self-efficacy measurement which neglected more current situated, socio-cultural, and disciplinary perspectives on writing. Pajares and Valiante’s (2006) description of tool structure were followed through use of "I can” ability assessments for each item and 0-100 visual analog scales. Theoretically, item development considered Bandura’s self-efficacy theory (Bandura, 1997) and a socially constructed theory of writing (Mitchell, 2018; Mitchell et al., 2019). This perspective on writing identified the domains of socially constructed writing as identity, creativity, emotions, relational aspects, and context. These five domains informed item development. The developed items were reviewed by the author team (three nurses and one population health researcher) and one local writing instructor who teaches first year writing to nursing students. Finally, the items were presented in a poster session at a nursing discipline international conference.

2. A Delphi panel of international experts was established and included both writing researchers, teachers, and scholars, and nursing faculty interested in writing. Ethical approval was obtained in order to publish direct quotes from the panellists. 
3. A cognitive interview phase followed, where a diverse sample of 20 undergraduate students were asked to think aloud while rating themselves on the Delphi-panel-revised questionnaire.

4. For the final phase, a sample of nursing students was recruited to establish the factor structure of the instrument.

\section{The Writing Self-Efficacy Delphi Method}

The remainder of the paper will focus on the Delphi process that was established to revise and refine the Situated Academic Writing Self-Efficacy Scale. The Delphi panel included 7 nursing and 8 writing scholars. These scholars represented five countries, Australia, Canada, Germany, the United Kingdom, and the United States of America, and ranged in teaching experience at the post-secondary level from 3 to 30 years. The Delphi study included two rounds of surveys with feedback provided to the scholars between rounds and after the final round. The following sections will describe general decision making with respect to sampling procedures, the processes and adaptations, and the analysis procedures for each round. A Figure was developed to represent the visual pathway of decision-making steps for analysis and can be referred to while reading the narrative. 


\section{Figure 1: Visual Pathway for Delphi Decision-Making}

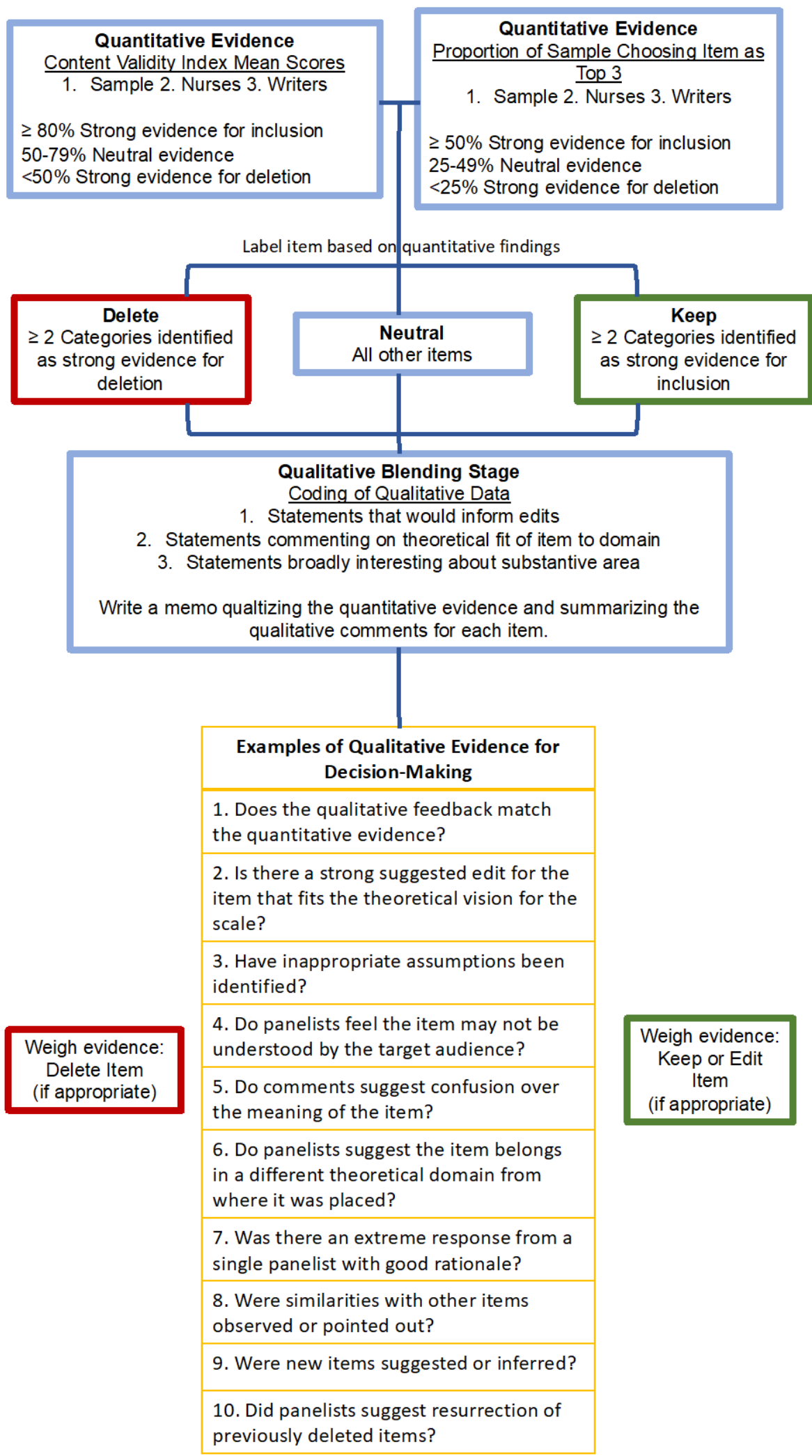




\section{Sampling}

Sampling in the Delphi requires understanding what expertise means in the context of the research question. The view of writing being assessed was a socially constructed situated perspective (Mitchell et al., 2019), thus the inclusion of writing scholars who understood this perspective was important for assessing the items. Because writing is disciplinary and the instrument development project was being conducted with nursing students, nursing scholars also offered a critical perspective.

Sample size issues are also a topic of debate in the Delphi literature with sample sizes typically ranging from 10 to 100 (Keeney et al., 2011). A sample size between 10 and 15 participants became the target. The use of both qualitative and quantitative data would mean less participants would be needed to inform decision making on edits to the pre-developed tool items, but yet large enough to gain content validity index (CVI) scores for each item (Polit \& Yang, 2016).

Scholars were recruited via three routes: 1) scholars met at national and international academic conferences who expressed an interest in the research; 2) Twitter contacts, and; 3) the academic listserv for the European Association for the Teaching of Academic Writing. Diverse strategies were harnessed in order to internationalize the sample. The success of each recruitment strategy is presented in Table 1 . Survey invites were sent to 27 interested participants (13 nursing, 14 writing) with 15 scholars committing to the project through two rounds (7 nursing [53.8\%], 8 writing [57.1\%]). The pattern of participation matches reports in the literature where participants that have had face-to-face contact with the researcher were more likely to commit to the Delphi panel (McKenna, 1994). The most effective recruitment strategy was the conference conversation route. Twitter participants most likely to follow through were scholars who had already been engaging extensively with the first author prior to study recruitment. While the 
listserv was also a successful recruitment strategy, none of the listserv participants were known to the researchers prior to participation.

Table 1: Success of Three Recruitment Strategies by Target Group

\begin{tabular}{|l|l|l|l|l|}
\hline Strategy & $\begin{array}{l}\text { Nurse Scholars } \\
\text { Expressing } \\
\text { Interest }\end{array}$ & $\begin{array}{l}\text { Writing Scholars } \\
\text { Expressing } \\
\text { Interest }\end{array}$ & $\begin{array}{l}\text { Total } \\
\text { Invites } \\
\text { Sent }\end{array}$ & $\begin{array}{l}\text { Follow through with } \\
\text { survey completion }\end{array}$ \\
\hline $\begin{array}{l}\text { Conference Contacts, } \\
\text { personal contacts, and } \\
\text { one snowball }\end{array}$ & 7 & 1 & 8 & $\begin{array}{l}6(75.0 \%) \\
\text { (5 nurses, 1 writing) }\end{array}$ \\
\hline Twitter & 6 & 2 & 8 & $\begin{array}{l}3 \text { (37.5\%) } \\
\text { (2 nurses, } 1 \text { writing) }\end{array}$ \\
\hline Writing Listserv & 0 & 11 & 11 & $\begin{array}{l}6(54.5 \%) \\
(6 \text { writing) }\end{array}$ \\
\hline Totals & 13 & 14 & 27 & $\begin{array}{l}15(55.6 \%) \\
\text { (7 nurses, 8 writing) }\end{array}$ \\
\hline
\end{tabular}

\section{Delphi Round 1}

The surveys for this study were prepared using the Qualtrics survey platform

(www.qualtrics.com). The initial questionnaire presented 41 items. Each item was grouped within its theoretical domain (identity, creativity, emotions, relational, context) (Mitchell, 2018). In the initial invitation email, the panel members were given an attachment containing a description of the theoretical perspective. This document described the overall instrument development plan and defined each of the writing domains. Panellists rated the relevance of each item using a 0-100 sliding scale. Relevance was defined as relevance to assessing writing selfefficacy as a construct according to the description of the theoretical perspective. Open-ended questions under each item and two open-ended questions that were general to the domain of writing being assessed (e.g. identity) were also available (see Box 1). 


\author{
Box 1: Round 1 Open-Ended Questions: \\ Following each item rating participants were asked: \\ Please provide any comments, reactions, concerns or thoughts about this item. For example. \\ Did you rate the item very high or very low? Provide your reasons for your choice of rating. \\ Does the item require editing in any way for grammar, clarity or meaning? \\ Does the item fit within this domain [identity]? \\ Would you recommend deleting this item? If so why? \\ For each domain of identity, creativity, emotional, relational, and context participants were \\ asked: \\ From the above [7] items, what would you select as the top three most important items to \\ assessing the domain of [identity]? (You may identify questions by their number). \\ Do you have any additional suggested items that you feel would help assess the [identity] \\ domain? If so, write them below.
}

While participants were asked to comment if they felt an item should be deleted, they were not explicitly told that we hoped to significantly reduce the number of items on the questionnaire. The reason for not sharing this key goal was to keep participants responses to the items organic so they weren’t viewing the questionnaire with a constant eye toward eliminating items.

\title{
Round 1 Analysis Strategies
}

Analyses which integrate qualitative and quantitative data can provide opportunities to draw conclusions that have a greater impact on the decisions made than each paradigm could contribute independently (Bazeley, 2018). Bazeley reports that integrative analysis is an evolving field requiring further theoretical discussion. Mixed-method analysis strategies tend to be highly 
complex, integrate seemingly incompatible epistemological realities, and are subject to the demands of the research question. The complexities make it difficult to write clear instructions for researchers to follow in a step-by-step guide. There are also complexities within each type of data collected. For example, descriptive statistics are less complex than a structural equation model. Quantifying qualitative findings is less complex than interpreting several one-on-one qualitative interviews. The respective weight the researcher gives to qualitative or quantitative data in the analysis process adds an additional layer of complexity (Hitchock \& Onwuegbuzie, 2019); hence why few authors attempt to describe their integrative methods, or when they do make the attempt, the product is often jargon-filled, unwieldy, and difficult to apply in a practical research analysis (Bazeley, 2018). The described analysis in this paper attempts to simplify the multimethod processes within the context of instrument development item editing decisionmaking.

Table 2 presents the quantitative evidence for five case-study items which will be used as exemplars to describe the analytical processes. Three sources of information for editing the questionnaire were gathered within the survey for round 1: 1) CVI ratings of the relevance of each item (quantitative); 2) Participant opinions on the top three items for each domain of writing (quantitative); 3) Qualitative comments on each of the items. The analysis proceeded by blending the information gathered from both the quantitative and qualitative response options using the following strategies (see Figure).

1. All the CVI scores for each item averaged the $0-100$ relevance ratings for the total sample, nursing, and writing samples. Scores $80 \%$ and above (include) and below 50\% (delete) were identified and flagged. All scores between 50\% and 79\% were considered neutral.

2. Top three items were tallied by proportion for the total, nursing, and writer samples. An item chosen as top three by $50 \%$ or greater of the sample were flagged for inclusion. An item 
chosen by less than $25 \%$ of the sample was deemed strong evidence for deletion. Item selected as top three by $25 \%$ to $49 \%$ of the sample were labeled neutral.

3. The above quantitative calculations provided six pieces of strong evidence for inclusion or exclusion of an item: total sample, nursing, and writer CVI ratings; total sample, nursing, and writer top three items. If an item scored in the strong evidence for deletion category in two or more of the six categories, it was labeled as “delete”. Items that received a score in the strong evidence for inclusion in two or more categories was labeled as "keep”. All other items were labeled as "neutral”.

4. The qualitative data were transferred into a Word document. Three coding categories became apparent upon reading the data: 1) statements which would inform item wording edits; 2) statements which informed the theoretical structure of the questionnaire; 3) statements which were participant reflections and insights about writing pedagogy or writing theory related to the item. 
Table 2: Quantitative Results for 5 Case Study Items and Final Decision After Blending Qualitative Evidence

\begin{tabular}{|c|c|c|c|c|c|c|c|c|c|}
\hline \multirow[b]{2}{*}{ Case } & \multirow[b]{2}{*}{ Item } & \multicolumn{3}{|c|}{ Mean CVI (\%) } & \multicolumn{3}{|c|}{$\begin{array}{c}\text { Proportion of Sample Choosing as } \\
\text { Top } 3 \text { Item n(\%) }\end{array}$} & \multirow[t]{2}{*}{$\begin{array}{c}\text { Quantitative } \\
\text { Evidence Label }\end{array}$} & \multirow{2}{*}{$\begin{array}{c}\text { Final } \\
\text { Decision } \\
\text { After Blending Qualitative and } \\
\text { Quantitative Data } \\
\end{array}$} \\
\hline & & $\begin{array}{l}\text { Sample } \\
\mathrm{N}=15\end{array}$ & $\begin{array}{l}\text { Nurse } \\
\mathrm{n}=7\end{array}$ & $\begin{array}{c}\text { Writers } \\
\mathrm{n}=8\end{array}$ & $\begin{array}{l}\text { Sample } \\
\mathrm{N}=15\end{array}$ & $\begin{array}{l}\text { Nurse } \\
\mathrm{n}=7\end{array}$ & $\begin{array}{l}\text { Writers } \\
\mathrm{n}=8\end{array}$ & & \\
\hline 1 & $\begin{array}{l}\text { I can creatively bring together } \\
\text { multiple sources into an original } \\
\text { written product. (Creativity) }\end{array}$ & 85.1 & 87.0 & 83.4 & $9(60.0)$ & $6(85.7)$ & $3(37.5)$ & Keep & Edit \\
\hline 2 & $\begin{array}{l}\text { I can visualize the connected parts of } \\
\text { a paper I have written and see how it } \\
\text { tells the complete story of my topic } \\
\text { or argument. (Creativity) }\end{array}$ & 78.5 & 84.4 & 73.3 & $10(66.7)$ & $5(71.4)$ & $5(62.5)$ & Keep & Keер \\
\hline 3 & $\begin{array}{l}\text { When I am preparing for a writing } \\
\text { assignment, I can often find myself } \\
\text { thinking, at unusual times and } \\
\text { places, about how to approach the } \\
\text { writing. (Identity) }\end{array}$ & 58.0 & 78.9 & 37.1 & $3(20.0)$ & $2(28.6)$ & $1(12.5)$ & Delete & Delete \\
\hline 4 & $\begin{array}{l}\text { The connections I feel with the } \\
\text { sources I find on my topic can } \\
\text { motivate me to express my own } \\
\text { ideas on that topic in writing. } \\
\text { (Relational) }\end{array}$ & 67.9 & 72.3 & 64.0 & $7(46.7)$ & $4(57.1)$ & $3(37.5)$ & Neutral & Edit \\
\hline 5 & $\begin{array}{l}\text { I can consider the needs of nursing } \\
\text { when I choose the topics I write } \\
\text { about in my courses. (Context) }\end{array}$ & 67.2 & 67.1 & 67.3 & $6(40.0)$ & 2(28.6) & $4(50.0)$ & Neutral & Delete \\
\hline
\end{tabular}




\section{Round 1: Blending of Qualitative and Quantitative Data}

From the initial 41 items presented to the panel, in round 1, 10 items were kept without revision - 5 rated high enough to keep, and 5 with high neutral ratings; 17 items were deleted 12 deleted outright based on low scores and matching critical or indifferent qualitative comments, 5 items rated neutrally which were deleted based on blending qualitative feedback; and 14 items were edited - 7 rated high enough to keep but had recommended wording changes, and 7 rated neutral but qualitative evidence suggested the lower ratings were more due to objections to wording than relevance of the item.

Five decision making scenarios emerged when blending the qualitative and quantitative data.

1) Quantitatively an item had strong evidence for inclusion but required edits.

2) Quantitatively an item had strong evidence for inclusion (or strong neutral evidence) for inclusion and it was included as written.

3) Quantitatively an item had strong evidence for deletion and it was deleted.

4) Quantitatively an item had neutral evidence and it was edited.

5) Quantitatively an item had neutral evidence and it was deleted.

In addition, there were two other scenarios that were possible, but never emerged, in this study. Items could also have had strong quantitative evidence for inclusion but were deleted, or items could have strong quantitative evidence for deletion but were instead included or edited. The five case study items presented in Table 2, will be examined for the strategies used to blend the quantitative and qualitative results together and come to a final decision on the status of an item.

Case 1: Quantitatively an item had strong evidence for inclusion but required edits. Memos were written to summarize the qualitative comments for each individual item. The first 
sentence of those memos was a narrative statement summarizing the quantitative evidence. Writing narrative statements about quantitative findings is a strategy known as data transformation or qualtizing (Onwuegbuzie et al., 2010). The creativity domain item, I can creatively bring together multiple sources into an original written product, had the following researcher memo written to summarize its quantitative evidence: "This item rated high for inclusion quantitatively and was a common choice (except among writing scholars) as a top three item.”

The qualitative comments indicated panel members recognized this item was asking about synthesis and agreed synthesis was an example of creativity in academic writing. The comments reflect the theoretical relationship between the word original and the perception of creativity. Panelists expressed misgivings about use of the word creativity. One writing scholar identified that some students might “interpret [the word creatively] too literally” (writer 3) as being “artistic.” Another panellist wrote a suggested revision which eventually inspired the revision that was made:

For me creativity has to do with bringing together multiple sources, but doing that in a way that is unexpected, surprising, that somehow draws the reader in to think about the topic in a way they hadn't imagined doing before” (nurse 7)

This item was edited to take into account both of the qualitative comments described here: I can bring together multiple sources in ways that are unexpected to create an original product or text.

Case 2: Quantitatively an item had strong evidence for inclusion or neutral evidence for inclusion and it was included as written. While highly rated, the item, I can visualize the connected parts of a paper I have written and see how it tells the complete story of my topic or argument, received a mix of qualitative comments. There were a variation in beliefs about the 
effectiveness of the word visualize and panellists reflected on how "visualize” may be perceived in a writing context. One panellist said, "I like the focus on visualization in this question" (writer 3), with others saying, "not everyone thinks visually about words” (writer 1). Other scholars had difficulty with the idea that visualizing the entirety of the connected parts of the paper was actually an act of creativity, "It seems more a question of structure, with fixes that are more mechanical than creative” (writer 7). The following memo was written in the face of this evidence.

This item has an interesting quantitative pattern. It rates high enough for inclusion among nurses and was likely to be chosen as a top three item by all the participants but moderately as opposed to a strong top three inclusion. Qualitatively, very mixed bag comments with no unity. This is an item I think I may just keep as is and trial with students keeping in mind the problematic issues with visualization and the issues that it may not really speak to creativity but rather organizational structure. The item is supposed to reflect cohesiveness in writing which may or may not really be about creativity - the factor analysis will tell us if it loads with the other creative items. This item represents an example of how data importation, or deferring a decision until future rounds, could influence decision making (Onwuegbuzie et al., 2010). The word "visualize” needed to be tested with undergraduates directly and that could only happen in the cognitive interview phase. The item may also not be a good representation of the domain of creativity but domain decisions could be deferred to the exploratory factor analysis stage.

\section{Case 3: Quantitatively an item had strong evidence for deletion and it was deleted.}

The item, When I am preparing for a writing assignment, I can often find myself thinking, at unusual times and places, about how to approach the writing, presented conflicting quantitative 
evidence and disciplinary differences of opinion on the relevance of the item. Writers did not rate the item high, nor did they rank it as a top three item. Nurses did rate it high but were neutral about the item as a top three choice. The qualitative data also supported the disciplinarity of the item. Nurses, who value reflection as a function of critical thinking, liked the item: “It's another way of getting students to identify the process of deep learning” (nurse 5). Writers, questioned the necessity of the item and its assumptions:

Would that be a good thing or a bad thing if a person thought about their writing at unusual times and places? Are you suggesting that persons who fully identify with their writing do not separate writing from the rest of their lives? (writer 5)

This comment suggested that reflection away from the writing process should not be assumed to be a trait of a strong, confident writer. Both writers and nurses found the word "unusual" problematic. If a student always reflected about their writing in the car while driving, that may not seem unusual. The faulty assumption along with the presence of another item that asked about reflective practices contributed to the decision to delete the item.

Case 4: Quantitatively an item had neutral evidence and it was edited. Nurses liked the item, The connections I feel with the sources I find on my topic can motivate me to express my own ideas on that topic in writing, as a top three choice in the relational category. Qualitatively, their comments indicated the item was capturing an important and developmental aspect of writing: "Highly important to get to synthesis of ideas toward thinking like a nurse and heading toward new nursing knowledge! Is this a developmental result of the learner?” (nurse 3) or, "I also might think of this as inspiration rather than motivation. I often feel inspired by thinking about and working with other peoples’ ideas” (nurse 7). Writers were more skeptical that students would relate to this task of writing or would, instead, relate to it inappropriately: 
"Does it mean an emotional connection? Is that because I agree with the ideas in those sources or maybe disagree? Is it that when I read and think about other people's ideas, it helps me to express my own?” (writer 6). The qualitative comments made it seem valuable to attempt a trial of the item with students with a few minor wording changes: The connections I feel with the ideas of other authors as I research my paper, inspire me to express my own ideas on my topic in my writing.

Case 5: Quantitively an item had neutral evidence and it was deleted. The item, I can consider the needs of nursing when I choose the topics I write about in my courses, was more likely to be selected as a top three item by writers than by nurses. The main concern was with the vagueness of the item: "Clarify what is meant by needs of nursing” (nurse 4). One writer observed that students may only be thinking about their teacher's needs, "Is the focus meant to be on the needs of nursing faculty members (who will be marking the assignments) or on nursing as a discipline?” (writer 3). The item was intended to capture how students were developing the thinking skills of a nurse in aspects of writing such as topics choice and their drive to advance their own nursing knowledge through writing. The confusion over the meaning of the item as indicated in the qualitative comments, as well as the existence of other items that connected writing to disciplinary priorities, supported the deletion of this neutral item.

\section{Controlled Feedback and the Initiation of Round 2}

Personalized quantitative feedback was prepared for each participant which consisted of presenting the CVI scores for each item for the total sample, the nursing sample, and the writer sample along with a column which provided the participant with their individual ratings to facilitate panellist comparisons of their own scores with the entire panel and with their disciplinary panel. A qualitative summary which was general to all participants was also shared. 
This summary provided an overview of the decision-making process and gave impressions of the panel's broad thoughts about each of the five writing domains.

\section{Delphi Round 2}

The round 2 survey presented only the 14 items edited during round 1 and panelists were asked to rate their level of agreement with the edit made on a 4-point Likert scale: strongly agree, moderately agree, moderately disagree, and strongly disagree. An open-ended text box was provided in each domain in order to expand on rationale and suggest additional edits to items as necessary.

While the personalized results summary from round 1 presented a general overview of the issues that emerged in each domain, within the round 2 survey each edited item was presented with a specific rationale for the edit made. See Box 2 for an example presentation of an edited item.

\section{Box 2: Round 2 Presentation of the Case 1 Edited Item}

This item received high ratings from participants and was a frequent top three item choice. The intention of the item was to explore the elements of synthesis that went beyond just the serial citing of source after source. There were numerous suggested revisions to wording which have been incorporated into this revision. Most notably, at least two panel members suggested removing the word creatively.

Original item: I can creatively bring together multiple sources into an original written product.

Revised item: I can bring together multiple sources in ways that are unexpected to create an original product or text.

The round 2 survey also presented a list of the items that were included without edits and the items that were deleted. Each list had its own open-ended response box to allow participants to protest or validate the decisions made with these items. The analysis in round 1 was also mindful of suggestions made for new items. One panellist made a comment which flagged a gap 
in the overall questionnaire. Writer 7 wrote: "Part of learning to use feedback usefully, I believe, is learning how to determine what to use and what to ignore.” This comment inspired the development of a new relational item: I can read feedback given to me by peers or teachers and decide when that feedback should be ignored or incorporated into a revision in my writing. This new item was presented to the panel and rated with the same 0-100 relevance scale used in round 1.

\section{Round 2 Analysis Strategies}

During this round, an item receiving a high agreement with edit score (>80\% strongly or moderately agree combined), and, in one case, disagreement with edit score ( $>50 \%$ strongly or moderately disagreed combined) did not necessarily result in automatically keeping an item as is or outright deleting the item. Much of the panel's qualitative feedback given during this phase was wordsmithing - tinkering with existing phrasing either grammatically, for word choice, or for simplification of the item due to multi-clause phrasing. When numerous options for editing were presented, pros and cons of editing immediately, versus deferring decision-making to the cognitive interview phase were considered in decision-making.

The Case 1 and Case 4 items which were edited in round 1 both underwent subsequent editing after receiving round 2 feedback. The revised case 1, creativity item, I can bring together multiple sources in ways that are unexpected to create an original product or text, received strong disagreement with edit ratings (the only item that did) with 53\% of the sample moderately disagreeing with the edit. The primary objection to the edit was use of the phrase "ways that are unexpected.” The perception of writing as "unexpected” was thought to be a reader-based perception. A writer would have no way of knowing if their writing choices were going to be received as "unexpected.” The item was edited a second time to: I can bring together multiple 
sources to create an original product or text. This item provides an example of how without the opportunity for participants to give rationale in the form of qualitative statements the problem with the item may have been difficult to identify.

The Case 4 relational item, The connections I feel with the ideas of other authors as I research my paper, can inspire me to express my own ideas on my topic in my writing, received strong agreement with edit ratings with $80 \%$ of the sample indicating strong agreement, and 13.3\% moderately agreeing. The relational item underwent edits to trim its wordiness and was revised to read: As I do research for my paper, the connections I feel with the ideas of other authors can inspire me to express my own ideas in my writing

The new relational item presented to the panel, I can read feedback given to me by peers or teachers and decide when that feedback should be ignored or incorporated into a revision in my writing, received high relevance ratings and was automatically moved forward to the cognitive interview phase.

One new item emerged based on a qualitative comment from one of the nurse participants who observed: "Each revision makes the writing process in nursing very uniform and uncreative. How can we advance the profession if we do not allow creativity?” (nurse 5). This observation prompted the development of a new broad creativity item: I can use creativity when writing an academic paper.

One item was resurrected in response to a comment by another nurse expressing disappointment over the removal of the question asking students if they worried about using American Psychological Association (APA) format guidelines. That nurse wrote: "Why eliminate APA or format? This is an area of concern and does impact written assignments” (nurse 3). The item was revised to ask students if they worried about APA rather than ask about 
their ability to implement the format itself: I can write without worrying about my ability to correctly apply the rules of the required style guideline (e.g. APA format).

After all the editing decisions were made, we noticed a context domain item that had been revised based on new feedback from round 2: With each new writing assignment, I can adjust my writing process to meet the needs of that assignment, was very similar to a creativity item which was automatically included in round 1: I can choose a writing process that will best fit the writing I have been assigned. A decision was made to delete the creativity item and keep the newly edited context item.

\section{Controlled Feedback and End of Panel Responsibilities}

After this round's feedback it seemed appropriate to disband the Delphi panel. The types of feedback provided in this round felt stabilized to semantic and wording changes. The personalized feedback summary sent to participants after round 2, provided a summary of the agreement-disagreement proportions for each edited item for total sample, nurse and writer groups. The participants were reminded of their own rating. Qualitative feedback provided a description of the decision-making process. The seven newly revised items, the new creativity item, and the resurrected emotions item about APA, were presented with rationales for the decision made. Panellists were emailed their personalized feedback and were invited to provide any additional feedback by email, however no panellist provided additional feedback.

\section{Implications}

The Delphi method and its history of lack of uniformity of approach, makes it a method that is open to interpretability based on the nature of the research question (Skulmoski et al., 2007). In the Delphi described in this article, the participants provided their opinions through ratings of the relevance of each presented questionnaire item and directed the editing of each 
item by providing suggested wording changes. Spontaneous stream-of-consciousness reflections on what item wording meant to the participants were also valuable contributions to decision making. We also chose to change the nature of the type of data we gathered about each item between round 1 and round 2, with round 1 collecting data about the relevance of the item, while round 2 collected evidence about agreement with an edit made. According to Boulkedid et al.'s (2011) systematic review, only 18\% of Delphi studies in their analysis changed their selection criteria between rounds, suggesting that changing approaches might be considered running a distinct Delphi. In an instrument development Delphi, when many of the items that were being re-presented to the panel had already been rated as relevant or were nearly rated as relevant, it seemed redundant to recollect information on item relevance when agreement with the edit made was a larger concern.

Boulkedid et al. (2011) observed that $64 \%$ of the Delphi studies they reviewed allowed panellists to make open-ended comments about the statements presented. Quantitative scores could have been interpreted exclusively into decisions to accepting or rejecting an item. The qualitative comments provided a sense of richness that explained the score and inspired edits beyond the literal edits suggested by participants. Edit suggestions were also blended based on suggestions from more than one participant. There was often concrete evidence of the need to edit an item, when that item's relevance ratings fell short of $80 \%$ or direct suggestions for wording or phrasing changes were provided. Other evidence was more subtle. Occasionally, there were panelists who wrote reflections about their impressions of an item that indicated they were misinterpreting the item's intent. Sometimes these reflections inspired a new item, as was the case when the decision was made to write the item asking students if they felt they knew when to accept or ignore a suggested revision based on feedback. 
Blending qualitative and quantitative data can result in numerous Gestalt switches between the cognitive processes required to interpret numbers and those required to interpret language (Onwuegbuzie et al., 2010). Many of Onwuegbuzie et al.’s strategies for blending the two paradigms were applied in this Delphi study including both qualitative and quantitative data transformation into the other paradigmatic format. Data comparison was also used to assess if the qualitative comments matched the quantitative ratings. Avoiding premature deletion of an item was critical and sometimes, a suggestion made by a single panellist could have huge implications for decision-making.

Not all qualitative comments need to be treated equally when making editing decisions (Tapio et al., 2011). Knowing when to ignore or incorporate a suggested revision is critical to maintaining the overall vision for the tool being developed. One great idea from a panellist can help with identifying gaps or cleverly capture complex ideas in the fewest amount of words. Often, when the opinion of one panellist was used to construct a revision, that panellist was presenting an extreme response that distinguished their opinion from the rest of the panel (Bazeley, 2018). The multi-round format of the Delphi allows researchers to confirm the validity of decision-making as items are re-presented for confirmation. Re-presenting items provides the researchers with the opportunity to check unrecognized assumptions. Finding panellists who are willing to critique decisions rather than acquiesce to the researcher are ideal Delphi participants.

Deciding when to terminate a Delphi is also an important consideration, especially since in most Delphi studies, the Delphi phase is rarely the endpoint for the assessment of the quality of the developing items. A multi-phase study can mean less Delphi rounds are needed, which is important given the high response burden that Delphi panellists face when responding to a questionnaire that involves both rating items and open-ended responses. Debates in the Delphi 
literature about what defines consensus or agreement among panel members express concern that post-round feedback is designed to essentially manipulate panellists to change their minds from their original opinion and conform to the majority (Keeney et al., 2001). Other authors assert that the intention of the Delphi might not be consensus at all but rather other alternative end-points are desired such as seeking differing opinions or schools of thought (Tapio et al., 2011), the creation of new shared knowledge or collaborative learning (Guzys et al., 2015), or stability in responses (Sekayi \& Kennedy, 2017).

In returning to the debate on the paradigmatic perspective of the Delphi, objectivist perspectives would require a finalized endpoint before completion of the Delphi phase. The Delphi contributes to the constrictive reality of a developing questionnaire but is only one layer within the formation of that reality. In an instrument development study, $100 \%$ agreement on the perfect wording for an item may not be possible. For example, by the second round of the Situated Academic Writing Self-Efficacy Scale Delphi, it felt like much of the feedback focused on wordsmithing rather than theoretical or conceptual issues with the item itself. The suggestions were numerous and needed to be trialed with the target population for the questionnaire students. After round 2, a decision to terminate the Delphi was made even though items were still being edited, developed, or resurrected from past deletion; however, having future phases where tool editing would continue provided confidence that the Delphi was not prematurely terminated. Balancing consensus needs with risk of attrition due to tiring participants is an ongoing consideration in Delphi research (Bouilkedid et al., 2011; Sekayi \& Kennedy, 2017). Partial consensus seems to be an acceptable endpoint when future stages of an overall instrument development study will bring in the target population for the new instrument and help fill in gaps or note unrecognized problems at the Delphi panel phase. 


\section{Data Importation and Impact of the Delphi on Future Questionnaire Development Phases}

Onwuegbuzie et al.’s (2010) strategy of data importation should also be considered in Delphi decision-making in particular when the Delphi panel is not the final stage of construct validation on the instrument being developed. Data importation involves using data suggested in one phase and carrying that knowledge forward to the next phase. In this study, panelists highly rated an item and didn't object to its wording but sometimes questioned whether an item would be understood by undergraduate students. Items that received this kind of feedback were ideal to carry forward unedited to the cognitive interview phase. The panellists in this study often made observations about possible incorrect domain assignment which could be carried forward to the exploratory factor analysis stage. Tracking such observations may prove useful if an item crossloads on two factors or fails to load on any factor.

Sometimes additional suggestions for wording were given that were not applied to an edit. Notes were made regarding unused pieces of feedback and placed in a table to guide prompting during the undergraduate student interviews. If problems with an item were apparent, the interviewer was able to on-the-spot trial unused suggestions made by Delphi panellists. Table 3 provides an example of how unused Delphi comments were carried forward to the cognitive interviews. 
Table 3: Data Importation Example Carried Forward to Cognitive Interview Phase

\begin{tabular}{|c|c|}
\hline Item & $\begin{array}{l}\text { Delphi panel comments carried forward as } \\
\text { prompts for cognitive interview decision } \\
\text { making. }\end{array}$ \\
\hline $\begin{array}{l}\text { I can bring together multiple sources to create an } \\
\text { original product or text. (Creativity Domain) }\end{array}$ & $\begin{array}{l}\text { Looks at synthesis. Do students get this and } \\
\text { see this as creative? } \\
\text { Is originality needed at the undergraduate } \\
\text { level?-writing original work within } \\
\text { boundaries might be more undergrad } \\
\text { applicable. } \\
\text { This might be similar to Q1 } \\
\text { Relational? }\end{array}$ \\
\hline $\begin{array}{l}\text { I can visualize the connected parts of a paper I have } \\
\text { written and see how it tells the complete story of my } \\
\text { topic or argument. (Creativity Domain) }\end{array}$ & $\begin{array}{l}\text { Caution with the word visualize. Some may } \\
\text { not see words and text visually. } \\
\text { Do they see the paper as a story? } \\
\text { Creativity or organizational structure } \\
\text { addressed here? }\end{array}$ \\
\hline $\begin{array}{l}\text { As I do research for my paper, the connections I feel } \\
\text { with the ideas of other authors can inspire me to } \\
\text { express my own ideas in my writing. (Relational } \\
\text { Domain) }\end{array}$ & $\begin{array}{l}\text { Will students understand what this means? } \\
\text { Creativity? }\end{array}$ \\
\hline $\begin{array}{l}\text { When I receive feedback from peers or teachers, I } \\
\text { can decide when that feedback should be ignored, or } \\
\text { incorporated into a revision in my writing. } \\
\text { (Relational Domain) }\end{array}$ & $\begin{array}{l}\text { Do students feel that feedback from a teacher } \\
\text { can be ignored? } \\
\text { Are students able to distinguish between } \\
\text { helpful and not so helpful feedback? } \\
\text { Is there a developmental aspect to this item? } \\
\text { "When I receive feedback on a draft of my } \\
\text { paper, I can decide....” (takes the specific } \\
\text { feedback giver out of the item) } \\
\text { “.... I have the confidence to decide when... “ } \\
\text { “... I can figure out when...." “.... I can judge } \\
\text { when....” } \\
\text { “... I am able to decide....” }\end{array}$ \\
\hline $\begin{array}{l}\text { I can write without worrying about my ability to } \\
\text { correctly apply the rules of the required style } \\
\text { guideline (e.g. APA format). (Emotional Domain) }\end{array}$ & $\begin{array}{l}\text { Relational? } \\
\text { Is a skill or effectiveness domain needed? } \\
\text { Ensure they are not taking this as lack of care } \\
\text { about APA } \\
\text { Does knowing if it is a first or subsequent } \\
\text { draft change the perception of this item? }\end{array}$ \\
\hline
\end{tabular}




\section{Conclusion}

Making decisions to revise a questionnaire involve combining the best quantitative and qualitative evidence to draw conclusions. Revision decisions were not made to privilege the most common opinion; rather, the method focused on simultaneously moving back and forth between quantitative evidence, qualitative evidence, individual opinions of the panel, and collective opinions of the panel. The weight given to qualitative or quantitative sources of evidence was done with a lens toward maintaining the theoretical integrity of the questionnaire and its structure as ability-based, “I can” statements. Editing suggestions from panellists were helpful, but the best feedback emerged when panellists pointed out faulty assumptions or when they shared stream-of-consciousness reflections about how they perceived the act of writing. Items were deleted, included, or newly developed based on interpretive processes that considered more than suggested wording changes.

Most importantly, consideration of the function of future rounds of the instrument development made data importation an important multimethod analysis strategy. While developing quantitative instruments bears the overall goal of a constructive reality that represents the best items to assess a construct, the Delphi is rarely the final endpoint. Considering the goals of future phases meant the questionnaire did not need to be perfect before moving on to the next phase. In fact, similar to writing revision itself, over-editing can often have unintended negative effects. Discovering if an item would be interpreted correctly by students could only be established by asking students. Discovering the best fit of an item for a particular questionnaire domain, when an item seemed to straddle two domains, would be best established through exploratory factor analysis. Decisions were made by layering the multiple complexities of the data gathered in the survey. This meant considering what the quantitative evidence showed, the match with the qualitative evidence, its theoretical congruence with the vision of the 
questionnaire, and how the editing of one item affected its positioning within or similarity to other existing items on the questionnaire. Deletion decisions often arose, and were most easily made, when it appeared the problematic item contained conceptual overlaps with other items. This paper contributes to the literature by describing through use of specific examples how qualitative and quantitative data can be effectively integrated in order to make decisions in multimethods instrument development research and should be useful for all beginning and seasoned researchers attempting tool development. 


\section{References}

Bandura, A. (1997). Self-efficacy: The exercise of control. W. H Freeman.

Bazeley, P. (2018). Integrating analysis in mixed methods research. Sage.

Boulkedid, R., Abdoul, H., Loustau, M., Sibony, O., \& Alberti, C. (2011). Using and reporting the Delphi method for selecting healthcare quality indicators: A systematic review. PLoS ONE 6(6), e20476. https://doi.org/10.1371/journal.pone.0020476

Creswell, J. W., \& Creswell, J. D. (2018). Research design: Qualitative, quantitative, and mixed methods approaches ( $5^{\text {th }}$ ed.). Sage.

Durepos, P., Orr, E., Ploeg, J., \& Kaasalainen, S. (2018). The value of measurement for development of nursing knowledge: Underlying philosophy, contributions and critiques. Journal of Advanced Nursing, 74(10), 2290-2300. https://doi.org/10.1111/jan.13778

Eberman, L. E., \& Cleary, M. A. (2011). Development of a heat-illness screening instrument using the Delphi panel technique. Journal of Athletic Training, 46(2), 176-184. https://doi.org/10.4085/1062-6050-46.2.176

Guzys, D., Dickson-Swift, V., Kenny, A., \& Threlkeld, G. (2015). Gadamerian philosophical hermeneutics as a useful methodological framework for the Delphi technique. International Journal of Qualitative Studies on Health and Well-being, 10, 26291. https://doi.org/10.3402/qhw.v10.26291

Hasson, F., \& Keeney, S. (2011). Enhancing rigour in the Delphi technique research. Technological Forecasting \& Social Change, 78(2011), 1695-1704. https://doi.org/10.1016/j.techfore.2011.04.005 
Hawkins, R. J., Swanson, B., \& Kremer, M. J. (2014). Content validity testing of questions for a patient satisfaction with general anesthesia care instrument. Journal of PeriAnesthesia Nursing, 29(1), 28-35. https://doi.org/10.1016/j.jopan.2013.05.011

Hitchock, J. H., \& Onwuegbuzie, A. J. (2019). Developing mixed-method crossover analysis approaches. Journal of Mixed-Method Research, 14(1), 63-83. https://doi.org/10.1177/1558689819841782

Keeney, S., Hasson, F., \& McKenna, H. P. (2001). A critical review of the Delphi technique as a research methodology for nursing. International Journal of Nursing Studies, 38, 195-200. https://doi.org/10.1016/S0020-7489(00)00044-4

Keeney, S., Hasson, F., \& McKenna, H. (2011). The Delphi technique in nursing and health research. Wiley-Blackwell.

McKenna, H. P. (1994). The Delphi technique: A worthwhile research approach for nursing? Journal of Advanced Nursing, 19, 1221-1225. https://doi.org/10.1111/j.13652648.1994.tb01207.x

Mitchell, K. M. (2018). Constructing writing practices in nursing. Journal of Nursing Education, 57(7), 399-407. https://doi.org/10.3928/01484834-20180618-04

Mitchell, K.M., McMillan, D.E., \& Lobchuk, M.M. (2019). Applying the “social turn” in writing scholarship to perspectives on writing self-efficacy. Journal of Learning Development in Higher Education,15(2019).

http://journal.aldinhe.ac.uk/index.php/jldhe/article/view/512/pdf

Okoli, C., \& Pawlowski, S. D. (2004). The Delphi method as a research tool: An example, design considerations and applications. Information \& Management, 42, 15-29.

https://doi.org/10.1016/j.im.2003.11.002 
Onwuegbuzie, A. J., Bustamante, R. M., \& Nelson, J. A. (2010). Mixed research as a tool for developing quantitative instruments. Journal of Mixed Methods Research, 4(1), 56-78. https://doi.org/10.1177/1558689809355805

O’Rourke, J., Abraham, J., Riesenberg, L. A., Matson, J, \& Lopez, K. D. (2018). A Delphi study to identify the core components of nurse to nurse handoff. Journal of Advanced Nursing, 74, 1659-1671. https://doi.org/10.1111/jan.13565

Pajares, F., \& Valiante, G. (2006). Self-efficacy beliefs and motivation in writing development. In C.A. MacArthur, S. Graham, \& J. Fitzgerald (Eds.), Handbook of writing research (pp. 158-170). Guilford Press.

Polit, D. F. \& Yang, F. M. (2016). Measurement and the measurement of change. Wolters Kluwer.

Rodrigues, I. B., Adachi, J. D., Beatie, K. A., \& MacDermid, J. C. (2017). Development and validation of a new tool to measure the facilitators, barriers and preferences to exercise in people with osteoporosis. BMC Musculoskeletal Disorders, 18, 540. https://doi.org/10.1186/s12891-1914-5

Sekayi, D., \& Kennedy, A. (2017). Qualitative Delphi method: A four round process with a worked example. The Qualitative Report, 22(10), 2755-2763. https://nsuworks.nova.edu/tqr/vol22/iss10/15/

Skulmoski, G. J., Hartman, F. T., \& Krahn, J. (2007). The Delphi method for graduate research. Journal of Information Technology Education, 6, 1-24. http://www.jite.org/documents/Vol6/JITEv6p001-021Skulmoski212.pdf 
Tapio, P., Paloniemi, R., Varho, V., \& Vinnari, M. (2011). The unholy marriage? Integrating qualitative and quantitative information in Delphi process. Technological Forecasting \& Social Change, 78(2011), 1616-1628. https://doi.org/10.1016/j.techfore.2011.03.016

Thomas, E. (2011). From qualitative data to instrument development: The women’s breast conflict scale. The Qualitative Report, 16(4), 908-932. http://nsuworks.nova.edu/tqr/vol16/iss4/1

Wickwar, S., Buerkle, K., McBain, H., Ciciriello, S., Osborne, R. H., Wedderburn, L. R., \& Newman, S. P. (2013). Adaptation of the methotrexate in rheumatoid arthritis knowledge questionnaire (MiRAK) for use with parents of children with juvenile idiopathic arthritis: A qualitative study. Pediatric Rheumatology, 11, 27. http://www.pedrheum.com/content/11/1/27 
Get people talking. Learn to ask questions that will elicit answers about that is most interesting or vivid in their lives. Nothing so animates writing as someone telling what he thinks or what he does in his own words. His own words will always be better than your words, even if you are the most elegant stylist in in the land.

William Zinsser 


\section{Interlude 3}

Maybe it's the former literature student in me or maybe it's just my very active quantitative side, but I discovered during the analysis of the cognitive interview data that I don’t enjoy coding. I prefer longer passages and stories and what they embody emotionally and the symbolism within. This preference is very hermeneutic, even though I don’t lay any claims to hermeneutic philosophy in what I present in this next paper. The interviews were far too structured for that. I did enjoy every second of conversation I had with the 20 students who stepped forward and gave their time. I could have taken this data so many places. The coding helped me find those quotes and longer passages I needed to tell the story of the journeys I saw my student's taking. The journeys seemed to be about navigating an activity system involving rules set by others from disciplinary rules, to institutional rules, to instructional rules all while battling their own personal goals and motives. This analysis allowed me to really hear what the students were saying about their writing experiences. During the interviews themselves, my primary goal was editing the questionnaire.

It wasn’t just one journey. They learned to take the path they had to take within the context they were writing in. They learned to be the writer they had to be to get the grade, please the teacher, and sometimes I felt they were selling their souls in the process. Some of them would have sold their souls if they could have figured out who the buyer was. No matter what some students did, they felt they could never get it right - they were like the cymbal player in the band whose clangs are just slightly off the beat.

I suspected it would be hard to recruit students who didn't like writing so I developed the question, “Are you someone who generally likes writing, generally dislikes writing, or somewhere in between,” to track representation of different writing attitudes. The cognitive interviews taught me what it meant to like, dislike, or be ambivalent about writing. As a student 
(still) and faculty member I always liked writing even when I didn’t like what I was writing.

Their responses were so interesting I added the question to the survey studies in the next phase. The "somewhere in between" students gave the best of both worlds. In most cases these students tended to lean more to liking writing. They just didn’t like writing for school. Not liking writing for school usually meant, as it also did for the students who didn't like writing, not liking the rigidity of the process, writing just for a grade, or writing about topics they didn’t like. They resented being put into a box and told who they had to be in that moment. But even students who were highly risk adverse in their writing choices or felt like they could never get the writing to be what the teacher expected, all had moments where they liked writing.

I tell a little bit of my journey with this data in the paper but it's only enough to serve the purpose of explaining my analytical method. As with all research projects, there are numerous parts of the experience for which the research paper genre just doesn’t provide the space. I listened to each of these students' interviews four times each. I read each of their transcripts twice. I will probably do both one or more additional times before I defend this work. I read my re-organized document of quotes by systemic layers about five times.

The thing about writing is that once it is "out there” a writer has very little control over how the reader adopts your word and ideas into their own identities. You are welcome to take the headings I use in the findings and discussion section as traditional qualitative "themes” (codeswitching within a rigid writing context, successfully "figuring out” the teacher, valuing), but I see them as more than themes. They are not disjointed parts of the student writing journey but are rather dynamic and iterative and thus feed off each other.

The findings evolved through retelling the narratives of these students in various forms. It started with conversations with my advisor and committee or conversations in the hallway with my colleagues or students. I had a flash of inspiration and created a poster for the Helen Glass 
Symposium, before it was cancelled due to the COVID shutdown, and established 4 student writing identities, composites of all 20 students in my study, because those composites reminded me of the four main travellers in the Wizard of Oz: the Lion looking for courage (the risk adverse student); the Tin Man looking for a heart (the student looking to preserve their self at all costs); the Scarecrow looking for a brain (the grade hungry student); and Dorothy looking to go home (the student trying to fit in). To be honest, I never expected these four composite students to survive beyond this poster presentation. It surprised me that they did.

To write about these four students in an academic format I first had to write a version of my findings in a casual format. That was a blog I called, "It depends on the professor" (found at: https://academicswrite.ca/2020/02/21/navigating-undergraduate-academic-writing-guess-what-itdepends-on-the-professor/). The Helen Glass Symposium also required writing a three-minute thesis script (below) which had to consider the aurality of an oral performance piece. I shared this three-minute thesis script with my student participants when I provided them with a summary of the findings, and one wrote back and told me it was exactly what writing was like in nursing. She said it reminded her of slam poetry. And, except for the fact that I don't do rhyming, that's exactly the tone I was going for. I also made the script into a short animated video which can be viewed here: https://www.youtube.com/watch?v=IrLYSL5LlfA\&t=3s

\section{Follow the Rubric}

"Follow the rubric, follow the rubric." The student said.

This became the ear worm in my head as I read through the rest of the data and, unconsciously, I found myself humming, "Follow, follow, follow, follow, follow the yellow brick road." The data came as "leftovers" from one phase of my instrument development study - to find out if students understood my questions about writing self-efficacy. Extra little nuggets of goodness from the student writing trenches.

Instead what emerged was the sense that writing in nursing wasn't much about writing at all and was instead about navigating systems. Lions and Tigers and Bears. Oh My!

Rigid systems, that value objectivity and rule following in the name of rigour and reliability. Follow the rubric. The teachers in us are thinking "good strategy" to keep your A+ grade.

But dig a little deeper and you hear other messages:

“Gotta stay on script.” If not, "It’s too risky”

“You can’t write opinions, right?” 


\begin{abstract}
"You have to play the game."
They told me: I'm going to feed you what you want to hear, I'm going to use your words from class, because this writing isn't going to go anywhere. I'm getting a grade and, "Thanks! See you next term.”

What if writing self-efficacy is about success figuring out the teacher? Bye-bye independent thinking. We should just, "let go of all these weird boundaries" ... and just let them write. Really, are we that oblivious to our own power? Given, we are also slaves to systemic power structures. The relationships they build with us during the writing experience can lead to demoralization, indifference, or transformation. They carry those emotions forward with them every time they sit down to the blinking cursor on a blank page.
\end{abstract}

I know which one I aim to leave them with. How about you?

They learn to play the role required:

Sometimes they grade seek.

Sometimes they preserve their own sense of self at all costs - judging their relationship with you to see if you can "take it."

Sometimes when they fail the lesson learned is to never ever take a risk.

Sometimes they are searching for their place in this new nursing world with its strange language. Even by their final year they might still wonder if they are "trying too hard". They are aware that nursing language has been seeping into their everyday conversations. There is something about the casualness of the spoken word. When they put on an academic writing cloak, the words don't feel like a good fit.

And they can slip in and out of these roles, their peers by their side. How they adapt, "It depends on the professor."

We've created this systemic paradox where to help solve the problem of the inconsistencies we know students hate, we've robbed their environment of the flexibility for creativity and originality. We demand sources for everything and perfect APA — we tell them:

Please, just follow the guideline and "fill in the blanks."

It's all right there in the rubric.

"You're not a novelist, don’t write like that."

Despite it all they grow anyway and when they get the opportunity to write about something they care about - even the ones who say they hate writing get excited about what they learn. It becomes a part of them. It's something they carry with them into their identities as nurses.

But what about our own teacher identities as writers? I leave you with that rhetorical thought. They know which of us know writing and which of us don't. How can they learn to identify as nurse writers, if you do not? 


\section{Author contributions}

I (Kim Mitchell), the student, established the research question, the method, conducted the interviews, analyzed the videos and transcripts, wrote the writing exercises that formed part of the method of inquiry, and wrote the manuscript. Dr. McMillan audit trailed the analysis at the stage where the participant quotes were connected to the systemic layers of influence on student writing (institutional/program, instructional, other players, and student personal characteristics). Dr. McMillan, Dr. Lobchuk, and Dr. Nickel, commented on a presentation of findings given during a committee meeting on March 13, 2019. All committee members approved the methods and provided substantive feedback on the manuscript which informed the editing process. 


\title{
Paper 4: "Follow the Rubric is the Thing in Nursing": Navigating Systemic, Instructional, and Personal Influences on Writing Activities
}

\begin{abstract}
Background: There are transformative benefits to writing that are often not captured in the academic essays assigned to grade text for mastery. In previous qualitative research, students have reported that writing assignments have developmental benefits to their nursing practice and identity.

Objectives: To capture what students describe about the contextual and disciplinary impacts to writing self-efficacy in nursing education.

Design: Cognitive interviews conducted in the context of the development of the Situated Academic Writing Self-Efficacy Scale.

Settings: Two Baccalaureate nursing programs in a prairie province in Canada.

Participants: 20 nursing student representatives from all years of both nursing program.

Methods: Qualitative content analysis through an Activity Theory lens formed the analysis.

Three writing approaches as a method of inquiry were also used to explore the data.

Results: The journeys of four composite nursing students navigating their academic writing contexts are presented in a narrative. Student focus when navigating the systemic influences on writing center around attempting to "figure out" what the teacher wants visible in the final written product. Depending on students’ beliefs about writing and their degree of success at navigating the often-rigid writing environment presented to them, students switch personas in a form of behavioural codeswitching, stimulated by their readings of teacher preferences and their perception of the value of the assignment.

Conclusion: Pedagogy should focus on reducing the rigidity of the writing environment, allowing for greater topic choice, and transparent writing expectations to help students redirect
\end{abstract}


their energies from "figuring out" the teacher to the act of writing itself. Relationship building between faculty and student is key to engaged writing. 


\section{"Follow the Rubric is the Thing in Nursing": Navigating Systemic, Instructional, and Personal Influences on Writing Activities}

Writing assignments are a common nursing pedagogy with intended benefits to critical thinking and identity development (Mitchell, 2018). Individuals who identify as writers know that writing contributes transformative benefits to learning and self-reflection; however, the evaluative assessment of writing within the tight boundaries of university classrooms is often limited to scrutinizing the final written text without consideration for individual student gains in learning or confidence (Yagelski, 2011). Writing expectations often shift from course to course and teacher to teacher which can create further disconnects when understanding student writing confidence. With contexts constantly shifting, student writing grades may not show a parallel growth over a curriculum. Writing, even for experienced writers, can feel like it never gets easier. Student's perceptions of their own developmental growth may be obscured when new struggles emerge as writing contexts become more complex (Camp, 2012).

Writing self-efficacy, an oft discussed assessment of student confidence and agency in their writing skills, is a component of social cognitive theory (Bandura, 1997). Self-efficacy contributes to our understanding of student motivation to improve writing ability but has been criticized for its superficial consideration of the impacts of social context (Mitchell et al., 2019). Qualitative interviews with nursing students about their writing experiences and confidences have demonstrated that relationship building with faculty members assigning the writing are critical for writing success and enjoyment of writing (Chaudoir et al., 2016; Chaudoir, 2015; Lundgren \& Halversson, 2015). Camfield (2016), in a qualitative study of writing self-efficacy in freshmen university students, identified that the instructor is an important mediator between the writing students are asked to do and their target academic audiences. 
To develop understanding of what social and contextual factors influence writing selfefficacy, nursing students were invited to provide feedback during one phase of the Situated Academic Writing Self-Efficacy Scale development project. This project considered both Bandura’s (1997) self-efficacy theory and more current perspectives on writing theory which understand writing to be situated and socially constructed within disciplines. The items on the developing instrument were piloted with 20 undergraduate students in two nursing programs using cognitive interview methods. This paper reports the findings of that analysis of interviews, which sought to capture what students described about the contextual and disciplinary impacts to writing self-efficacy in nursing.

\section{Method}

Cognitive interview protocols use cognitive psychological theory to understand how participants engage with a questionnaire and its content (Galasinski \& Kozlowski, 2013; Willis, 2005). The cognitive processes underlying interaction with questionnaires originate with Tourangeau and Rasinski (1988) and include: 1) interpretation and expression of understanding of the meaning of an item; 2) exploration of retrieval processes for memories related to the item presented; 3) understanding how judgements are made about item responses and factors important to the formulation of a score; and 4) analysis of how a respondent concludes their rating matches their judgement of their writing self-efficacy. The goal of cognitive interviewing is to identify if survey items are understood and if they are capable of eliciting self-reflections from participants which match the intended meaning of the questionnaire. The data analyzed from the SAWSES cognitive interviews focused on narrative descriptions of writing experiences within stories students told to support their writing self-efficacy assessments.

The interviews, conducted by Kim Mitchell used processes described in Willis (2005). Participants read each item of the developing SAWSES questionnaire out loud and were asked to 
think-aloud about memories they felt contributed to their self-assessed ratings. The questionnaire items were presented electronically with a 0 (completely sure I cannot) to 100 (completely sure I can) drag and drop sliding scale. We used concurrent researcher prompting with students to define terms, expand upon thoughts, and clarify descriptions of writing experiences. Interviews were videotaped for consideration of body language from the student in response to the items, and the interviewer in response to student statements. Items were edited or deleted throughout the interview process after 3, 6, 12, and 17 participants. Interview times ranged from 30 minutes to 60 minutes.

\section{Participants}

In July of 2019, 20 students were recruited via emails sent from program coordinators in two baccalaureate nursing programs in Canada. The study was approved by the research ethics boards at both institutions and participation was voluntary. Program 1 is an applied college offering a three-year accelerated program. In first year, students take a required disciplinespecific writing course. Program 2 is a research university where students take a pre-nursing year, including a writing-focused elective, then complete three years in the nursing faculty. Sampling goals included recruiting: representation from all years of both programs, cultural diversity, second language and domestic students, students with and without previous degrees, a range of ages, and students who liked or disliked writing. Seventy students volunteered to participate. The high response rate was attributed to the $\$ 50$ cash honorarium offered for participation combined with interviews taking place when classes were out of session. Twelve students were initially interviewed, then gaps in student personal characteristics were considered to purposively select the remaining eight participants. See Table 1 for characteristics of the sample. For instrument revision, sampling required conducting three interviews where the 
questionnaire was no longer in need of major edits to improve item clarity and interpretation

(Willis, 2005). This endpoint was reached after 20 interviews.

Table 1: Demographic Characteristics of the Sample

\begin{tabular}{|c|c|}
\hline & $\mathrm{n}(\%)$ \\
\hline $\begin{array}{l}\text { Ins } \\
\text { Ins }\end{array}$ & $\begin{array}{r}8(40 \%) \\
12(60 \%)\end{array}$ \\
\hline $\begin{array}{r}\text { Irsing program: } \\
1 \\
2 \\
3 \\
\text { Final Practicum }\end{array}$ & $\begin{array}{l}3(15 \%) \\
7(35 \%) \\
7(35 \%) \\
3(15 \%)\end{array}$ \\
\hline $\begin{array}{r}\text { Diversity } \\
\text { Indigenous } \\
\text { Caucasian } \\
\text { Persons of Colour } \\
\text { Mixed race }\end{array}$ & $\begin{array}{r}2(10 \%) \\
5(25 \%) \\
11(55 \%) \\
2(10 \%)\end{array}$ \\
\hline $\begin{array}{r}\text { Entry into Program } \\
\text { Domestic Student } \\
\text { International Student }\end{array}$ & $\begin{array}{r}14(70 \%) \\
6(30 \%)\end{array}$ \\
\hline $\begin{array}{l}\text { Language History } \\
\text { English on } \\
\text { English plus another langua } \\
\text { English as a second langua }\end{array}$ & $\begin{array}{r}6(30 \%) \\
11(55 \%) \\
3(15 \%)\end{array}$ \\
\hline $\begin{array}{r}\text { Female } \\
\text { Male }\end{array}$ & $\begin{array}{r}16(80 \%) \\
4(20 \%)\end{array}$ \\
\hline $\begin{array}{l}\text { Writing Attitude } \\
\text { Generally, likes writing } \\
\text { Somewhere in between } \\
\text { Generally, dislikes writing }\end{array}$ & $\begin{array}{r}4(20 \%) \\
12(60 \%) \\
4(20 \%)\end{array}$ \\
\hline $\begin{array}{l}\text { Previous Degree } \\
\text { Previous University } \\
\text { Previous Completed Diploma } \\
\text { Previous Competed Degree }\end{array}$ & $\begin{array}{r}14(70 \%) \\
3(15 \%) \\
3(15 \%)\end{array}$ \\
\hline Mean age in & $\begin{array}{r}25.9 \\
20.1-42.0\end{array}$ \\
\hline
\end{tabular}


Figure 1: Visual Representation of the Activity System

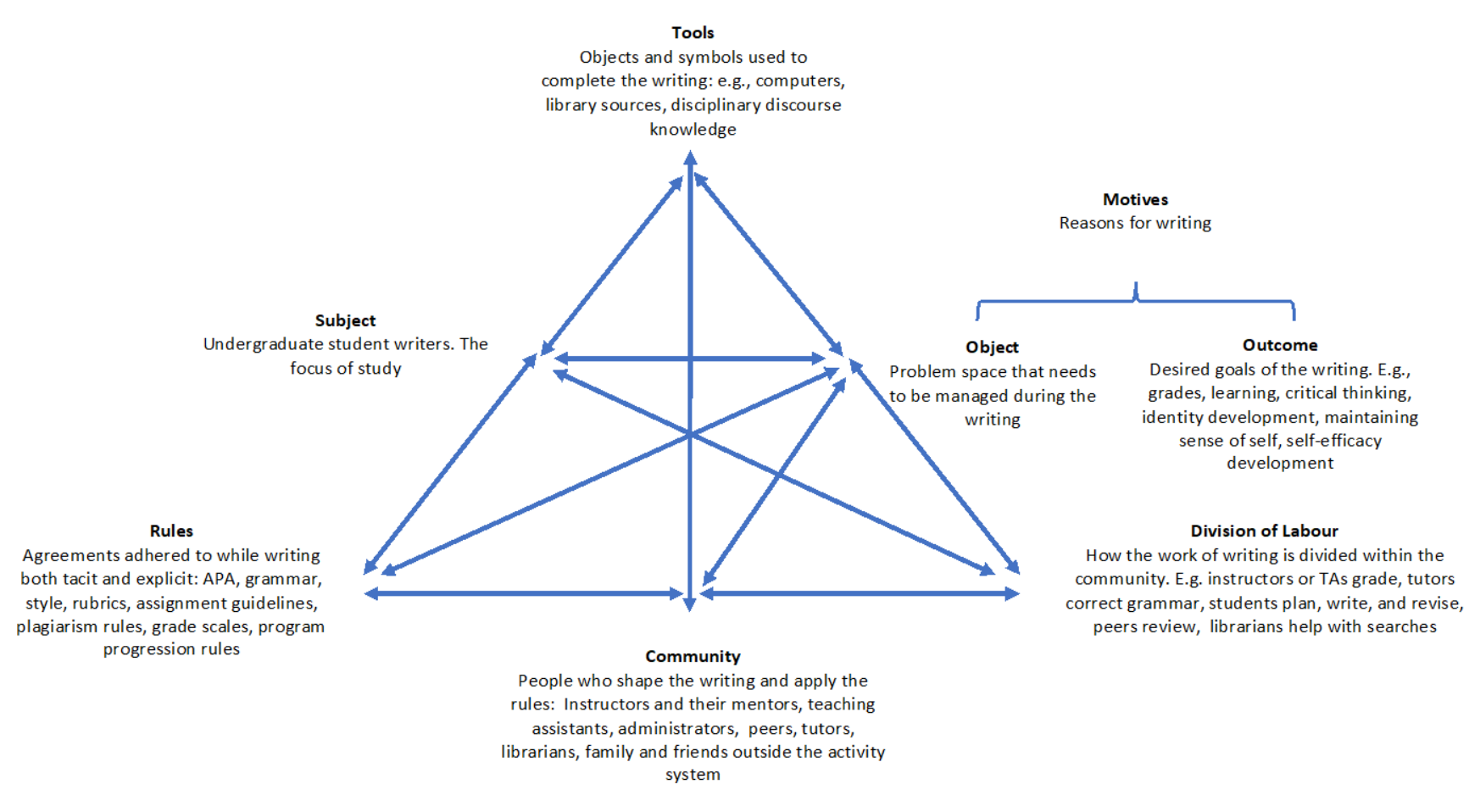

\section{Activity System}

The intersecting players of writing in nursing education

(adapted from Kain \& Wardle, 2005) 


\section{Data analysis}

Activity theory (Engeström, 2001) was adopted as the theoretical lens for analysis. Activity theory is visually depicted as interconnected triangles relating subject, object, tools, community, division of labour, and rules attached to the system (see Figure). The major strength of activity theory is the ability to analyze contexts, diagnose areas of conflict, identify barriers within subjects, the tools they work with, relationships with other community members, or intersecting communities, all of whom have their own motives within the system (Kain \& Wardle, 2005; Roth \& Lee, 2007). Activity systems have histories (Russell, 1995). One feature of the nursing writing activity system is mistrust from nursing practitioners of nursing academia and a student population who places higher value on practice skills (Mitchell, 2018). Effects on writing self-efficacy can emerge through any interaction in the activity system.

Data analysis employed several triangulated approaches to explore common experiences among the students, while simultaneously the individual experience of each student was respected. The videos were watched several times to assess item interpretation. Memos were written reflecting on each individual interview in attempt to understand the essence of that student's experience. Interviews were transcribed verbatim and relevant storytelling excerpts extracted. These activities all serve to enhance reflexivity and therefore the credibility and trustworthiness of the data. Member checking was also used to enhance credibility. Participants were offered the opportunity to read and edit their transcripts prior to the open-coding phase. Only one student offered minor wording corrections, and two others responded to say they were happy with the transcript as it was.

Transcripts were uploaded into Atlas.ti then open-coded using a combination of inductive and deductive qualitative content analysis approaches with the overall goal to systematically describe meaning (Bhattacharya, 2017; Cho \& Lee, 2014). Inductive coding was used to chunk the data into manageable units while considering descriptive pieces of text. Through coding, and 
viewing the data from an Activity Theory lens, a deductive coding phase followed. Various systemic layers were observed within the student experience that were all present in activity theory. The layers included: 1) program/institutional (community/tools such as nursing discourse/rules); 2) instructional (community/rules/problem space/division of labour); 3) other influencers such as family, peers, librarians and tutoring services (community/division of labour); and 4) student personal characteristics, values, and goals (subject/motives/outcomes) that influenced writing behaviours. The codes identified in the open coding process were examined for their fit within each systemic layer. Quotes were cut and paste into a document reflecting the systemic layers and recoded as needed. Codes were often split (e.g. program/institutional rules versus instructional rules), re-grouped, or re-labelled depending on their fit within the systemic layer categories. This portion of the analysis was audited by the second author. The systemic layers were then examined for various narratives present in the student experience and the first author used this document to inspire writing exercises that told the stories of students on a journey with writing in nursing (Bhattacharya, 2017).

Writing as a method of inquiry (Richardson \& St. Pierre, 2005) recognizes that ideas and interpretation of knowledge occur most significantly during the writing process. This method, “displays the writing process and the writing product as deeply intertwined; both are privileged. The product cannot be separated from the producer, the mode of production, or the method of knowing” (p. 962). The first author’s (K.M.) writing exercises began with the emerging sense that students were expending tremendous energy “figuring out” their instructors. The exercises were used to help understand how students, and what kinds of students, were successful or not successful at reading teacher expectations. The first writing inquiry was to blog. Through blogging, the writer is required to become "simultaneously reader, writer and audience” (Barnes, 2017, p. 17) in an assemblage of scholarship and the personal. The blog: "Navigating Undergraduate Writing: Guess What? It 
Depends on the Professor” (Mitchell, 2020), was shared publicly via Twitter and elicited favorable community feedback. Second, a "three-minute thesis" exercise produced a short spoken-word summary of the findings (see interlude 3 in this thesis). Through writing as an inquiry, insights can be gained through narrative forms highlighting critical moments in the participants' experience that act as a re-presentation of the data (Bhattacharya, 2017). These writing exercises employed different writing voices and genres, targeted faculty audiences, were deeply imbedded in personal experience, and contributed to the overall interpretation of the findings. The final writing as a method of inquiry exercise was conducted during the preparation of this manuscript. These writing exercises connected me (K.M.) with my 18 years of experience as a nurse educator assigning and facilitating undergraduate student writing experiences, my personal identification as a writer, and my own perspectives based on observations of and conversations with students navigating writing within my own nursing faculty.

\section{Findings and Discussion}

The core of the academic writing that baccalaureate nursing students navigate in their programs is situated in systemic layers of influence on their behaviours. Students who entered nursing with a previous degree, previous university experience, or were later in their nursing programs recognized that one expectation of university students is adaptability. This adaptability was often not to the assignment itself, but to the teacher who assigned the writing. One third-year student described the systemic layers as: "Well you have to follow APA to start with. So, they have their set of rules and then you have your assignment sheet and then you have your specific instructor” (14). APA is a program/institution assigned formatting process while the assignment guidelines are an instructional process. Notice this student separates the assignment guidelines, which are designed by a specific instructor, from the instructor as a person. Systemic influences filter through to the kinds of assignments that instructors create and the kinds of grading practices 
instructors enact, which then filter down to student behaviours when attempting to implement instructor intentions. These systemic influences dictate discourse preferences for a discipline and discourse is one tool students appropriate within their activity system (Russell, 1995). Another systemic influence is an assessment culture that prioritizes surface level textual corrections - an academia-wide problem among content expert graders who are not writing experts, which can narrow gains made to writing development (Camp, 2012). The academic writing journey of nursing students suggests that students work within a rigid writing environment and then "codeswitch" their behaviours depending on their skill level for "figuring out the teacher." Their goal is to maximize their grade while considering how their personal "valuing” of the assignment fits with their motives.

The journey into the data begins by introducing four pseudonymous students, each created through a composite of several participants. Their beliefs about writing, and their personal choices when navigating systems, are described. Some select anonymized student characteristics are presented in Table 2 along with a participant number for quote identification.

Table 2: Students by Participant Number and Demographic Characteristics

\begin{tabular}{|l|l|l|l|l|l|}
\hline $\begin{array}{l}\text { Participant } \\
\text { Number }\end{array}$ & Year in Program* & Sample Diversity & Language & Gender & Likes Writing \\
\hline $\mathbf{1}$ & P & Indigenous & English & F & Between \\
\hline $\mathbf{2}$ & 3 & POC & B & M & Between \\
\hline $\mathbf{3}$ & 2 & Caucasian & B & F & Between \\
\hline $\mathbf{4}$ & 3 & Indigenous & B & F & Between \\
\hline $\mathbf{5}$ & 3 & POC & B & M & Between \\
\hline $\mathbf{6}$ & 3 & POC & B & M & Between \\
\hline $\mathbf{7}$ & 1 & Caucasian & English & F & Likes \\
\hline $\mathbf{8}$ & P & Caucasian & English & F & Dislikes \\
\hline $\mathbf{9}$ & 2 & POC & B & F & Likes \\
\hline $\mathbf{1 0}$ & 1 & POC & ESL & F & Between \\
\hline $\mathbf{1 1}$ & 2 & Mixed & English & F & Between \\
\hline $\mathbf{1 2}$ & 3 & Caucasian & B & F & Likes \\
\hline $\mathbf{1 3}$ & P & POC & English & F & Likes \\
\hline $\mathbf{1 4}$ & 3 & Mixed & English & F & Between \\
\hline $\mathbf{1 5}$ & 2 & POC & B & M & Dislikes \\
\hline $\mathbf{1 6}$ & 1 & Caucasian & B & F & Dislikes \\
\hline $\mathbf{1 7}$ & 2 & POC & B & F & Between \\
\hline
\end{tabular}




\begin{tabular}{|l|l|l|l|l|l|}
\hline $\mathbf{1 8}$ & 3 & POC & B & F & Between \\
\hline $\mathbf{1 9}$ & 2 & POC & ESL & F & Between \\
\hline $\mathbf{2 0}$ & 2 & POC & ESL & F & Dislikes \\
\hline
\end{tabular}

$\mathrm{P}$ = Final Practicum; POC = Person of Colour; $\mathrm{F}$ = female; $\mathrm{M}$ = male; $\mathrm{B}=$ Bilingual, English+; ESL = English as a second language (learned English in middle school or older)

*represents time after admission to a nursing program

\section{Imagine Four Nursing Student Writers}

They are students we've all taught. Hailey is grade hungry. Marcus is afraid to take risks. Grace is unwilling to sellout her opinions, values, and interests no matter what you ask her to write. Busola wonders where she fits in.

\section{Hailey}

At the end of the day I just want the A, which is sad, but it shows something where many undergraduates students are striving for academic excellence. Part of that, whether we like it or not, is when I submit something, I want to know that my professor is going to like it when they read it. (9)

Hailey knows how to "play the game." To her, writing is "something to do for my A+ grade” (5). She navigates coursework with that goal in mind and is very successful. She studies teacher word choice in class. Sometimes she writes to what she perceives as her instructor's biases even if it isn't something she is interested in or agrees with. Sometimes, if she doesn’t have a personal experience that fits what is required of the assignment guideline, she'll "make things up” $(5,13)$. Hailey says it is a requirement of the university that you do a little digging: "You have to find out a little bit about your professor when you sign up for a class” (11)

\section{Marcus}

I don't think I've ever been shown any benefit to being original or unique. [If] I get a 75\%, I think that's way better than taking the generous 1 in 10 chance of getting a 90\% because there's no point. It's like, why would you ever do that? (6) 
Marcus describes himself as an “analytical student” (6). He hasn’t had a lot of success writing in courses so attempting creativity is "very risky" (17). One risk is, "some professors, if you put the creative spark in, you're losing 10\% of your mark” (4). His repeated low grades leave him feeling demoralized and left wondering, “why does writing even exist in nursing school?” (15).

\section{Grace}

It's a balancing act of wanting to enjoy writing and wanting a good grade so that's sort of what I'm tippy toeing in between. I want to enjoy what I'm writing, at the same time I don't want to change my opinion just because I want to get an A+. I'd rather get an A and enjoy what I'm writing than an A+ and not really. (2)

Grace likes to write especially when it’s a topic she is passionate about. Rubrics rarely contain things she wants to say so she has "to make them work a bit” (1). Some instructors love her willingness to take risks - others, not so much - but she's willing to risk her grade to be in love with what she writes. Grace describes herself as “stubborn”: “I don’t want to write your paper; I want to write my paper” (1).

\section{Busola}

Sometimes I don’t even fully understand what this assignment wants me to do... sometimes I thought I do match what the needs of the assignment are. But then the rubric come back and says, no you don’t. And then that's the time I get confused like I answered every little thing. And then I try to adjust my writing for whatever it is. But then, turns out it’s not. (20). Busola might be an immigrant student who feels writing in her country was more "freestyle” (18). Maybe she's a domestic student who went to high school in a low socioeconomic community or she’s a first-year student with limited writing experience, trying to figure out nursing's concepts, language, and values and what topics are acceptable. Busola has many faces, but she's always 
uncertain about her abilities and it’s hit-or-miss if she achieves her writing goals. She feels alone:

“It’s almost like I have to overcome those things by myself on my own” (19).

\section{Codeswitching Within a Rigid Writing Context}

Our four students are not mutually exclusive and writing navigation in nursing contexts means repeated persona switching. They will codeswitch based on context, flexibility of the teacher, how much they value the assignment, and because their writing development is evolving. They codeswitch because the motives of writing change for them within the activity system. Using the phrase “codeswitch” is a small departure from its traditional linguistic definition of altering speaking style based on audience. Here we refer to changes in behavioural responses to context, not unlike Bartholomae’s (1986) description of students re-inventing themselves for every university writing experience. This observation is supported in previous research where students were found to roleplay invented and recycled scripts from course to course (Chaudoir, 2015).

Sometimes, grade hungry students, like Hailey, will stubbornly stick to their values, like Grace, or refuse to take a risk, like Marcus. Sometimes Grace will take too big a risk with her writing and will become risk adverse like Marcus on her next assignment. Sometimes Busola, sensing futility, becomes insistent on writing “her way” regardless of consequences. More often than not, Busola relates most to Marcus and becomes risk adverse - heavily reliant on tutors, peers and family - avoidant of speaking to teachers. When writing is viewed from a situated perspective, student response to the writing context will not remain stable from course to course (Slomp, 2012).

Student participants described an activity system where writing privileged objectivity such as requiring heavy reliance on sources, or impeccably implemented American Psychological Association (APA) style guide format (Gimenez, 2012; Lundgren \& Halvarsson, 2009; Whitehead, 2002). Students described this rigidity as being required to "stay within script," (15) or writing that needed to be “eccentrically professional," (1) where there was "no wiggle room to be creative or 
original” (15). Even first-year students understood that requiring APA was, “so you're not just writing messy,” but yet APA didn’t teach thinking: “But I feel like it’s like too picky. The style itself doesn’t actually teach you anything. Just like the professional” (16). They lamented, like Chaudoir’s (2015) participants, how heavily penalized these surface level writing structures (the activity system “rules”) were to their ultimate grade, “that’s where you lose marks is like all the tiny little things here and there” (14).

Grading variation was also perceived from context to context (Gimenez, 2012; Slomp, 2012; Whitehead, 2002). “There’s always those little things that they want that someone else didn’t care about” (14). As one second-year student observed:

They mark different as well.... I don’t really know what to do after. I’m like, oh this paper worked really well. I'm going to write similar to that style. And then I write similar and then I’m like, oh, this didn’t work out how I thought. (3)

Following rubrics was a key to success. One third-year student said, "Follow the rubric. Follow the rubric is the thing in nursing, follow the rubric” (5). Rubrics could also make students feel, according to one practicum student, as if the paper was little more than, "please, just get the research and fill in the blanks” (8). Rubrics made figuring out teacher intentions easy but rubric prescriptiveness could have a downside where it didn't take much effort to meet the needs of the rubric: "You have assignment rubrics. You have exactly what the instructor wants....Like everything is right there. To score 5 points, you need to put this, this, this. You don't even have to be the best researcher” (5). Students described writing in nursing as, “simple” (11), “pretty low level of writing” (13), “not as complex” (19), and "very narrow” (3) in scope. The activity system rules implied in detailed rubrics seemed to bear the consequence of removing depth, creativity, and the freedom to explore within their written work. Tightening the boundaries of writing may be at the expense of loss of assignment validity. What remains is an assignment that no longer elicits the 
learning that prompted its design. Faculty often perceive detailed rubrics as a solution to ensuring reliability in grading or interrater reliability among multiple markers (Slomp, 2012); but participants still perceived inconsistency between instructors and teaching assistants to be high despite a context of detailed rubrics and rigid expectations.

Language codeswitching was also observed. Nursing students are not only learning how to write, they are also learning to use nursing language (Chaudoir et al., 2016; Lundgren \& Halvarsson, 2009) which contributed to some conflicts in the grading process. Students reported some faculty grading strategies micro-edited their words and silenced their personal voice, "If you didn’t use her words, her way, her everything. It was like you got a bad grade which was a 72 for me” (12). Some students attributed faculty over-correction of wording as a problem more associated with novice faculty who don’t know writing. “They don’t have a teaching background...They’re nurses” (1). Faculty knowledge about facilitating writing appeared lacking to some students. Similar conclusions about faculty self-doubt in guiding writing has been reported in other nursing qualitative studies (Borglin \& Fagerstrom, 2012; Friberg \& Lyckhage, 2013; Whitehead, 2002) and in studies outside of nursing (Camfield, 2016). Nursing discourse skills need to be fostered using strength-based approaches. Late-in-program students report starting to "include nursing language in our everyday life,” but continue to describe feeling like they are "trying too hard” (2) when using nursing language in their writing. These challenges were attributed by some students to the added formality of writing, “it’s not like you and me speaking. It’s more like academic thing” (20). When speaking, they could “just say it,” be understood, and not worry about academic exactness.

\section{Successfully “Figuring Out” the Teacher}

Writing assignments in nursing means always writing under conditions where your audience is your teacher, and as one first-year student said, "it's just to get a grade in class and then it never matters again. Right? Who cares?” (16) A second-year student said: 
I am writing for my teacher .... But in terms of contributing to the nursing profession or generating something that'll be part of this body of knowledge that'll make nursing better overall, I feel like as an undergraduate student it's very hard to feel that way when you write one paper and you get an A, B, C, or, God forbid, D or F on it. And then somebody marks it ... and they’re like, “OK, thanks.” Um. "See you next term.” (9)

Students like Marcus and Busola tended to report receiving grades they were unhappy with, despite high effort, and this resulted in feelings of frustration, indifference, or disengagement with writing. These students then redirected efforts to focusing on avoiding heavy penalties for APA - a process Chaudior (2015) described as recognition of the need to align themselves with faculty values. Student engagement became task oriented. Even students like Hailey who received high grades, at times displayed characteristics of disengagement with writing because they repeatedly delivered performance-oriented writing that sold out their values in their personal activity system (an opinion) for values of the academic activity system (a high grade).

Student focus on variation between teachers was also reported in Whitehead (2002). Students, like Hailey, were successful at figuring out the teacher. Students, like Grace focused on, “gauging [their] relationship with the professor” (9) to figure out which teachers could "take it” (4) when they took a risk with creativity or expressed a controversial opinion. Students like Marcus or Busola, found they were rarely successful reading the teacher. One practicum student felt there were often hidden rules, “They put so much weight into different areas without expressing that to us” (1).

Students who were successful at reading the teacher gave clear descriptions of their strategies for doing so, and those strategies involved scoping out information from peers ahead of them in the program. Removal of power structures allowed for easier communication:

And I've always asked people ahead of me, how do they, how do they normally like it? Do they like it more opinion based or like do they like it more facts, facts, facts. Results. ...I do 
ask that [of teachers] but most of the time it's other students just because they've - It's like a different level of thinking when you're the professor, and the student when you're writing a paper just because the professor knows what they want. And the students sort of have to figure it out. And I like that challenge of still having to figure out how they want it. But also having an idea of how they want it so I'm not going to completely bomb it. (2)

Other students were successful at reading teachers because they were skilled at reading overt and between-the-lines information provided in class. Vocabulary words, topic choice preferences, and instructor personal biases were often revealed during course lectures:

I'm meeting the needs of the professor, not necessarily meeting the needs of the assignment. I'm very guilty of tailoring my writing style and the language that I use to who will be marking.... A professor will portray certain things or certain opinions that they have that you know that if they read that in your paper, they'll be like, YES, I so agree with that. A+ to this person for taking what I said in class and agreeing with it. (9)

Students successful at reading the teacher, were also readily willing to approach the teacher and ask questions. As one practicum student indicated, “if you're worried about missing the mark completely, that worry can be alleviated I think” (13).

Students who expressed in their interviews that they were reluctant to approach the teacher had perceptions that their teachers were “too busy” (19), held fears of “looking stupid,” (20) or had negative past experiences where they felt brushed aside and were told, "please just help yourself, .... they just referred me back to the rubric or the guidelines and they said, just look at this” (15). Negative past experiences can carry forward to future writing endeavours (Shellebarger et al., 2015). Students who reported these experiences were most likely to be “non-traditional” students immigrant students, Indigenous students, students with English as a second language, male students - exactly the kind of student we would want to approach and ask questions but their own feelings of 
lack of belonging became a barrier. Students who reported having difficulty reading teacher expectations identified that writing more than once for a teacher helped, however, this was a rare experience: "The problem again with writing here is that I only write one paper per class. And sometimes I feel like the classes are so short and I don’t really know my instructors” (1). There is a division of labour in the writing activity system of the classroom that faculty only intermittently activate through initiating conversations about writing with students.

\section{Valuing}

When students valued and felt passionate about their assignments writing engagement was positively impacted and contributed to the writing outcome submitted for grading. Disliking what they had to write was disengaging. They reported putting less effort into the research, “It's going to like be first thing I find, Boom!” (16) They would write, “for the sake of doing it” (2) Described that it "dulls that creative side of you" (4). They felt "robotic" (2) like they were "giving a safety demonstration on an airplane that nobody listens to" (9). When they enjoyed what they were writing it had important benefits:

And it, it almost becomes part of your identity. Like you care more about that subject when you go to other places. And then you're looking into the literature so what do other people know and you're sort of building yourself and your knowledge base. (14)

When students enjoy writing, the knowledge gained is retained longer (Lundgren \& Halvarsson, 2009). Even students who disliked writing felt topics they were passionate about resulted in learning. They cared less about their poor grade:

Writing that paper was just like so much passion for me.... OK, done. Final sentence and I'm done. Oh I love this paper. I submit it and I get a 60\% and I'm like, screw it, I love that paper anyway, you know. (15) 
Benefits are achieved by opening up the flexibility for assignment choice and individual student approach, as one practicum student wished, “They need to let go of these weird boundaries they have and let us just write” (1).

\section{Study Limitations}

The data gathered for this study had the primary purpose of validating and revising items for the SAWSES and data was limited to issues triggered by the items on the questionnaire. The interview schedule was highly structured. However, many follow-up questions were asked to clarify the stories told, and all participants were asked if they felt they had talked about everything salient to their writing experience. Nevertheless, the interview process may not have fully captured the entire experience of writing in nursing.

\section{Conclusion}

Writing contexts in nursing point to several novice to expert continuums: students writing development and discourse language skills, students when learning to read teacher intentions, and faculty when learning to facilitate writing. Students need to be nurtured in their writing experiences so that the energy exerted to read context and "figure out" the teacher can be redirected to the act of writing itself. Students may codeswitch their identities when navigating the writing environment in order to maximize their grade or reduce the effect of grade loss from misreading expectations. Relationship building with faculty is a critical factor for improving writing and ensuring the writing is a transformative experience rather than a performance-oriented activity done just for a grade. Ensuring students can always write on topics they engage with, building flexibility into rubric criteria, and developing a consciousness that students will flounder when learning the language of nursing are critical writing facilitation strategies to improve student writing. 


\section{References}

Bandura, A. (1997). Self-efficacy: The exercise of control. W. H Freeman.

Barnes, N. (2017). Blogging as a method of inquiry. Reconceptualizing Educational Research Methodology, 8(1). https://doi.org/10.7577/rerm.2236

Bartholomae, D. (1986). Inventing the university. Journal of Basic Writing, 5(1), 4-23.

Bhattacharya, K. (2017). Fundamentals of qualitative research: A practical guide. Routledge Taylor \& Francis

Borglin, G., \& Fagerström, C. (2012). Nursing students’ understanding of critical thinking and appraisal and academic writing: A descriptive, qualitative study. Nurse Education in Practice, 12, 356-360. https://doi.org/10.1016/j.nepr.2012.04.009

Camfield, E. (2016). Mediated-efficacy: Hope for helpless writers. Journal of Developmental Education, 39(3), 2-11. https://escholarship.org/uc/item/89f1r469

Camp, H. (2012). The psychology of writing development - And its implications for assessment. Assessing Writing, 17, 92-105. https://doi.org/10.1016/j.asw.2012.01.002

Chaudoir, S. (2015). Learning writing assignments across the undergraduate nursing curriculum. [Doctoral dissertation, University of Alberta]. University of Alberta Library. https://era.library.ualberta.ca/items/e70a5d4f-04d6-4363-801d700d1dac4228/view/caebf57d-62af-4f03-8444e523a1521bf0/Chaudoir_Susan_201501_PhD.pdf

Chaudoir, S., Lasiuk, G., \& Trepanier, K. (2016). Writing assignments: A relatively emotional experience of learning to write in one baccalaureate nursing program. Quality Advancement in Nursing Education, 2(2), 1-21. https://qane-afi.casn.ca/journal/vol2/iss2/3/ 
Cho, J. Y., \& Lee, E.-H. (2014). Reducing confusion about grounded theory and qualitative content analysis: Similarities and differences. The Qualitative Report, 19(64), 1-20. http://www.nova.edu/ssss/QR/QR19/cho64.pdf

Engeström, Y. (2001). Expansive learning at work: Toward an activity theoretical reconceptualization. Journal of Education and Work, 14(1), 133-156.

Friberg, F., \& Lyckhage, E. (2013). Changing essay writing in undergraduate nursing education through action research: A Swedish example. Nursing Education Perspectives, 34(4), 226232. https://doi.org/10.5480/1536-5026-34.4.226

Galasinski, D., \& Kozlowska, O. (2013). Interacting with a questionnaire: Respondents’ constructions of questionnaire completion. Quality \& Quantity, 47, 3509-3520.

\section{https://doi.org/10.1007/s11135-012-9733-0}

Gimenez, J. (2012). Disciplinary epistemologies, generic attributes and undergraduate academic writing in nursing and midwifery. Higher Education, 63, 401-419.

\section{https://doi.org/10.1007/s10734-011-9447-6}

Kain, D., \& Wardle, E. (2005). Building context: Using activity theory to teach about genre in multi-major professional communication courses. Technical Communication Quarterly, 14(2), 113-139. https://doi.org/10.1207/s15427625tcq1402_1

Lundgren, S., \& Halvarsson, M. (2009). Students' expectations, concerns, and comprehensions when writing a theses as part of their nursing education. Nurse Education Today, 29, 527532. https://doi.org/10.1016/j.nedt.2008.11.010

Mitchell, K. M. (2018). Constructing writing practices in nursing. Journal of Nursing Education, 57(7), 399-407. https://doi.org/10.3928/01484834-20180618-04

Mitchell, K. M. (2019, February 21). Navigating undergraduate academic writing: Guess what? It depends on the professor. AcademicsWrite. 
https://academicswrite.ca/2020/02/21/navigating-undergraduate-academic-writing-guesswhat-it-depends-on-the-professor/

Mitchell, K.M., McMillan, D.E., \& Lobchuk, M.M. (2019). Applying the “social turn” in writing scholarship to perspectives on writing self-efficacy. Journal of Learning Development in Higher Education,15(2019).

http://journal.aldinhe.ac.uk/index.php/jldhe/article/view/512/pdf

Richardson, L., \& St. Pierre, E. A. (2005). Writing: A method of inquiry. In N. K. Denzin \& Y. S. Lincoln (Eds.). The Sage handbook of qualitative research (3rd. ed., pp. 959-978). Sage.

Roth, W-M., \& Lee, Y-J. (2007). “Vygotsky’s neglected legacy”: Cultural-historical activity theory. Review of Educational Research, 77(2), 186-232.

\section{https://doi.org/10.3102/0034654306298273}

Russell, D. (1995). Activity theory and its implications for writing instruction. In J. Petraglia (Ed.), Reconceiving writing, rethinking writing instruction (pp. 51-78). Erlbaum.

Shellenbarger, T., Hunker, D., \& Gazza, E. (2015). Understanding the scholarly writing development of nurses enrolled in US clinical doctoral programs. Nursing Forum, 50(2), 101-108. https://doi.org/10.1111/nuf.12063

Slomp, D.H. (2012). Challenges in assessing the development of writing ability: Theories, constructs and methods. Assessing Writing, 17(2012), 81-91. https://doi.org/10.1016/j.asw.2012.02.001

Tourangeau, R., \& Rasinski, K.A. (1988). Cognitive processes underlying context effects in attitude measurement. Psychological Bulletin, 103(3), 299-314. https://doi.org/10.1037/0033$\underline{2909.103 .3 .299}$ 
Whitehead, D. (2002). The academic writing experiences of a group of student nurses: A phenomenological study. Journal of Advanced Nursing, 38(5), 498-506. https://doi.org/10.1046/j.1365-2648.2002.02211.x

Willis, G.B. (2005). Cognitive interviewing: A tool for improving questionnaire design. Sage.

Yagelski, R. (2011). Writing as a way of being: Writing instruction, nonduality, and the crisis of sustainability. Hampton Press. 
If there is a book that you want to read, but it hasn't been written yet, you must be the one to write it.

\section{Toni Morrison}




\section{Interlude 4}

The final paper in this thesis encompasses the entire instrument development project into one manuscript. The project involved two submissions to ethics at the University of Manitoba, five ethical amendments, four Manitoba post-secondary institutions, and over 1000 participants in four independent sample data collections. Data collection took place starting with the Delphi panel in April 2019 and ended on March 13, 2020 when the COVID-19 pandemic caused campuses around Manitoba to close their doors and work remotely. The fourth institution, The University of Winnipeg ( $\mathrm{U}$ of $\mathrm{W}$ ), was scheduled to send the interdisciplinary survey to their students on March 19. We decided by mutual agreement to abort the data collection due to the crisis. I am grateful to the staff and faculty at the $\mathrm{U}$ of $\mathrm{W}$ for working with me to launch this project. Having their students participate would have been wonderful, but their IT department was overwhelmed, my sample size was already more than sufficient, and I was unsure what a rapid transition to online learning in a crisis would do to influence student responses about their writing self-efficacy.

The manuscript presented explores the aspects of the Delphi panel and the cognitive interviews that resulted in edits to the questionnaire before being tested in two major survey studies. I immersed myself in learning statistical methods for measurement starting with the course Measurement and Scaling Theory that I took with the Psychology Department at the University of Manitoba. I nearly dropped out in the first class when I had to "fake” my way through an in-class assignment on matrix algebra. I lived to tell about it. Then we learned to code exploratory and confirmatory factor analysis and structural equation models in R and I sat there in a class with a lot of (very young) mostly psychology graduate students who'd clearly had more exposure to advanced statistical methods than me. I lived to tell about that too. The course, 
perhaps, wasn’t exactly what I had anticipated but my statistical methods were inspired and derived from methods I was introduced to in that context.

Thus, my methods are psychology methods. I took several introductory courses from the Centers for Health Innovation to advance my coding knowledge in R. I fretted for a year over how I was going to learn to code a structural equation model on my own, but I was determined to do it. It turned out to be relatively easy. I found the You Tube account "Statistics of Doom" and the videos posted by a professor at the University of Missouri, Dr. Erin Buchanan.

Buchanan, E. M. (2020, March 15). Structural Equation Modeling. https://doi.org/10.17605/OSF.IO/2Y67F

I worked my way through most of her course on Structural Equation Modelling using R and it was invaluable. She enhanced my understanding of the methods you see presented within the paper and taught me how to use what are, apparently, newer procedures for multigroup confirmatory factor analysis. When I took my first R course in the winter of 2018, I was a pretty good R coding monkey. I could copy and paste code and make it run like nobody’s business. By the end of this project, my troubleshooting skills are immensely improved. I'm not an expert. I still have much to learn.

The study I had planned, ended with the structural equation model with the nursing students. Despite what seem like objective methods on the surface, there are many controversies in psychological science with respect to statistical methods. One controversy my project butted up against was the question of if you should conduct a confirmatory factor analysis on the same group of participants that established the factor structure of the scale in exploratory factor analysis. There are two arguments. You want to do this, because the same sample that established the factor structure means you are more likely to confirm that factor structure. The other argument is don’t do it - for the same reason. I decided that the “don’t do it” side had a 
better argument and I would need another sample. There are other arguments that state you can do it if you have additional predictive variables inserted into your model. This is the route I took with the nursing sample.

It was still important to me to confirm the factor structure using the stronger methodological choice of obtaining an independent sample. I chose to move the scale validation to an interdisciplinary sample for two main reasons. The first was pragmatics. I felt I had tapped out the nursing student population in Manitoba in the first survey and the thought of a half dozen or more additional ethical approvals at other institutions across Canada was keeping me awake at night. The second reason I moved interdisciplinary was for generalizability. A scale only developed in a nursing population would not necessarily be of use (or found by) other disciplines. With an interdisciplinary confirmation study, I would have some evidence of the scale's validity in a generalized sample of undergraduate students. The graduate student population was a bonus population I added due to having a lot of graduate student followers on Twitter.

Lastly, as a side interest, I have dabbled in following the open science movement which primarily started in psychology but is spreading rapidly to other quantitative disciplines. Open science values full transparency of methods, pre-print publication, registered reports, sharing of data, and open access publication. The open science movement arose in response to the replication crisis in psychology and also acknowledges the rapid increase in publication retractions due to data problems and other sly things researchers do to get statistical significance like changing their research question or their main dependent variable at the analysis stage. In accordance with principles of open science, I have decided to make my data and code publicly available in anonymized format to readers, educators, and curious researchers. The individual 
coding and data files are cited within the paper. My personal Harvard Dataverse can be accessed at the following link: https://dataverse.harvard.edu/dataverse/drmitchellkmm/

The Dataverse specific to this project can be found here

https://dataverse.harvard.edu/dataverse/sawsesvalidation

\section{Author contributions}

I (Kim Mitchell), the student designed the study, collected the data, analyzed the data, performed all the statistical analysis, and wrote and edited the manuscript. My committee (Dr. McMillan, Dr. Lobchuk, and Dr. Nickel) approved all processes and provided feedback on the manuscript which informed editing. Dr. McMillan and Dr. Lobchuk provided feedback on a presentation and demonstration of the results for the nursing student sample during a committee meeting December 12, 2019. Dr. McMillan, Dr. Lobchuk, and Dr. Nickel provided feedback on a presentation and demonstration of the analysis for the interdisciplinary sample during a committee meeting March 13, 2020. There are two additional authors to credit on this paper. Dr. Rasheda Rabbani, from the Center for Healthcare Innovation, provided valuable statistical consultation and auditing of the applied statistics for the nursing and interdisciplinary samples. She also provided feedback on the statistical analysis portions of the manuscript. Dr. Johnson Li, from the Department of Psychology, approved the initial project proposal while acting as external member to the committee for the proposal defense. He contributed to the method during that process but also during the time I spent taking his course, Measurement and Scaling Theory. He provided valuable feedback on the methods used for the exploratory factor analysis and structural equation model. He also provided feedback on the prepared manuscript which informed editing. 


\title{
Paper 5: Development and Validation of the Situated Academic Writing Self-Efficacy Scale (SAWSES)
}

\begin{abstract}
Background: Writing is a pedagogical strategy that facilitates critical thinking, identity development, and ways of knowing. Existing writing self-efficacy instruments have focused on assessing writing self-efficacy through examining mechanical and process features of writing, to the neglect of the situated context and its influence. The purpose of this study was to develop and test the Situated Academic Writing Self-Efficacy Scale (SAWSES) based on Bandura's selfefficacy theory and a model of socially constructed writing.

Methods: A sequential multimethod approach to instrument development was planned. The items were developed and revised through engagement with the literature, a Delphi panel, and cognitive interviews with undergraduate students. Study 1 piloted a 20-item instrument with 255 nursing students. Exploratory factor analysis and a hypothesis testing with a structural equation model tested construct validity. Concurrent validity was assessed through comparison with established measures of writing self-efficacy. Study 2 tested the 3-factor structure established in Study 1 with an interdisciplinary sample of undergraduate $(\mathrm{N}=543)$ and graduate students $(\mathrm{N}=$ 264) using multi-group confirmatory factor analysis.

Results: Study 1: Exploratory factor analysis reduced the scale to 16 items and established scale structure as represented by three factors 1) Writing Essentials (3 items); 2) Relational Reflective (8 items), and; 3) Creative Identity (5 items). Structural equation model procedures identified that writing apprehension and supportive environment were the strongest predictors of SAWSES. Study 2: confirmed the factor structure identified in study 1 and detected no meaningful statistical differences in the response to items between the samples of interdisciplinary
\end{abstract}


undergraduate and graduate students. Additional analysis and comparison between the three samples detected possible developmental features between the three factors.

Conclusions: Findings from these studies support reliability and validity for SAWSES.

SAWSES will offer educators a validated tool to research student writing self-efficacy, stimulate student reflection on writing and significantly inform writing pedagogy. The three identified factors present a structure to the questionnaire which is developmental and has the potential to detect gaps in student self-assessed ability to master various facets of disciplinary writing: 1) writing essentials (synthesis, emotional control); 2) relationship building with writing facilitators (teachers, the writing of authors in their sources) and the self through reflection; and 3) explore gaps in student achievement of transformative writing (creativity, voice, and disciplinary identity), where confidence can help identify the most engaged writers. 


\section{Development and Validation of the Situated Academic Writing Self-Efficacy Scale (SAWSES)}

In 1986, David Bartholomae wrote that students entering post-secondary education and adapting to a new writing context had to "invent the university for the occasion” (p. 4). By inventing the university, students are repeatedly trying on new identities in order to think, reflect, argue, evaluate, and use language when writing. Writing research has demonstrated over more than 40 years of study that the cloaks students must wear to succeed in producing acceptable written texts, change from discipline to discipline (Lea \& Street, 1998), as they progress across curriculums (Mitchell \& McMillan, 2018), and from teacher to teacher in individual classes (Mitchell et al., 2020b). With contexts in a constant state of flux, student writing approaches are also in a constant state of flux. Writing becomes more complex as a writer moves from one level of education to another (e.g. high school to undergraduate to graduate writing). Simultaneously, students must also learn to self-assess their ability to communicate to a remote audience (Plakhotnik \& Rocco, 2016), pay attention to numerous rhetorical demands of the genre of writing assigned, employ strategies of cognition and metacognition, and manage their emotions (Mitchell, McMillan, \& Lobchuk, 2019). This cognitive and situative multitasking inevitably affects students' confidence in their writing.

Self-efficacy, "people’s beliefs in their ability to produce desired effects by their actions” (Bandura, 1997, p. vii), is a motivational construct that functions to promote human agency. In a learning environment, agency provides individuals with power to act to improve learning, grades, or act upon any individual high priority motivating factor in their context. Low writing self-efficacy and struggles with writing ability have been connected to delayed student progression through academic disciplinary programs (Mitchell \& McMillan, 2018).Through human agency, writing self-efficacy has the potential to act as the bridge to knowledge transfer 
between the classroom and practice environments (Bandura, 2006; Jefferies et al., 2018; Mitchell, 2018).

Writing is disciplinary, which means that different academic disciplines have forged their own expectations as to what defines effective writing and how knowledge should be communicated among disciplinary members (Hyland, 2003). Writing is social; thus, a writer is unable to produce an effective written product without knowledge of the norms and conventions of the environment within which they write. While Bandura's self-efficacy theory, a branch of his larger social cognitive theory, acknowledges the social context that surrounds people's development of self-beliefs in their abilities, social cognitive theory reduces the social context to the periphery and instead emphasizes individual goals and motivations. Self-efficacy as a construct is typically examined as the plight of an individual battling internal angels and demons or, as Paré (2014) has observed, reduces the writer to one, “struggling ... alone in a loft, seeking inspiration” (p. A-90). Those angels and demons either prevent or facilitate the writer's ability to develop personal agency.

In studies of writing self-efficacy, measurement of the construct has also focused on the individual writer and their ability to accomplish concrete tasks contained to the cognitive process categories originally developed by Flower and Hayes (1981) of planning, translating (composing), and revising stages of writing (Mitchell, Rieger, \& McMillan, 2017). In process and social cognitive perspectives, writing contexts are acknowledged but their influence on the development of writing ability, and consequently writing self-efficacy, are not addressed (Russell et al., 2009); however, the context is central in the more modern situated perspectives on writing that have been present in the literature since the 1980s. Situated perspectives acknowledge, that successful writing emerges through activities that are not visible in texts produced and those activities are more complex than individualistic writing process strategies. 
Writing functions to develop the identity of a writer in a discipline, facilitates the maintenance of disciplinary norms and values within genres, and helps communities develop an understanding of how meaning is negotiated between readers and writers (Bawarshi, 2003; Mitchell, 2018; Paré, 2014; Russell, 1997). Thus, new approaches to measuring writing self-efficacy, that consider that social and situated context are needed.

Despite the refocusing of writing scholarship on these contextual and relational aspects of writing, the assessment of writing self-efficacy has not kept pace with the epistemological evolution of writing theory (Mitchell, McMillan, \& Lobchuk, 2019). Camfield (2016) also observed how measurement of self-efficacy had not yet begun to incorporate the social movement perspectives on writing, which is what motivated her to explore writing from within the qualitative paradigm. Part of the reason for this lack of consideration for social movements of writing in the measurement of writing self-efficacy is that the social cognitive literature and the socio-cultural literature operate in silos with a few scholars recognizing the potential benefits to their merger (e.g. Greeno, 2015; Mitchell, McMillan, \& Lobchuk, 2019; Turner \& Nolen, 2015). Considering the social perspectives on writing in the measurement of writing-self efficacy could help researchers and educators understand how contexts work to limit self-efficacy development. Hence, this instrument development project began with this goal in mind: to develop a measure of writing self-efficacy for post-secondary use that incorporated student reflection of their writing context that affect their writing self-efficacy.

\section{Current Measures of Writing Self-Efficacy}

In a previous exploration of writing self-efficacy measures used in post-secondary contexts, 11 existing writing self-efficacy measures were identified (Mitchell, Rieger, \& McMillan, 2017). More related instruments have emerged since that publication, for example, Teng et al. (2018) who explored a new instrument to examine English language learner's writing 
self-efficacy, and Golombek et al., (2019) who developed an instrument to assess self-efficacy for self-regulation of academic writing. Despite approximately 80 studies in post-secondary populations exploring the concept, no measure has emerged as the gold standard. One classic measure (Shell et al., 1989) is one of the more frequently used, however, heavily focuses on assessment of self-efficacy with grammar and mechanical aspects of writing. Another measure that has been used in multiple studies includes the Post-Secondary Writerly Self-Efficacy Scale (Schmidt \& Alexander, 2012), a scale of cognitive origins, which was developed for use in writing center contexts but has also been used in classroom assessments of writing, many of those in the nursing context (Miller et al., 2015; 2018; Mitchell \& McMillan, 2018). Instead of seeking a gold standard, researchers tend to develop their own measures, many of which are used only once and then never appear in the literature again or are used exclusively by the developing researcher over several studies but not adopted by other research teams. Others cobble together their own versions by patchworking together various items from existing measures, measures targeted to children, or measures of academic self-efficacy. The inability of the writing selfefficacy research community to settle on a gold standard instrument may be a sign that contextual differences leave researchers feeling dissatisfied with existing instruments causing them to prefer to create new instruments rather than use something they feel inadequately represents the process tasks applicable to their context of writing.

Given the complexity of writing in the post-secondary context, it is unlikely that existing writing self-efficacy measures are capturing the complete writing experience. Acontextual assessments of writing are especially problematic in a disciplinary profession such as nursing which uses writing to explain relationships between patients, health, and the nursing context (Mitchell, 2018; Ryan et al., 2013). Thus, this project, began with nursing students. Nursing may seem an unusual place to begin an exploration of writing given its practice focus and its tendency 
to devalue writing over patient care activities (Mitchell, 2018); however nursing’s unique issues with writing instruction, proved to highlight particular contextual problems such as rigidity of writing expectations, focus on objectivity, and faculty that were uncertain about their skills to guide writing, all of which are academia-wide issues associated with writing in higher education (Yagelski, 2011). To improve generalizability of the final scale, the study was extended to further validate the instrument with an interdisciplinary sample.

\section{Theoretical Premise of the Scale Development}

The Situated Academic Writing Self-Efficacy Scale (SAWSES) was developed from within two theoretical perspectives: 1) Bandura’s self-efficacy theory (Bandura, 1997); 2) and a socially constructed model of writing (Mitchell, 2018). Bandura’s work contributed to item development process by adhering to key recommendations for self-efficacy scale construction including, a focus on a specific domain of self-efficacy (in this case writing) and paying attention to developing items with various degrees of difficulty (Pajares \& Valiante, 2006). The strength of Bandura’s cognitive perspective is on his recognition of how emotions are stimulated (emotional arousal) in self-efficacy experiences, and how significant others (peers/teachers) can influence self-perceptions through modelling (vicarious experiences) and feedback provision (verbal persuasion).

Because Bandura's work does not provide guidance as to how to evaluate the influence of the writer's social context on self-efficacy appraisals, a model of writing from a situated and socially constructed perspective which considers the influence of disciplinary and contextual aspects of writing also guided item development within five intertwined domains (Mitchell, 2018). 
1) Identity: Identity involves understanding of discipline specific language and how students use metacognition to reflect upon the relationship between what they write and their personal connection with disciplinary values.

2) Creativity: Novelty and originality as defined by a discipline informs creativity. Idea generation, synthesis, ability to manipulate a genre, and interpretive abilities all require creativity. A writer's self-efficacy will be impacted if they feel that they are not allowed to be creative or if their version of creativity is not shared by the faculty who assigns the writing.

3) Emotions: Emotions are present at all phases of writing from planning to feedback. Ability to control emotions, write in the face of difficulties, and an environment that validates or does not validate the normality of writing emotions will impact writing self-efficacy.

4) Relationality: Writers form relationships with the sources they incorporate through citation, inspiration, or interpretation. Students also form relationships with their teachers during pedagogical processes and feedback interactions. Students also form relationships with their selves during the process of writing, through understanding their relationship to disciplinary identity and knowledge, and writerly identity.

5) Context: Writing context encompasses aspects of the environment for writing including the impact of disciplinary and/or faculty tacit and explicit beliefs on writing. Writing selfefficacy will be impacted if students feel unsupported, devalue the assigned writing, or if they do not feel their actions in their writing context are likely to lead to success within the writing genre they need to produce.

Item development proceeded by categorizing developing items into the above five categories with explicit understanding that due to the intertwined nature of the socially constructed model of writing, when examined through rigourous statistical methods, items may factor in unexpected but pragmatic ways that remain theoretically relevant. As items were edited 
throughout the revision phases of this project (Delphi and Cognitive Interviews), they were not moved from their original theoretical category; hence, even if an edit changed the nature of the item to a degree that it might be a better fit for a different theoretical domain, it was not moved. For these reasons, there was never any intention to force items to remain within the five apriori domains.

\section{Methods and Results}

The overall scale development project uses a multimethod sequential design. Five study phases were planned, with the first three focusing on item development and revision. The final two phases comprised two studies with the goal of scale validation through statistical procedures.

1. Initial drafting of items based on a review of the literature, personal experience with writing and writing instruction, and the model reported in Mitchell (2018).

2. Delphi panel of nurse educators and writing scholars for expert analysis of the relevance and importance of the items designed in Phase I.

3. Interviews with undergraduate nursing students using cognitive interview procedures (Willis, 2005) to ensure the instrument was understood in the way it was intended, and to assess effectiveness for gathering data of interest to understanding writing self-efficacy.

4. Study 1 piloted the questionnaire in survey format with undergraduate nursing students along with two previously established writing self-efficacy scales (Mitchell, Harrigan, et al., 2017; Shell et al., 1989), a measure of writing apprehension (Daly \& Miller, 2014), a measure of nursing identity (Adams et al., 2006), and items developed for this study assessing the writing context. Exploratory factor analysis and structural equation modelling methods were employed. 
5. Study 2 tests the scale as established in the exploratory factor analysis in Study 1 with an interdisciplinary sample of undergraduate and graduate students from various disciplines and educational contexts.

Ethical approval was obtained in two separate applications. The first for the Delphi study and the second for the student recruitments which required additional ethical approvals at all participating sites. All participants were volunteers. The Delphi participants consented to releasing their anonymity and were offered a \$25 CAD Amazon gift card for their time. The cognitive interview students were given a \$50 cash honorarium. Study 1 participants were provided the opportunity of five draws for $\$ 100$ each for a gift card of choice. No honorariums were offered in interdisciplinary Study 2.

\section{Item Development and Revision}

Forty-one (41) items for the proposed Situated Academic Writing Self-Efficacy Scale (SAWSES) were developed. The full set of items, listed by their hypothesized domain of the theoretical framework, and their evolutions across all phases of the study are presented in Appendix A. The phrasing of the items was chosen based on the advice provided by Bandura (1997), for self-efficacy scales in general, and by Pajares and Valiante (2006) specific to writing self-efficacy measures. These authors advised that items be presented as a 0-100 rating scale and phrased as “I can” statements reflecting current ability (rather than "I will” reflecting a future state). All items were positively worded because mixtures of positively and negatively worded items tend to increase the cognitive load on participants and negative items tend to factor together when subjected to factor analysis regardless of the content of that item (Barnette, 2000). The sliding scale was anchored with the phrases, “completely sure I cannot” to "completely sure I can.” 
The development of these items emerged from a variety of strategies including personal experience as a writer and teacher of writing, and an extensive prolonged engagement with the literature. Some key steps in item development included:

1. The first author's through engagement with the literature and 18-years experience mentoring undergraduate nursing students in their writing produced an initial list of 35 items.

2. The initial list was vetted by the remaining author team, and one local writing scholar who teaches a discipline-specific writing course for nurses. This process resulted in minor edits to item wording and three additional items.

3. The 38 items were presented at a poster session at an international nursing conference in Melbourne, Australia (Mitchell et al., 2018) and three additional items were created following engagement with scholars at the conference and additional reading on writing for a total for 41 items.

Two studies, a Delphi study and a cognitive interview study, were then conducted in order obtain the strongest and most parsimonious item pool that still reflected the theoretical premise of the questionnaire

\section{Delphi Panel}

The goal for the Delphi panel was item reduction and to increase understanding of the relevance of the questionnaire items to their theoretical domain. A more detailed report of the methods used in the Delphi panel are reported in Mitchell et al. (2020a).

\section{Participants}

An online survey was developed in the Qualtrics platform to gather feedback from an international panel of nurse educators and writing scholars. Participants were recruited via social media, personal contacts, a writing scholar listserv, and scholars met at international and national conference sessions. Twenty-seven scholars (13 nurses, 14 writers) were sent the initial survey 
with 15 scholars completing the survey (7 nurses, 8 writers). All 15 continued to participate through 2 Delphi panel rounds. These scholars were from five countries, Australia (5), Canada (3), Germany (2), the United Kingdom (2), and the United States of America (3), and ranged in teaching experience at the post-secondary level from 3 to 30 years.

\section{Procedures}

The round 1 survey presented each item within its theoretical domain. Each item was rated for relevance within its theoretical domain (e.g. identity) with a sliding scale ranging from 0 (not at all relevant) to 100 (completely relevant). Participants were given the option to provide open-ended comments related to their perceptions about each item. For each theoretical domain, two additional open-ended response boxes were provided asking participants to identify their top three items for that domain and provide suggestions for new items. Data was analyzed by blending the qualitative and quantitative findings. Items were kept, edited, or deleted based on evidence from the average rating of relevance for each item, the frequency of choice of an item as a top three item, and the qualitative comments. Following the completion of the round, participants were sent a summary of the findings that included the average ratings of the sample and their own ratings. A summary of the qualitative comments were also included.

For round 2, participants were only asked to rate edited items. Participants were presented with the original item and the edited version of the item and were provided with a rationale for the edit choices. They were asked to indicate if they agreed or disagreed with the edit on a 4-point Likert scale. An open-ended text box was presented for each theoretical domain to allow additional suggested edits and comments. Participants were also provided with a list of deleted items and a list of items retained without edit, and were given the opportunity to comment on each list. Proportions of agreement or disagreement with an item edit were tabulated but items were edited primarily from the qualitative feedback and editing suggestions. 
At the end of the round participants were sent a summary sheet which compared their personal agreement ratings to the sample ratings along with a summary of the decisions made for the items. The Delphi phase was terminated after this round.

\section{Results}

Refer to Appendix A for a record of the evolution of item editing. During round 1, of the 41 items presented, 10 items were kept without revision; 17 items were deleted; and 14 items were edited based on suggestions made in the qualitative comments (see Appendix F for a summary of the round 1 Delphi results). One new item was created and presented in round 2 in the same format as round 1 . Of the 15 items presented in round 2, seven items were retained, and seven items underwent additional revisions. One item was deleted due to lukewarm ratings, qualitative comments, and similarity to a previously kept item. Another item was deleted from the previously kept list due to its similarity to a newly revised item. One item was resurrected from deletion and edited due to a suggestion from a nurse educator. One new item was created to reflect what one nurse educator felt was a diminishing of the importance of creativity to the questionnaire (see Appendix $\mathrm{H}$ for a summary of the round 2 Delphi results). Because the majority of additional qualitative statements from participants were limited to suggested wording changes, we felt that the feedback had stabilized enough to move the remaining 25 items on the questionnaire forward to the cognitive interview phase with the nursing undergraduates with notations added to the interview guide offering alternative phrasing that could be presented to students in the event of a misinterpretation of the item.

\section{Cognitive Interviews}

The goal of the cognitive interview phase was to gather information from undergraduate students with respect to the phrasing and interpretability of the items. A secondary analysis of the 
interviews was also conducted in order to understand the influence of systemic, instructional, and personal factors on student writing self-efficacy (Mitchell et al., 2020b).

\section{Participants}

Twenty students (16 females, 4 males) were recruited from two Baccalaureate nursing programs and represented students from all years of both programs, including senior practicum students. The students were highly diverse in terms of ethnic background, international student status, age, previous exposure to writing in other disciples, and attitudes about writing.

\section{Procedures}

All interviews were conducted in July of 2019. Interview procedures followed recommendations from Willis (2005). Students were presented with an electronic version of the items in the Qualtrics platform. They were asked to read each item out loud, rate how they would score themselves on each item, by interacting with the sliding scale on the computer screen, and describe any thoughts, stories, or examples from their own writing experiences that contributed to their responses. A warmup exercise asked the students to talk through how they would go about preparing to write on a short essay topic paper provided in a prompt. The warm-up allowed students to practice the think-aloud protocols for the interview. Concurrent prompting was used throughout the interview in order to encourage out loud thinking, clarify understanding of terms in the items, and gain deeper explanations of the stories students described. Interviews were video recorded for analysis.

The process for analyzing the cognitive interviews followed the steps outlined in Knafl et al. (2007) who provide a step by step process for analyzing cognitive interviews specifically for the purpose of questionnaire revision.

1. Videos for each interview were watched within 1 to 2 days. Notes were taken that flagged issues with item misinterpretations or an unusual reaction to an item. Student lack of 
engagement with an item (e.g. items that they didn’t want to answer or appeared indifferent to) were noted. Students also verbalized observations about similarities between items which were also recorded.

2. A summary was written for each item describing any noted problematic responses. Patterns of multiple interpretations, areas of overlapping content between items, and misunderstood words were noted.

3. Decisions were then made to either edit, watch, or delete particular items based on observations related to interpretation, degree of student interest in the item, and scoring patterns.

The goal was to sample until three interviews demonstrated minimal problems with items. This endpoint was reached after 20 participants.

\section{Results}

Refer to Appendix A for a record of the evolution of item editing. The 25 items were edited at periodic but inconsistent intervals after 3 (5 items), 6 (six items), 12 (five items), and 17 (1 item) interviews with one minor wording change made after interview 18 with a second language student. Most items were only edited one time. Two items were edited two times and two items were edited 3 times. Two items were deleted after 12 interviews and three items were deleted after 17 interviews. Item deletion was considered if the students felt indifferent to the issue presented in the item, the item produced a ceiling effect in chosen scores, or if issues of item wording failed to make the item understandable to undergraduate students. At the end of the cognitive interview phase, 20 items moved forward to statistical testing.

\section{Study 1: Exploratory Factor Analysis and Hypothesis Testing}

The primary goal of study 1 was to evaluate the questionnaire for its factor structure. Additional psychometric properties were also assessed during this phase including Cronbach’s 
alpha, parallel form reliability, and concurrent validity with two previously established writing self-efficacy instruments. A structural equation model was hypothesized and predicated that writing apprehension, nursing identity, and three measures of writing context would predict scores on the SAWSES.

\section{Participants}

Table 1 presents the demographic characteristics of the samples that participated in Study 1 as compared to those who participated in Study 2. All participants in Study 1 were nursing students in three Baccalaureate nursing programs located in a prairie province in Canada. Student participants were enrolled in a course that required an academic writing assignment where they were expected to locate, read, and incorporate research sources into a minimum three-page paper. Responses were included up to point of completion. The sample size for the exploratory factor analysis was 255. Participants who did not complete tools for apprehension, identity, and writing context were excluded listwise from the structural equation model for final $\mathrm{N}$ of 234 .

Table 1: Demographic Characteristics of the Samples for Study $1(N=234)$ and Study 2 Undergraduates $(N=543)$; graduate students $(N=264)$

\begin{tabular}{|c|c|c|c|}
\hline & $\begin{array}{c}\text { Study } 1 \\
\text { Nursing } \\
\text { Baccalaureate } \\
\text { Only } \\
\end{array}$ & $\begin{array}{c}\text { Study } 2 \\
\text { Interdisciplinary } \\
\text { Undergraduate } \\
\text { Students }\end{array}$ & $\begin{array}{c}\text { Study } 2 \\
\text { Interdisciplinary } \\
\text { Graduate } \\
\text { Students } \\
\end{array}$ \\
\hline & $\mathrm{n}(\%)$ & $\mathrm{n}(\%)$ & $\mathrm{n}(\%)$ \\
\hline $\begin{array}{r}\text { Institution } 1 \\
\text { Institution } 2 \\
\text { Institution } 3 \\
\text { Other Canadian } \\
\text { USA } \\
\text { International }\end{array}$ & $\begin{array}{l}116(49.6 \%) \\
77(32.9 .2 \%) \\
41(17.5 \%)\end{array}$ & $\begin{array}{l}10(1.8 \%) \\
422(77.7 \%) \\
87(16.0 \%) \\
8(1.5 \%) \\
11(2.0 \%) \\
7(1.3 \%)\end{array}$ & $\begin{array}{l}0 \\
171(64.8 \%) \\
6(2.3 \%) \\
15(5.7 \%) \\
40(15.2 \%) \\
32(12.1 \%)\end{array}$ \\
\hline $\begin{array}{r}\text { Canada } \\
\text { USA } \\
\text { Great Britain/Ireland } \\
\text { Other }\end{array}$ & 234(100\%) & $\begin{array}{l}526(96.9 \%) \\
11(2.0 \%) \\
2(0.4 \%) \\
4(0.7 \%)\end{array}$ & $\begin{array}{l}192(72.7 \%) \\
40(15.2 \%) \\
15(5.7 \%) \\
17(6.4 \%)\end{array}$ \\
\hline Discipline & $234(100 \%)$ & $28(5.2 \%)$ & $28(10.6 \%)$ \\
\hline
\end{tabular}




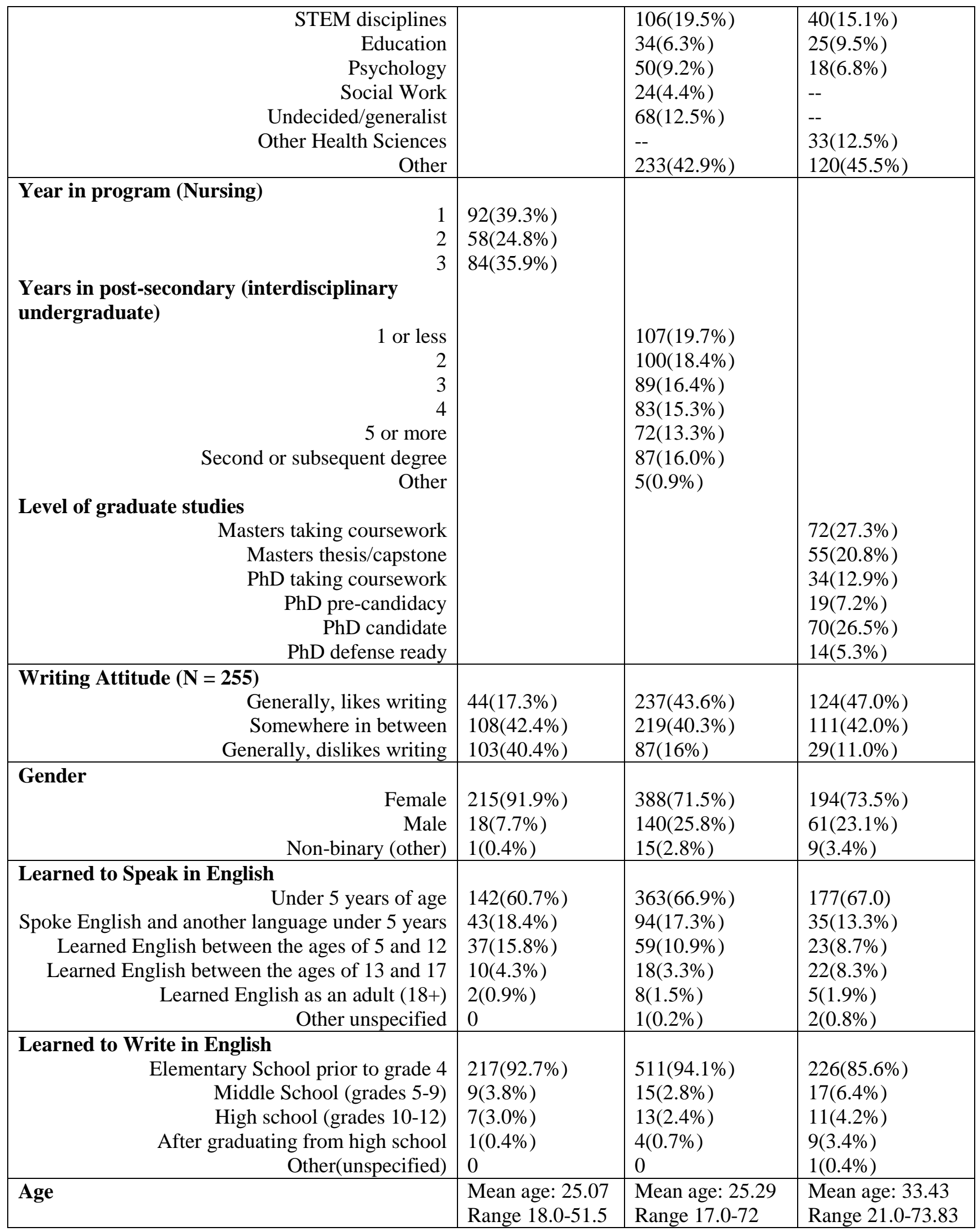

STEM = Science, Technology, Engineering, Mathematics 


\section{Procedures}

Student recruitment occurred through faculty members at each participating institution. Faculty were emailed a description of the study from a representative within the nursing department and were asked to consider inviting the researcher to come and speak to their class about the survey. If a faculty member agreed, a designated person within the program emailed the Qualtrics survey link to the specific class on the date of the in-class presentation. Presentations were made to 12 individual classrooms, 5 of whom gave class time for survey completion. A reminder was sent a week after the classroom visit. In order to ensure that all students were sent the survey it was emailed to the entire nursing student population at a later date or posted on student message boards in the program learning management system.

In two classrooms (one first- and one third-year at institution 1) students were provided a paper version of the developing SAWSES in order to assist with assessing the reliability between the electronic version and a parallel paper and pencil version. The paper version included a visual analog scale where students placed an $\mathrm{X}$ on a line to indicate their score between the two anchor phrases of “completely sure I cannot” and “completely sure I can.” The paper form was completed first and the electronic form was in most cases completed within 10 minutes; however, it was possible some students completed the electronic survey at a later time or date. Each paper survey was assigned a number which the students entered into the Qualtrics survey to facilitate matching. The paper form required ruler measurements and manual entry of data. A two person check of measurements and data entry was completed. Errors of greater than $1 \mathrm{~mm}$ were observed in 12 item responses and they underwent a third check and were reduced to being within 0-1 mm of difference. The two rater scores were averaged for correlational analysis.

Missing data was minimal in this study $<1 \%$ usually with no more than a single item not answered on the SAWSES scale. Missing responses to SAWSES were replaced with the average 
score of the participants' remaining SAWSES responses. If more than two item responses were missing from SAWSES, the sample size was deemed large enough to eliminate the participant from the study.

\section{Instruments}

Six instruments and a demographic survey were included within the main survey in the order described:

1. The developing SAWSES instrument - The 20 items that remained after the cognitive interviews were presented in the form of a 0-100 sliding scale with no gridline indicating the score they were giving themselves and were anchored by the phrases, “complete sure I cannot” (0) and “completely sure I can” (100). The questions were ordered on the survey by approximate degree of difficulty of the item as assessed based on conversations that took place during the cognitive interviews.

2. The Self-Efficacy Scale for Academic Writing - The SESAW was included in order to provide concurrent validity evidence. The SESAW was previously developed and tested in a nursing context (Mitchell, Harrigan, et al., 2017). The scale was originally developed in a 10item 4-point Likert format, however exploratory factor analysis has established that a 9-item 2-factor scale provided a stronger model fit: RMSEA $=.053,90 \% \mathrm{CI}=.016-.82$, $\mathrm{TLI}=.96$, representing $41 \%$ of overall variance (unpublished data). The two factors are Interpretive Activities (items 5, 6, 7) and Writing Efficacy and Emotions (Items 1, 2, 3, 4 8, 9). The 10item scale has exhibited strong internal consistency reliabilities with alpha ranging from .82-.90. Concurrent validity with the Post-Secondary Writerly Self-Efficacy Scale (Schmidt \& Alexander, 2012) ranged from .76-.81 (Mitchell \& McMillan, 2018). In this study, the 9-item scale had a Cronbach’s alpha of .85. 
3. Writing Self-Efficacy Instrument - Developed by Shell et al. (1989), the writing self-efficacy instrument was developed in two subscales for tasks and skills. Only the 8-item skills subscale was used in this study and was presented as originally designed with a 0-100 scale with 0 meaning "no chance” and 100 meaning “completely certain.” The writing self-efficacy instrument focuses on elements of grammar and mechanics and was used for discriminant validity with the hypothesis that mechanical elements of writing and constructionist elements of writing are low to moderately correlated. This scale has continued to be used in whole or in adapted form in research as recent as 2017 by Vanhille and colleagues. Vanhille et al. obtained a Cronbach’s alpha of .93 for the skills subscale. Pajares and Johnson (1994) found the scale had good predictive ability with writing performance. In this study, a Cronbach’s alpha .93 was obtained.

4. Writing Apprehension Test - The writing apprehension test (Daly \& Miller, 1975) is a classic instrument readily available on the internet in the Measurement Instrument Database for Social Science (Daly \& Miller, 2013). It has established high Cronbach’s alpha scores (.94) both in its original development and in more recent use (Vanhille et al., 2017). A 20item version of the scale from the measurement instrument database was adapted for use and presented to students as a 5-point Likert format (strongly disagree to strongly agree). Adaptations to the scale included small wording changes to reflect more modern language and language likely to be more understandable to nursing students (e.g. the word “composition” was edited to “essay”). The WAT contains both positive and negative worded items and produces scores where a high score means high apprehension. To avoid negative values for the structural equation model tests, the scoring was reversed so that a high score meant low apprehension. The Cronbach’s alpha for the current study was .92. 
5. Nursing Identity - The Macleod Clark professional identity scale (Adams et al., 2006) was included to assess student identification as a member of the nursing profession. This 8-item, single factor, scale was presented to students in a 5-point Likert format ranging from strongly disagree to strongly agree and assesses sense of belonging and identification with the nursing profession. Cronbach's alpha was assessed at .79 in original development (Adams et al., 2006) but has been assessed at .83 in more recent research where student nurses were the population of interest (Worthington et al., 2013). Worthington et al. were also able to use the scale to predict student retention in a nursing program after 12-months. Cronbach's alpha for the current study was .83.

6. Context items - Three author developed items assessing students' appraisal of their writing context were included. These items target areas of the constructionist writing theory context domain and were rated on a 0-100 sliding scales as follows:

Support: This class and/or my institution can support me in the way I need to be successful with writing this essay assignment (“not at all true” to "completely true”).

Stakes: It is important for my future that I get the grade I need on this writing assignment so I do well in this course (“not at all important” to "completely important”).

Value: I feel that the writing assignment in this class will be important for my learning in the nursing program (“not at all important” to “completely important”).

\section{Data Analysis}

The Statistical Package for the Social Sciences (SPSS v.24) was used for the descriptive analysis. Exploratory factor analysis was conducted in RStudio (v. 1.2.5033) using the Psych package (Revelle, 2017). The Lavaan package (Rosseel, 2017) was used for the structural equation model. Data files and R code are publicly available (Mitchell, 2020b; 2020c; 2020e). 


\section{Results}

\section{Exploratory Factor Analysis}

To assess factorability of the scale the Kaiser-Meyer-Olkin (KMO) index of sampling adequacy was assessed in Rstudio at .95 indicating high suitability for factor analysis (Revelle, 2017). Each individual item produced high KMO index scores $>.90$ ranging from .91 to .98. Parallel analysis was conducted, and a scree diagram was produced in Rstudio (see Figure 1) which suggested that both 1 and 3 factor solutions should be tested. Principal axis methods were used with oblique rotation for greatest interpretability (Revelle, 2017).

\section{Figure 1: Scree Diagram for Exploratory Factor Analysis}

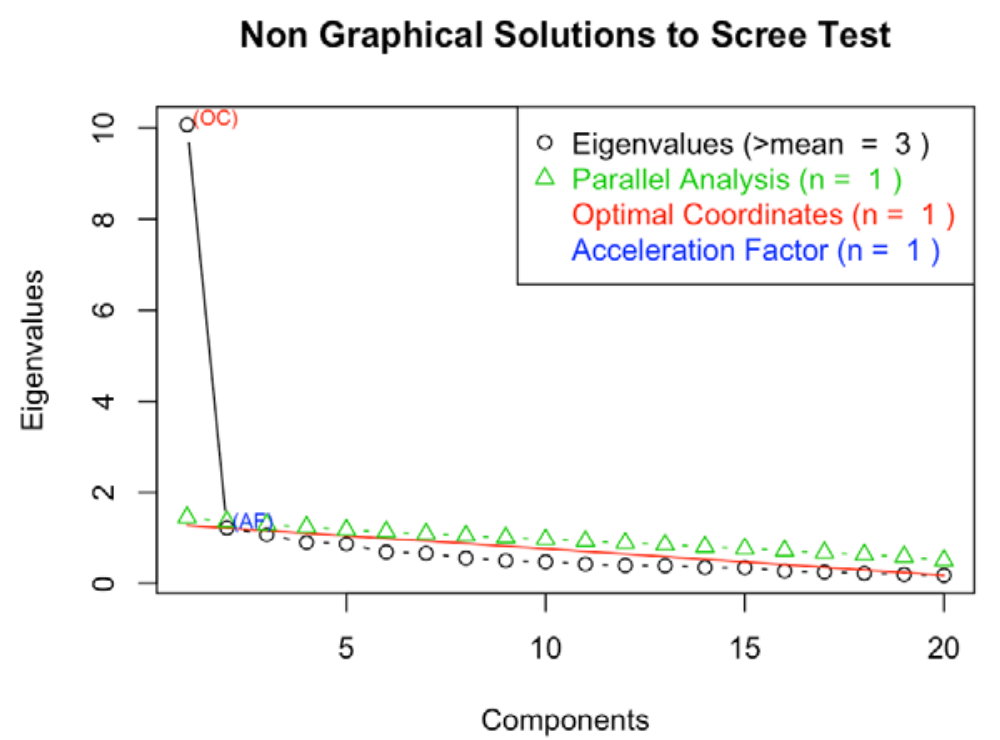

Numerous models were tested within the factor range established via statistical analysis and four are reported in Table 2 and include reports of key goodness of fit indexes including Root Mean Square Error of Approximation (RMSEA, excellent fit < .06, acceptable fit < .08), Tucker Lewis Index (TLI ideal > .95), Comparative Fit Index (CFI ideal >.95), and Root Mean Square of the Residuals (RMSR ideal < .05) (Beaujean, 2014). Items were retained on a factor if the factor loading was $>$.30. Cross loading items were considered for deletion in combination 
with knowledge of participant reaction to that item and its similarity to other items based on the cognitive interviews. A single factor model demonstrated that all 20 items produced factor loadings greater than .50 with the exception of item 2 which loaded .42 . This model had less than adequate fit with a RMSEA $=.096 . \mathrm{TFI}=.86$, and CFI $=.87$. The three factor 20-item model had adequate fit but items 4 and 9 demonstrated cross loadings on two factors and item 14 did not produce factor loadings $>.30$ as required. Examination of items 4 and 9 from a theoretical perspective and cognitive interview data identified elements of these items that were likely also being captured in items 1 and 17 respectively. A decision was made to run a third model which removed items 4, 9, and 14 with slight improvement to fit. Item 2 (“If I get stuck, I can contact a teacher or tutor to help me move forward with my writing ideas”), the weakest item in the single factor model, also elicited questions from students during in-class data collection sessions. Students indicated confusion in how to respond to the item if they felt they could contact a teacher, but probably wouldn't contact a teacher. Based on being the lowest loading item and on student response to the item during testing, we made a decision to remove item 2. A fourth model with items 2, 4, 9, and 14 removed explained 61\% of variance and provided the best fit with all remaining items loading $>.45$ on an independent factor. Goodness of fit indices were acceptable to excellent with RMSEA = .068 (90\% confidence interval .052-.081), TLI = .95, CFI $=.97$, and $\mathrm{RSMR}=.03$. 
Table 2: Four exploratory factor analysis models SAWSES Nursing student sample $(N=255)$, with goodness of fit analysis

\begin{tabular}{|c|c|c|c|c|c|c|c|c|c|c|c|}
\hline & \multirow{3}{*}{$\begin{array}{l}\text { Exploratory Factor Analysis } \\
\text { Situated Academic Writing Self-Efficacy } \\
\text { Scale (Model Testing) }\end{array}$} & \multicolumn{10}{|c|}{ Factor Loadings } \\
\hline & & $\begin{array}{c}\text { Model 1 } \\
\text { 1-Factor 20- }\end{array}$ & 3-Fact & $\begin{array}{l}\text { Model } 2 \\
\text { or 20-ite }\end{array}$ & n scale & 3-Fact & $\begin{array}{l}\text { Model } 3 \\
\text { or 17-ite }\end{array}$ & n scale & 3-Fact & $\begin{array}{l}\text { Model } 4 \\
\text { or 16-iter }\end{array}$ & scale \\
\hline & & & $\begin{array}{c}\text { Factor } \\
1\end{array}$ & $\begin{array}{c}\text { Factor } \\
2\end{array}$ & $\begin{array}{c}\text { Factor } \\
3\end{array}$ & $\begin{array}{c}\text { Factor } \\
1\end{array}$ & $\begin{array}{l}\text { Factor } \\
2\end{array}$ & $\begin{array}{c}\text { Factor } \\
3\end{array}$ & $\begin{array}{c}\text { Factor } \\
1\end{array}$ & $\begin{array}{l}\text { Factor } \\
2\end{array}$ & $\begin{array}{l}\text { Factor } \\
3\end{array}$ \\
\hline 1 & $\begin{array}{l}\text { Even when the writing is hard, I can find ways to } \\
\text { overcome my writing difficulties. }\end{array}$ & .62 & & & .55 & & & .63 & & & .58 \\
\hline 2 & $\begin{array}{l}\text { If I get stuck, I can contact a teacher or tutor to } \\
\text { help me move forward with my writing ideas }\end{array}$ & .42 & .48 & & & .45 & & & & m remo & \\
\hline 3 & $\begin{array}{l}\text { I can successfully use scholarly academic words } \\
\text { and phrases when writing in my courses. }\end{array}$ & .62 & & & .63 & & & .82 & & & .82 \\
\hline 4 & $\begin{array}{l}\text { I can write a major writing assignment without } \\
\text { letting my emotions prevent me from making } \\
\text { progress. }\end{array}$ & .57 & .31 & & .38 & & m remo & & & m remo & \\
\hline 5 & $\begin{array}{l}\text { I can combine or synthesize multiple sources I've } \\
\text { read to create an original product or text. }\end{array}$ & .66 & & & .57 & & & .52 & & & .48 \\
\hline 6 & $\begin{array}{l}\text { I can use creativity when writing an academic } \\
\text { paper. }\end{array}$ & .77 & & .62 & & & .64 & & & .62 & \\
\hline 7 & $\begin{array}{l}\text { When I write, I can think about my audience and } \\
\text { write so they clearly understand my meaning. }\end{array}$ & .75 & .42 & & & .43 & & & .49 & & \\
\hline 8 & $\begin{array}{l}\text { When I receive feedback on my writing, no matter } \\
\text { how it makes me feel, I can use that feedback to } \\
\text { improve my writing in the future. }\end{array}$ & .60 & .74 & & & .84 & & & .82 & & \\
\hline 9 & $\begin{array}{l}\text { Writing assignments relevant to nursing can help } \\
\text { me to feel part of the nursing profession. }\end{array}$ & .55 & .62 & & -.33 & & m remo & & & m remo & \\
\hline 10 & $\begin{array}{l}\text { When I reflect on what I am writing I can make } \\
\text { my writing better. }\end{array}$ & .76 & .80 & & & .71 & & & .75 & & \\
\hline 11 & $\begin{array}{l}\text { I feel I can give my writing a creative spark and } \\
\text { still sound professional. }\end{array}$ & .77 & & .75 & & & .73 & & & .72 & \\
\hline 12 & $\begin{array}{l}\text { When I read articles about my topic, the } \\
\text { connections I feel with the ideas of other authors } \\
\text { can inspire me to express my own ideas in writing. }\end{array}$ & .75 & .70 & & & .67 & & & .69 & & \\
\hline 13 & $\begin{array}{l}\text { When I look at the overall picture I've presented in } \\
\text { my writing, I can assess how all the pieces tell the } \\
\text { complete story of my topic or argument. }\end{array}$ & .84 & .60 & & & .63 & & & .75 & & \\
\hline
\end{tabular}




\begin{tabular}{|c|c|c|c|c|c|c|c|c|c|c|c|}
\hline 14 & $\begin{array}{l}\text { I can write without worrying about my ability to } \\
\text { correctly apply the rules of the required style } \\
\text { guideline (e.g. APA format). }\end{array}$ & .52 & $\begin{array}{l}\text { No } \\
\text { load }\end{array}$ & $\begin{array}{l}\text { No } \\
\text { load }\end{array}$ & $\begin{array}{l}\text { No } \\
\text { load }\end{array}$ & \multicolumn{3}{|c|}{ Item removed } & \multicolumn{3}{|c|}{ Item removed } \\
\hline 15 & $\begin{array}{l}\text { I feel I can develop my own writing voice (ways of } \\
\text { speaking in my writing that are uniquely me). }\end{array}$ & .75 & & .91 & & & .92 & & & .91 & \\
\hline 16 & $\begin{array}{l}\text { Even with very specific assignment guidelines, I } \\
\text { can find ways of writing my assignment to make it } \\
\text { original or unique. }\end{array}$ & .76 & & .85 & & & .85 & & & .87 & \\
\hline 17 & $\begin{array}{l}\text { I can comfortably express nursing concepts, } \\
\text { language, and values in my writing assignments. }\end{array}$ & .81 & & .55 & & & .48 & & & .47 & \\
\hline 18 & $\begin{array}{l}\text { I can recognize when I’ve wandered away from } \\
\text { writing what my audience needs to know and have } \\
\text { begun writing about interesting, but unrelated, } \\
\text { ideas. }\end{array}$ & .71 & .32 & & & .33 & & & .45 & & \\
\hline 19 & $\begin{array}{l}\text { With each new writing assignment, I can adapt my } \\
\text { writing to meet the needs of that assignment. }\end{array}$ & .81 & .39 & & & .43 & & & .51 & & \\
\hline 20 & $\begin{array}{l}\text { When I seek feedback on my writing, I can decide } \\
\text { when that feedback should be ignored or } \\
\text { incorporated into a revision in my writing. }\end{array}$ & .60 & .34 & & & .44 & & & .53 & & \\
\hline & Eigen Values & 9.60 & 4.48 & 4.17 & 2.43 & 3.95 & 3.69 & 2.65 & 4.26 & 3.47 & 2.06 \\
\hline & Variance Explained (Cumulative) & .48 & .22 & .43 & .55 & .23 & .45 & .59 & .27 & .48 & .61 \\
\hline & RMSEA (90\%CI) & $\begin{array}{c}.096(.085- \\
1.02)\end{array}$ & & ) & & & (.053 & & & $(.052$ & \\
\hline & Tucker Lewis Index & .86 & & .93 & & & .94 & & & .95 & \\
\hline & Comparative Fit Index & .87 & & .95 & & & .96 & & & .97 & \\
\hline & RMSR & .06 & & .03 & & & .03 & & & .03 & \\
\hline
\end{tabular}


Despite five theoretical model domains guiding the development of the questionnaire items, three factors were considered sufficient as it was accepted from the onset that theoretical dimensionality and statistical dimensionality may not match (Locke \& Johnston, 2016). Items from all five initial domains of the questionnaire were maintained (see Appendix A) and the items clustered statistically with theoretical relevance. The eight items on Factor 1 were given the name Relational Reflective Writing. Relational Reflective acts of writing include interaction with others in the writing context, response to feedback, audience awareness, relating to source materials when reading, adapting writing to the assignment (which often meant adapting to teachers according to student statements in the cognitive interviews but could also mean adapting to different writing genres), or represented reflective elements of writing process. Factor 2 was labelled Creative Identity because the five items represented high level writing acts about integrating creativity in a prescripted writing environment, developing personal voice, or learning the language of a discipline. The three items on the third factor were labelled "Writing Essentials” because ability to move forward despite difficulties, ability to integrate and synthesize numerous sources, and ability to use academic language suitable for post-secondary writing are essential skills required to produce an effective academic writing assignment.

\section{Reliability Testing}

Reliability was assessed using Cronbach’s alpha and a parallel form analysis. Cronbach’s alpha is a common test of internal consistency by examining repeated split halves of a questionnaire. Parallel form compares two alternative forms of the questionnaire - in this case a comparison between the electronic version of the questionnaire and a paper form of the questionnaire completed by the same individuals. The mean, standard deviation, and 95\% confidence intervals for the total scale, subscales, and individual items are present in Table 3 for 
both Study 1 and 2. Cronbach's alpha scores are also indicated. These ranged from .79 for Writing Essentials to .95 for the complete scale. The parallel form analysis $(n=56)$ found correlations between the paper and electronic versions of the scale were satisfactory and produced reliability coefficients of .91 (total scale), .88 (Relational Reflective), .88 (Creative Identity), and .85 (Writing Essentials). 
PAPER 5: DEVELOPMENT AND VALIDATION OF SAWSES

Table 3: Mean, Standard Deviations, and 95\% Confidence Intervals (CI) for Scale, Subscales, and Items on the Situated Academic Writing Self-

Efficacy Scale (SAWSES): Study 1 Nursing sample ( $N=255) ;$ Study 2 Interdisciplinary Undergraduate Students (N = 543); Interdisciplinary

Graduate Students $(N=264)$ (Possible Range of Scores 0-100)

\begin{tabular}{|c|c|c|c|c|c|c|c|c|c|c|}
\hline \multirow[b]{2}{*}{ Items } & \multirow[b]{2}{*}{ Item\# } & \multicolumn{3}{|c|}{$\begin{array}{c}\text { Study } 1 \\
\text { Nursing Sample }\end{array}$} & \multicolumn{3}{|c|}{$\begin{array}{c}\text { Study } 2 \\
\text { Interdisciplinary } \\
\text { Undergraduate Sample }\end{array}$} & \multicolumn{3}{|c|}{$\begin{array}{c}\text { Study } 2 \\
\text { Interdisciplinary Graduate } \\
\text { Sample } \\
\end{array}$} \\
\hline & & Mean & $\mathrm{SD}$ & 95\%CI & Mean & $\mathrm{SD}$ & $95 \% \mathrm{CI}$ & Mean & $\mathrm{SD}$ & $95 \%$ CI \\
\hline Total Scale $(\alpha=.95, .94, .95)$ & & 63.49 & 18.52 & 61.20-65.77 & 72.68 & 17.24 & 71.23-74.13 & 74.27 & 17.77 & 72.11-76.42 \\
\hline Creative Identity $(\alpha=.91, .88, .90)$ & & 56.84 & 22.66 & $54.05-59.64$ & 68.02 & 21.09 & 66.24-69.80 & 69.03 & 22.41 & 66.31-71.74 \\
\hline $\begin{array}{l}\text { I can use creativity when writing an } \\
\text { academic paper. }\end{array}$ & 6 & 56.36 & 26.32 & $53.11-59.61$ & 69.91 & 25.21 & $67.78-72.03$ & 69.55 & 25.49 & $66.46-72.64$ \\
\hline $\begin{array}{l}\text { I feel I can give my writing a creative } \\
\text { spark and still sound professional. }\end{array}$ & 11 & 55.87 & 25.58 & $52.72-59.03$ & 64.52 & 27.50 & $62.20-66.83$ & 63.63 & 28.89 & 60.13-67.13 \\
\hline $\begin{array}{l}\text { I feel I can develop my own writing } \\
\text { voice (ways of speaking in my writing } \\
\text { that are uniquely me). }\end{array}$ & 15 & 57.54 & 28.43 & 54.04-61.05 & 69.42 & 26.29 & $67.21-71.64$ & 68.20 & 27.76 & 64.84-71.57 \\
\hline $\begin{array}{l}\text { Even with very specific assignment } \\
\text { guidelines, I can find ways of writing } \\
\text { my assignment to make it original or } \\
\text { unique. }\end{array}$ & 16 & 53.57 & 25.92 & $50.37-56.77$ & 63.17 & 26.20 & 60.96-65.38 & 67.26 & 27.05 & 63.98-70.54 \\
\hline $\begin{array}{l}\text { I can comfortably express nursing } \\
\text { concepts, language, and values in my } \\
\text { writing assignments. } \\
\text { I can comfortably express the } \\
\text { concepts, language, and values of my } \\
\text { discipline or major in my writing } \\
\text { assignments (Modification for Study } \\
\text { 2) }\end{array}$ & 17 & 60.89 & 25.40 & $57.76-64.02$ & 73.10 & 23.60 & $71.11-75.09$ & 76.50 & 22.28 & 73.80-79.20 \\
\hline $\begin{array}{l}\text { Relational Reflective ( } \alpha \\
=.91, .88, .89)\end{array}$ & & 65.92 & 18.99 & 63.58-68.26 & 73.76 & 17.57 & $72.28-75.24$ & 74.91 & 17.84 & 72.74-77.07 \\
\hline
\end{tabular}




\begin{tabular}{|c|c|c|c|c|c|c|c|c|c|c|}
\hline $\begin{array}{l}\text { When I write, I can think about my } \\
\text { audience and write so they clearly } \\
\text { understand my meaning. }\end{array}$ & 7 & 65.76 & 23.71 & \begin{tabular}{|l|}
$62.84-68.69$ \\
\end{tabular} & 72.11 & 23.42 & $70.14-74.08$ & 72.75 & 23.49 & $69.91-75.60$ \\
\hline $\begin{array}{l}\text { When I receive feedback on my } \\
\text { writing, no matter how it makes me } \\
\text { feel, I can use that feedback to } \\
\text { improve my writing in the future. }\end{array}$ & 8 & 75.61 & 24.29 & 72.61-78.60 & 80.67 & 22.85 & $78.75-82.60$ & 82.50 & 19.04 & $80.19-84.81$ \\
\hline $\begin{array}{l}\text { When I read articles about my topic, } \\
\text { the connections I feel with the ideas } \\
\text { of other authors can inspire me to } \\
\text { express my own ideas in writing. }\end{array}$ & 12 & 60.41 & 25.56 & 57.27-63.56 & 70.64 & 25.75 & $68.46-72.81$ & 73.09 & 25.91 & 69.95-76.24 \\
\hline $\begin{array}{l}\text { When I look at the overall picture I've } \\
\text { presented in my writing, I can assess } \\
\text { how all the pieces tell the complete } \\
\text { story of my topic or argument. }\end{array}$ & 13 & 63.86 & 23.44 & $60.97-66.75$ & 72.34 & 22.76 & $70.42-74.26$ & 75.31 & 22.52 & $72.58-78.03$ \\
\hline $\begin{array}{l}\text { I can recognize when I've wandered } \\
\text { away from writing what my audience } \\
\text { needs to know and have begun writing } \\
\text { about interesting, but unrelated, ideas. }\end{array}$ & 18 & 61.70 & 25.10 & 58.61-64.80 & 69.30 & 25.24 & 67.17-71.43 & 67.65 & 26.33 & $64.46-70.84$ \\
\hline $\begin{array}{l}\text { With each new writing assignment, I } \\
\text { can adapt my writing to meet the } \\
\text { needs of that assignment. }\end{array}$ & 19 & 66.79 & 23.09 & 63.94-69.64 & 74.34 & 22.56 & $72.44-76.24$ & 74.70 & 23.39 & $71.87-77.53$ \\
\hline $\begin{array}{l}\text { When I seek feedback on my writing, } \\
\text { I can decide when that feedback } \\
\text { should be ignored or incorporated into } \\
\text { a revision in my writing. }\end{array}$ & 20 & 64.73 & 25.83 & 61.55-67.92 & 73.29 & 24.80 & $71.20-75.38$ & 74.74 & 25.01 & 71.71-77.77 \\
\hline
\end{tabular}




\begin{tabular}{|c|c|c|c|c|c|c|c|c|c|c|}
\hline $\begin{array}{l}\text { I can successfully use scholarly } \\
\text { academic words and phrases when } \\
\text { writing in my courses. } \\
\text { (courses/program for grad student } \\
\text { survey) }\end{array}$ & 3 & 66.62 & 24.93 & 63.54-69.70 & 76.95 & 22.79 & $75.03-78.87$ & 83.18 & 20.26 & $80.72-85.63$ \\
\hline $\begin{array}{l}\text { I can combine or synthesize multiple } \\
\text { sources I've read to create an original } \\
\text { product or text. }\end{array}$ & 5 & 67.62 & 23.54 & 64.71-70.52 & 78.41 & 21.46 & $76.60-80.22$ & 83.81 & 18.83 & 81.53-86.09 \\
\hline \multicolumn{11}{|l|}{ Items removed from Scale in EFA } \\
\hline $\begin{array}{l}\text { If I get stuck, I can contact a teacher } \\
\text { or tutor to help me move forward with } \\
\text { my writing ideas }\end{array}$ & 2 & 66.51 & 28.89 & $62.95-70.07$ & & & & & & \\
\hline $\begin{array}{l}\text { I can write a major writing assignment } \\
\text { without letting my emotions prevent } \\
\text { me from making progress. }\end{array}$ & 4 & 61.92 & 26.62 & $58.64-65.20$ & & & & & & \\
\hline $\begin{array}{l}\text { I can write without worrying about } \\
\text { my ability to correctly apply the rules } \\
\text { of the required style guideline (e.g. } \\
\text { APA format). }\end{array}$ & 14 & 53.61 & 30.40 & 49.86-57.36 & & & & & & \\
\hline
\end{tabular}




\section{Concurrent Validity}

The SESAW scale, previously used in a nursing population and the WSEI instrument, a historical measure of writing self-efficacy which focused on surface level writing abilities were completed in the survey by all participants as the same time as the SAWSES scale and used to test concurrent validity. Both instruments were developed under different theoretical premises, but it was hypothesized that the SESAW would be more strongly correlated to the new instrument than the WSEI. The SESAW validity co-efficient was adequate $r=.59$ and the WSEI was $r=.50$ indicating some conceptual differences between these established scales and the SAWSES. Descriptive data for the SESAW, WSEI and measures of writing apprehension, nursing identity and three writing context items are presented in Table 4.

Table 4: Mean, Standard Deviation of Supporting Scales $(N=228)$

\begin{tabular}{|l|l|l|l|}
\hline Scales & $\begin{array}{l}\text { Possible } \\
\text { range in } \\
\text { scores }\end{array}$ & Mean & SD \\
\hline Writing Self-Efficacy Instrument (WSEI) ( $\alpha=.93)$ & $0-800$ & 616.2 & 154.4 \\
\hline $\begin{array}{l}\text { Self-Efficacy Scale for Academic Writing (SESAW) } \\
(\boldsymbol{\alpha}=\mathbf{8 5})\end{array}$ & $9-36$ & 26.54 & 3.78 \\
\hline Writing Apprehension Test (WAT) $(\boldsymbol{\alpha}=.92)$ & $20-100$ & 60.63 & 12.91 \\
\hline Professional Identity Questionnaire (PIQ) $(\boldsymbol{\alpha}=\mathbf{. 8 3})$ & $8-40$ & 33.55 & 4.09 \\
\hline $\begin{array}{l}\text { This class and/or my institution can support me in the } \\
\text { way I need to be successful with writing this essay } \\
\text { assignment (Context perceived support item) }\end{array}$ & $0-100$ & 65.81 & 23.93 \\
\hline $\begin{array}{l}\text { It is important for my future that I get the grade I need } \\
\text { on this writing assignment so I do well in this course. } \\
\text { (Context perceived stakes item) }\end{array}$ & $0-100$ & 82.30 & 19.88 \\
\hline $\begin{array}{l}\text { I feel that the writing assignment in this class will be } \\
\text { important for my learning in the nursing program. } \\
\text { (Context perceived value item) }\end{array}$ & $0-100$ & 63.76 & 28.63 \\
\hline
\end{tabular}




\section{Structural Equation Modelling}

A structural equation model (SEM) was hypothesized for Study 1 which proposed that measures of nursing identity, writing apprehension, and assessments of writing context would predict the SAWSES. The variable of writing apprehension was chosen because of its known high correlation with writing self-efficacy in previous studies (Goodman \& Cirka, 2009; Pajares \& Johnson, 1994; Sanders-Reio et al., 2014; Vanhille et al., 2017). The nursing identity and context items were chosen or developed due to hypothesized relationships within the theoretical framework but, to our knowledge, no previous studies have used similar variables to predict writing self-efficacy.

Examining the histograms on the SAWSES items showed visible negative skews to the data, using Lavaan, the estimator chosen for the procedure was maximum likelihood robust (MLR) to account for lack of normality (Rosseel, 2017). The original hypothesized model was first tested and decisions for additional models were made based on the parameters observed in the base SEM. Three models will be reported here (see Table 5 for goodness of fit statistics).

Table 5: Model Goodness of fit for three SEM models with MLR estimator $N=228$

\begin{tabular}{|c|c|c|c|c|c|c|c|}
\hline Model & Model Details & $\mathrm{X}^{2}$ & df & $\begin{array}{c}p \text { - } \\
\text { value }\end{array}$ & CFI & TLI & $\begin{array}{l}\text { RMSEA } \\
(90 \% \mathrm{CI})\end{array}$ \\
\hline 1 & $\begin{array}{l}\text { Hypothesized model with } \\
\text { apprehension, nursing } \\
\text { identity, and the context } \\
\text { items (support, stakes, } \\
\text { value) inputted as } \\
\text { composite predictors of the } \\
\text { higher order SAWSES } \\
\text { latent variable. (Figure 2) }\end{array}$ & 318.74 & 200 & $<.001$ & .93 & .92 & $.066(.054-.078)$ \\
\hline 2 & $\begin{array}{l}\text { Hypothesized model with } \\
\text { modification indices } \\
\text { considered from Model } 1 \\
\text { (Figure 3) } \\
\text { Modification covariance: }\end{array}$ & 269.79 & 200 & $<.001$ & .96 & .95 & $.056(.042-.068)$ \\
\hline
\end{tabular}




\begin{tabular}{|l|l|l|l|l|l|l|l|}
\hline & $\begin{array}{l}\text { Items 5 and 6, 3 and 17, 8 } \\
\text { and 20, 6 and 11 }\end{array}$ & & & & & & \\
\hline 3 & $\begin{array}{l}\text { Only the two strongest } \\
\text { predictors (Writing } \\
\text { apprehension and context- } \\
\text { support) and modification } \\
\text { indices considered. (Figure } \\
\text { 4) }\end{array}$ & 189.45 & 152 & $<.001$ & .97 & .96 & $.052(.036-.067)$ \\
\hline
\end{tabular}

Model 1 was developed with three latent variables based on the factors established in the EFA procedures (see Figure 2). A higher order latent variable, SAWSES, was created from the three factor latent variables. Apprehension, identity, and three context items (perceived support, stakes, and value) were together added as composite variables predicting the higher order latent variable. This model had adequate fit but examining the modification indices $>10$ provided theoretically logical options for adding error covariance between items 5 and 6 (two items developed as creativity items in the theoretical premise), 3 and 17 (two items referring to use of words and language), 8 and 20 (two feedback items), 6 and 11 (two creativity items). These same covariances emerged as suggested modifications in all tested models thus were coded into the analysis for model 2 and 3. 
Figure 2: Hypothesized Structural Equation Model 1 in Nursing Student Sample

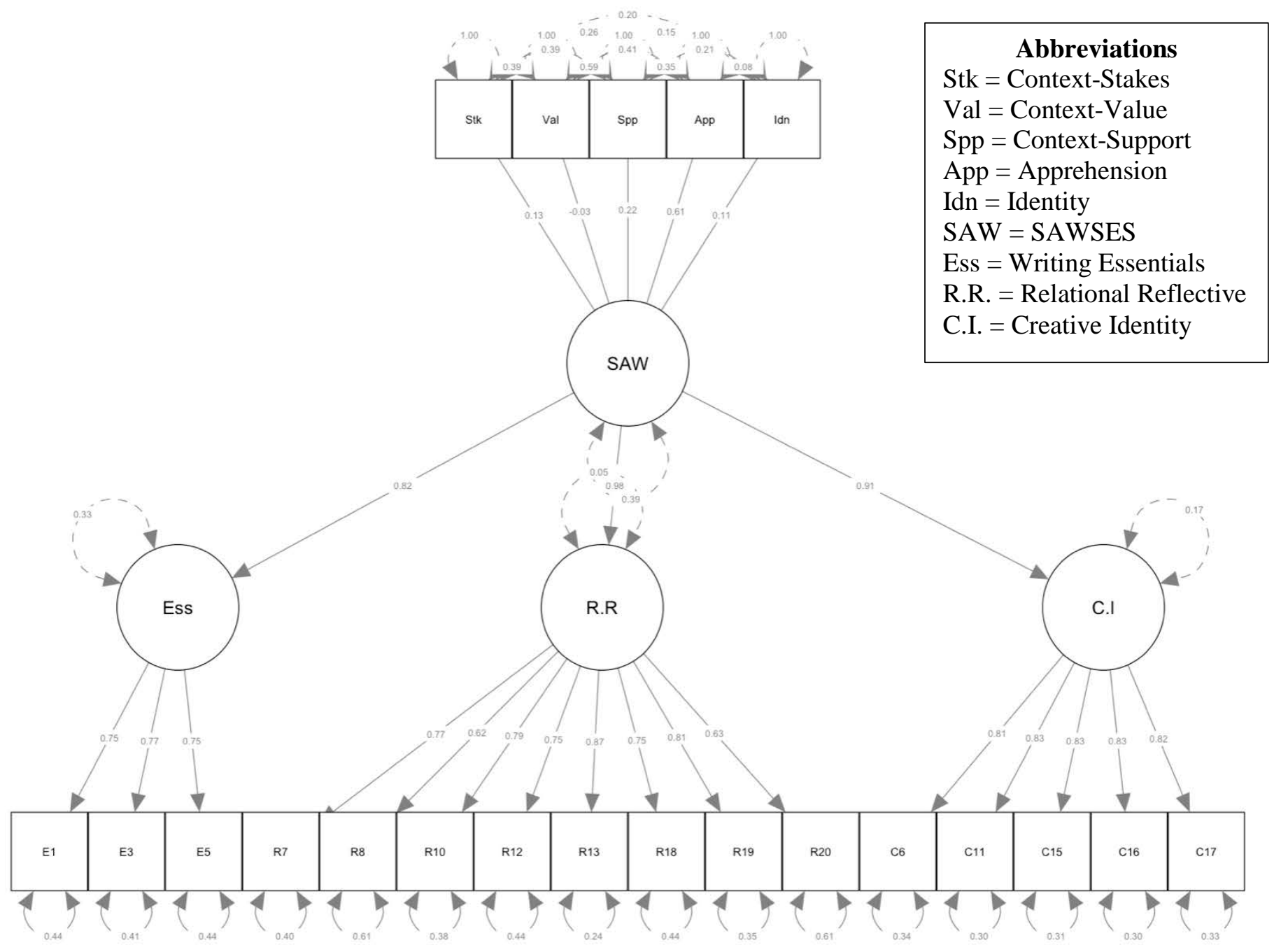


Figure 3: Hypothesized Model 2 with Modification Indices Considered in Nursing Student Sample

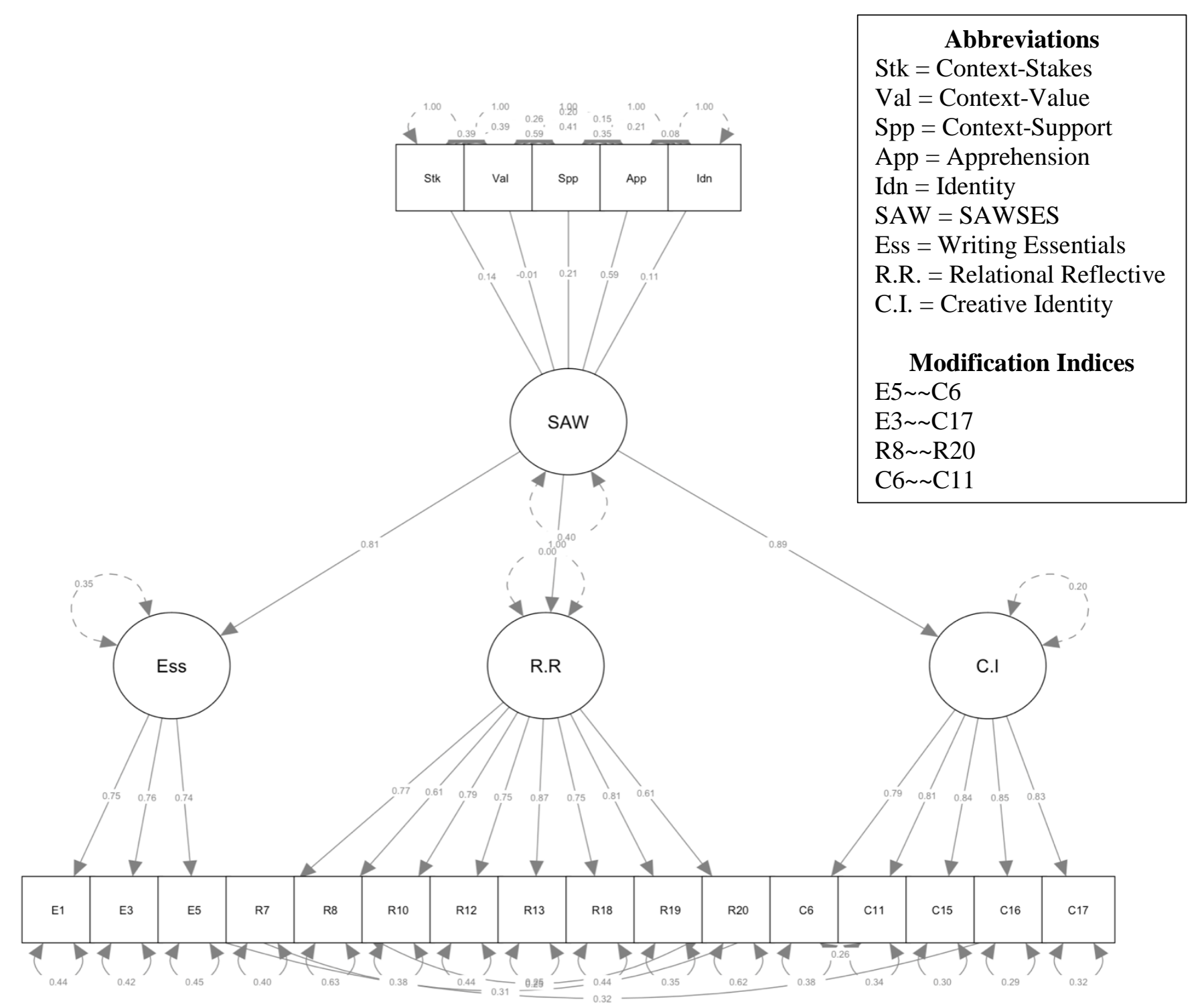


Figure 4: Best Fit Model 3 Apprehension and Context-Support as Predictors and Modification Indices Considered in Nursing Student Sample

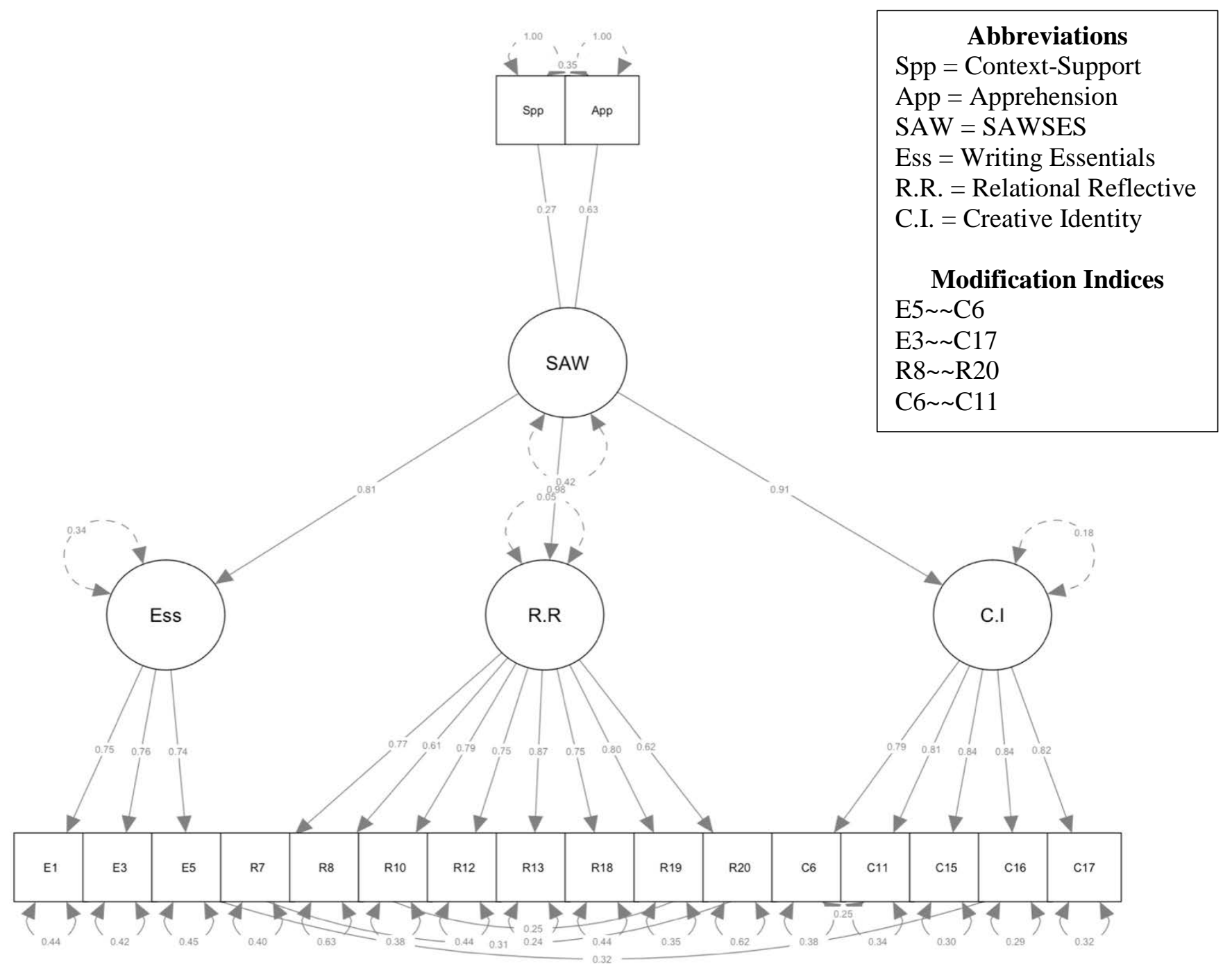


The context-value variable $(\beta=-0.013$, z-value $=-0.21 ; p=.83)$ was non-significant in the composite analysis and was an insignificant contributor to model 2 (Figure 3). Nursing identity $(\beta=0.12 ; z$-value $=2.28 ; p=.02)$ and context-stakes $(\beta=0.14 ; z$-value $=2.74 ; p=.01)$ were significant, however were weak contributors to the predicting SAWSES. Model 3 (Figure 4) thus removed context-value, context-stakes, and nursing identity. In model 3 apprehension was the strongest predictor of SAWSES $(\beta=.625$; z-value $=9.63 ; p<.001)$ with context-support making small contribution $(\beta=.271$; z-value $=4.64 ; p<.001)$. The parameter estimates and factor loadings for the latent variables for model 3 are presented in Table 6 . The table show that the z scores for each item on its latent variable were statistically significant. Unstandardized (B) factor loadings act like a regression coefficient and reflect the linear change in response of the item to a unit change in the predictor; thus for each 1 standard deviation increase in the latent variable Writing Essentials we can expect a 9.59 unit increase in the score for item 1. For comparison, standardized factor loadings are presented in the Beta column and are a representation of loading of each item on its associated latent variable with a higher Beta meaning a stronger relationship between the item and its latent variable. 
Table 6: Parameter Estimates and Factor Loadings for Model 3

\begin{tabular}{|l|l|l|l|l|l|l|}
\hline Latent Factor & Indicator (Item) & B & SE & Z & p-value & Beta \\
\hline Writing Essentials & 1 & 9.59 & 1.14 & 8.39 & $<.001$ & .75 \\
\hline & 3 & 10.73 & 1.36 & 7.89 & $<.001$ & .76 \\
\hline & 5 & 10.20 & 1.21 & 8.45 & $<.001$ & .74 \\
\hline Relational Reflective & 7 & 3.88 & 1.75 & 2.21 & .03 & .77 \\
\hline & 8 & 3.14 & 1.48 & 2.12 & .03 & .61 \\
\hline & 10 & 3.95 & 1.83 & 2.16 & .03 & .79 \\
\hline & 12 & 4.10 & 1.89 & 2.16 & .03 & .75 \\
\hline & 13 & 4.37 & 2.03 & 2.15 & .03 & .87 \\
\hline & 18 & 4.04 & 1.90 & 2.13 & .03 & .75 \\
\hline & 19 & 3.96 & 1.78 & 2.22 & .03 & .80 \\
\hline & 20 & 3.35 & 1.59 & 2.11 & .04 & .62 \\
\hline Creative Identity & 6 & 8.48 & 1.70 & 4.98 & $<.001$ & .79 \\
\hline & 11 & 8.65 & 1.76 & 4.91 & $<.001$ & .81 \\
\hline & 15 & 10.01 & 2.09 & 4.79 & $<.001$ & .84 \\
\hline & 16 & 9.11 & 2.00 & 4.57 & $<.001$ & .84 \\
\hline & 17 & 8.80 & 1.80 & 4.90 & $<.001$ & .83 \\
\hline SAWSES & Writing Essentials & 0.91 & 0.13 & 6.87 & $<.001$ & .81 \\
\hline & Relational Reflective & 2.95 & 1.47 & 2.01 & .04 & .98 \\
\hline & Creative Identity & 1.40 & 0.31 & 4.48 & $<.001$ & .91 \\
\hline
\end{tabular}

\section{Discussion}

The SAWSES tool tested in a single discipline (nursing) demonstrated some interesting properties which support its initial reliability and validity. First, it captures unique aspects of the writing context which differentiates it from other tools as demonstrated by the moderate correlations with previously validated writing self-efficacy tools (SESAW, $r=.59$; WSEI $r$ $=.50)$. Second, initial reliability demonstrates high Cronbach's alpha scores for all subscales indicating the sale has excellent internal consistency. Parallel form analysis showed the scale holds similar properties when completed by paper and pencil which may be beneficial for researchers who are unable to deliver the questionnaire electronically. Exploratory factor analysis demonstrated three practical and relevant subscales, 1) Writing Essentials, 2) Relational 
and Reflective Writing, 3) Creative Identity, potentially useful for diagnosing areas of low selfefficacy theoretically important to assessing writing contexts in the classroom. Three structural equation models demonstrated that writing apprehension has a strong association with the SAWSES scale, a relationship previously established in several other writing self-efficacy studies (Goodman \& Cirka, 2009; Huerta et al., 2017; Pajares \& Johnson, 1994; Sanders Reio et al., 2014) and supports construct validity of SAWSES. Nursing identity and items assessing the relationship between student assessments of their present writing context were contributors in the initial hypothesized model (Model 1 and 2) however only the context-support item made a meaningful contribution to the final model (Model 3). The identity tool was likely too practiceoriented to assess nursing knowledge identity, however, that it produced a small effect on writing self-efficacy is promising initial evidence of the proposed theoretical relationship. Perceptions of feeling supported in the writing environment as an important contributor to self-efficacy were also confirmed in statements made by students during the cognitive interviews where need to understand the teacher and their expectation was an important factor in student self-beliefs in their writing ability (Mitchell et al., 2020b). These exploratory findings warrant further investigation.

Given these successes, it was necessary to confirm if the factor structure was still relevant in a broader population of interdisciplinary undergraduate and graduate students who may have different writing contexts and additional concerns about writing not captured in the nursing population.

\section{Study 2: Multigroup Confirmatory Factor Analysis}

The goal of Study 2 was to perform multigroup confirmatory factor analysis on SAWSES in an independent sample of interdisciplinary undergraduate and graduate students. 
Undergraduate and graduate students write for different purposes and face different writing expectations within their disciplinary contexts which may impact the structure and functioning of the items on the SAWSES scale and enlighten researchers to possible discipline specific features of the tool.

\section{Participants}

The characteristics of participants in Study 2 are also presented in Table 1 for easy comparison of population differences from the original nursing student population.

Undergraduate and graduate students were recruited via two routes: social media recruitment through Twitter to gain an international sample of mostly graduate students $(13.2 \%$ of the sample), and from the same three institutions where nursing students had been sampled in Study 1 (86.8\% of the sample). A fourth institution without a nursing program was also intended for sampling, but data collection was abandoned by mutual agreement in March 2020 when COVID19 pandemic protocols were instituted placing additional demands on institutions and students. Sample sizes from the survey included 543 undergraduate and 264 graduate student surveys for a total sample of 807 . The interdisciplinary population had a higher proportion of male respondents. The mean age of the graduate students was 8 years older than the undergraduates from both the nursing and interdisciplinary groups. Both the undergraduate and graduate interdisciplinary populations had a higher proportion of students who reported that they “generally liked writing” and a much smaller proportion who "generally disliked writing," compared to the undergraduate nursing-only sample. Over 40 specialties or research focuses were identified in each of the undergraduate and graduate groups and the most common specialties are reported in Table 1. 


\section{Procedures}

The survey was created in Qualtrics and contained the 16 items retained in the EFA, one open-ended text box to allow participants to comment on any of the items and help the research team identify factors affecting interpretability of scoring of the item, and a demographic survey. The social media posts were sent from the first author's personal academic Twitter account with over 10,000 followers during the month of December 2019. An ethically approved amendment for new procedures was obtained from all the local institutions and registered students were sent an email with the survey link via a third party within each institution. Both the email and social media posts introduced the study with a graphic asking students the question, "What defines you as a student writer?” A) I like writing. B) I hate writing. C) It depends. The phrasing was chosen to signal the students who disliked writing, a population of students presumed to feel less enthusiastic about participating, that their opinions about writing were valid and were important as respondents to the survey.

Missing data on SAWSES was $<1 \%$. If more than two item responses were missing from SAWSES, the sample size was deemed large enough to eliminate the participant from the study. In addition, because the survey was publicly available on social media, for quality control, survey respondents were deleted if they did not disclose their institution of study. Participants who indicated they had graduated were also removed from analysis.

\section{Data Analysis}

The Statistical Package for the Social Sciences (SPSS v.24) was used for the descriptive analysis and the multigroup confirmatory factor analysis (MGCFA) was conducted in RStudio (v. 1.2.5033) primarily using the Lavaan package (Rosseel, 2017) and the equaltestMI package (Jiang et al., 2017). The processes for analysis, interpretation, and reporting were drawn from 
recommendations from Beaujean (2014), Putnick and Bornstein (2016), Fischer and Karl (2019) and Cheung and Rensvold (2002). Data and R code files are publicly available (Mitchell 2020a; 2020d)

\section{Results}

The MGCFA analysis used processes of invariance testing to explore differences between groups using several steps: 1) testing the fit of the model on the entire sample; 2) testing the fit of the model in undergraduate and graduate students separately; 3) testing four measurement invariance steps (See Table 7). The factor structure that emerged during the exploratory factor analysis stage in Study 1 was the model explored for the full sample ( $\mathrm{N}=807)$ CFA. This model demonstrated reasonable fit with CFI of .942 and RMSEA = .074 (90\% CI .066-.082). Many modification indices could have been taken into consideration in order to improve the model but since fit was adequate, the focus turned to identifying how the two groups differed from each other on responses to the individual items. Exploring the fit of the model in undergraduate $(\mathrm{n}=$ 543) and graduate $(n=246)$ students independently demonstrated poorer fit in graduate students, however, exploring differences in recommended modification indices identified no outstanding differences or theoretically relevant anomalies between the groups. A hierarchy of stacked constraints was then placed on the two model groups simultaneously to establish if the groups differed in any meaningful way in their response to the individual items. While a non-significant chi square difference test is most valued in model testing, this parameter is highly sensitive to sample size and was therefore not able to be achieved in this study (Beaujean, 2014). Change in CFI scores from step to step was monitored for a drop in index > .01 (Cheung \& Rosenvald, 2002). Additionally, recommendations that RMSEA changes no more than .015 and SRMR changes no more than .015-.03 have also been suggested as ideal (Putnick \& Bornstein, 2016). 
Constraints were added in the following order: configural invariance explores how the groups differ in factor structure (configural model), metric invariance forces equivalent factor loadings on both groups (metric model), scalar invariance forces equivalent item intercepts (scalar model), and strict residual models forces equivalent item residuals and error variances (strict model). CFI scores did not drop in excess of .01 indicating that the differences in item responses between undergraduate and graduate students were not statistically meaningful.

Table 7: Multigroup CFA Tests of Goodness of Fit and Measurement Invariance on SAWSES

\begin{tabular}{|l|c|c|l|l|l|l|l|l|}
\hline Model & $\mathbf{X}^{\mathbf{2}}$ & $\mathbf{d f}$ & $\mathbf{R M S E A ~ ( 9 0 \% C I )}$ & $\mathbf{C F I}$ & $\mathbf{S R M R}$ & $\Delta$ RMSEA & $\Delta$ CFI & $\Delta$ SRMR \\
\hline Overall Model & 376.97 & 101 & $0.074(.066-.082)$ & 0.942 & 0.043 & -- & -- & -- \\
\hline $\begin{array}{l}\text { Undergraduate } \\
\text { Model }\end{array}$ & 261.72 & 101 & $0.068(.058-.078)$ & 0.947 & 0.041 & -- & -- & -- \\
\hline Graduate Model & 257.39 & 101 & $0.093(.079-.107)$ & 0.919 & 0.057 & -- & -- & -- \\
\hline $\begin{array}{l}\text { Configural } \\
\text { Invariance }\end{array}$ & 519.30 & 202 & $0.077(.069-.085)$ & 0.937 & 0.046 & -- & -- & -- \\
\hline Metric Invariance & 547.56 & 215 & $0.076(.068-.084)$ & 0.935 & 0.055 & .001 & .002 & -.009 \\
\hline Scalar Invariance & 594.49 & 228 & $0.076(.069-.084)$ & 0.930 & 0.057 & 0 & .005 & -.002 \\
\hline Strict Invariance & 628.47 & 244 & $0.076(.069-.083)$ & 0.926 & 0.058 & 0 & .004 & -.001 \\
\hline
\end{tabular}

\section{Discussion}

The results of the MGCFA on an independent large sample of interdisciplinary undergraduate and graduate students provides preliminary evidence that the factor structure of the Situated Academic Writing Self-Efficacy Scale is applicable to a more heterogeneous student population of varying levels of experience in writing. These findings provide initial evidence that generalizability of the scale to wider post-secondary writing contexts may be possible. However, the slightly poorer model fit in graduate students when considered independently without invariance constraints, does suggest that additional testing of the instrument in more homogeneous disciplinary graduate student samples may provide additional understanding about the factor structure of the scale. 


\section{Exploring Differences Between Study 1 and Study 2 Samples}

Additional tests exploring patterns of responses between the nursing and interdisciplinary undergraduate and graduate students to assess patterns in known groups were undertaken. These included using one-way analysis of variance on the demographic categories of student type, writing attitude and an exploration of item difficulty and discrimination patterns between samples. Large group size differences precluded a valid assessment of SAWSES differences between English language speaking groups.

Overall the sample means identified that undergraduate nursing student group selfassessed lower means on all scales and subscales (see Table 3 for means and standard deviations). A one-way analysis of variance (ANOVA) identified statistically significant differences in reported means scores between student types with F scores as follows: Total SAWSES $F(2,1061)=29.93, p<.001$; Writing Essentials $F(2,1061)=36.30, p<.001$; Relational Reflective $F(2,1061)=20.55, p<.001$; Creative Identity $F(2,1061)=27.15, p$ $<$.001. Post hoc Tukey HSD showed that the statistical significance was present between the nursing and interdisciplinary undergraduate students (Total SAWSES $p<.001$; Writing Essentials $p<.001$; Relational Reflective $p<.001$; Creative Identity $p<.001$ ), and the nursing and graduate student group (Total SAWSES $p<.001$; Writing Essentials $p<.001$; Relational Reflective $p<.001$; Creative Identity $p<.001$ ). Between the interdisciplinary undergraduate group and graduate students, statistical significance was only observed on the Writing Essentials subscale $(p=.021)$.

\section{Writing Attitude}

Demographic differences in student writing attitudes (whether they liked, disliked, or felt somewhere in between about writing) were evident with nurses reporting higher rates of 
disliking writing and interdisciplinary students reporting lower rates of disliking writing. These relationships were tested using a chi-square test for independence which found a significant difference between student type and attitude toward writing, $X^{2}(4,1062)=104.9, p<.001$ with a medium effect size Cramer's $\mathrm{V}=.222(p<.001)$. Isolating the two most comparable groups (nursing undergraduates and interdisciplinary undergraduates) the chi-square test of independence identified significance $X^{2}(2,798)=77.8, p<.001$ with a medium effect size Cramer's $\mathrm{V}=.312(p<.001)$. These differences in groups prompted the exploration of patterns of means in responses to SAWSES by subscale. The expectation was that students who disliked writing would report lower mean scores than the other two groups. SPSS was used to conduct a one-way analysis of variance (ANOVA) and confirmed that differences indeed emerged between attitude groups in all samples and on post hoc analysis were all highly significant between attitude by subscale $(\mathrm{p}<.001)$ (see Table 8$)$.

Table 8: Mean, Standard Deviation, and One-Way ANOVA Results for Self-Reported Writing Attitude and SAWSES in all Student Samples

\begin{tabular}{|c|l|l|l|l|}
\hline & Likes Writing & $\begin{array}{l}\text { Somewhere In } \\
\text { Between }\end{array}$ & $\begin{array}{l}\text { Dislikes } \\
\text { Writing }\end{array}$ & $\begin{array}{l}\mathrm{F}^{*} \\
\text { (df=2) }\end{array}$ \\
\hline $\begin{array}{c}\text { Nursing (N = 255) } \\
\text { Total Scale }\end{array}$ & $\mathrm{n}=44$ & $\mathrm{n}=108$ & $\mathrm{n}=103$ & \\
Writing Essentials & $89.92(15.2)$ & $65.47(16.4)$ & $54.39(16.5)$ & 39.53 \\
Relational Reflective & $80.95(14.4)$ & $69.29(17.7)$ & $59.60(18.9)$ & 31.63 \\
Creative Identity & $75.25(20.5)$ & $59.95(20.8)$ & $45.73(19.2)$ & 35.49 \\
& & & & \\
\hline Interdisciplinary Undergraduate & & & & \\
(N = 543) & $\mathrm{n}=237$ & $\mathrm{n}=219$ & $\mathrm{n}=87$ & \\
Total Scale & $81.52(13.5)$ & $69.72(15.0)$ & $56.10(16.9)$ & 102.55 \\
Writing Essentials & $84.98(15.2)$ & $75.16(16.8)$ & $63.62(20.5)$ & 55.32 \\
Relational Reflective & $81.73(13.8)$ & $71.03(16.0)$ & $58.92(18.8)$ & 73.64 \\
Creative Identity & $79.10(16.4)$ & $64.35(18.8)$ & $47.10(18.7)$ & 110.65 \\
\hline Total Scale & $\mathrm{n}=124$ & $\mathrm{n}=111$ & $\mathrm{n}=29$ & \\
Writing Essentials & $81.24(14.4)$ & $70.82(16.0)$ & $57.67(22.5)$ & 29.54 \\
Relational Reflective & $87.28(14.1)$ & $78.44(15.3)$ & $66.62(23.8)$ & 22.90 \\
Creative Identity & $80.53(14.9)$ & $72.55(16.8)$ & $59.90(22.6)$ & 33.61 \\
\hline Graduate (N = 264) & $78.74(17.6)$ & $63.48(21.3)$ & $48.73(24.9)$ & 19.89 \\
\hline
\end{tabular}


For comparison purposes, each item scored 0-100; Scale and subscale means calculated as total score/\#items on scale

*All $\mathrm{F}$ values $p<.001$

\section{Exploring Item Difficulty and Discrimination}

Exploring trends in mean scores on the three identified subscales (refer to Table 3)

demonstrated patterns in means where all groups reported their highest scores in the Writing

Essentials subscale and their lowest scores in the Creative Identity subscale. This pattern

suggested that there may be varying degrees of difficulty and discriminant ability among the

items between the three subscales and in the different populations. The SjPlot package in Rstudio

(Lüedecke, 2020) was used to assess item difficulty and item discrimination for each item. Item

difficulty scores typically fall between .20 and .80 and higher scores indicate an easier item.

Discrimination refers to an item's ability to discriminate between individuals where those who

score high on an item are also more likely to obtain a higher score for the scale. Discrimination

scores can range between .20 and 1.00 and higher scores are an indication of an item that is more

discriminating. An average was recorded for each subscale to explore possible degrees of

difficulty between subscales (see Table 9).

Table 9: Item Difficulty and Discrimination for all student groups

\begin{tabular}{|c|c|c|c|c|c|c|}
\hline & \multicolumn{3}{|c|}{ Item Difficulty } & \multicolumn{3}{|c|}{ Item Discrimination } \\
\hline Writing Essentials & $\mathrm{N}$ & UG & $\mathrm{G}$ & $\mathrm{N}$ & $\mathrm{U}$ & $\mathrm{G}$ \\
\hline $\begin{array}{l}\text { Even when the writing is hard, I can find ways to overcome my } \\
\text { writing difficulties. }\end{array}$ & .70 & .77 & .77 & .64 & .63 & .61 \\
\hline $\begin{array}{l}\text { I can successfully use scholarly academic words and phrases } \\
\text { when writing in my courses. (courses/program for grad student } \\
\text { survey) }\end{array}$ & .67 & .77 & .83 & .66 & .64 & .69 \\
\hline $\begin{array}{l}\text { I can combine or synthesize multiple sources I've read to create } \\
\text { an original product or text. }\end{array}$ & .67 & .78 & .84 & .62 & .69 & .66 \\
\hline Subscale Average & .68 & .77 & .81 & .64 & .65 & .65 \\
\hline Relational Reflective Writing & & & & & & \\
\hline $\begin{array}{l}\text { When I write, I can think about my audience and write so they } \\
\text { clearly understand my meaning. }\end{array}$ & .65 & .72 & .73 & .71 & .70 & .74 \\
\hline
\end{tabular}




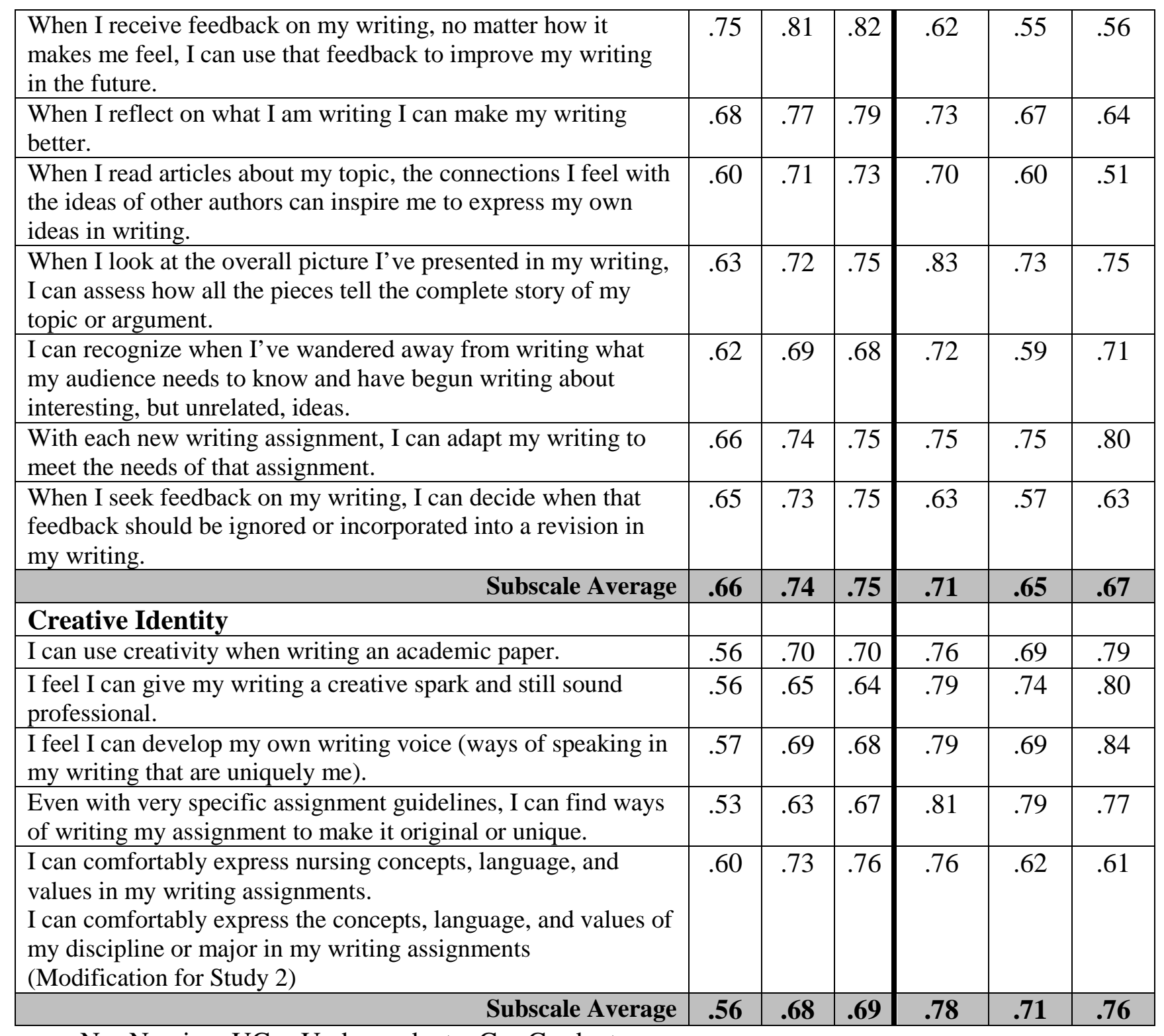

$\mathrm{N}=$ Nursing, $\mathrm{UG}=$ Undergraduate, $\mathrm{G}=$ Graduate

In most cases, the Writing Essentials category contains the easiest items. This subscale is also the least discriminating. The Creative Identity subscale contains the most difficult and most discriminating items. Relational Reflective items contain a mix of item difficulties and discriminations. Scores on this subscale trended toward falling between Writing Essentials and Creative Identity but in some groups (difficulty for nurses and discrimination for undergraduate and graduate interdisciplinary students) had similar scores to Writing Essentials. 


\section{Discussion}

This project represents a large sample size instrument development study on three independent samples only limited by convenience sample recruitment. The Situated Academic Writing Self-Efficacy Scale was designed to detect situated (or contextual) influences on students' self-beliefs about their writing. The findings of this validation study point to numerous applications where the questionnaire may be useful in practice and research. Overall SAWSES has demonstrated that it has strong reliability in nursing and interdisciplinary post-secondary students. Construct validity in its relationship to writing apprehension, previously established measures of writing self-efficacy, and perception of contextual writing support in nursing students is also evident. The elimination of item 14 ("I can write without worrying about my ability to correctly apply the rules of the required style guideline (e.g. APA format).”) due to lack of loading with the other items, is also indicative that the SAWSES is targeting different cognitive appraisal systems than those required to appraise abilities to attend to more mechanical surface aspects of writing such as grammar or style guide implementation.

The SAWSES scale also is able to detect differences in writing self-efficacy in students who report liking, disliking, or feeling somewhere in between about writing in all samples. Interdisciplinary confirmation of the scale structure is promising evidence of expanded generalizability of the scale beyond the nursing student population where the scale was developed. As writing genres, expectations, and disciplinary influences are known to change from context to context and influence writing self-efficacy in the process (Mitchell \& McMillan, 2018; Sanders-Reio et al., 2014; Van de Poel \& Gasiorek, 2012), the instrument's structure and function would benefit from testing in more homogeneous populations of disciplinary students. In addition, as graduate students often face higher expectations in terms of reach of their work 
through publication, expectations that they create new knowledge, and communication with knowledge users and non-academics, they often write for a higher variety of audiences and in higher stakes contexts. The scale was initially developed for undergraduate student writing in nursing - a population that often feels they write primarily for their teacher to obtain a grade in a course (Mitchell et al. 2020b). This questionnaire may trigger graduate students to reflect on different aspects of writing that may not have been considered in the questionnaire development. The fit of the scale structure to a generalized population of graduate students was less adequate than it was for undergraduates which may indicate the scale may require some additional revisions to better capture the writing self-efficacies of graduate students.

The developmental patterns evident in item difficulty and discrimination scores between the subscales is also a pragmatic finding that may be useful to researchers and writing instructors. Different writing demands are made in every writing context (Slomp, 2012) meaning that scores on each subscale could fluctuate from context to context. The Writing Essentials subscale includes items that are base needs for being able to manage the academic writing environment at the post-secondary level. The Relational Reflective subscale includes actions that writers need to consider outside of the act of writing, including connecting with others, engaging with source materials, and being self-reflective about process. The Creative Identity subscale represents items where writing's transformative benefits are assessed - where mastery may only be seen in writers who have achieved the highest expertise in writing and disciplinary identity development. High scores on the Creative Identity factor may identify the most engaged writers. Low scores among students in any factor could help writing faculty target areas for intervention within disciplinary populations. 
Item difficulty and discrimination should also be viewed with the knowledge that students in previous writing self-efficacy studies have exhibited tendencies to overinflate scores when facing contexts that are unfamiliar (Jones, 2008; Meier et al., 1984; Miller et al., 2018; Mitchell, Harrigan \& McMillan, 2017; Raedts et al., 2007; Stewart et al., 2015; Zimmerman \& Kitsantas, 2002). A student can only appraise their own abilities with reflection upon past experience. The tendency to underestimate the writing knowledge required in a new context may be most pronounced as students move from discipline to discipline, switch between very different writing genres (e.g. academic writing to reflective writing or creative writing), or from one level of writing to another, such as when starting a graduate program. Students develop abilities to think more sophisticatedly about their writing and their use of disciplinary language as they progress through programs or begin targeting additional audiences - a context that is often the case for graduate students seeking publication of their work for the first time. Increased complexity in writing means new writing struggles can be revealed (Camp, 2012). This effect can be seen in how the results of this study demonstrate only minor differences between undergraduate and graduate interdisciplinary students. They were similar not just on patterns in the way they responded to the items as demonstrated in the MGCFA but also on means scores for the individual items, and item difficulty and discrimination. As new contexts for writing are introduced, new uncertainties about how to manage those contexts emerge. The instrument can be a conversation starter to help students understand how to navigate increasing complexities in writing and develop realistic self-appraisals of their writing as they move from undergraduate to graduate school.

One notable marker of contextual understanding of writing was how students perceived creativity in their writing environment. Some nursing student participants in the cognitive 
interviews felt they were not allowed to be creative. Comments about inability to use creativity in academic writing were also common in the open-ended box provided in the interdisciplinary survey in Study 2. Knowing what defines creativity and where it is appropriate within a discipline or within a specific writing genre requires engagement within a disciplinary community and self-identification within that community (Antoniou \& Moriarty, 2008; McVey, 2008; Mitchell, 2018). The Creative Identity subscale could be a useful tool for starting discussions with students about the definitions of creativity in academic writing in their discipline and stimulating reflections on writing voice.

The cognitive interviews conducted when piloting the instrument items with a nursing student population, provided evidence that the items triggered students to closely examine the conditions of writing in their discipline, and within the various experiences of individual classrooms when providing an explanation for how they scored items. Thus, the tool holds potential beyond its measurement capabilities as a reflective device for classroom instructors, writing centre tutors, graduate student advisors, and others who wish to understand the lived experience of writing of their students within their post-secondary context.

\section{Conclusion}

This validation study has demonstrated that the SAWSES instrument is a reliable and valid instrument for use in interdisciplinary post-secondary writing contexts and research studies. The tool has the potential to detect domains of contextual writing requiring intervention in areas such as basic writing tasks, navigating relational and reflective writing, or starting conversations about what creativity means to identity development within a discipline. SAWSES could serve as a reflective tool while working with individual students to identify beliefs about writing within post-secondary contexts or identify where students are underestimating the complexities of their writing context. 


\section{References}

Adams, K., Hean, S., Sturgis, P., \& Macleod Clark, J. (2006). Investigating the factors influencing professional identity of first-year health and social care students. Learning in Health and Social Care, 5(2), 55-68. https://doi.org/10.1111/j.1473-6861.2006.00119.x

Antoniou, M., \& Moriairty, J. (2008). What can academic writers learn from creative writers? Developing guidance and support for lecturers in higher education. Teaching in Higher Education, 13(2), 157-167. https://doi.org/10.1080/13562510801923229

Bandura, A. (1997). Self-efficacy: The exercise of control. W. H Freeman.

Bandura, A. (2006). Toward a psychology of human agency. Perspectives on Psychological Science, 1(2), 164-180. https://doi.org/10.1111/j.1745-6916.2006.00011.x

Barnette, J. J. (2000). Effects of stem and Likert response option reversals on survey internal consistency: If you feel the need, there is a better alternative to using those negatively worded items. Educational and Psychological Measurement, 60(3), 361-370. https://doi.org/10.1177/00131640021970592

Bartholomae, D. (1986). Inventing the university. Journal of Basic Writing, 5(1), 4-23.

Bawarshi, A. S. (2003). Genre and the invention of the writer: Reconsidering the place of invention in composition. Utah State University Press

Beaujean, A. A. (2014). Latent variable modeling using R: A step-by-step guide. Routledge. Camfield, E. (2016). Mediated-efficacy: Hope for helpless writers. Journal of Developmental Education, 39(3), 2-11. https://escholarship.org/uc/item/89f1r469

Camp, H. (2012). The psychology of writing development - And its implications for assessment. Assessing Writing, 17, 92-105. https://doi.org/10.1016/j.asw.2012.01.002 
Cheung, G. W., \& Rensvold, R. B. (2002). Evaluating goodness-of-fit indexes for testing measurement invariance. Structural Equation Modeling, 9(2), 233-255. https://doi.org/10.1207/S15328007SEM0902_5

Daly, J. A., Miller, M. D. (1975). The empirical development of an instrument to measure writing apprehension. Research in the Teaching of English, 9(3), 242-249. https://www.jstor.org/stable/40170632

Daly, J. A., Miller, M. D. (2013). Writing apprehension test (WAT). Measurement Instrument Database for the Social Science. http://www.midss.org/sites/default/files/writing_apprehension_test.pdf

Fischer, R., \& Karl, J. A. (2019). A primer to (cross-cultural) multi-group invariance testing possibilities in R. Frontiers in Psychology, 10, 1507. https://doi.org/10.3389/psyg.2019.01507

Flower, L., \& Hayes, J. R. (1981). A cognitive process theory of writing. College Composition and Communication, 32(4), 365-387. https://doi.org/10.2307/356600

Golombek, C., Klingsieck, K. B., Scharlau, I. (2019). Assessing self-efficacy for self-regulation of academic writing: Development and validation of a scale. European Journal of Psychological Assessment, 35(5), 751-761. https://doi.org/10.1027/1015-5759/a000452

Goodman, S. B., \& Cirka, C. C. (2009). Efficacy and anxiety: An examination of writing attitudes in a first-year seminar. Journal on Excellence in College Teaching, 20(3), 5-28.

Greeno, J. G. (2015). Commentary: Some prospects for connecting concepts and methods of individual cognition and situativity. Educational Psychologist, 50(3), 248-251. https://doi.org/10.1080/00461520.2015.1077708 
Huerta, M., Goodson, P., Beigi, M., \& Chlup, D. (2017). Graduate students as academic writers: Writing anxiety, self-efficacy and emotional intelligence. Higher Education Research \& Development, 36(4), 716-729. https://doi.org/10.1080/07294360.2016.1238881

Hyland, K. (2003). Genre-based pedagogies: A social response to process. Journal of Second Language Writing, 12(2003), 17-29. https://doi.org/10.1016/S1060-3743(02)00124-8

Jefferies, D., McNally, S., Roberts, K., Wallace, A., Stunden, A., D’Souza, S., \& Glew, P. (2018). The importance of academic literacy for undergraduate nursing students and its relationship to future professional clinical practice: A systematic review. Nurse Education Today, 60, 84-91. https://doi.org/10.1016/j.nedt.2017.09.020

Jiang, G., Mai, Y., \& Yuan, K-H. (2017). EqualtestMI: Examine measurement invariance via equivalence testing and projection method [R package version 0.1.0]. https://CRAN.Rproject.org/package=equaltestMI

Jones, E. (2008). Predicting performance in first-semester college basic writers: Revisiting the role of self-beliefs. Contemporary Educational Psychology, 33, 209-238. https://doi.org/10.1016/j.cedpsych.2006.11.001

Knafl, K., Deatrick, J., Gallo, A., Holcombe, G., Bakitas, M., Dixon, J., \& Grey, M. (2007). The analysis and interpretation of cognitive interviews for instrument development. Research in Nursing \& Health, 30, 224-234. https://doi.org/10.1002/nur.20195

Lea, M. R., \& Street, B. V. (1998). Student writing in higher education: An academic literacies approach. Studies in Higher Education, 23(2), 157-172. https://doi.org/10.1080/03075079812331380364 
Lock, T., \& Johnston, M. (2016). Developing an individual and collective self-efficacy scale for the teaching of writing in high schools. Assessing Writing, 28, 1-14.

\section{https://doi.org/10.1016/j.asw.2016.01.001}

Lüedecke, D. (2020). SjPlot: Data visualization for statistics in social science [R package version 2.8.3]. http://doi.org/10.5281/zenodo.1308157

McVey, D. (2008). Why all writing is creative writing. Innovations in Education and Teaching International, 45(3), 289-294. https://doi.org/10.1080/1470329082176204

Meier, S., McCarthy, P. R., \& Schmeck, R. R. (1984). Validity of self-efficacy as a predictor of writing performance. Cognitive Therapy and Research, 8(2), 107-120. https://doi.org/10.2307/357865

Miller, L. C., Russell, C. L., Cheng, A. L., \& Skarbek, A. J. (2015). Evaluating undergraduate nursing students' self-efficacy and competence in writing: Effects of a writing intensive intervention. Nurse Education in Practice, 15(3), 174-180.

https://doi.org/10.1016/j.nepr.2014.12.002

Miller, L. C., Russell, C. L., Cheng, A-L., \& Zembles, S. (2018). Testing the efficacy of a scaffolded writing intervention with online degree-completion nursing students: A quasiexperimental design. Nurse Education in Practice. https://doi.org/10.1016/j.nepr.2018.06.011

Mitchell, K. M. (2018). Constructing writing practices in nursing. Journal of Nursing Education, 57(7), 399-407. https://doi.org/10.3928/01484834-20180618-04

Mitchell, K. M. (2020a). Interdisciplinary undergraduate and graduate student data (Version V1) [Data set]. Harvard Dataverse. https://doi.org/10.7910/DVN/M07HQ7 
Mitchell, K. M. (2020b). Nursing student data (Version V2) [Data set]. Harvard Dataverse. https://doi.org/10.7910/DVN/MQ8EP0

Mitchell, K. M. (2020c). Replication data for: $R$ code for exploratory factor analysis SAWSES validation (Version V1) [Data set]. https://doi.org/10.7910/DVN/CHJKJM

Mitchell, K. M. (2020d). Replication data for: R code for multi-group CFA SAWSES validation (Version V1) [Data set]. https://doi.org/10.7910/DVN/UDXOGA,

Mitchell, K. M. (2020e). Replication data for: R code for structural equation model SAWSES validation (Version V1) [Data set]. https://doi.org/10.7910/DVN/ZKFYT6

Mitchell, K. M., Harrigan, T., \& McMillan, D. E. (2017). Writing self-efficacy in nursing students: The influence of a discipline-specific writing environment. Nursing Open, 1-11. https://doi.org/10.1002/nop2.90

Mitchell, K. M., Harrigan, T., Stefansson, T., \& Setlack, H. (2017). Exploring self-efficacy and anxiety in first-year nursing students enrolled in a discipline-specific scholarly writing course. Quality Advancement in Nursing Education, 3(1), 4. https://doi.org/10.17483/2368-6669.1084

Mitchell, K. M., \& McMillan, D. E. (2018). A curriculum-wide assessment of writing selfefficacy in a baccalaureate nursing program. Nurse Education Today, 70, 20-27. https://doi.org/10.1016/j.nedt.2018.08.003

Mitchell, K.M., McMillan, D.E., \& Lobchuk, M.M. (2019). Applying the “social turn” in writing scholarship to perspectives on writing self-efficacy. Journal of Learning Development in Higher Education,15(2019).

https://journal.aldinhe.ac.uk/index.php/jldhe/article/view/512/pdf 
Mitchell, K. M., McMillan, D. E., Lobchuk, M., \& Nickel, N. (2018). Psychometric Testing of a New Instrument to Measure Writing Self-Efficacy: A Proposed Mixed-Methods Delphi Study. International Nursing Research Congress - Sigma Theta Tau - Melbourne, Australia. https://sigma.nursingrepository.org/handle/10755/624591

Mitchell, K. M., McMillan, D. E., Lobchuk, M., \& Nickel, N. (2020a). Delphi Decision Making: Blending Qualitative and Quantitative Methods in Tool Development Research. Unpublished Manuscript in this thesis

Mitchell, K. M., McMillan, D. E., Lobchuk, M., \& Nickel, N. (2020b). "Follow the Rubric is the Thing in Nursing”: Navigating Systemic, Instructional, and Personal Influences on Writing Activities. Unpublished Manuscript in this thesis

Mitchell, K. M., Rieger, K. L., \& McMillan, D. E. (2017). A template analysis of writing selfefficacy measures. Journal of Nursing Measurement, 25(2), 205-223. https://doi.org/10.1891/1061-3749.25.2.205

Pajares, F., \& Johnson, M. J. (1994). Confidence and competence in writing: The role of selfefficacy, outcome expectancy, and apprehension. Research in the Teaching of English, 28(3), 313-331. http://www.jstor.org/stable/40171341

Pajares, F., \& Valiante, G. (2006). Self-efficacy beliefs and motivation in writing development. In C.A. MacArthur, S. Graham, \& J. Fitzgerald (Eds.), Handbook of writing research (pp. 158-170). Guilford Press.

Paré, A. (2014). Rhetorical genre theory and academic literacy. Journal of Academic Language and Learning, 8(1), A83-A94. 
Plakhotnik, M. S., \& Rocco, T. S. (2016). Increasing writing self-efficacy of adult learners:

Different approaches, different results. Adult Learning, 27(4), 160-167. https://doi.10.1177/1045159515611879

Putnick, D. L., \& Bornstein, M. H. (2016). Measurement invariance conventions and reporting: The state of the art and future directions for psychological research. Developmental Review, 41, 71-90, https://doi.org/10.1016/j.dr.2016.06.004

Raedts, M., Rijlaarsdam, G., van Waes, L., \& Daems, F. (2007). Observational learning through video-based models: Impact on students’ accuracy of self-efficacy beliefs, task knowledge and writing performances. In G. Rijlaarsdam (Series Ed.) and P. Boscolo \& S. Hidi (Volume Eds.), Studies in Writing: Vol, 19. Writing and Motivation (pp. 219-238). Elsevier.

Revelle, W. (2017, September 9). Package 'psych'. https://cran.rproject.org/web/packages/psych/psych.pdf

Rosseel, Y. (2017, December 18). The lavaan tutorial. http://lavaan.ugent.be/tutorial/tutorial.pdf

Russell, D. R. (1997). Rethinking genre in school and society: An activity theory analysis. Written Communication, 14(4), 504-554. https://doi.org/10.1177/0741088397014004004

Russell, D., Lea, M., Parker, J., Street, B., \& Donahue T. (2009). Exploring notions of genre in academic literacies and writing across the curriculum: Approaches across countries and contexts. In C. Bazerman et al. (Eds.), Genre in a changing world: Perspectives on writing (pp. 459-491). WAC Clearinghouse.

Ryan, M. M., Walker, M., Scaia, M., \& Smith, V. (2013). (un)Disciplining the nurse writer: Doctoral nursing students’ perspectives on writing capacity. Nursing Inquiry, 21(4), 294300. https://doi.org/10.1111/nin.12045 
Sanders-Reio, J., Alexander, P. A., Reio, T. G., \& Newmann, I. (2014). Do students’ beliefs about writing relate to their writing self-efficacy, apprehension, and performance? Learning and Instruction, 33, 1-11. https://doi.org/10.1016/j.learninstruc.2014.02.001

Schmidt, K. M., \& Alexander, J. E. (2012). The empirical development of an instrument to measure writerly self-efficacy in writing centers. Journal of Writing Assessment, 5(1), 62. http://www.journalofwritingassessment.org/article.php?article=62

Shell, D. F., Murphy, C. C., \& Bruning, R. H. (1989). Self-efficacy and outcome expectancy mechanisms in reading and writing achievement. Journal of Educational Psychology, 81(1), 91-100. https://doi.org/10.1037/0022-0663.81.1.91

Slomp, D.H. (2012). Challenges in assessing the development of writing ability: Theories, constructs and methods. Assessing Writing, 17(2012), 81-91.

\section{https://doi.org/10.1016/j.asw.2012.02.001}

Stewart, G., Seifert, T. A., \& Rolheiser, C. (2015). Anxiety and self-efficacy’s relationship with undergraduate students' perceptions of the use of metacognitive writing strategies. The Canadian Journal for the Scholarship of Teaching and Learning, 6(1), 4. https://doi.org/10.5206/cjsotl-rcacea.2015.1.4

Teng, L. S., Peigian, P. S., \& Xu, L. (2018). Conceptualizing writing self-efficacy in English as a foreign language contexts: Scale validation through structural equation modeling. TESOL Quarterly, 52(4), 911-942. https://doi.org/10.1002/tesq.432

Turner, J. C., \& Nolen, S. B. (2015). Introduction: The relevance of the situative perspective in educational psychology. Educational Psychologist, 50(3), 167-172. https://doi.org/10.1080/00461520.2015.1075404 
Van de Poel, K., \& Gasiorek, J. (2012). Effects of an efficacy-focused approach to academic writing on students' perceptions of themselves as writers. Journal of English for Academic Purposes, 11, 294-303. https://doi.org/10.1016/j.jeap.2012.07.003

Vanhille, J., Gregory, B., \& Corser, G. (2017). The effects of mood on writing apprehension, writing self-efficacy, and writing performance. Psi Chi Journal of Psychological Research, 22(3), 220-230. https://doi.org/10.24839/2325-7342JN22.3.220

Willis, G. B. (2005). Cognitive interviewing: A tool for improving questionnaire design. Sage. Worthington, M., Salamonson, Y., Weaver, R., \& Cleary, M. (2013). Predictive validity of the Macleod Clark professional identity scale for undergraduate nursing students. Nurse Education Today, 33, 187-191. https://doi.org/10.1016/j.nedt.2012.01.012

Yagelski, R. (2011). Writing as a way of being: Writing instruction, nonduality, and the crisis of sustainability. Hampton Press.

Zimmerman, B. J., \& Kitsantas, A. (2002). Acquiring writing revision and self-regulatory skill through observation and emulation. Journal of Educational Psychology, 94(4), 660-668. https://doi.org/10.1037//0022-0663.94.4.660 
My only advice is to stay aware, listen carefully, and yell for help if you need it.

Judy Blume 


\section{Epilogue - What's Next for Writing and Writing Self-Efficacy?}

"Writing is clearly a more multi-dimensioned process than current theory and practice would have us believe, and one that begins long before it is appropriate to commence working with strategies for invention. If we are going to teach our students to need to write, we will have to know much more than we do about the kinds of contexts that conduce - sometimes even force, certainly enable - the impulse to write. The "microtheory" of process now current in composition studies needs to be expanded into a "macro-theory" encompassing activities, processes, and kinds of knowing that come into play long before the impulse to write is even possible. To bring about that expansion, we need to press some new questions; and we need to know more than we now know, not only about cognitive processes during composing, but also about processes involved in coming to know generally” (Reither, 1985, p. 623)

I began this project with the intent to move measurement and assessment, if not theoretical understanding, of student writing self-efficacy into new epistemological realms in the nursing discipline. Discussions of the concept of writing self-efficacy needed to expand beyond textual examinations and beyond concrete writing tasks that individuals perform which may or may not have any relationship to the quality of the text produced. What defines a quality text, is a process negotiated within communities, and participants in those communities initiate new members, or new writers, to processes and textual features that are acceptable to them. Writing is situated.

Reither’s words, published 35 years ago, highlight the slow process of paradigm shifts of writing. His identified gap, present in the final sentence of the passage quoted above, has still not reached the point of general acceptance in academic contexts outside of composition studies. It is also work that has to be done, not by outsiders to a discipline, but must originate within the 
community membership. My goal with the studies completed for this thesis was to introduce nursing education to alternative views about writing, student perceptions of their writing, and writing pedagogies that would support creating writing contexts that would "enable the impulse to write” in nursing students. The purpose of this chapter is to provide an overview of the papers produced for this thesis and the contributions they make to advancing understanding about writing self-efficacy and the writing context in nursing education and academia as a whole. Pedagogical implications that arise from the understanding of writing self-efficacy as a socially constructed process as well as areas for future research will also be discussed.

\section{Summary and Key Contributions from Each Included Paper}

\section{Paper 1: Constructing Writing Practices in Nursing}

This paper was fundamental to the overall instrument development project. First, it mapped the evidence of how nursing as a discipline has fallen behind in their research and teaching of writing. Nursing continues to promote objectivist preferences for writing and perpetuates product (textual) focused writing assessments on mechanical and surface writing features. Composition studies, however, has moved on to situated and socially constructed approaches. Secondly, this paper describes how situated approaches to writing are a good fit for nursing as it helps better connect writing, critical thinking, and identity development to the nursing practice environment. The paper culminates with the description of a socially constructed model of writing outlining five domains of writing: identity, creativity, emotions, relational aspects, and context. The five domains are tightly intertwined through a writer's reflective processes. The main contribution of the paper is identification of the need for a paradigm shift in nurses' writing and the development of the model. The five domains of the model structured the item development of the Situated Academic Writing Self-Efficacy Scale the overall goal and outcome of this doctoral thesis. 


\section{Paper 2: Applying the 'Social Turn' in Writing Scholarship to Perspectives on Writing Self-Efficacy}

The goal of this paper was to understand if Bandura's self-efficacy theory and socially constructed perspectives on writing, were epistemologically compatible. Both the situated and the cognitive branches of these theories are descendants of Vygotskian psychology on the theoretical family tree, which allowed for a promising re-merger of the bloodlines. This paper expanded the initial ideas presented in Mitchell (2018) which found that identity, creativity, emotional response, relationality, and contextual features structure writing approaches and ways of knowing in post-secondary education. Three situated perspectives, rhetorical genre theory, activity theory, and communities of practice could be synthesized with Bandura's self-efficacy theory using the intertwined model framework I described in Mitchell (2018). The paper contributed to the discussion that there were elements of context, identity development, and deeper elements of relationality, such as intertextual relationships with sources read while developing writing ideas, that were not well articulated by relying on Bandura's self-efficacy theory alone.

Social perspectives advocate that writing is a community activity and communities establish motivations for writing, creativity allowances, appropriate diction and language use, and how identity development within a discipline helps a writer better understand the rhetorical choices needed to reach a defined audience. The cognitive perspective more clearly defines the role of emotional arousal in writing agency and how modelling and feedback pedagogies can impact actions students take to improve their writing. The paper also helps readers to understand why individual disciplines and individual classrooms must take ownership for the writing instruction required in their context. Previous mastery of writing in one context may not guarantee automatic acquisition of writing in a new context. Social cognitive perspectives on 
writing self-efficacy leave gaps which can be filled by recognizing community understanding for acceptable forms of argument, writing voice, and emotional connection to ideas. This understanding can help direct educators to consider relational pedagogies, such as the ones introduced in the paper and expanded upon later in this chapter.

\section{Paper 3: Delphi Decision Making: Blending Qualitative and Quantitative Methods in Tool}

\section{Development Research}

The second paper is a departure from focusing on writing, writing self-efficacy, and writing pedagogy. The Delphi method is a popular crowdsourcing research method applied to instrument development and the goal of the paper was to contribute pragmatic guidance to researchers about the Delphi processes and analysis. As I searched the literature on the Delphi in preparation for developing the Situated Academic Writing Self-Efficacy Scale, I was unable to locate a methods paper that focused specifically on Delphi use with instrument development. The procedures I identified for my own Delphi study were adapted from policy or clinical guideline Delphi studies or were identified in various instrument development papers employing Delphi methods for their own tool development. There was no guidance, beyond use of the content validity index, for analyzing panelists responses about the quality of individual items. When I conduced my analysis, I relied primarily on my own ingenuity in establishing an acceptable process for analyzing my data. I felt sharing my process might be of benefit to other instrument development researchers. In the paper, I included discussions about using various triangulated assessments of individual items and how qualitative comments were merged with the quantitative assessments. I gave an example of memo writing and demonstrated how to present questions to panelists and what to write in summaries provided to participants.

What this paper contributes, beyond step by step guidance to instrument developers who wish to use Delphi panels in their studies, is consideration of how the Delphi method requires 
modifications for assessing questionnaire items that may not necessarily be considerations in clinical guideline or policy Delphi methods. Instrument development Delphi studies usually present pre-prepared items to their panellists. They are also rarely the end point to the questionnaire under study so finalized decisions for item editing can sometimes be deferred until future phases of the study. The kinds of circumstances that may arise in Delphi panels that would make researchers consider deferring a decision, are also outlined in the paper.

\section{Paper 4: "Follow the Rubric is the Thing in Nursing": Navigating Systemic, Instructional, and Personal Influences on Writing Activities}

Galasinski and Kozlowski (2013) introduced me to the idea of the cognitive interview. These authors described how participants in research have a reflexive drive to explain why they score themselves the way they do on individual items on a questionnaire. The same authors also demonstrated that those stories participants told as they responded to questionnaire items could also provide rich data to help delineate a construct under investigation - in this case, contextual contributors to writing self-efficacy perceptions within nursing students. The cognitive interviews were designed with the primary intent to ensure that the items on the Situated Academic Writing Self-Efficacy Scale were understood and being interpreted correctly. This paper, however, tells a narrative of writing in nursing education based on the experiences of four composite students: a grade hungry student, a risk adverse student, the student who wished to preserve their identity, and the student trying to fit in. As the situated perspective that focused on interactions between players in a context, activity theory, described in Paper 1 (Mitchell et al., 2019), became the lens for analyzing the interviews using a qualitative content analysis approach.

The most prominent finding was the degree to which students were exerting energy trying to figure out the teacher. In fact, the writing in nursing was not much about writing at all 
for some students; it was about being a detective to figure out what was going on in their classroom to maximize their grade or minimize grade loss. Students talked to peers ahead of them in the program or payed attention to clues given during class time to figure out teacher preferences and biases. The goal for some students was to figure out where the boundaries were for this teacher, in this context, in this subject matter, with this assignment, and just never cross that boundary even if they didn’t agree with the prescribed approach. Most interestingly, a student would alter their approaches to writing in a form of behavioural "codeswitching” in order to achieve their goals. Some students desired to preserve their sense of self so they were continuously on the watch for faculty members that were more open to them being original versus those that expected them to follow the rules. Experienced students talked about the need to adapt from class to class with a bit of nonchalance: this is just how you have to be at the university. Others felt outraged that they couldn’t just be themselves. Sometimes that outrage turned to rebellion where a student would write in the way they wanted regardless of the consequences. Other students exhibited signs of learned helplessness and resigned themselves to the idea that they might never get a good writing grade.

There were many examples given of a sense of rigidity in writing in nursing. Heavy emphasis on heavily penalized APA format, and grammar, overly prescriptive rubrics were common. There were many examples given of large grade loss for straying from the guidelines or being creative in a way that the faculty grader felt was inappropriate. One of my favorite quotes from the qualitative cognitive interviews came as sort of an off-hand remark from a very successful student. Several students pointed out that the overly structured writing assignments in nursing made them really quite basic and simple. To be successful at writing in nursing, one student said, all that was required was to "Follow the rubric." Everything you need to do for a good grade is in the rubric right down to the exact number of points you get for particular content 
items. "You don’t even have to be the best researcher." This remark, to me, is a symptom of how rigidifying assignments causes students to treat writing as a functional task, where students put as little effort as possible into researching and reading on their topics. This context drives student behaviour. It matches what I had previously written about in two papers (Mitchell, 2017; 2018) that nursing education continues to hold views that writing is an academic activity that is entrenched in an objectivist epistemological paradigm.

Activity theory was the ideal lens for viewing this process, the strength of activity theory is its ability to help researchers understand the intersecting players in a context and how those interactions are negotiated. Students navigated discourse rules of language in nursing, tacit rules of needing to adapt to the university, rules of the APA style guide, and rules of the classroom. And, most importantly, the relationship between students and instructors.

As this qualitative study is descriptive in nature, the primary contribution of this work is in understanding the critical nature of relationship building with faculty during the writing process. Conversations about writing are critical to that relationship building. While students may not understand all the complexities of what it means to be in the role of educator grading writing, they do have some clear ideas about how they wish the writing environment was more flexible and transparent. The take home message from this work is that transparency of expectations can help students redirect their energy from trying to figure out the teacher to finding ways to connect with topics with passion and engagement. Students are conscious of their need to learn the language of nursing. They often feel more comfortable with nursing language in conversation, where they don't have the added worry of conventions and rules, than they do in writing. 
Paper 5: Development and Validation of the Situated Academic Writing Self-Efficacy Scale (SAWSES)

Paper 5 outlined the finding of the entire SAWSES development project which involved four data collection phases with independent samples. This paper outlines how the Self-Efficacy Scale for Academic writing evolved from 41-items each assigned to one of the five socially constructed categories of writing (identity, creativity, emotions, relational aspects, context) to a 16-item 3-factor validated questionnaire. The Delphi phase reduced the item count to 25 and the cognitive interviews reduced the scale items to 20. Two independent samples were gathered to statistically validate the questionnaire. Study 1 included a sample of 255 undergraduate nursing students and the items factored into 3 independent factors: Writing Essentials, RelationalReflective, and Creative Identity. This scale structure explained 61\% of the variance in writing self-efficacy scores. Table 1 outlines the finalized items on the questionnaire by their new factor category identified in Study 1 and acknowledges the item's original theoretical domain. 
Table 1: Self-Efficacy Scale for Academic Writing - Final Items, Factor Structure, and Original Theoretical Domain

\begin{tabular}{|c|c|}
\hline Item & $\begin{array}{c}\text { Original } \\
\text { Theoretical Domain }\end{array}$ \\
\hline \multicolumn{2}{|l|}{ Writing Essentials } \\
\hline $\begin{array}{l}\text { Even when the writing is hard, I can find ways to overcome my writing } \\
\text { difficulties. }\end{array}$ & Emotions \\
\hline $\begin{array}{l}\text { I can successfully use scholarly academic words and phrases when writing in } \\
\text { my courses. (edit: courses/program for grad student survey) }\end{array}$ & Context \\
\hline $\begin{array}{l}\text { I can combine or synthesize multiple sources I've read to create an original } \\
\text { product or text. }\end{array}$ & Creativity \\
\hline \multicolumn{2}{|l|}{ Relational Reflective } \\
\hline $\begin{array}{l}\text { When I write, I can think about my audience and write so they clearly } \\
\text { understand my meaning. }\end{array}$ & Relational \\
\hline $\begin{array}{l}\text { When I receive feedback on my writing, no matter how it makes me feel, I } \\
\text { can use that feedback to improve my writing in the future. }\end{array}$ & Emotions \\
\hline When I reflect on what I am writing I can make my writing better. & Identity \\
\hline $\begin{array}{l}\text { When I read articles about my topic, the connections I feel with the ideas of } \\
\text { other authors can inspire me to express my own ideas in writing. }\end{array}$ & Relational \\
\hline $\begin{array}{l}\text { When I look at the overall picture I've presented in my writing, I can assess } \\
\text { how all the pieces tell the complete story of my topic or argument. }\end{array}$ & Creativity \\
\hline $\begin{array}{l}\text { I can recognize when I've wandered away from writing what my audience } \\
\text { needs to know and have begun writing about interesting, but unrelated, ideas. }\end{array}$ & Relational \\
\hline $\begin{array}{l}\text { With each new writing assignment, I can adapt my writing to meet the needs } \\
\text { of that assignment. }\end{array}$ & Context \\
\hline $\begin{array}{l}\text { When I seek feedback on my writing, I can decide when that feedback should } \\
\text { be ignored or incorporated into a revision in my writing. }\end{array}$ & Relational \\
\hline \multicolumn{2}{|l|}{ Creative Identity } \\
\hline I can use creativity when writing an academic paper. & Creativity \\
\hline I feel I can give my writing a creative spark and still sound professional. & Creativity \\
\hline $\begin{array}{l}\text { I feel I can develop my own writing voice (ways of speaking in my writing } \\
\text { that are uniquely me). }\end{array}$ & Identity \\
\hline $\begin{array}{l}\text { Even with very specific assignment guidelines, I can find ways of writing my } \\
\text { assignment to make it original or unique. }\end{array}$ & Creativity \\
\hline $\begin{array}{l}\text { I can comfortably express nursing concepts, language, and values in my } \\
\text { writing assignments. } \\
\text { I can comfortably express the concepts, language, and values of my discipline } \\
\text { or major in my writing assignments (Modification for Interdisciplinary } \\
\text { Sample) }\end{array}$ & Context \\
\hline
\end{tabular}

Study 1 also assessed reliability and validity characteristics of SAWSES. Strong Cronbach's alpha scores $>.75$ were found for each subscale and the total scale. Parallel form reliability was found with a paper version of the scale using a $100 \mathrm{~mm}$ line visual analog scales for the items. Reliability coefficients were $r>.85$ for all subscales and the total scale. This 
finding will bring confidence to researchers who are unable to present the questionnaire to students in an electronic format.

Concurrent validity testing showed the scale had moderate correlations with two previously validated writing self-efficacy scales - one which heavily assessed mechanical features of writing (aspects of grammar) (Shell et al., 1989), and was expected to be discriminant and correlated in the moderate range, and one that was previously designed in a nursing context (Mitchell et al., 2017). Reliability coefficients were $r=.50$ and $r=.59$ respectively. The expectation was that the SAWSES would correlate higher with the Mitchell et al. scale but given that the scales were developed for very different purposes and the Mitchell et al. scale was designed based on course content rather than theory, the high moderate correlation is not a disappointment.

Several structural equation models were tested to assess construct validity of the scale based on hypothesized relationships with nursing identity, context, and writing apprehension. Of these variables, only writing apprehension had known relationships with writing self-efficacy in previous research. The structural equation model identified that writing apprehension had the strongest relationship with the SAWSES scale structure and perceptions of writing support had a small but statistically significant effect when apprehension and context-support were included alone in the predictive model. Nursing identity and the context item assessing the stakes of the assignment in their current term made a very small but statistically significant contributions to the model. How students valued the assignment in their term made very little contribution to the model and was non-significant. The Adams et al. (2006) measure of nursing identity may have been too clinically focused to represent the nature of identity that is established through writing. The SAWSES also assesses other elements of writing self-efficacy beyond identity and there may not have been enough identity representation in the tool to detect a strong relationship. The 
identified relationship between SAWSES and context as a supportive environment confirms student statements made during the cognitive interviews about the importance of instructor support to their self-efficacy when writing. Writing apprehension is a well-studied concept and Daly and Miller's (1975; 2014) tool has repeatedly demonstrated that low self-efficacy and high writing apprehension commonly appear as co-existing traits in post-secondary students.

In order to establish better disciplinary generalizability of the SAWSES scale, Study 2 established that the SAWSES 3-factor structure could be confirmed in interdisciplinary undergraduate and graduate student populations. Invariance testing through multigroup confirmatory factor analysis, revealed that the differences in item response patterns (factor structure, factor loadings, intercepts, and residuals and error variances) between graduate and undergraduate students were not statistically meaningful and the scale may be effectively used in both undergraduate and graduate populations. SAWSES however was developed with undergraduate students in mind and the fit of the scale to graduate students alone was not as ideal as it was in undergraduate populations, thus the scale does require further examination in graduate student populations to examine issues related to their unique writing context.

Since the scale was tested in nursing students, interdisciplinary undergraduate and graduate students, it was interesting to place these populations side by side and examine differences in writing self-efficacy experiences. Nursing students had a significantly higher proportion of students reporting they generally disliked writing. Nursing students reported significantly lower mean scores for the total scale and the subscale when compared to interdisciplinary undergraduate and graduate students. This is likely due to this higher proportion of students reporting disliking writing. What is unknown is if more nursing students dislike writing because of the nature of their expectations of nursing as a practice-based career choice, or if the rigid context they write within, as identified in the cognitive interviews, contributed to 
or reinforced their dislike of writing? Nevertheless, the scale was able to distinguish between students who identified as liking, disliking, or feeling somewhere in between about writing activities. Detecting these differences held for all student populations across Studies 1 and 2.

The three factors identified on the scale have potential for assessing the developmental nature of writing. The Writing Essentials category contains items deemed essential for surviving writing assignments at the post-secondary level. Most post-secondary students were able to score these items high making the factor less discriminating and the items easier than other items on the scale. Relational Reflective items capture many metacognitive activities required of writing in terms of reflection, connecting with audiences, and being able to communicate with their teachers through feedback or adaptation to the writing environment. This factor contains the next most difficult items. On average, these items were more difficult and more discriminating than the Writing Essentials items but there was more variability among the items themselves on these assessments. The Creative Identity subscale contained the items that were most difficult and most discriminating. This subscale may be useful in identifying post-secondary writers who are most able to benefit from the transformative nature of writing experience.

The main contribution of this paper is the development of a new writing self-efficacy scale, the Situated Academic Writing Self-Efficacy Scale that exhibits strong reliability and validity. More importantly, this scale is the first to overtly consider the situated nature of writing from within a socially constructed epistemology. The scale exhibits properties that may be able to detect differences in student response to contextual issues of writing between disciplines. Pragmatically, it holds developmental properties that may guide pedagogical decisions in the classroom.

Given that the pragmatics of this work are critical to its uptake, the contributions of these studies beg the question of how this collected body of work and the SAWSES tool itself can 
contribute to pedagogical strategies easily implemented in the writing classroom to support student writing and enhance writing self-efficacy.

\section{Implications for Pedagogy in Nursing Education and Beyond}

Earlier in this epilogue, I indicated that one goal for this work was to enable a paradigm shift in how nursing education thinks about writing so that the writing we assign can "enable the impulse to write” (Reither, 1985, p. 623). Student participants in the cognitive interviews described how having the option to write on a topic they felt passionate about increased engagement with writing and facilitated learning. These benefits were present whether the student liked or disliked writing. In my investigations into the epistemology of writing (Mitchell, 2018; Mitchell et al., 2019), I focused much of my attention to the social and community nature of writing. As Bawarshi (2003) says, "writers are never alone, even when they are physically alone,” (p. 5). Disciplines establish what is acceptable knowledge, acceptable conventions for communicating that knowledge through genres, and define what mastery or expertise looks like in their context (Wegner, 1998). Nevertheless, the act of writing is still conducted by an individual. That individual can, in the right circumstances, experience transformative benefits. Yagelski (2011) postulates that writing is ontology unto itself; writing is a way of being. Yet current practices in teaching writing continue to reward only the text produced in a Cartesian dualistic fashion that considers the text separate from the producer of that text. Writing, when all is considered, might, "help us be differently” in the world (Yagelski, 2011, p. 33). When considering pedagogies, from both a socially constructed and a writing as ontology perspective, one must also recognize that writing is an experience, and "the experience matters without the telling” (Yagelski, 2011, p. 75). As the writing to learn movement postulates, writing is not about regurgitating factual knowledge, it is about incorporating knowledge into identity, it's about critical thinking, it's driven by reflexivity, and it's about learning the conceptual language of a 
discipline (Allen et al., 1989; Bolton, 2010). There is learning and writing growth that takes place during the act of writing that will never be visible to the grader of the text.

A second important consideration in examining writing pedagogies is that nursing programs are phenomenally complex. Nursing programs must mindfully integrate and evaluate numerous competencies designed to graduate safe and effective practitioners. Writing in courses needs to hold value to students, but at the same time, it should not increase workloads of faculty. The goal then is to shift faculty workload from the grading process, to opportunities to dialogue about writing and learning with students. What should be the most disconcerting finding of this study is that nursing students dislike writing more than the general undergraduate population. We need to know why, and we need to attend to this problem. These dialogues will improve writing self-efficacy particularly in the relational domain.

The cognitive interview data helped us understand that nursing students currently live in this rigid writing environment. That environment prescripts nearly everything for them, assumes its own objectivity, privileges standardization whenever possible, and leaves students feeling robbed of their own creativity - and yet, students still complain of inconsistency between teachers. Nursing has tightened the reigns on writing in ways unlike what I remember writing in nursing to be from the 29 papers I wrote as a student in the mid 1990s. Students being allowed to express themselves freely without some governing template are rare. The writing they hand in as assignments is still not great writing. It is boring and often superficial. Could it be the solution is not to tighten the reigns more but to loosen the reigns significantly? Students need to be in control of their own ideas and passions. They should be allowed to play. Do we as faculty structure the life out of writing assignments because we feel there are benefits to structure? Do those benefits better serve our needs or student needs? Or do we have a fatal allergy to the messiness involved in flexibility and freedom of choice? How does our own instructional self- 
efficacy come into play? I ask that readers consider these questions while reading the rest of the chapter and the suggested pedagogies being presented.

The remainder of my discussion on implications will focus on pedagogical strategies which I will structure using the three factors established in the Situated Academic Writing SelfEfficacy Scale, with one caveat. An ongoing conversation in educational research, and one I raised in a recent publication on knowledge translation as it relates to pedagogical research (Mitchell, 2019) is that from day to day in our classrooms we are "standing in data” (Channock \& Vardi, 2005) valuable to our practices that are difficult to research due to ethical issues involved in researching our own students. Objectivist perspectives on writing and knowledge privilege peer reviewed and published ideas over experiential knowledge. Yet, even knowledge translation scholars emphasize that experiential knowledge is valuable, if not privileged, in uptake of research (Greenhalgh \& Wieringa, 2011). In our day to day teaching we often prefer to walk down the hall and speak to a trusted colleague about a problem than turn to the published literature. Often pedagogists turn to the informal public literature, such as blogs or social media, to share their pedagogical insights, because their raw lived experience can’t be published in its pragmatic and reflective form (Mitchell, 2019). From time to time in my discussion of writing pedagogies, I may refer to my own teaching experiences or this “grey” literature on pedagogy for pragmatic solutions to facilitating writing and enhancing writing self-efficacy.

\section{Attending to Writing Essentials}

One myth of good writing is the notion that the basic skills of writing are clear prose and impeccably implemented grammar and style (Warner, 2018); however, grammar is too limiting of a criterion for defining what is perceived as good writing (Mitchell, 2018). It is possible to write with correct grammar and sentence structure and produce a text that is devoid of depth and insight. Situated perspectives on writing tell us that writing conventions, including grammar, 
sentence structure and style, are not generic and they can vary within disciplines and communities. Warner states that the basics of writing have nothing to do with textual appearance at all - the basics of writing are ideas. Nevertheless, basic needs of individual writing assignments cannot be taken for granted. Given the known tendency for students to inflate their self-efficacy levels in new or unfamiliar contexts or writing genres, some practical strategies must be acknowledged in any classroom that assigns writing. The Writing Essentials factor on the SAWSES scale contains items that the students in all disciplines were able to most easily endorse as skills that they felt capable of accomplishing in their writing. These include not letting writing difficulties prevent progress, ability to synthesize numerous sources, and comfortable use of academic words and phrasing. Conversations about expectations for professional language, tone of writing, synthesis expectations, and check-ins about emotional status during writing preparation should be common classroom practice. Normalizing writing anxiety at every phase of writing is a teacher responsibility in scaffolding theories (Benko, 2013).

The cognitive interviews identified that students find use of disciplinary language challenging and it is the formalization of that language in academic writing that provides the most uncertainties. This knowledge provides awareness to be cautious when grading language usage. It is common for graders to mistake problems of discourse for incorrect grammar (Mitchell, 2018). Learning the language of nursing and health care is like learning a new language. An added complication is that each nursing specialty area has its own discourse (e.g. palliative care, obstetrics). Students will use incorrect phrasing of medical terminology and concepts in a new content area until they are comfortable in that discourse. It may be prudent to correct discourse without penalty in many situations.

Synthesis is a complex expectation in academic writing. Blondy et al. (2016) identify that synthesis is more than juxtaposition or the placing of information side by side but is instead a 
creative act that intertwines information from multiple sources: "True synthesis makes new meaning; therefore, synthesis results in knowledge transformation” (p. 670). Different genres may require different synthesis strategies that can be explicitly taught. For example, for many years I have asked students to write an academic paper for a research course that required finding five primary studies on a self-chosen research question. One of those papers asked students to synthesize the findings of qualitative research studies. I introduced them to a system of using index cards to write a brief summary of one qualitative finding "theme" per card for every theme in each of their five studies. Once their themes were written, they could group together all the cards with similar themes and pick the two or three most prominent themes across their five studies to write about in their papers. This exercise not only provided the student with point-form discussion notes for writing their papers, it also helped them recognize when they had chosen a study that was not a good fit with the other studies in their collection. An exercise such as this, can be conducted during class time, can teach important course content in a flipped classroom format, and allows students to progress with their paper. I always rewarded the exercise with grade points toward the final course. It ensures attendance, engagement with the exercise, and allows me to connect with every student, in small ways, one-on-one - even in large class sizes of greater than 50 students. Another important consideration is that I never require students to do the exercise "my way.” There are numerous routes to the same synthesis endpoint and experienced students often have their own strategies which are also given credit. A description of the academic paper, the synthesis, and an associated peer review activity can be found in the following blog (https://academicswrite.ca/2018/11/25/student-peer-review-process-heres-myversion/).

The final writing essential I wish to address has nothing to do with essentials from the SAWSES subscale but are instead related to essentials required by faculty to facilitate writing. 
One barrier to effective writing pedagogy in undergraduate nursing education is faculty inexperience in guiding writing. Faculty lack of experience was not lost on many of the participants in the cognitive interviews. They were, in many cases, quite pointed in identifying that some inexperienced faculty "mess up” writing for students through unwillingness to further explain guidelines, nitpicking at APA, and grading by rewriting sentences rather than focusing on content. Whitehead (2002) has suggested that student observations of faculty floundering with writing guidance are because many of the faculty who teach in nursing undergraduate programs are not PhD prepared and not required to maintain a program of research where they write for themselves. Our practice focus is also a barrier. Inherent features of excellent nursing care rigour, adherence to protocol, deference to seniority, overcautiousness, and clinical sterility - are often erroneously transferred into the classroom and into writing practices in nursing education. However, the attempts at rigour in the form of tightly controlled detailed rubrics, limited assignments with no flexibility for student choice or approach, and meticulous attention to grading APA format, are likely contributing to or reinforcing students’ dislike of writing. Workshops exposing faculty to writing theory may help, but attention to faculty’s own selfefficacy for writing instruction is likely a more direct route to understanding the desire of many faculty to cling to ridged notions of writing and obsession with superficial textual and style guide errors. The final student quote in the cognitive interview study bears repeating here: “They need to let go of these weird boundaries they have and let us just write.” Lack of faculty confidence, along with disciplinary objectivist beliefs about writing, I hypothesize, is what prevents faculty from immersing themselves in the relational pedagogies needed for improving writing selfefficacy. 


\section{Attending to the Relational and the Reflective}

One common refrain from the student participants in the cognitive interviews - and a piece of data that didn't make it into the final analysis - was the wish that nursing programs would provide their own writing tutors. Other Canadian studies on writing in nursing education (Chaudoir et al., 2016) have reported the same wish from nursing students. Tutoring services “can only go so far” (Chaudoir et al., 2016, p. 7) in helping students with their writing primarily due to non-nurses not being able to provide effective feedback on nursing content and discourse. One student participant in the cognitive interviews reported being surprised when a tutor asked her what dementia was - and dementia is a fairly ubiquitous medical concern. I asked the same student if she had ever come across any nursing students working in the tutoring centre and she had not. Most of the tutors are upper level students in a variety of disciplines. Another student, who had tried tutoring services but didn’t find it valuable, pondered if nursing could hire their own students to act as tutors. This student immediately rejected his own idea because, "we are too busy.”

Nursing, nevertheless, could stand to take back responsibility for their own writing education. It has been well established in the literature that nursing programs are more likely to shunt writing education to other disciplines such as English departments when discipline specific approaches are preferred (Andre \& Graves, 2013). The preference for discipline-specific writing instruction stems from the critical importance of discourse and language within a discipline to faculty perceptions of what successful writing looks like. It can also help with building a relational writing community.

With students identifying that their relationship with and understanding of their instructors in terms of writing expectations and assignment clarification being a critical factor in their writing self-efficacy, relational pedagogies require involvement with the instructor. The 
instructor already invests a tremendous amount of time creating, explaining, and then grading written assignments; thus, the goal in many relational approaches is to redirect faculty time away from grading and on to writing facilitation tasks. The principle behind effort redirection is that by supporting students with more basic elements of the writing process, the result will be clearer, easier to read, higher quality assignments. For example, I regularly request that students share with me aspects of their writing planning such as the synthesis exercise described above. I have also required that students share with me their five primary studies they have chosen to include in their paper so that together we can have conversations about how well the chosen articles fit together as a unit. This expectation also benefits me as I then do not have to spend time while grading ensuring they have chosen the right literature to work with. I introduced some relational pedagogies in the first thesis paper (Mitchell et al., 2019) but I will expand on the ideas of scaffolded instruction and iterative feedback strategies.

Scaffolding learning (Benko, 2013; Gazza \& Hunker, 2012) is a metaphor which facilitates the relational, emotional, and contextual components of the writing model (Mitchell, 2018). Scaffolded instruction introduces the writing tasks in stages with each stage increasing in complexity. The educator act as the "scaffold” providing ongoing support to students using a collaborative approach that also considers the need for anxiety and frustration control among students. Draft reviews and peer support are often characteristics of writing scaffold methods. The interaction between educator and student builds writing self-efficacy and is where learning takes place, so the "scaffold” can be removed and the writer can proceed independently.

Grading and feedback can be built into the scaffold. Grading of student work is a relational practice (O’Flynn-Magee \& Clauson, 2013) - or at least it should be. In socially constructed perspectives, feedback is not viewed as a one-way transmissive process, rather holistic and iterative methods are preferred (Evans, 2013; Rust et al., 2005). Power relationships 
in feedback situations are acknowledged as educators control grades and academic futures, and function as the experts in the tacit aspects of disciplinary discourse (Lea \& Street, 1998). Feedback exchanges facilitate student ability to navigate the writing context, seek emotional support, and develop their identity as writers. Traditionalism in undergraduate classrooms seems to dictate that the student produces a written text, hands it in, and the instructor gives it a grade. Rarely do the instructor and student communicate about the work again. As one student in the cognitive interviews said, “I don't see like the point in why I'm doing it. Like if it’s just to get a grade in class and then it never matters again. Right? Who cares?” She’s not wrong. Transmissive grading practices perpetuate the devaluing of writing as a pedagogy for both faculty and students. It could be much more effective and valuable.

A perhaps radical suggestion for the grading of writing is the suggestion that we don't grade writing at all - that we instead put all our instructional energy and evaluation efforts into the facilitating and conversational stages of writing pedagogies. Subjectivities inevitably creep into the grading of writing. We recognized the negative impact of such subjectivities in evaluation of clinical performance and many programs converted to pass-fail evaluation approaches in clinical practice as a result. A grade in a theory course is often required for administrative purposes so pedagogical experts have proposed the notion of ungrading (Stommel, 2018). Ungrading involves coming to an agreement with a student about their final grade for a course or for individual elements of course material through a combination of interviews with the student, qualitative feedback, peer review, and student self-grading. The goal is to shift evaluative emphasis to what the student learned and gained from the writing experience, rather than on a final text produced.

In many cases the ungrading process emphasizes reflection on writing. Individual reflection on writing is only one route to coming to know how the writing has influenced identity 
development and knowledge. During the cognitive interviews, students often reported that they didn’t necessarily reflect alone but rather reflected in conversation with friends or family and sometimes, but less frequently, teachers, on their topic of choice. Reflection is the metacognitive process that allows for the intertwining of all the layers of the writing model. Fernsten and Reda (2011) suggested students be asked to incorporate, as a component of their writing assignments, various reflective writing exercises in the form of “author's notes.” One of my suggested uses for the SAWSES in Paper 5, beyond its measurement capabilities, was for classroom instructors to use it as a reflective tool in order for students to ponder their writing context and where their self-efficacy fit within it. These author notes, including self-assessments and reflections on responses to SAWSES, could be included as part of a portfolio that contributes to the ungrading process. Author's notes could include descriptions of their past experiences with writing, thoughts about the audience for their work, reflective linking chapters between writing samples provided in portfolios, or responses to feedback. Reflection teaches personal knowing, selective self-disclosure, and allows students to write in a more casual, emotional, and "freeing” voice with their teacher or peers as the audience.

Relational pedagogies are not only about external relationships. They are also about building relationships with sources. Rhetorical Genre Theory provides guidance for relationally considering sources explored during the writing process. As addressed in Paper 2 (Mitchell et al., 2019), genre is the study of different types of text and their intended social actions that influence the production, interpretation, and responses to those texts (Bawarshi, 2003; Miller, 1984). Genre-based approaches influence contextual understanding and facilitate relational interpretation of sources. Teaching students the purpose of different types of academic literature and the appropriate and inappropriate uses of writing “voice,” considering the author’s background and writing motives for a text, exposing students to writing from different 
disciplines, and facilitating study of sources, are all genre-based approaches. Scaffolding genre exposure begins with supported reading and recognition of source types and expands to teaching critical analysis and exploration of different rhetorical strategies of argument. When a writer understands genre, they are able to creatively "play” within and modify that genre - an indicator of a highly skilled writer.

\section{Attending to Creative Identity}

Ability to play within academic genres in the classroom - stray from the sterile academic voice and get away with it - requires a writing context that is flexible, open to innovation, and an instructor that values the same. The creative identity factor on the SAWSES gathered a collection of items that were the most difficult for students to endorse and therefore were the most discriminating items on the questionnaire. These findings mean this factor is the factor to attend to when trying to identify student writers who are most connected to their discipline, most comfortable with taking writing risks, and can explain what creativity means in their writing context. In Paper 2 (Mitchell et al., 2019) I stated that having writing self-efficacy in a discipline may be a marker of identity development. The creative identity subscale may assess this level of writing self-efficacy best. Items representing creativity and identity factoring together on the scale is unsurprising. Often representations of creativity, are very much connected to one’s identity. However, some participants questioned the value of assessing creative ability in academic writing. An English student wrote in the open-ended response box within the survey, "I think the focus on creativity in the questionnaire is a little disingenuous. Academic writing isn't creative writing.” I can point to two sources who disagree with this student assessment that academic writing isn’t creative (Antoniou \& Moriarty, 2008; McVey, 2008). Creativity in academic writing isn’t equated with artistic ability necessarily. It’s also not poetry or a short story - but it could be if a faculty member is open to that. As one more experienced nursing 
student writer said, “I think we are allowed to be creative. It's just that we have to be creative within the dimensions that they want us to be.” Inability to endorse items asking about creativity, could be because students fail to recognize how creativity is defined in their discipline and in their disciplinary genres of writing.

Creativity allowances were certainly some of the writing components in nursing that students found most mysterious. Genre theorists have described that students who have tried and failed at being creative in assignments have misrepresented the expected genre to a degree that the faculty grader evaluated their attempt as an error rather than an innovation (Devitt, 2000). Paré (2014) observed that to challenge the expected form of a genre, and by extension being creative with that genre, requires power within a discipline. Bawarshi (2003, p. 92) points out that some genres are more "baggy" than others and are more accepting of transgressions from the expected form. Academic writing, in particular the traditional literature review assignment, likely isn’t one of those genres. Faculty often experience difficulties explaining what is meant by creativity. Creativity - you know it when you see it, but defining it is a whole other challenge. It is possible, when attempting to be creative, to go too far and lose portions of an audience. We've all watched critically acclaimed movies that we've assessed as “weird” or "strange.” There is a much finer line in academic contexts between writing viewed as acceptable and making your audience uncomfortable because you've violated the expected. But creativity doesn’t have to be inserting poetry in the middle of a research paper. Creativity can also mean thinking outside the box when researching a topic or taking a risker topic choice and applying it to a new context or organizing information into a unique presentation or framework. In graduate studies it should be considered creative to identify an unrecognized gap or take theoretical perspectives that have never been fully explored and place them side-by-side and identify if they are compatible. All writing has creative elements, and it is the responsibility of the instructor who made the 
assignment to identify what those creative elements might look like. Sometimes our students can identify those creative elements for us when they approach us with ideas that take a bit of a left turn from the assignment as presented. Be open to those ideas and alternative approaches.

Creativity can also mean willingness to stray from traditionalism. If I have changed my mind about anything over the course of this project, it is that that the academic paper, which often takes the form of a literature review, may not be the only route to development of disciplinary discourse and identity. Writing is involved in many other multimodal types of assignments which may hold equal and even superior value to student learning. These alternative forms of writing often attend to the aurality of language and how words sound (Selfe, 2009). Cadence is privileged over sentence structure and grammar (Mitchell \& Clark, 2018). For example, writing scripts for podcasts, creating short videos targeting patient audiences or producing patient education materials also require similar research intense efforts and allow students to play with their voice and language choices to grab the attention of audiences beyond their teacher. The three-minute thesis script presented in the interlude chapter prior to the cognitive interview study (Paper 4) is another example. However, it can be difficult to tear students away from continuing to use traditional academic conventions in alternative assignments, as those conventions have been the mostly highly rewarded in the past. For example, I've seen reflective assignments with academic-style introductions and conclusions and multimedia assignments, to be targeted at patients, with jargon-filled textbook regurgitations of anatomy and physiology. In the creative domain this is where the cognitive process concept of modelling can be useful. Students need examples in order to feel out the boundaries of creative allowances and build self-efficacy levels in those domains.

Writing is a developmental process and being comfortable within the boundaries of creativity is part of that developmental process. Another myth of writing (Branson, 2017) is the 
notion that one writing course is enough to establish basic skills that can be used over and over again in "the more 'legitimate' courses in the university” (p. 18). As a former course leader of a writing course for nursing, I have countless memories of hallway conversations and emails received that all started with, “Did you teach them how to....?” followed by a description of some (often mechanical) failing in writing that they were observing in the papers they were grading. Writing scholars have been trying to solve the problem of lack of transfer of writing skills (Brent, 2011). Transfer can happen, but it has to be facilitated by those instructors in the “legitimate” theory courses of nursing. It's not that students forget how to write, but rather something changes in the writing context that makes them not able to see the similarities between what they were taught and what they are currently writing.

Writing growth happens over a lifetime. I wrote a critical reflection of my own writing growth in the prologue of this thesis to illustrate this exact point. I had written 1500 pages of journals as a teenager and had an A+ average in high school writing, and it still wasn’t an automatic ticket to an A+ grade, or even an A in a lot of cases, in my first-year university courses. I wrote a paper in my Master of Nursing degree that I still remember being my greatest writing struggle, but yet I also know that paper would be less of a challenge now given my current writing achievements. The issue wasn’t that I couldn't put a sentence onto paper as an undergraduate or that I didn’t have reasonably good grammar, or that I wasn’t already a pretty skilled writer as a master’s student. The problem was, at that time in my writing life, expectations were completely different from any previous writing I had done, and I didn’t always know they had changed, nor did I know how to manage that change.

What is known about writing self-efficacy, is that it is subject to hyperinflation, in particular at points of - to use community of practice language - boundary crossings (Wegner, 1998). In post-secondary education this means students new to the university with only high 
school as past experience. It also means students who switch disciplines and students who begin graduate studies. It is also why writers often feel like they never get ahead in their writing selfefficacies. Every time you switch contexts or move up a level, you lose a little of your familiar identity as a writer. In the SAWSES validation, undergraduate students reported similar mean scores on all items to graduate students. The stakes get higher for graduate students, they value the assignments more, their realized expectations of support are tenuous and variable, all of which impacts writing self-efficacy.

The most interesting students I interviewed during the cognitive interview phase were the practicum students. They could look back and point to the moments of their writing growth. One practicum student who was a bit of an outlier in the study - hated writing, consistently got A range grades - she underinflated herself on SAWSES because she could not control her emotions while writing and she was intimidated by the kind of writing she read in polished published articles. Her drafts sounded nothing like that. But yet, she could still see how far she had come. Her interview is full of epiphany statements. One of my favorites is this one:

But now, looking back, I realize that it is helpful to do that research and just, it is a part of nursing that you need to do it, like that continuing competency. Like you need to keep up to date. And now I do know how to read an article, even though I don’t love doing it. But as... you know, now it makes me feel part of the nursing profession. But then, no. Like in the midst of it? No. Now I feel very grateful that I, you know, like we talk about it in the staff room at practicum. I go, “oh this new article I read where...” you know, it does make you a part of the profession.

Doing the work of writing, invites students into the conversation. It teaches them the language to use when describing that article they read (and wrote about) to others in the staff room. It teaches 
them when it is appropriate to raise that knowledge in a professional context and how to communicate that knowledge in a way that demonstrates their professional competence.

The SAWSES subscale of Creative Identity is important for starting conversations about writing development with students. The students in all samples reported the lowest average scores on this subscale. Having conversations about distributions of scores across subscales can identify areas where students require intervention. It can detect where students are overinflating sense of ability when facing unrecognized advanced expectations in a context. The tool can be used to have individual conversations that may point to issues with reading self-efficacy in addition to issues with writing. The tool can also be used in research contexts to detect disciplinary patterns in self-efficacy and the elements of contexts which are acting as barriers to writing development. Staunch rigidity in guidelines and rubrics may be such a barrier in nursing education.

\section{Areas for Future Research}

Several areas for future research became evident throughout this collection of work.

1. While the multigroup confirmatory factor analysis failed to detect any statistically meaningful differences between the undergraduate and graduate student interdisciplinary samples, the scale was not initially developed with graduate writing in mind. The factor structure fit was less adequate in graduate students. Prior to use in this population, it would be useful to begin understanding if gaps are present in the tool for assessing writing selfefficacy in graduate student contexts.

2. The tool has been tested in an interdisciplinary population and in nursing students. There was no one discipline in the interdisciplinary sample that had a large enough sample size to assess for patterns of response in disciplines outside of nursing. The tool should be tested in other 
homogeneous samples of disciplinary students to explore disciplinary patterns to writing selfefficacy.

3. The potential for assessments of developmental growth in writing and writing self-efficacy should be investigated in future studies to be able to understand if there is a real world meaningfulness to the observation that the Writing Essentials factor contains easier items to endorse and the Creative Identity factor contains the most difficult items to endorse.

4. The relationship between nursing identity and its ability to predict writing self-efficacy scores was statistically significant in one model but too small to hold practical significance. A different tool better focused to the kinds of disciplinary identities theorized to be developed by writing may provide greater insights into this relationship.

5. The cognitive interviews highlighted the importance of students having a relationship with their teacher during the writing process. As this finding has also been observed in other studies (Borglin \& Fagerström, 2012; Chaudoir et al., 2016; Lundgren \& Halversson, 2015; Tyndall \& Scott, 2016), a focus on the needs of faculty members and their approaches to guiding student writing are a necessary next step. There is very little research, beyond the small numbers of faculty members who have been interviewed in the student centric studies, to understand how faculty beliefs about writing and teaching writing develop. Studies with faculty could take a qualitative approach. Measures of teacher efficacy for teaching writing also exist. I particularly like the questionnaire developed by Locke and Johnson (2016) which in addition to assessing an individual faculty member's self-efficacy, also asks faculty to assess how they perceive their colleagues collectively manage writing in the classroom. Understanding faculty writing self-efficacy may point to suitable approaches for reducing the inflexibility and rigidness of writing observed by students in nursing education. 
6. There are connections between writing self-efficacy, reading ability, and student progression through nursing programs. This suggested area for future research refers more to research I conducted outside of this doctoral work (Mitchell \& McMillan, 2018), but it might constitute additional information about SAWSES construct validity if this relationship is also found with the new scale. Literacy assessments are an important emerging concern in nursing competency evaluations and readiness for practice. Writing self-efficacy assessments may hold additional clues to the relationship between literacy and practice.

\section{Conclusion}

This thesis represents the culmination of four years of intense immersion into the world of writing theory, writing self-efficacy, and instrument development methodology. The final product is a valid and reliable 16-item 3-factor instrument, the Situated Academic Writing SelfEfficacy Scale. The scale contains three meaningful and theoretically relevant subscales, Writing Essentials, Relational Reflective, and Creative Identity, which separately and collectively can provide educators with information about the students in their classroom and provide researchers with information about writers in their discipline. Ultimately, the goal of writing in any discipline should be to acculturate students to the identities, languages, and discourses of their disciplines. A higher order goal is to graduate nursing students who love writing, recognize the learning potential through writing, and feel their identities are transformed as a result. 


\section{References}

Adams, K., Hean, S., Sturgis, P., \& Macleod Clark, J. (2006). Investigating the factors influencing professional identity of first-year health and social care students. Learning in Health and Social Care, 5(2), 55-68. https://doi.org/10.1111/j.1473-6861.2006.00119.x

Allen, D. G., Bowers, B., \& Diekelmann, N. (1989). Writing to learn: A reconceptualization of thinking and writing in the nursing curriculum. Journal of Nursing Education, 28(1), 611.

Andre, J. D., \& Graves, R. (2013). Writing requirements across nursing programs in Canada. Journal of Nursing Education, 52(2), 91-97. https://doi.org/10.3928/01484834$\underline{20130114-02}$

Antoniou, M., \& Moriairty, J. (2008). What can academic writers learn from creative writers? Developing guidance and support for lecturers in higher education. Teaching in Higher Education, 13(2), 157-167. https://doi.org/10.1080/13562510801923229

Bawarshi, A. S. (2003). Genre and the invention of the writer : Reconsidering the place of invention in composition. Utah State University Press

Benko, S. L. (2013). Scaffolding: An ongoing process to support adolescent writing development. Journal of Adolescent \& Adult Literacy, 56(4), 291-300. https://doi.org/10.1002/JAAL.00142

Blondy, L. C., Blakeslee, A. M., Scheffer, B. K., Rubenfeld, M. G., Cronin, B. M., \& LusterTurner, R. (2016). Understanding synthesis across disciplines to improve nursing education. Western Journal of Nursing Research, 38(6), 668-685. https://doi.org/10.1177/0193945915621720

Bolton, G. (2010). Reflective practice: Writing and professional development ( $3^{\text {rd }}$ ed.). Sage. 
Borglin, G., \& Fagerström, C. (2012). Nursing students’ understanding of critical thinking and appraisal and academic writing: A descriptive, qualitative study. Nurse Education in Practice, 12, 356-360. https://doi.org/10.1016/j.nepr. 2012.04/009

Branson, T. (2017). First-year composition prepares students for academic writing. In C. E. Ball and D. M. Loewe (Eds.). Bad Ideas About Writing. West Virginia University Libraries. https://textbooks.lib.wvu.edu/badideas/badideasaboutwriting-book.pdf

Brent, D. (2011). Transfer, transformation, and rhetorical knowledge: Insights from transfer theory. Journal of Business and Technical Communication, 25(4), 396-420. https://doi.org/10.1177/1050651911410951

Chanock, K., \& Vardi, I. (2005). Data: We’re standing in it! Teaching and Learning Forum. Retrieved from https://clt.curtin.edu.au/events/conferences/tlf/tlf2005/refereed/chanock.html

Chaudoir, S., Lasiuk, G., \& Trepanier, K. (2016). Writing assignments: A relatively emotional experience of learning to write in one baccalaureate nursing program. Quality Advancement in Nursing Education, 2(2), 1-21. https://qaneafi.casn.ca/journal/vol2/iss2/3/

Daly, J. A., Miller, M. D. (1975). The empirical development of an instrument to measure writing apprehension. Research in the Teaching of English, 9(3), 242-249. https://www.jstor.org/stable/40170632

Daly, J. A., Miller, M. D. (2013). Writing apprehension test (WAT). Measurement Instrument Database for the Social Science. Retrieved from http://www.midss.org/sites/default/files/writing_apprehension_test.pdf

Devitt, A. (2000). Integrating rhetorical and literary theories of genre. College English, 62(6), 696-718. 
Evans, C. (2013). Making sense of assessment feedback in higher education. Review of Educational Research, 83(1), 70-120. https://doi.org/10.3102/0034654312474350

Fernsten, L. A., \& Reda, M. (2011). Helping students meet the challenges of academic writing. Teaching in Higher Education, 16(2), 171-182. https://doi.org/10.1080/13562517.2010.507306

Galasinski, D., \& Kozlowska, O. (2013). Interacting with a questionnaire: Respondents’ constructions of questionnaire completion. Quality \& Quantity, 47, 3509-3520. https://doi.org/10.1007/s11135-012-9733-0

Gazza, E. A., \& Hunker, D. F. (2012). Facilitating scholarly writer development: The writing scaffold. Nursing Forum, 47(4), 278-285. https://doi.org/10.1111/j.1744$\underline{6198.2012 .00275 . X}$

Greenhalgh, T., \& Wieringa, S. (2011). Is it time to drop the "knowledge translation” metaphor? A critical literature review. Journal of the Royal Society of Medicine, 104, 501-509. https://doi.org/10.1258/jrsm.2011.110285

Lea, M. R., \& Street, B. V. (1998). Student writing in higher education: An academic literacies approach. Studies in Higher Education, 23(2), 157-172, https://doi.org/10.1080/03075079812331380364

Lock, T., \& Johnston, M. (2016). Developing an individual and collective self-efficacy scale for the teaching of writing in high schools. Assessing Writing, 28, 1-14. https://doi.org/10.1016/j.asw.2016.01.001

Lundgren, S., \& Halvarsson, M. (2009). Students' expectations, concerns, and comprehensions when writing a theses as part of their nursing education. Nurse Education Today, 29, 527532. https://doi.org/10.1016/j.nedt.2008.11.010 
McVey, D. (2008). Why all writing is creative writing. Innovations in Education and Teaching International, 45(3), 289-294. https://doi.org/10.1080/1470329082176204

Miller, C. (1984). Genre as social action. Quarterly Journal of Speech, 70, 151-167. https://doi.org/10.1080/00335638409383686

Mitchell, K.M. (2017). Academic voice: On feminism, presence, and objectivity in writing. Nursing Inquiry, 24(4). https://doi.org/10.1111/nin.12200

Mitchell, K. M. (2018). Constructing writing practices in nursing. Journal of Nursing Education, 57(7), 399-407. https://doi.org/10.3928/01484834-20180618-04

Mitchell, K. M. (2019). Social media storytelling: Using blogs and Twitter to create a community of practice for writing scholarship. Canadian Journal for Studies in Discourse and Writing/Rédactologie, 29, 1-23. https://doi.org/

Mitchell, K. M., \& Clark, A. M. (2018). Five steps to writing more engaging qualitative research. International Journal of Qualitative Methods, 17, 1-3. https://doi.org/10.1177/1609406918757613

Mitchell, K. M., Harrigan, T., Stefansson, T., \& Setlack, H. (2017). Exploring self-efficacy and anxiety in first-year nursing students enrolled in a discipline-specific scholarly writing course. Quality Advancement in Nursing Education, 3(1), 4. https://doi.org/10.17483/2368-6669.1084

Mitchell, K. M., \& McMillan, D. E. (2018). A curriculum-wide assessment of writing selfefficacy in a baccalaureate nursing program. Nurse Education Today, 70, 20-27. https://doi.org/10.1016/j.nedt.2018.08.003

Mitchell, K.M., McMillan, D.E., \& Lobchuk, M.M. (2019). Applying the “social turn” in writing scholarship to perspectives on writing self-efficacy. Journal of Learning Development in 
Higher Education,15(2019).

http://journal.aldinhe.ac.uk/index.php/jldhe/article/view/512/pdf

O’Flynn-Magee, K., \& Clauson, M. (2013). Uncovering nurse educators’ beliefs and values about grading academic papers: Guidelines for best practices. Journal of Nursing Education, 52(9), 492-499. https://doi.org/10.3928/01484834-20130819-01

Paré, A. (2014). Rhetorical genre theory and academic literacy. Journal of Academic Language and Learning, 8(1), A83-A94.

Reither, J. A. (1985). Writing and knowing: Toward redefining the writing process. College English, 47(6), 620-628. https://doi.org/ 10.2307/377164

Rust, C., O’Donovan, B., \& Price, M. (2005). A social constructivist assessment process model: How the research shows us this could be best practice. Assessment \& Evaluation in Higher Education, 30(3), 231-240. https://doi.org/10.1080/02602930500063819

Self, C. L. (2009). The movement of air, the breath of meaning: Aurality and multimodal composing. College Composition and Communication, 60(4), 616-663. http://www.jstor.org/stable/40593423 .

Shell, D. F., Murphy, C. C., \& Bruning, R. H. (1989). Self-efficacy and outcome expectancy mechanisms in reading and writing achievement. Journal of Educational Psychology, 81(1), 91-100. https://doi.org/10.1037/0022-0663.81.1.91

Stommel, J. (2018, March 18). How to ungrade. https://www.jessestommel.com/how-to-ungrade/

Tyndall, D., \& Scott, E. (2017). Writing development in associate degree in nursing-tobaccalaureate degree in nursing students: Moving out of the comfort zone. Journal of Nursing Education, 56(3), 182-185. https://doi.org/10.3928/01484834-20170222-11

Warner, J. (2018). Why they can't write: Killing the five-paragraph essay and other necessities. John Hopkins University Press. 
Wenger, E. (1998) Communities of practice: learning, meaning, and identity. Cambridge University Press.

Whitehead, D. (2002). The academic writing experiences of a group of student nurses: A phenomenological study. Journal of Advanced Nursing, 38(5), 498-506. https://doi.org/10.1046/j.1365-2648.2002.02211.x

Yagelski, R. (2011). Writing as a way of being: Writing instruction, nonduality, and the crisis of sustainability. Hampton Press. 


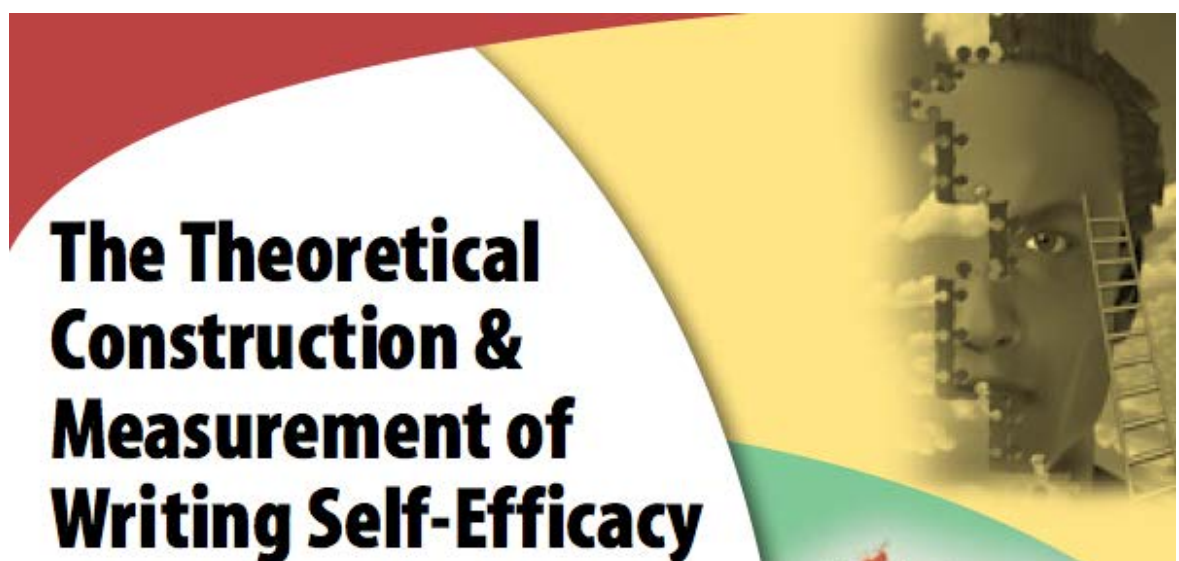

Kim M. Mitchell, RN, MN, Doctoral Student

Committee:

Dr. Diana McMillan (Advisor);

Dr. Michelle Lobchuk (Internal member);

Dr. Nathan Nickel (External member)

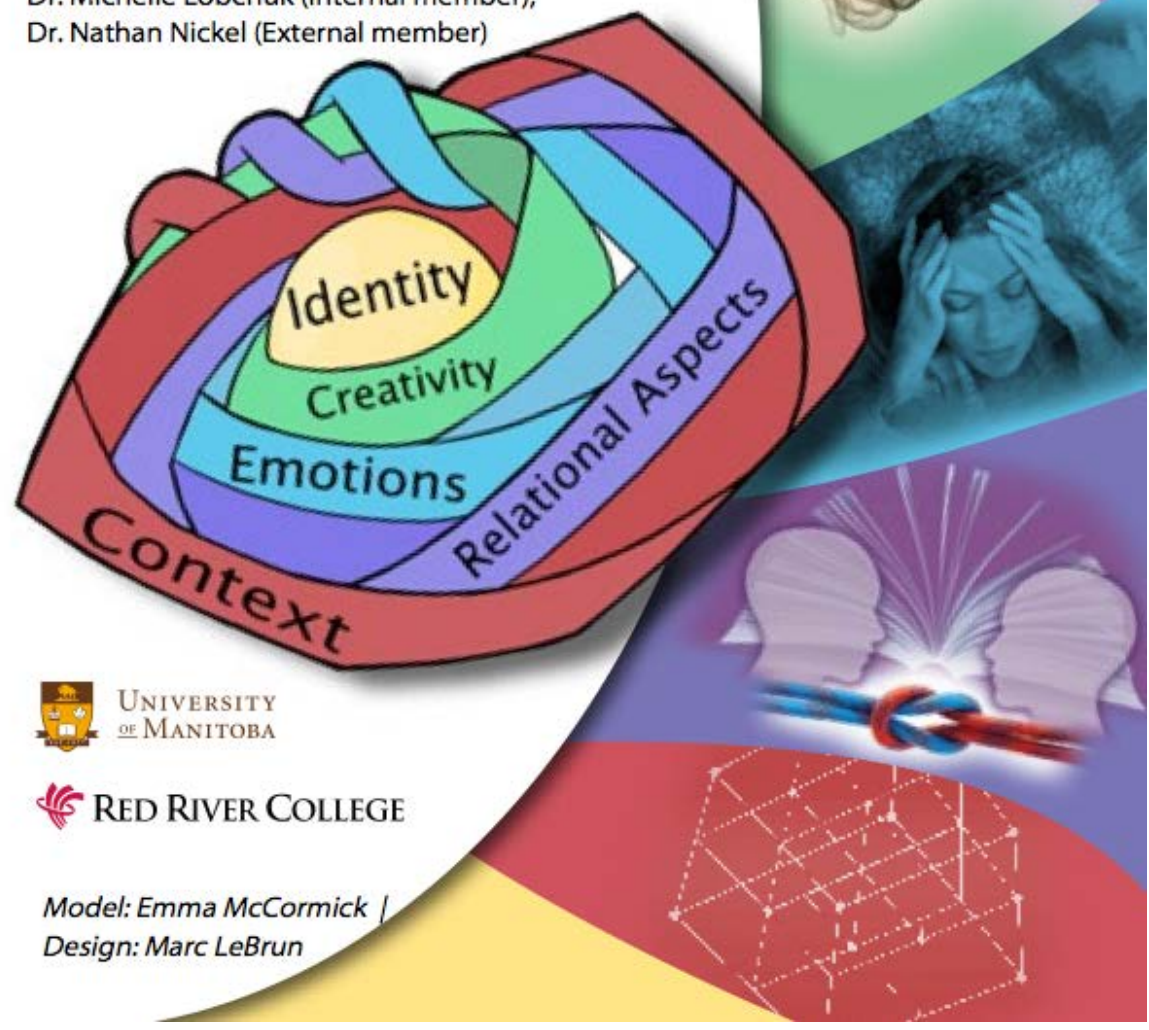


Appendix A - Situated Academic Writing Self-Efficacy Scale Evolution of Item Editing

\begin{tabular}{|c|c|c|c|c|c|c|c|c|}
\hline $\begin{array}{l}\text { Developed } \\
\text { Items }\end{array}$ & $\begin{array}{c}\text { Round } 1 \\
\text { Delphi } \\
\text { Edits }\end{array}$ & $\begin{array}{c}\text { Round } 2 \\
\text { Delphi } \\
\text { Edits }\end{array}$ & $\begin{array}{c}\text { Cognitive } \\
\text { Interviews } \\
\text { (edits after } 3 \\
\text { students) }\end{array}$ & $\begin{array}{c}\text { Cognitive } \\
\text { Interviews } \\
\text { (edits after } 6 \\
\text { students) }\end{array}$ & $\begin{array}{c}\text { Cognitive } \\
\text { Interviews } \\
\text { (edits after } 12 \\
\text { students) } \\
\end{array}$ & $\begin{array}{c}\text { Cognitive } \\
\text { Interviews } \\
\text { (edits after } 17 \\
\text { students) } \\
\end{array}$ & $\begin{array}{c}\text { Exploratory } \\
\text { Factor } \\
\text { Analysis }\end{array}$ & Final Scale \\
\hline \multicolumn{9}{|c|}{ Identity Items } \\
\hline $\begin{array}{l}\text { 1. I can write so } \\
\text { the final product } \\
\text { of that writing } \\
\text { feels like it } \\
\text { belongs to me. }\end{array}$ & $\begin{array}{l}\text { 1. I can write so } \\
\text { the final text or } \\
\text { product feels } \\
\text { like it came } \\
\text { from me. }\end{array}$ & & $\begin{array}{l}\text { 1. Even if I } \\
\text { paraphrase and } \\
\text { cite many } \\
\text { sources, I can } \\
\text { feel I've } \\
\text { contributed } \\
\text { ideas and the } \\
\text { writing has } \\
\text { come from me. }\end{array}$ & & $\begin{array}{l}\text { Delete - } \\
\text { Initially like } \\
\text { voice item then } \\
\text { edited was } \\
\text { similar to } \\
\text { creativity item } \\
\text { 2. Also, } \\
\text { difficulty with } \\
\text { student } \\
\text { understanding }\end{array}$ & & & \\
\hline $\begin{array}{l}\text { 2. Writing } \\
\text { assignments can } \\
\text { help me feel } \\
\text { like I am a part } \\
\text { of the nursing } \\
\text { profession. }\end{array}$ & $\begin{array}{l}\text { 2. Relevant } \\
\text { writing } \\
\text { assignments } \\
\text { about nursing } \\
\text { can help me to } \\
\text { see how I am } \\
\text { part of the } \\
\text { nursing } \\
\text { profession. }\end{array}$ & $\begin{array}{l}\text { 2. Writing } \\
\text { assignments } \\
\text { relevant to } \\
\text { nursing can help } \\
\text { me to feel part } \\
\text { of the nursing } \\
\text { profession. }\end{array}$ & & & & & $\begin{array}{c}\text { Delete } \\
\text { Cross loaded on } \\
2 \text { factors }\end{array}$ & \\
\hline $\begin{array}{l}\text { 3. No matter } \\
\text { what it is I am } \\
\text { asked to write, I } \\
\text { can write it } \\
\text { well. }\end{array}$ & $\begin{array}{l}\text { Delete - low } \\
\text { ratings }\end{array}$ & & & & & & & \\
\hline $\begin{array}{l}\text { 4. When I write, } \\
\text { I can look past } \\
\text { any negative } \\
\text { experiences I } \\
\text { may have had } \\
\text { with writing } \\
\text { assignments and }\end{array}$ & $\begin{array}{l}\text { Delete-low } \\
\text { ratings }\end{array}$ & & & & & & & \\
\hline
\end{tabular}




\begin{tabular}{|c|c|c|c|c|c|}
\hline \multicolumn{6}{|l|}{$\begin{array}{l}\text { get the job } \\
\text { done. }\end{array}$} \\
\hline $\begin{array}{l}\text { 5. When I am } \\
\text { preparing for a } \\
\text { writing } \\
\text { assignment, I } \\
\text { can often find } \\
\text { myself thinking, } \\
\text { at unusual times } \\
\text { and places, } \\
\text { about how to } \\
\text { approach the } \\
\text { writing. }\end{array}$ & $\begin{array}{l}\text { Delete-low } \\
\text { ratings }\end{array}$ & & & & \\
\hline $\begin{array}{l}\text { 6. I feel I can } \\
\text { develop my } \\
\text { own writing } \\
\text { voice. }\end{array}$ & & & & $\begin{array}{l}\text { 6. I feel I can } \\
\text { develop my } \\
\text { own writing } \\
\text { voice (ways of } \\
\text { speaking in my } \\
\text { writing that are } \\
\text { uniquely me). }\end{array}$ & $\begin{array}{l}\text { Loaded to } \\
\text { Factor 3: } \\
\text { Creative } \\
\text { Identity }\end{array}$ \\
\hline $\begin{array}{l}\text { 7. When I } \\
\text { reflect on my } \\
\text { writing, I can } \\
\text { make my } \\
\text { writing better. }\end{array}$ & & & & $\begin{array}{l}\text { 7. When I } \\
\text { reflect on what I } \\
\text { am writing I can } \\
\text { make my } \\
\text { writing better. }\end{array}$ & $\begin{array}{l}\text { Loaded to } \\
\text { Factor 2: } \\
\text { Relational-Self- } \\
\text { reflective }\end{array}$ \\
\hline \multicolumn{6}{|c|}{ Creativity Items } \\
\hline $\begin{array}{l}\text { 1. When I } \\
\text { choose a topic, I } \\
\text { feel I can make } \\
\text { more unique } \\
\text { choices than } \\
\text { most of my } \\
\text { classmates. }\end{array}$ & $\begin{array}{l}\text { Delete-low } \\
\text { ratings }\end{array}$ & & & & \\
\hline $\begin{array}{l}\text { 2. I can } \\
\text { creatively bring } \\
\text { together } \\
\text { multiple sources } \\
\text { into an original } \\
\text { written product. }\end{array}$ & $\begin{array}{l}\text { 2. I can bring } \\
\text { together } \\
\text { multiple sources } \\
\text { in ways that are } \\
\text { unexpected to } \\
\text { create an } \\
\text { original product } \\
\text { or text. }\end{array}$ & $\begin{array}{l}\text { 2. I can bring } \\
\text { together } \\
\text { multiple sources } \\
\text { to create an } \\
\text { original product } \\
\text { or text. }\end{array}$ & $\begin{array}{l}\text { 2. I can } \\
\text { combine or } \\
\text { synthesize } \\
\text { multiple sources } \\
\text { I've read to } \\
\text { create an } \\
\text { original product } \\
\text { or text. }\end{array}$ & & $\begin{array}{l}\text { Loaded to } \\
\text { Factor 1: } \\
\text { Writing } \\
\text { Essentials }\end{array}$ \\
\hline
\end{tabular}




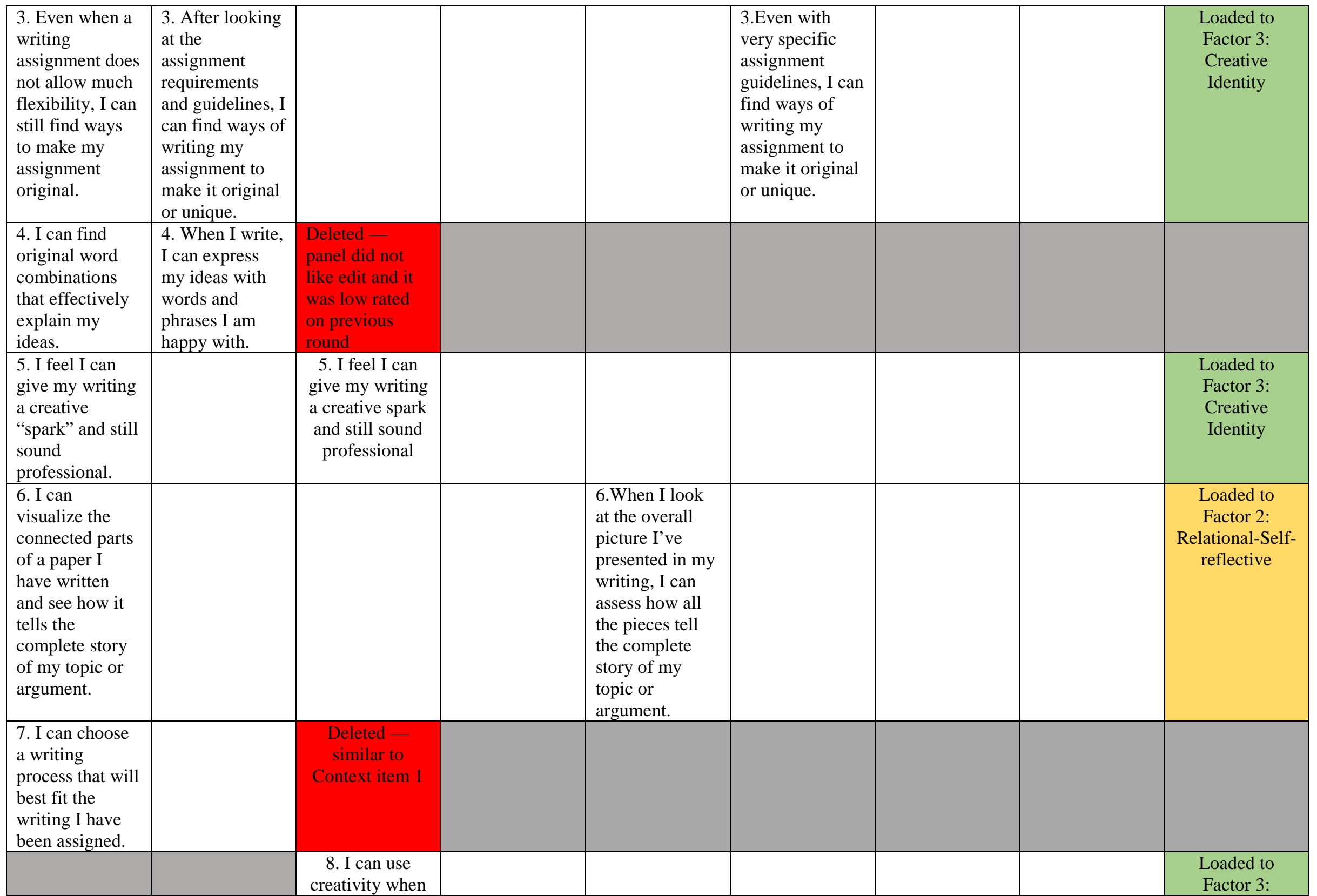




\begin{tabular}{|c|c|c|c|c|c|c|c|c|}
\hline & & $\begin{array}{c}\text { writing an } \\
\text { academic paper. }\end{array}$ & & & & & & $\begin{array}{l}\text { Creative } \\
\text { Identity }\end{array}$ \\
\hline \multicolumn{9}{|c|}{ Emotions Items } \\
\hline $\begin{array}{l}\text { 1. I can write a } \\
\text { major } \\
\text { assignment } \\
\text { without letting } \\
\text { my emotions } \\
\text { paralyze me. }\end{array}$ & $\begin{array}{l}\text { 1. I can write a } \\
\text { major writing } \\
\text { assignment } \\
\text { without letting } \\
\text { my emotions } \\
\text { prevent me } \\
\text { from making } \\
\text { progress. }\end{array}$ & & & & & & $\begin{array}{c}\text { Deleted in } \\
\text { factor analysis: } \\
\text { Cross loaded on } \\
2 \text { factors }\end{array}$ & \\
\hline $\begin{array}{l}\text { 2. I can remain } \\
\text { calm and in } \\
\text { control through } \\
\text { the writing } \\
\text { process. }\end{array}$ & $\begin{array}{l}\text { Delete-low } \\
\text { ratings }\end{array}$ & & & & & & & \\
\hline $\begin{array}{l}\text { 3. When I am } \\
\text { excited about } \\
\text { what I am } \\
\text { writing, I can } \\
\text { work with that } \\
\text { excitement to } \\
\text { write a better } \\
\text { paper. }\end{array}$ & & & & & $\begin{array}{l}\text { Delete-ceiling } \\
\text { effect }\end{array}$ & & & \\
\hline $\begin{array}{l}\text { 4. I can use my } \\
\text { enjoyment of } \\
\text { writing as a } \\
\text { positive } \\
\text { motivator to be } \\
\text { a better writer. }\end{array}$ & $\begin{array}{l}\text { 4. I can use the } \\
\text { ups and downs } \\
\text { of my emotions, } \\
\text { emerging from } \\
\text { the many } \\
\text { challenges of } \\
\text { writing, as a } \\
\text { motivator to } \\
\text { stay engaged } \\
\text { with my } \\
\text { writing. }\end{array}$ & $\begin{array}{l}\text { 4. I can use the } \\
\text { positive and } \\
\text { negative } \\
\text { emotions of } \\
\text { writing as a } \\
\text { motivator to } \\
\text { stay engaged } \\
\text { with my } \\
\text { writing. }\end{array}$ & $\begin{array}{l}\text { 4. I can use any } \\
\text { difficult } \\
\text { emotions I'm } \\
\text { having about } \\
\text { my writing } \\
\text { process as a } \\
\text { motivator to } \\
\text { stay engaged } \\
\text { with my writing }\end{array}$ & $\begin{array}{l}\text { 4. I can use any } \\
\text { difficult } \\
\text { emotions } \\
\text { brought on by } \\
\text { writing as a } \\
\text { motivator to } \\
\text { stay engaged } \\
\text { with my } \\
\text { writing. }\end{array}$ & $\begin{array}{l}\text { 4. I can use my } \\
\text { emotional } \\
\text { responses to } \\
\text { writing as a } \\
\text { motivator to } \\
\text { stay engaged } \\
\text { with my } \\
\text { writing. }\end{array}$ & $\begin{array}{c}\text { Delete - not } \\
\text { effectively } \\
\text { understood after } \\
6 \text { revisions. } \\
\text { May be too high } \\
\text { level for } \\
\text { undergraduates. }\end{array}$ & & \\
\hline $\begin{array}{l}\text { 5. Even when } \\
\text { the writing is } \\
\text { hard, I can find } \\
\text { ways to } \\
\text { overcome my }\end{array}$ & & & & & & & & $\begin{array}{c}\text { Loaded to } \\
\text { Factor 1: } \\
\text { Writing } \\
\text { Essentials }\end{array}$ \\
\hline
\end{tabular}




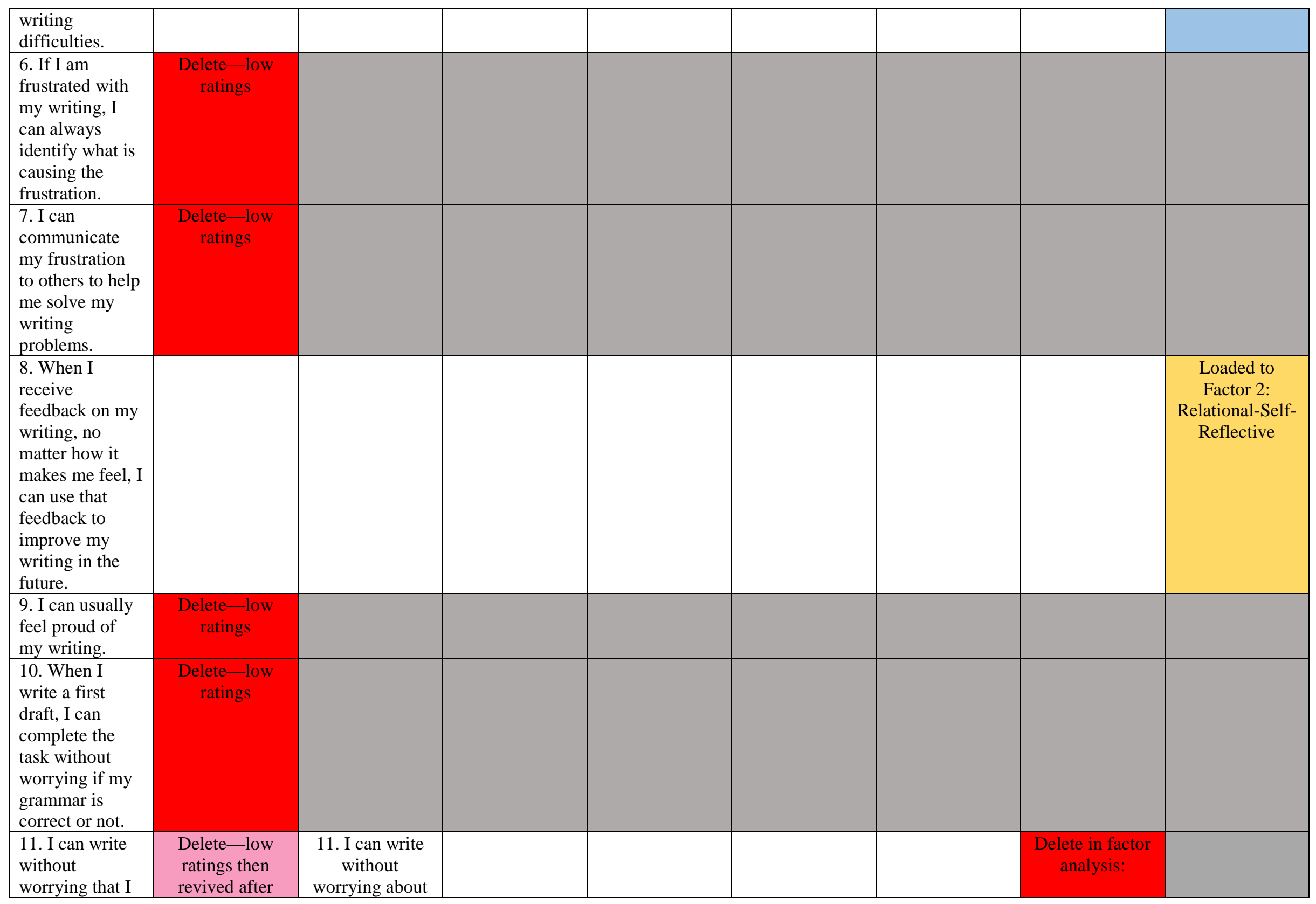




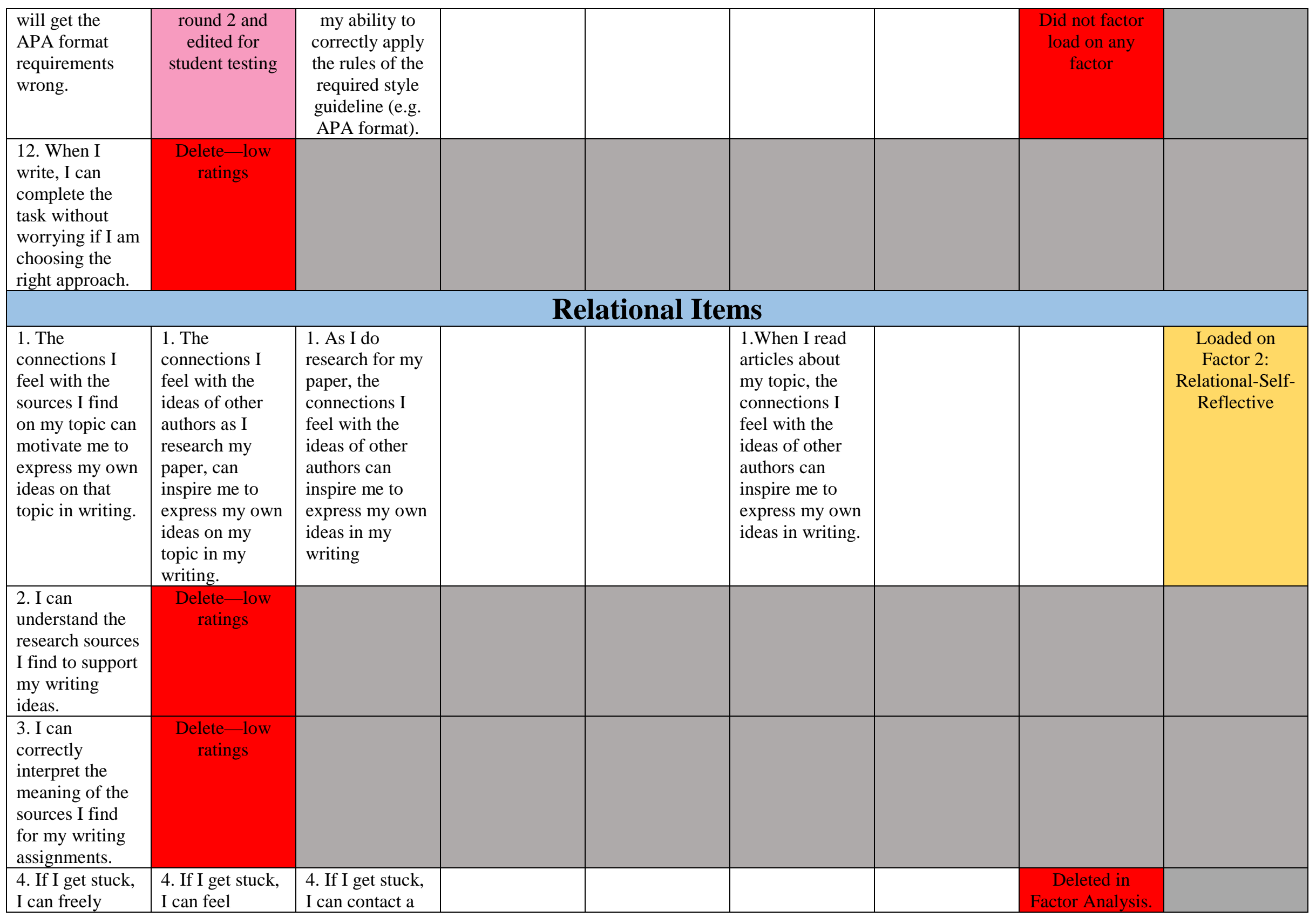




\begin{tabular}{|c|c|c|c|c|c|c|c|}
\hline $\begin{array}{l}\text { contact a } \\
\text { teacher or tutor } \\
\text { to help me } \\
\text { move forward } \\
\text { with my writing } \\
\text { ideas. }\end{array}$ & $\begin{array}{l}\text { comfortable } \\
\text { contacting a } \\
\text { teacher or tutor } \\
\text { to help me } \\
\text { move forward } \\
\text { with my writing } \\
\text { ideas. }\end{array}$ & $\begin{array}{l}\text { teacher or tutor } \\
\text { to help me } \\
\text { move forward } \\
\text { with my writing } \\
\text { ideas. }\end{array}$ & & & & $\begin{array}{l}\text { Low loading on } \\
\text { single factor } \\
\text { scale in } \\
\text { preliminary } \\
\text { analysis. Had } \\
\text { low } \\
\text { communality } \\
\text { and high } \\
\text { uniqueness in } \\
\text { final data set. } \\
\text { Also some } \\
\text { students } \\
\text { verbally said: “I } \\
\text { can do this, I } \\
\text { don’t do it” }\end{array}$ & \\
\hline $\begin{array}{l}\text { 5. I can write so } \\
\text { the audience I } \\
\text { am writing for } \\
\text { can clearly } \\
\text { understand my } \\
\text { meaning. }\end{array}$ & $\begin{array}{l}\text { 5. When I write, } \\
\text { I can think } \\
\text { about my } \\
\text { audience and } \\
\text { write so they } \\
\text { clearly } \\
\text { understand my } \\
\text { meaning. }\end{array}$ & & & & & & $\begin{array}{c}\text { Loaded on } \\
\text { Factor 2: } \\
\text { Relational-Self- } \\
\text { Reflective }\end{array}$ \\
\hline $\begin{array}{l}\text { 6. I can always } \\
\text { think about my } \\
\text { audience when I } \\
\text { write. }\end{array}$ & $\begin{array}{c}\text { Delete-low } \\
\text { ratings }\end{array}$ & & & & & & \\
\hline \multirow[t]{2}{*}{$\begin{array}{l}\text { 7. I can } \\
\text { prioritize } \\
\text { writing what my } \\
\text { audience needs } \\
\text { to know over } \\
\text { my needs for } \\
\text { self-expression. }\end{array}$} & $\begin{array}{l}\text { 7. I can focus } \\
\text { my writing to } \\
\text { what my } \\
\text { audience needs } \\
\text { to know over } \\
\text { my needs for } \\
\text { self-expression }\end{array}$ & & $\begin{array}{l}\text { 7. I can } \\
\text { recognize when } \\
\text { I've strayed } \\
\text { from writing } \\
\text { what my } \\
\text { audience needs } \\
\text { to know and } \\
\text { wandered into } \\
\text { writing about } \\
\text { interesting, but } \\
\text { unrelated, } \\
\text { details. }\end{array}$ & $\begin{array}{l}\text { 7. I can } \\
\text { recognize when } \\
\text { I've strayed } \\
\text { from writing } \\
\text { what my } \\
\text { audience needs } \\
\text { to know and } \\
\text { have wandered } \\
\text { into writing } \\
\text { about } \\
\text { interesting, but } \\
\text { unrelated, ideas. }\end{array}$ & $\begin{array}{c}\text { 7. I can } \\
\text { recognize when } \\
\text { I've wandered } \\
\text { from writing } \\
\text { what my } \\
\text { audience needs } \\
\text { to know and } \\
\text { have begun } \\
\text { writing about } \\
\text { interesting, but } \\
\text { unrelated, ideas. }\end{array}$ & & $\begin{array}{c}\text { Loaded on } \\
\text { Factor 2: } \\
\text { Relational-Self- } \\
\text { Reflective }\end{array}$ \\
\hline & $\begin{array}{l}\text { 8. New: When I } \\
\text { receive }\end{array}$ & & $\begin{array}{l}\text { 8. When I seek } \\
\text { feedback on }\end{array}$ & $\begin{array}{l}\text { 8. When I seek } \\
\text { feedback on my }\end{array}$ & & & $\begin{array}{l}\text { Loaded on } \\
\text { Factor 2: }\end{array}$ \\
\hline
\end{tabular}




\begin{tabular}{|c|c|c|c|c|c|c|}
\hline & $\begin{array}{l}\text { feedback from } \\
\text { peers or } \\
\text { teachers, I can } \\
\text { decide when } \\
\text { that feedback } \\
\text { should be } \\
\text { ignored or } \\
\text { incorporated } \\
\text { into a revision } \\
\text { in my writing. }\end{array}$ & & $\begin{array}{l}\text { early drafts of } \\
\text { my writing, I } \\
\text { can decide } \\
\text { when that } \\
\text { feedback should } \\
\text { be ignored or } \\
\text { incorporated } \\
\text { into a revision } \\
\text { in my writing. }\end{array}$ & $\begin{array}{l}\text { writing, I can } \\
\text { decide when } \\
\text { that feedback } \\
\text { should be } \\
\text { ignored or } \\
\text { incorporated } \\
\text { into a revision } \\
\text { in my writing. }\end{array}$ & & $\begin{array}{c}\text { Relational-Self- } \\
\text { Reflective }\end{array}$ \\
\hline \multicolumn{7}{|c|}{ Context Items } \\
\hline $\begin{array}{l}\text { 1. With each } \\
\text { new writing } \\
\text { assignment, I } \\
\text { can adjust my } \\
\text { writing style to } \\
\text { meet the needs } \\
\text { of that } \\
\text { assignment. }\end{array}$ & $\begin{array}{l}\text { 1. With each } \\
\text { new writing } \\
\text { assignment, I } \\
\text { can adjust my } \\
\text { writing style } \\
\text { and process to } \\
\text { meet the needs } \\
\text { of that } \\
\text { assignment } \\
\text { and/or course } \\
\text { requirements }\end{array}$ & $\begin{array}{l}\text { 1. With each } \\
\text { new writing } \\
\text { assignment, I } \\
\text { can adjust my } \\
\text { writing process } \\
\text { to meet the } \\
\text { needs of that } \\
\text { assignment. }\end{array}$ & & $\begin{array}{l}\text { 1. With each } \\
\text { new writing } \\
\text { assignment, I } \\
\text { can adjust my } \\
\text { writing to meet } \\
\text { the needs of that } \\
\text { assignment. }\end{array}$ & $\begin{array}{l}\text { 1. With each } \\
\text { new writing } \\
\text { assignment, I } \\
\text { can adapt my } \\
\text { writing to meet } \\
\text { the needs of that } \\
\text { assignment. }\end{array}$ & $\begin{array}{c}\text { Loaded on } \\
\text { Factor 2: } \\
\text { Relational-Self- } \\
\text { Reflective }\end{array}$ \\
\hline $\begin{array}{l}\text { 2. I can } \\
\text { successfully use } \\
\text { scholarly } \\
\text { academic words } \\
\text { and writing } \\
\text { styles when } \\
\text { writing in my } \\
\text { courses. }\end{array}$ & & & & $\begin{array}{l}\text { 2. I can } \\
\text { successfully use } \\
\text { scholarly } \\
\text { academic words } \\
\text { and phrases } \\
\text { when writing in } \\
\text { my courses. }\end{array}$ & & $\begin{array}{c}\text { Loaded on } \\
\text { Factor 1: } \\
\text { Writing } \\
\text { Essentials }\end{array}$ \\
\hline $\begin{array}{l}\text { 3. I can consider } \\
\text { the needs of } \\
\text { nursing when I } \\
\text { choose the } \\
\text { topics I write } \\
\text { about in my } \\
\text { courses. }\end{array}$ & $\begin{array}{l}\text { Delete-low } \\
\text { ratings }\end{array}$ & & & & & \\
\hline $\begin{array}{l}\text { 4. I can usually } \\
\text { figure out the } \\
\text { way a teacher } \\
\text { wants me to }\end{array}$ & $\begin{array}{l}\text { Delete-low } \\
\text { ratings }\end{array}$ & & & & & \\
\hline
\end{tabular}




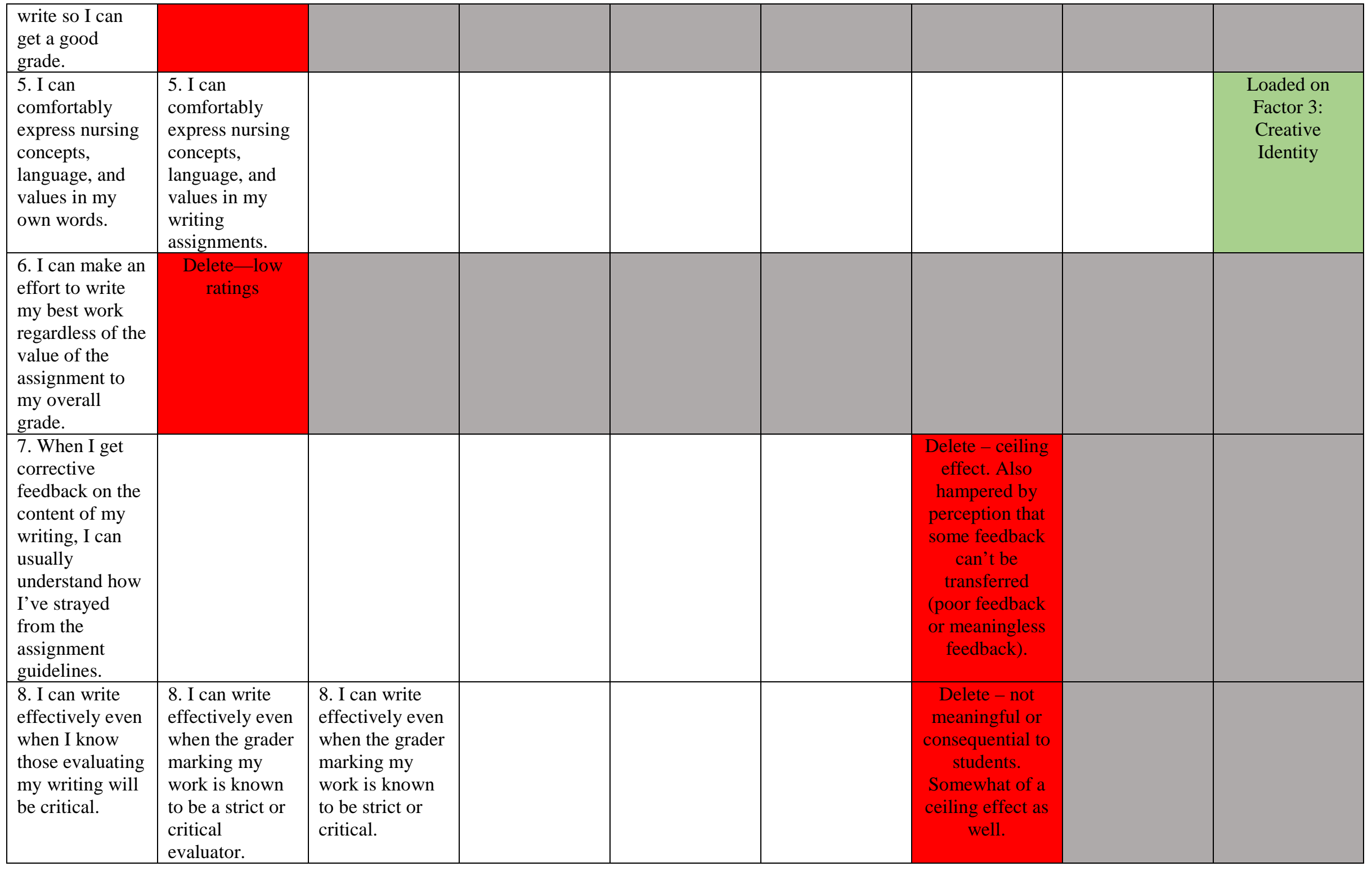




\section{Appendix B - Round 1 Delphi Survey}

\section{Delphi Survey Description, Open-Ended Questions, and Writing Self-Efficacy Questionnaire Items}

\section{Description of general survey format:}

The survey link will be emailed to each participant from within the Qualtrics survey platform. The survey will be organized into 7 pages:

Page 1 - Informed consent

Page 2 - Identity items and related questions

Page 3 - Creativity items and related questions

Page 4 - Emotions items and related questions

Page 5 - Relational items and related questions

Page 6 - Context items and related questions

Page 7 - Demographic questions

A description of each theoretical domain will be included on its page.

An electronic sliding scale similar to the following will be associated with each item:

By clicking on and sliding the bar on each scale, rate each item for its relevance to the assessment of writing self-efficacy:

Not at all

Completely

Relevant (0)

Relevant (100)

Each item will also be presented with a text box for open ended responses that says:

Please provide any comments, reactions, concerns or thoughts about this item. For example.

- $\quad$ Did you rate the item very high or very low? Provide your reasons for your choice of rating.

- Does the item require editing in any way for grammar, clarity or meaning?

- Does the item fit within this domain (identity)?

- Would you recommend deleting this item? If so why?

Additionally, general open-ended questions will be asked about each domain as a whole:

1. What would you select as the top three most important items to assessing the domain of [identity]?

2. Are there any items that should be added to this domain?

3. In future Delphi rounds, any items that were rated for inclusion in the survey will be listed and a general question will be asked: The following items have been approved by the panel for inclusion. Do you have any further comments about any of these approved items? 


\section{The survey items and their domain descriptions are as follows:}

\section{Identity Items:}

Identity incorporates writing voice, the self as it appears within a written text, past experiences with writing and their influence on present writing, and degree of writing mastery. A writer's perceived identity in the discipline of nursing will also be relevant. Reflexivity facilitates the metacognition and intertwining required to activate the other components of the model as they relate to writing and nursing identity. A writer's self-efficacy will be negatively impacted when they do not identify with their discipline or its writing or when they feel their personal self and ideas are not valued in the writing process.

1. I can write so the final product of that writing feels like it belongs to me.

2. Writing assignments can help me feel like I am a part of the nursing profession.

3. No matter what it is I am asked to write, I can write it well.

4. When I write, I can look past any negative experiences I may have had with writing assignments and get the job done.

5. When I am preparing for a writing assignment, I can often find myself thinking, at unusual times and places, about how to approach the writing.

6. I feel I can develop my own writing voice.

7. When I reflect on my writing, I can make my writing better.

\section{Creativity Items:}

Novelty and originality as defined by a discipline informs creativity. Idea generation, synthesis, ability to manipulate a genre, and interpretive abilities all require creativity. Creativity fuels passions and develops identity through a merger of the personal and the professional. A writer's self-efficacy will be impacted if they feel that they are not allowed to be creative or if their version of creativity is not shared by the faculty who assigns the writing.

1. When I choose a topic, I feel I can make more unique choices than most of my classmates.

2. I can creatively bring together multiple sources into an original written product.

3. Even when a writing assignment does not allow much flexibility, I can still find ways to make my assignment original.

4. I can find original word combinations that effectively explain my ideas.

5. I feel I can give my writing a creative "spark" and still sound professional.

6. I can visualize the connected parts of a paper I have written and see how it tells the complete story of my topic or argument.

7. I can choose a writing process that will best fit the writing I have been assigned.

\section{Emotions Items:}

Writing emotions can be positive or negative, are subject to roller-coaster extremes, and will drive or inhibit the writing act. Emotions are present at all phases of writing from planning to feedback. Ability to control emotions, write in the face of difficulties, and write in an 
environment that validates or does not validate the normality of writing emotions will impact writing self-efficacy.

1. I can write a major assignment without letting my emotions paralyze me.

2. I can remain calm and in control through the writing process.

3. When I am excited about what I am writing, I can work with that excitement to write a better paper.

4. I can use my enjoyment of writing as a positive motivator to be a better writer.

5. Even when the writing is hard, I can find ways to overcome my writing difficulties.

6. If I am frustrated with my writing, I can always identify what is causing the frustration.

7. I can communicate my frustration to others to help me solve my writing problems.

8. When I receive feedback on my writing, no matter how it makes me feel, I can use that feedback to improve my writing in the future.

9. I can usually feel proud of my writing.

10. When I write a first draft, I can complete the task without worrying if my grammar is correct or not.

11. I can write without worrying that I will get the APA format requirements wrong.

12. When I write, I can complete the task without worrying if I am choosing the right approach.

\section{Relational Items:}

Writers form relationships with the sources they incorporate through citation, inspiration, or interpretation. Writers write for an imagined audience and that audience connects with their writing when a writer reveals themselves in their work. Students also form relationships with their teachers and peers during pedagogical processes and feedback interactions. Ability to understand and relate to the sources read to inform their writing, position their own writing within a larger body of work, and connect with faculty and peers during the writing process will all affect student writing self-efficacy.

1. The connections I feel with the sources I find on my topic can motivate me to express my own ideas on that topic in writing.

2. I can understand the research sources I find to support my writing ideas.

3. I can correctly interpret the meaning of the sources I find for my writing assignments.

4. If I get stuck, I can freely contact a teacher or tutor to help me move forward with my writing ideas.

5. I can write so the audience I am writing for can clearly understand my meaning.

6. I can always think about my audience when I write.

7. I can prioritize writing what my audience needs to know over my needs for selfexpression.

\section{Context items:}

The writing context includes perceived difficulty of the writing task and writing evaluators, how they perceive the support they are receiving for their writing, the stakes involved in producing a well-received product, and the values and demands inherent in a disciplinary discourse. Writing 
self-efficacy will be impacted if students feel unsupported, devalues the assigned writing, or if they do not feel their actions in their writing context are likely to lead to success within the writing genre they need to produce.

1. With each new writing assignment, I can adjust my writing style to meet the needs of that assignment.

2. I can successfully use scholarly academic words and writing styles when writing in my courses.

3. I can consider the needs of nursing when I choose the topics I write about in my courses.

4. I can usually figure out the way a teacher wants me to write so I can get a good grade.

5. I can comfortably express nursing concepts, language, and values in my own words.

6. I can make an effort to write my best work regardless of the value of the assignment to my overall grade.

7. When I get corrective feedback on the content of my writing, I can usually understand how I've strayed from the assignment guidelines.

8. I can write effectively even when I know those evaluating my writing will be critical.

\section{Additional Survey Questions:}

The following additional survey questions will be asked of the participants after they have completed the item feedback section of the survey:

1. Your name

2. Gender of Reviewer:
o Male
o Female
o Non binary/other

3. Institutional affiliation

4. Discipline/Department

5. Rank/Position

o Graduate student

o Instructor/lecturer

o Senior lecturer/instructor

o Assistant professor

o Associate professor

o Full professor

6. Number of years teaching at a Post-secondary level 
7. Would you be willing to allow your name to appear in the acknowledgement section of Kim Mitchell's final thesis and in any future publications that may result from this project?

o Yes

o No

8. You participated in phase II of this study. Are you interested in receiving summaries of results from the completed research project after all phases are completed? (Approximately April 2020). Future phases include: cognitive interviewing with undergraduate nursing students (Phase III) and psychometric testing of the finalized instrument (Phase IV)?

o Yes

o No 


\section{8 \\ Rady Faculty of Health Sciences}

UNIVERSITY oF MANITOBA

College of Nursing

Helen Glass Centre for Nursing

Winnipeg, Manitoba

Canada

R3T 2N2

Telephone 204-474-9080

Fax 204-474-7682

\section{Appendix C - Email Invitation Script Delphi}

Dear [Name of Scholar],

You are receiving this email because we may have met at a past conference, communicated through Twitter, corresponded via a writing related listserv, or through a reference from another scholar contacted through one of those routes, and expressed interest in being a part of the Delphi panel to review the items developed for a new instrument measuring writing self-efficacy. This email will serve to introduce you to the specific procedures of the project. You have until [date 1 month from sending] to return your completed survey.

This email contains the instructions for the first [second, third etc...] round of this panel process. Included with this email are 3 important components for participating in this project:

1. Attached to this email you will find a letter of informed consent to participate. Please review this letter carefully and save or print a copy for your records. Your consent to participate will be assumed if you complete the Qualtrics survey link [this statement will only be included in the first round survey].

2. Also attached to this email is a 2-page description of the questionnaire and its theoretical premise. You may wish to print this document and have it in front of you as you complete the survey.

3. The link to the first round Qualtrics survey will be sent to you in a separate email from the Qualtrics platform. In the event this email does not arrive within the next hour, please check your junk mail folder. Reply to this email if you do not receive the link in this time frame.

Your involvement in this project is summarized in the bullets below:

- The panel will be consulted over several rounds (estimate between 2-4 rounds) with feedback on the results of the previous round provided with each round.

- This round's survey is expected to take between X and X minutes

- If you access the link to the survey from the Qualtrics email, you will be able to save your responses and complete the survey in more than one session.

- The survey will ask you to rate each individual item on the questionnaire for its relevance to the concept of writing self-efficacy.

- You will be asked to comment on edits needed to each item, its fit with the domain of the theory it has been assigned to, and if it should be deleted from the questionnaire and why. 
- You will be asked to identify what you feel are the top three most relevant items to the domain being assessed.

- You will also be given the opportunity to suggest additional items.

- You will also be asked for some limited personal information including name, country, gender, institutional affiliation, discipline, position/rank, and years teaching at a postsecondary level.

- Between survey rounds, you will be provided with a personalized summary of the previous round's results.

- Following the last round, you will be provided with a final summary of results.

This project has been approved by the Nursing Education Research Ethics Board at the University of Manitoba. If you have any questions about the approval of this study, please contact the Human Ethics Coordinator at humanethics@umanitoba.ca

If you have any questions regarding your role in this project, please feel free to reply to this email. Your continued participation in this project is voluntary and you may change your mind about participation at any time. If you are no longer able to participate in this project, please let me know and I will not send you any further reminders for completing this survey.

If you have any suggestions for other scholars that may be interested and have the expertise to complete this survey, please introduce them to me.

Your participation in this project is appreciated and has the potential to contribute to the development of a valid measurement instrument that will inform educators in nursing (as well as other disciplines) of the writing self-efficacy perspectives of undergraduate students which may have the potential to impact policy and pedagogy in academic programs.

Kind regards,

Kim Mitchell RN MN

Doctoral Candidate

College of Nursing, Rady Faculty of Health Sciences

University of Manitoba

Dr. Diana McMillan RN PhD

Advisor

College of Nursing, Rady Faculty of Health Sciences

University of Manitoba 


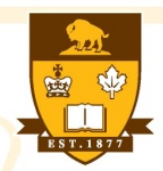

UNIVERSITY oF MANITOBA

Rady Faculty of Health Sciences
College of Nursing

Helen Glass Centre for Nursing

Winnipeg, Manitoba

Canada

R3T 2N2

Telephone 204-474-9080

Fax 204-474-7682

\section{Appendix D - Delphi Study Consent Form}

Title of Study: The Theoretical Construction and Measurement of Writing Self-Efficacy: A Proposed Mixed-Methods Validation Study in Four Phases -- Delphi Phase II

Principal Investigator: $\quad$ Kim Mitchell, Doctoral Student

Telephone:

Email:

\section{Committee:}

Advisor - Dr. Diana E. McMillan - College of Nursing, Rady Faculty of Health Sciences Internal - Dr. Michelle M. Lobchuk - College of Nursing, Rady Faculty of Health Sciences

External - Dr. Nathan C. Nickel - Department of Community Health Sciences, Rady Faculty of Health Sciences

This consent form, a copy of which will have also been emailed to you so you may print and/or save for your records and reference, is only part of the process of informed consent. It should give you the basic idea of what the research is about and what your participation will involve. If you would like more detail about something mentioned here, or information not included here, you should feel free to ask. Please take the time to read this carefully and to understand any accompanying information. This survey is a portion of the research being conducted for Kim Mitchell's doctoral thesis. While your role in this research project will be to peer review the writing self-efficacy questionnaire contained within the survey, you are being asked to consent to participating in this study so that the researchers have the option to anonymously include any qualitative statements that you make, regarding the relevance of these items, in future publications and presentations. You will also be given the option to allow your name to be mentioned in the acknowledgement sections of the final thesis and future publications. Submitting your responses to the survey through the provided survey link will be considered consent to participate in this research.

\section{Purpose of Study}

The purpose of this Delphi panel portion of the study is to have nursing and writing scholars review the items on the questionnaire contained in the survey for their applicability for assessing writing self-efficacy. You will also be asked to consider each item's fit for its theoretical domain - please see the description of the theoretical perspective for this study for a complete description. While there are many versions of Delphi method procedures and rationale for use, the goal of Delphi studies is to gain group consensus on a topic - in this case we are seeking 
agreement from experts on which items best reflect the concept of writing self-efficacy according to the constructionist framework presented to you as an attachment to the email invitation.

\section{Study Procedures}

Your participation as an expert reviewer of this questionnaire will take place over several rounds with feedback provided to you from Kim Mitchell between each round. The survey for each round is expected to take anywhere between 10 and 60 minutes of your time. The first phase (30-60 minutes) will take longer than any subsequent phases (10-30 minutes). As items are reviewed for inclusion through a rating process, some items will be removed from subsequent versions of the survey so future rounds of the survey presented to this panel will take less of your time. It is expected that this Delphi panel will require a minimum of 2 rounds, but more rounds may be required to achieve consensus. The start of any subsequent round will begin 2 to 3 weeks after the completion of a previous round. As it will be impossible to estimate the exact length of any subsequent round until the previous round is completed and the new survey is developed for the next phase, those estimates will be provided to you at the start of each round.

The first phase of this survey will present all of the 41 developed items on the writing self-efficacy questionnaire, each in five respective core categories: identity, creativity, emotions, relational aspects, and context. You will be asked to rate each item's relevance to writing self-efficacy on a 0-100 sliding scale in the Qualtrics survey program. You will also be invited to provide comments on the item's fit for the theoretical category it was attached to, suggest new items for that category, identify the items you feel are most relevant to the category, suggest edits to any items, and provide rationale if you believe an item should be deleted from the questionnaire.

You will also be asked for some limited personal information including name, country, gender, institutional affiliation, discipline, position/rank, and years teaching at a post-secondary level.

After each phase is completed, the researcher will compile the results and a results summary will be sent to you along with the next round's survey. This results summary will be personalized. It will provide you with the average rating score for each item for the entire panel alongside your own rating score from the previous round. It will alert you to which items have been approved for inclusion in the questionnaire and which items need to undergo further assessment. A summary of the comments made by the reviewers collectively for each item will also be included. This summary will help you with your decision making about the remaining items that will be presented in future rounds. When no more rounds are needed and the questionnaire structure has been established, you will be provided with a final results summary.

You will not be required to complete the survey in one sitting. If you start the survey and are unable to complete it, as long as you have accessed the survey via the link emailed to you from the Qualtrics platform, you can click on the link again and it will take you back to where you left off in the survey. You will not be required to complete all the rounds sent to you to participate in this process. You can withdraw from participation by sending an email to Kim Mitchell to alert her to your inability to respond to any round of this survey. 
During the study period, your identity will be known to the research team as the survey will ask you to type your name into the Qualtrics program. Being able to match your name with your responses is required for sending personalized summaries of the results. Your participation as an expert, your specific scores on the items, and your comments about those items will not be known to the other experts on the panel. You will be asked in every round of the survey if you will be willing to allow your name to be mentioned in the acknowledgement section of the final doctoral thesis and/or any publications that may result from this work. Only your final response to this question will stand as your true response. If you agree to allow your name to be mentioned in any acknowledgements, your identity as a participant will then be known to the other panel members and the general public. Your name will never be attached to any specific comments you may make within the survey if those comments are chosen as direct quotes for the thesis or any publications or presentations. If any direct quote the researcher may select for publication contains any other identifying information (e.g. your institution name) it will be redacted from the quote.

The electronic files containing the spreadsheet of results for the survey will be stored in a password protected University of Manitoba network drive accessible only by the researchers and on the password protected laptop owned by Kim Mitchell for the duration of the study until publication of the results in a peer-reviewed journal. The data will then be stored at the Manitoba Centre for Nursing and Health Research until its eventual destruction. Any paper copies of the spreadsheet, your personalized result summaries, and other researcher notes will be kept in a locked filing cabinet during the active study period in the home of Kim Mitchell. After the study period (completion expected January 2020), the data will be de-identified and will be kept for a minimum of 7 years but may be kept indefinitely and used for educational purposes.

The findings from this portion of the study will be presented in oral power point presentations, scientific poster presentations, and will be published in both the final thesis as well as in published manuscripts in academic journals. The researchers may choose to directly quote (with identifying information redacted) any comment you type into the open-ended response boxes in the Qualtrics platform. Your name or anything that identifies you will not be used in any presentation, manuscript, or publication unless you agree to include your name in any acknowledgments made in these venues.

\section{Possible Risks and Discomfort}

There are no known risks to participating in this study, beyond the risks inherent in daily living. Your contribution will be very similar to contributions made in other academic peer review contexts (journal publications, grant applications, or conference papers).

\section{Benefits}

There are no direct benefits to you for contributing your expertise to this research other than the knowledge that you will be contributing your expertise to the development of a valid measurement instrument that has the potential to inform educators in nursing (as well as other disciplines) of the writing self-efficacy perspectives of undergraduate students which may have the potential to impact policy and pedagogy in academic programs. You will be offered a \$25 CAD gift card to Amazon for your time as a thank-you for your contributions. 


\section{Cost for participation}

There will be no added cost to you for taking part in this study.

\section{Confidentiality}

We will do everything possible to ensure your confidentiality as a research participant. Only the above named researchers will know that you have chosen to participate and which data you have provided. All data collected from you will be stored on a password protected University of Manitoba network drive accessible only by the researchers. Your name will not be reported to anyone outside of the research team unless you provide us with permission to allow us to acknowledge your contribution in journal articles and presentations prepared from this work. You will be asked in the survey whether you consent to this being done. There is no obligation for you to allow your name to be publicly acknowledged. All data collected will be de-identified after study completion (January 2020).

\section{Voluntary Participation/Withdrawal from the Study}

Your decision to take part in this study is voluntary. There will be no negative repercussions if you decide not to take part or to withdraw from the study. To withdraw from this study, please email Kim Mitchell (kmmitch@myumanitoba.ca) stating that you wish to withdraw. No reasons are required. If you wish to have data that you have already provided removed from the study, you can let Kim know of this desire and your data will be deleted and not used in any reporting. However, once data analysis is complete at the end of the survey process, it will not be possible to remove your data from reporting as it will have already been used to make decisions about retaining, deleting or editing items on the questionnaire (by approximately May 31, 2019).

\section{Debriefing and Dissemination}

As you will be receiving summaries of the results of each round of the Delphi process, you will be aware of how the information you provide is being summarized and used to make decisions in this research study. After consensus is achieved, you will receive a final summary statement of the responses given by the panel shortly after the completion of the Delphi phase of this study. If you wish to be apprised of the final results of the larger study, please acknowledge this on the question proposed within the survey.

\section{Questions}

You are free to ask any questions that you may have about this survey, the overall research project and your rights as a research participant. If any questions come up during or after the study, you can contact Kim Mitchell at—kmmitch@myumanitoba.ca or her advisor Dr. Diana McMillan at diana.mcmillan@umanitoba.ca Do not complete the survey unless you have had a chance to ask questions and have received satisfactory answers to all of your questions.

\section{Consent}

Proceeding to complete the survey on the following pages indicates that you have understood to your satisfaction the information regarding participation in the research project and agree to participate as an expert reviewer. In no way does this waive your legal rights nor release the researchers, sponsors, or involved institutions from their legal and professional responsibilities. You are free to withdraw from the study at any time, and/or refrain from documenting any 
comments to the items you prefer to omit, without prejudice or consequence. Your continued participation should be as informed as your initial consent, so you should feel free to ask for clarification or new information throughout your participation.

The University of Manitoba may look at your research records to see that the research is being done in a safe and proper way.

This research has been approved by the Education/Nursing Research Ethics Board at the University of Manitoba. If you have any concerns or complaints about this project you may contact any of the above-named persons or the Human Ethics Coordinator (HEC) at 204-474-7122 or by email: humanethics@umanitoba.ca. A copy of this consent form has been given to you via email to keep for your records and reference.

If you consent to participate in this project as outlined in the above consent form, please click on the "Next" button below, to be taken to the first page of the survey. 


\section{Appendix E - Description of the Theoretical Perspective}

\section{Description of the Theoretical Perspectives for the Writing Self-Efficacy Questionnaire}

The theoretical perspective that has informed the development of the instrument has two primary sources, Bandura's self-efficacy theory and a model of socially constructed writing developed by the researcher and published in:

Mitchell, K. M. (2018). Constructing writing practices in nursing. Journal of Nursing Education, 57(7), 399-407. https://doi.org/10.3928/01484834-20180618-04

The questionnaire format follows the recommendations of Bandura who proposed that items on self-efficacy questionnaires should be phrased as "I can” statements and presented to participants in a 0-100 visual analogue scale format. When presented to participants, the visual analog for this questionnaire will include the anchors, "completely sure I cannot" to "completely sure I can.” The questionnaire has been divided into five domains as represented in the socially constructed model. The descriptions below describe the writing elements, activities, and interactions which comprise those domains. You can use these descriptions to help you identify if a proposed questionnaire item is a good fit for its theoretical category.

A constructionist model of writing is not linear but rather functions as an assemblage of factors with the nurse's writerly identity at the core (see Figure below). Each element of the writing model is intertwined with the others and any of the constructionist domains of writing can be the focus of the writing process at any moment. Reflective capacity is what intertwines the model together into a collective unit. The components of the model are as follows:

6. Identity: Incorporates writing voice, the self as it appears within a written text, past experiences with writing and their influence on present writing, and degree of writing mastery. A writer's perceived identity in the discipline of nursing will also be relevant. Reflexivity facilitates the metacognition and intertwining required to activate the other components of the model as they relate to writing and nursing identity. A writer's selfefficacy will be negatively impacted when they do not identify with their discipline or its writing or when they feel their personal self and ideas are not valued in the writing process.

7. Creativity: Novelty and originality as defined by a discipline informs creativity. Idea generation, synthesis, ability to manipulate a genre, and interpretive abilities all require creativity. Creativity fuels passions and develops identity through a merger of the personal and the professional. A writer's self-efficacy will be impacted if they feel that they are not allowed to be creative or if their version of creativity is not shared by the faculty who assigns the writing.

8. Emotions: Writing emotions can be positive or negative, are subject to roller-coaster extremes, and will drive or inhibit the writing act. Emotions are present at all phases of writing from planning to feedback. Ability to control emotions, write in the face of difficulties, and write in an environment that validates or does not validate the normality of writing emotions will impact writing self-efficacy. 
9. Relational Aspects: Writers form relationships with the sources they incorporate through citation, inspiration, or interpretation. Writers write for an imagined audience and that audience connects with their writing when a writer reveals themselves in their work. Students also form relationships with their teachers and peers during pedagogical processes and feedback interactions. Ability to understand and relate to the sources read to inform their writing, position their own writing within a larger body of work, and connect with faculty and peers during the writing process will all affect student writing self-efficacy.

10. Context: The writing context includes perceived difficulty of the writing task and writing evaluators, how they perceive the support they are receiving for their writing, the stakes involved in producing a well-received product, and the values and demands inherent in a disciplinary discourse. Writing self-efficacy will be impacted if students feel unsupported, devalue the assigned writing, or if they do not feel their actions in their writing context are likely to lead to success within the writing genre they need to produce.

The proposed writing self-efficacy instrument will be developed with items that fall into each of these five constructionist domains of writing. Self-efficacy theory blends into the constructionist perspective. Bandura's four sources of self-efficacy include mastery of a task, vicarious experiences, social persuasion, and emotional arousal. Being masterful in writing the genres of the nursing discipline is a sign that the writer is developing an identity in the discipline. Vicarious experiences and verbal persuasion are relational aspects of writing as vicarious experiences define how a writer views themselves in relation to their peers, and social persuasion explores how feedback, from faculty or other community members, affects self-perceptions of writing. Finally, emotional arousal merges with the emotional knowing domain of the constructionist perspective. Collectively, the constructionist theory fills in the many gaps present in self-efficacy theory for informing the measurement of writing self-efficacy.

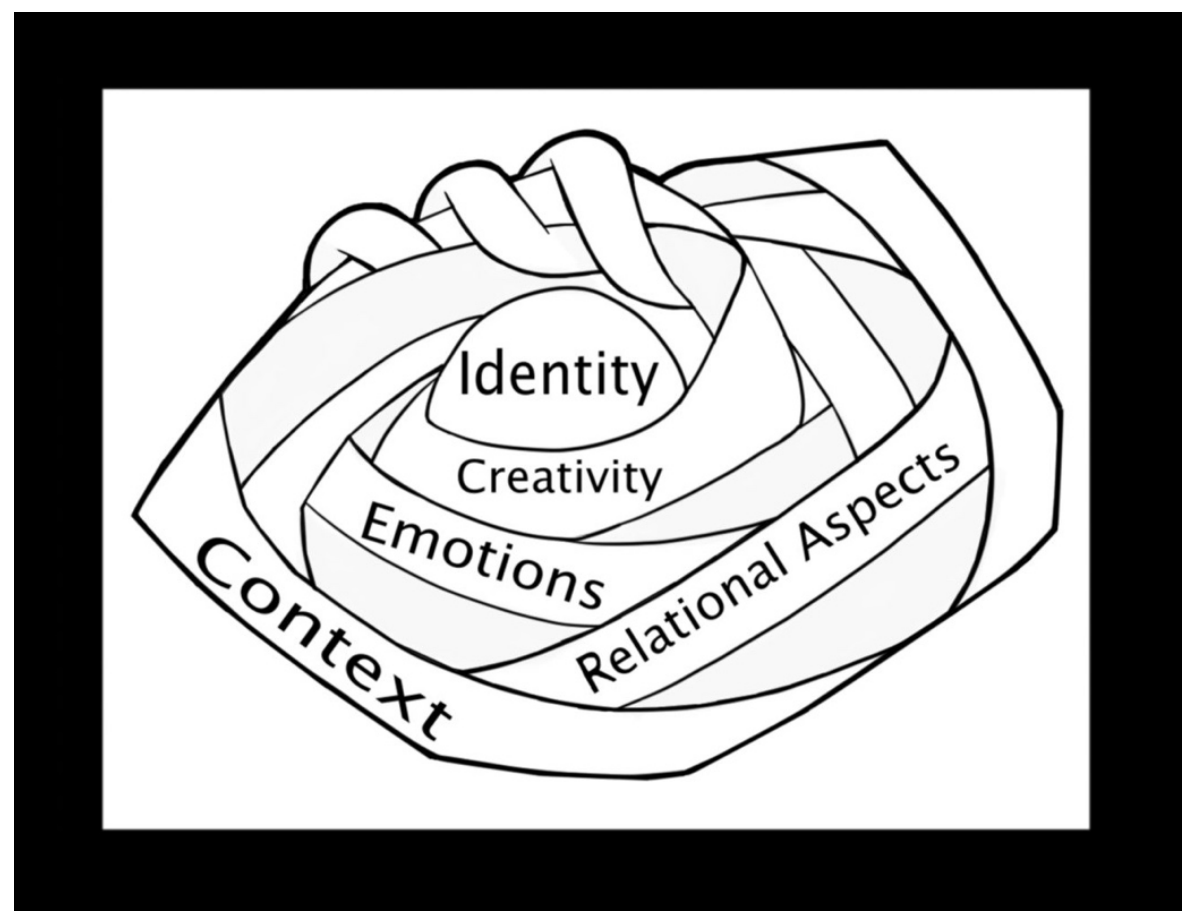




\section{Appendix F - Example of Summary of the Results Round 1}

The following table presents a summary of the relevance ratings for each individual item by mean score for the total sample $(N=15)$, nurse scholar sample $(n=7)$, writer scholar sample $(n=8)$. The final column represents your personal scores.

\begin{tabular}{|c|c|c|c|c|}
\hline \multirow{2}{*}{\begin{tabular}{|l|l} 
Item deleted \\
Identity
\end{tabular}} & \multicolumn{3}{|c|}{ Means/CVI } & \multirow{2}{*}{$\begin{array}{c}\text { Individual } \\
\text { Panelist } \\
\text { Scores } \\
\end{array}$} \\
\hline & Total & Nursing & Writing & \\
\hline $\begin{array}{l}\text { 1. I can write so the final product of that writing feels } \\
\text { like it belongs to me. }\end{array}$ & 85.0 & 87.4 & 82.9 & 100 \\
\hline $\begin{array}{l}\text { 2. Writing assignments can help me feel like I am a part } \\
\text { of the nursing profession. }\end{array}$ & 65.3 & 62.6 & 67.7 & 84 \\
\hline $\begin{array}{l}\text { 3. No matter what it is I am asked to write, I can write it } \\
\text { well. }\end{array}$ & 62.9 & 70.8 & 56.1 & 45 \\
\hline $\begin{array}{l}\text { 4. When I write, I can look past any negative } \\
\text { experiences I may have had with writing assignments and } \\
\text { get the job done. }\end{array}$ & 53.8 & 63.4 & 44.1 & 58 \\
\hline $\begin{array}{l}\text { 5. When I am preparing for a writing assignment, I can } \\
\text { often find myself thinking, at unusual times and places, } \\
\text { about how to approach the writing. }\end{array}$ & 58.0 & 78.9 & 37.1 & 20 \\
\hline 6. I feel I can develop my own writing voice. & 86.3 & 81.9 & 90.7 & 75 \\
\hline $\begin{array}{l}\text { 7. When I reflect on my writing, I can make my writing } \\
\text { better. }\end{array}$ & 90.1 & 89.7 & 90.6 & 98 \\
\hline \multicolumn{5}{|l|}{ Creativity } \\
\hline $\begin{array}{l}\text { 1. When I choose a topic, I feel I can make more unique } \\
\text { choices than most of my classmates. }\end{array}$ & 58.7 & 60.3 & 57.3 & 45 \\
\hline $\begin{array}{l}\text { 2. I can creatively bring together multiple sources into } \\
\text { an original written product. }\end{array}$ & 85.1 & 87.0 & 83.4 & 100 \\
\hline $\begin{array}{l}\text { 3. Even when a writing assignment does not allow much } \\
\text { flexibility, I can still find ways to make my assignment } \\
\text { original. }\end{array}$ & 63.9 & 57.0 & 70.0 & 77 \\
\hline $\begin{array}{l}\text { 4. I can find original word combinations that effectively } \\
\text { explain my ideas. }\end{array}$ & 68.0 & 71.7 & 64.8 & 89 \\
\hline $\begin{array}{l}\text { 5. I feel I can give my writing a creative "spark" and } \\
\text { still sound professional. }\end{array}$ & 69.7 & 79.4 & 61.1 & 94 \\
\hline $\begin{array}{l}\text { 6. I can visualize the connected parts of a paper I have } \\
\text { written and see how it tells the complete story of my topic } \\
\text { or argument. }\end{array}$ & 78.5 & 84.4 & 73.3 & 100 \\
\hline $\begin{array}{l}\text { 7. I can choose a writing process that will best fit the } \\
\text { writing I have been assigned. }\end{array}$ & 71.2 & 65.4 & 76.3 & 74 \\
\hline \multicolumn{5}{|l|}{ Emotions } \\
\hline $\begin{array}{l}\text { 1. I can write a major assignment without letting my } \\
\text { emotions paralyze me. }\end{array}$ & 82.1 & 70.1 & 92.6 & 92 \\
\hline $\begin{array}{l}2 . \quad \text { I can remain calm and in control through the writing } \\
\text { process. }\end{array}$ & 65.0 & 60.0 & 69.4 & 60 \\
\hline $\begin{array}{l}\text { 3. When I am excited about what I am writing, I can } \\
\text { work with that excitement to write a better paper. }\end{array}$ & 75.8 & 78.6 & 73.4 & 88 \\
\hline
\end{tabular}




\begin{tabular}{|c|c|c|c|c|}
\hline $\begin{array}{l}\text { 4. I can use my enjoyment of writing as a positive } \\
\text { motivator to be a better writer. }\end{array}$ & 65.8 & 65.4 & 66.1 & 100 \\
\hline $\begin{array}{l}\text { 5. Even when the writing is hard, I can find ways to } \\
\text { overcome my writing difficulties. }\end{array}$ & 80.3 & 87.7 & 73.9 & 99 \\
\hline $\begin{array}{l}\text { 6. If I am frustrated with my writing, I can always } \\
\text { identify what is causing the frustration. }\end{array}$ & 53.7 & 58.1 & 49.8 & 54 \\
\hline $\begin{array}{l}\text { 7. I can communicate my frustration to others to help } \\
\text { me solve my writing problems. }\end{array}$ & 59.7 & 60.7 & 58.9 & 61 \\
\hline $\begin{array}{l}8 . \text { When I receive feedback on my writing, no matter } \\
\text { how it makes me feel, I can use that feedback to improve } \\
\text { my writing in the future. }\end{array}$ & 73.9 & 85.4 & 63.9 & 100 \\
\hline 9. I can usually feel proud of my writing. & 68.3 & 75.1 & 62.3 & 62 \\
\hline $\begin{array}{l}\text { 10. When I write a first draft, I can complete the task } \\
\text { without worrying if my grammar is correct or not. }\end{array}$ & 63.6 & 66.4 & 61.1 & 38 \\
\hline $\begin{array}{l}\text { 11. I can write without worrying that I will get the APA } \\
\text { format requirements wrong. }\end{array}$ & 63.3 & 67.6 & 59.6 & 35 \\
\hline $\begin{array}{l}\text { 12. When I write, I can complete the task without } \\
\text { worrying if I am choosing the right approach. }\end{array}$ & 58.3 & 61.6 & 55.5 & 79 \\
\hline \multicolumn{5}{|l|}{ Relational } \\
\hline $\begin{array}{l}\text { 1. The connections I feel with the sources I find on my } \\
\text { topic can motivate me to express my own ideas on that } \\
\text { topic in writing. }\end{array}$ & 67.9 & 72.3 & 64.0 & 100 \\
\hline $\begin{array}{l}2 . \quad \text { I can understand the research sources I find to support } \\
\text { my writing ideas. }\end{array}$ & 71.8 & 68.1 & 75.0 & 94 \\
\hline $\begin{array}{l}\text { 3. I can correctly interpret the meaning of the sources I } \\
\text { find for my writing assignments. }\end{array}$ & 62.8 & 77.6 & 49.9 & 87 \\
\hline $\begin{array}{l}\text { 4. If I get stuck, I can freely contact a teacher or tutor to } \\
\text { help me move forward with my writing ideas. }\end{array}$ & 84.0 & 82.9 & 85.0 & 86 \\
\hline $\begin{array}{l}\text { 5. I can write so the audience I am writing for can } \\
\text { clearly understand my meaning. }\end{array}$ & 85.0 & 87.7 & 82.6 & 100 \\
\hline 6. I can always think about my audience when I write. & 69.1 & 76.7 & 62.5 & 54 \\
\hline $\begin{array}{l}\text { 7. I can prioritize writing what my audience needs to } \\
\text { know over my needs for self-expression. }\end{array}$ & 76.7 & 76.9 & 76.5 & 99 \\
\hline \multicolumn{5}{|l|}{ Context } \\
\hline $\begin{array}{l}\text { 1. With each new writing assignment, I can adjust my } \\
\text { writing style to meet the needs of that assignment. }\end{array}$ & 77.6 & 68.9 & 85.3 & 100 \\
\hline $\begin{array}{l}\text { 2. I can successfully use scholarly academic words and } \\
\text { writing styles when writing in my courses. }\end{array}$ & 86.3 & 83.3 & 89.0 & 79 \\
\hline $\begin{array}{l}\text { 3. I can consider the needs of nursing when I choose the } \\
\text { topics I write about in my courses. }\end{array}$ & 67.2 & 67.1 & 67.3 & 97 \\
\hline $\begin{array}{l}\text { 4. I can usually figure out the way a teacher wants me to } \\
\text { write so I can get a good grade. }\end{array}$ & 65.9 & 73.1 & 59.5 & 84 \\
\hline $\begin{array}{l}\text { 5. I can comfortably express nursing concepts, } \\
\text { language, and values in my own words. }\end{array}$ & 80.7 & 83.7 & 78.1 & 100 \\
\hline $\begin{array}{l}\text { 6. I can make an effort to write my best work regardless } \\
\text { of the value of the assignment to my overall grade. }\end{array}$ & 66.8 & 70.3 & 63.75 & 93 \\
\hline $\begin{array}{l}\text { 7. When I get corrective feedback on the content of my } \\
\text { writing, I can usually understand how I've strayed from } \\
\text { the assignment guidelines. }\end{array}$ & 81.5 & 83.1 & 80 & 100 \\
\hline $\begin{array}{l}8 . \quad \text { I can write effectively even when I know those } \\
\text { evaluating my writing will be critical. }\end{array}$ & 61.5 & 68.6 & 55.3 & 49 \\
\hline
\end{tabular}




\section{General thoughts about analysis:}

Thank you to every participant for the time they took providing feedback in this study. This summary presents a generalized summary of the study results with some rationale for decision making. While I did not share this at the start of the last round because I did not want it to influence the nature of your feedback, the overall goal of this phase was item reduction, and that goal was successfully achieved. Other rationale for decisions made will be presented to you in the phase two survey, the link to which should follow in a separate email within the hour after you receive this personalized results summary.

I anticipate that round 2 will be the final round of this Delphi panel. The next phase will involve cognitive interview piloting of the remaining items with undergraduate nursing students. Following the cognitive interviews, the items will undergo psychometric testing with a nursing student population. The new questionnaire will undergo concurrent analysis using several instruments: 2 other established writing selfefficacy instruments, writing apprehension, writing context assessments (about the value, stakes, and supportiveness of their writing environment), and nursing identity. While this instrument is being developed and tested in a nursing undergraduate context, my long-term goal is that the instrument can be adopted or modified by other disciplines. In summary:

From the original 41 items presented to the panel:

\begin{tabular}{|l|}
\hline Final Tally: \\
\hline 17 Deleted items \\
\hline 1 New item \\
\hline 10 items to move forward as is \\
\hline 14 items with revisions to be re-reviewed. \\
\hline 25 items remain on the questionnaire \\
\hline
\end{tabular}

\section{Notes:}

1. All items that were rated high for relevance quantitatively were kept or modified. All items that rated low were ultimately deleted with confirmation from the qualitative responses. All mid-range rated items were either kept or modified, or deleted based on the qualitative responses.

2. A decision was made to delete an item if it was rated low, was less likely to be chosen as a top three item for its domain, or if other problems were detected with its wording, its ability to assess a component of self-efficacy (was the item an actual ability?), being too vague or general, or with its overlap with other items.

3. A decision was often made to keep an item if it was rated high, was likely to be chosen as a top three item, or if, based on feedback, I felt that the item should be trialed by students. In many cases an item was liked, rated well, and the only major concern was that it may not be understandable to undergraduates. In these situations, a decision was made to send the item to be piloted with the cognitive interview participants in the next phase where further decisions about keeping, deleting or modifying items will be made.

4. An item was revised if issues with word choice or phrasing were identified by the panel. Other items were not understood in the way I intended them to be understood so, if possible, those items were revised. Modified items will be re-presented in the round 2 survey with an explanation as to how a decision was made to revise the item.

5. It was often observed that a particular item could fit into more than one domain (in particular, relational and emotions items). An item appearing in the incorrect domain may be possible. I have not as of yet moved any items from one domain to another. Exploratory factor analysis in the psychometric testing phase will help with domain movement or domain collapsing decisions. Your 
comments on fit for a domain will be helpful at that stage as well when deciding what subscale (if subscales emerge) a particular item belongs to.

6. I was very grateful for the comments that flagged when I was making assumptions about writing, the writing experience, or about how even negative emotions were valuable in writing. If you made such comments, you will likely see evidence of how I considered my own assumptions when revising and deleting items.

7. You will note by the ratings above that there were certain items that were subject to some pretty significant disciplinary differences of opinion.

8. Many (especially writing people) noted that some items would require different responses based on the genre of the writing. As of right now, the intentional genre focus is on academic writing requiring research involving source integration. But, yes, there are many other genres of writing in nursing where this questionnaire may not get at the needs of that type of writing.

A brief summary of findings related to each domain of writing:

Identity: Does writing help develop a nursing identity? This was an interesting debate that emerged from the group comments. Anecdotally, if you read many of the published papers about writing in nursing, they use identity development as rational for why we use writing as a pedagogy in nursing at all. One participant asked the question, is writing voice equated with nursing voice? It will be interesting if this questionnaire is able to help answer some of these questions, especially when the responses are compared in the psychometric testing phase to nursing identity ratings. Issues of the developmental nature of writing were also common in this category. Yes, I believe, writing self-efficacy is likely also developmental as is identity development in a profession, so items that can discriminate participants developmentally $\left(1^{\text {st }}, 2^{\text {nd }}, 3^{\text {rd }}, 4^{\text {th }}\right.$ years for example $)$ are useful and desired.

Creativity: Creativity in the face of need for objectivity was one of the debates that emerged here within participant comments - some genres do not allow for much creativity. This is a fair point, and I will be curious to see how the students react to some of the remaining items here. Many of your comments sparked some thoughtfulness in me about my assumptions: fancy/original/unique words are not always required for creativity, that everyone has creativity and can access it, not everyone thinks of words visually, does one need to be self-efficacious creatively in order be self-efficacious in academic writing? Many of the items here that were kept were kept because I wanted the students' views on them.

Emotions: Many of the emotions items were problematic for this Delphi panel of participants. The category was reduced from 12 to 5 items. Emotion items were difficult to write because having an emotion is a legitimate experience of writing. As several panelists pointed out, positive and negative emotions are both needed in writing and it would be an incorrect assumption to assign negative emotions to low self-efficacy and positive ones to high self-efficacy. Being calm does not necessarily mean one is in control of their emotions; it could mean indifferent. The idea that difficulty in writing is just as, or maybe more so, motivating as excitement or enjoyment of writing was a valuable observation. I'd say the items that survived this round focus on ability to manage emotions or to use emotions to move forward with writing. I had included grammar, APA, and process questions here because I find, in my face-to-face interactions with students, that these issues put some of them into a panic: “am I doing this assignment the right way?" "am I going to lose marks if....” Maybe this happens because their past experiences with losing marks on their writing seem to come from these mechanical aspects. However, I was quite happy to delete the grammar, APA and process items based on your feedback.

Relational: There are numerous relationships being examined in the relational category - relationships with ideas in sources, relationships with audiences or readers, and relationships with teachers being the most prominent. I loved the comment by one participant that talked about disrupting the audience through a little bit of self-expression in writing even if the audience doesn't NEED that self-expression. I'm not sure this is something an undergrad needs to do but scholars definitely do. The emotions category feedback inspired the 
development of a new item that I felt was more relational so you will see this item added to the relational category in the survey: "When I receive feedback from peers or teachers, I can decide when that feedback should be ignored or incorporated into a revision in my writing.”

Context: Some interesting controversies were debated because of the context items. Should students be writing to please a teacher? Does not writing to please the teacher assume low self-efficacy or does it actually presume high self-efficacy (because of the willingness to take a risk, perhaps). There were disciplinary differences here between writers and nurses. Nurses on average liked the items about meeting class or assignment requirements or writing what the teachers want or always putting in best effort or that we might be tough graders. Writing scholars very much disliked these items. Is this a reflection on a nursing culture preferring the illusion of "objectivity and rigour?” What does this say about nursing education? (rhetorical question). Keep in mind I, a nurse who has taught writing in nursing for 15+ years, wrote these items. Some of these diversely viewed items were deleted or modified in favor of exploring adaptability to context as the true measure of self-efficacy.

Thank you again for your time and enthusiastic response to my work. If you have any questions, please don't hesitate to email. 


\section{Appendix G - Round 2 Delphi Survey}

\Q9 In this round of the Delphi survey, which is expected to be the final round of the survey, you will be asked your level of agreement with any items that were edited during the previous round. There was one new item which you will rate and comment about its relevance in the same way you did in the previous survey. Please continue to refer to the Description of the Theoretical Perspective which was emailed to you during the previous round. If you cannot locate your copy, please feel free to email Kim Mitchell kmmitch@myumanitoba.ca to request another copy.

Each Survey Page from this point forward is organized by the theoretical domain of the questionnaire: 1) Identity, 2) Creativity, 3) Emotions, 4) Relational, and 5) Context.

This is the Page for evaluating the IDENTITY items:

Description: Identity Items:

Identity incorporates writing voice, the self as it appears within a written text, past experiences with writing and their influence on present writing, and degree of writing mastery. A writer's perceived identity in the discipline of nursing will also be relevant. Reflexivity facilitates the metacognition and intertwining required to activate the other components of the model as they relate to writing and nursing identity. A writer's self-efficacy will be negatively impacted when they do not identify with their discipline or its writing or when they feel their personal self and ideas are not valued in the writing process.

There are 2 items that were modified in the identity domain. Please identify your level of agreement with these item revisions by selecting your preferred response category from strongly agree to strongly disagree. You will also be able to provide an open ended response about your level of agreement with the edit made. You do not need to formulate a typed response about each item but please do provide comments if you have an enthusiastic or less than enthusastic response to an edited item for any reason.

For easy reference and comparison with your personalized result summary, the original item numbers have been maintained for each item.

Identity item 1: This item was well liked by the round 1 Delphi participants, rated high quantitatively, and was frequently chosen as a top three item. The main concern with the item was with the phrasing "belongs to me." At least two participants suggested rewording to the edit presented.

Original item: I can write so the final product of that writing feels like it belongs to me.

Revised item: I can write so the final text or product feels like it came from me.

QQ7 Do you agree with the edit presented for the above item?

Q. I strongly agree with the edit presented

I moderately agree with the edit presented

I moderately disagree with the edit presented

I strongly disagree with the edit presented 
Identity item 2: This item was neutrally ranked quantitatively. Writing scholars were more likely to rank it as a top three item in the domain of identity. There was also some skepticism about writing influencing professional identity development of nurses and that, perhaps, if the assignment was relevant it might have more of an influence over writing identity. There were some great suggested edits that I've taken into account here. I am interested in seeing how students react to this item and what they might have to say.

Original item: Writing assignments can help me feel like I am a part of the nursing profession.

Revised item: Relevant writing assignments about nursing can help me to see how I am part of the nursing profession.

Do you agree with the edit presented for the above item?

0111

I strongly agree with the edit presented

D. I moderately agree with the edit presented

I moderately disagree with the edit presented

I strongly disagree with the edit presented

Do you have any additional comments to provide regarding the above two items. If you continue to disagree with the relevance of these items as part of this questionnaire or you disagree with an edit, please explain why

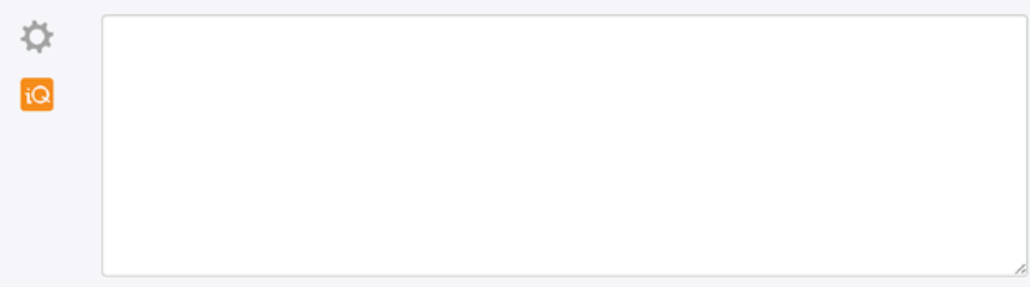

This is the Page for evaluating the CREATIVITY items:

Q24

Description: Creativity Items:

家

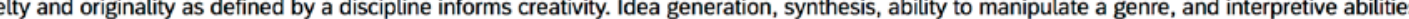
all require creativity. Creativity fuels passions and develops identity through a merger of the personal and the professional. A writer's self-efficacy will be impacted if they feel that they are not allowed to be creative or if their version of creativity is not shared by the faculty who assigns the writing.

There are 3 items that were modified in the creativity domain. Please identify your level of agreement with these item revisions by selecting your preferred response category from strongly agree to strongly disagree. You will also be able to provide an open ended response about your level of agreement with the edit made. You do not need to formulate a typed response about each item but please do provide comments if you have an enthusiastic or less than enthusastic response to an edited item for any reason.

For easy reference, and comparison with your personalized result summary, the original item numbers have been maintained for each item.

Creativity item 2: This item received high ratings from participants and was a frequent top three item choice. The intention of the item was to explore the elements of synthesis that went beyond just the serial citing of source after source. There were numerous suggested revisions to wording which have been incorporated into this revision. Most notably, at least two panel members suggested removing the word creatively.

Q

Original item: I can creatively bring together multiple sources into an original written product.

Revised item: I can bring together multiple sources in ways that are unexpected to create an original product or text.

Do you agree with the edit presented for the above item?

I strongly agree with the edit presented

1. I moderately agree with the edit presented

I moderately disagree with the edit presented

I strongly disagree with the edit presented 
Creativity item 3: This item had a range of ratings and rated higher with writing scholars than nurses. It was chosen as a top three item with writing scholars. Some edits were suggested in the feedback to adjust wording. I would like to trial it with the students to see what their reaction is to the question and if they understand its intent.

S.

Original item: Even when a writing assignment does not allow much flexibility, I can still find ways to make my assignment original

Revised item: After looking at the assignment requirements and guidelines, I can find ways of writing my assignment to make it original or unique.

Do you agree with the edit presented for the above item?

5113

I strongly agree with the edit presented

\. Imoderately agree with the edit presented

I moderately disagree with the edit presented

I strongly disagree with the edit presented

Creativity item 4: This item had mid-range ratings and was less likely to be chosen as a top three item. The main concern with the item was the implication that "original words" were required for creative academic writing. One participant suggested a great revision which I have incorporated.

2. Original item: I can find original word combinations that effectively explain my ideas.

Revised item: When I write, I can express my ideas with words and phrases I am happy with.

Do you agree with the edit presented for the above item?

I114 1 strongly agree with the edit presented
I moderately agree with the edit presented
I moderately disagree with the edit presented
I strongly disagree with the edit presented

Do you have any additional comments to provide regarding the above three items. If you continue to disagree with the relevance of these items as 0115 part of this questionnaire or you disagree with an edit, please explain why.

ba 
This is the Page for evaluating the EMOTIONS items: Description: Emotions Items:

Q

Writing emotions can be positive or negative, are subject to roller-coaster extremes, and will drive or inhibit the writing act. Emotions are present at al phases of writing from planning to feedback. Ability to control emotions, write in the face of difficulties, and write in an environment that validates or does not validate the normality of writing emotions will impact writing self-efficacy.

There are 2 items that were modified in the emotions domain. Please identify your level of agreement with these item revisions by selecting your preferred response category from strongly agree to strongly disagree. You will also be able to provide an open ended response about your level of agreement with the edit made. You do not need to formulate a typed response about each item but please do provide comments if you have an enthusiastic or less than enthusastic response to an edited item for any reason.

For easy reference, and comparison with you personalized result summary, the original item numbers have been maintained for each item.

Emotions item 1: This item received relatively high ratings from the entire sample, however writing scholars liked it better than nursing scholars. It was frequently chosen as a top three item. The biggest objection to the original item was use of the word "paralyze," therefore the item was edited to change the impact left by the word paralyze and emphasize that emotions impact progress.

O. Original item: I can write a major assignment without letting my emotions paralyze me.

Revised item: I can write a major writing assignment without letting my emotions prevent me from making progress.

Do you agree with the edit presented for the above item?

I strongly agree with the edit presented

I moderately agree with the edit presented

I moderately disagree with the edit presented

I strongly disagree with the edit presented

Emotions item 4: This item received mid-range ratings of relevance in its original form. Writing scholars selected it as a top three item but nurses did not. The main concern with the original item was the assumption that positive emotions equated with high self-efficacy. I was motivated to edit this item and keep it based on a wonderful comment from a participant which talked about how difficulties and challenges with writing could be more motivating than enjoyment at times. I was inspired to attempt to capture the idea that both sides of the emotional coin could motivate.

Original item: I can use my enjoyment of writing as a positive motivator to be a better writer.

Revised item: I can use the ups and downs of my emotions, emerging from the many challenges of writing, as a motivator to stay engaged with my writing.

Do you agree with the edit presented for the above item?

I strongly agree with the edit presented

I moderately agree with the edit presented

I moderately disagree with the edit presented

I strongly disagree with the edit presented

Do you have any additional comments to provide regarding the above two items. If you continue to disagree with the relevance of these items as part of this questionnaire or you disagree with an edit, please explain why.

L. 


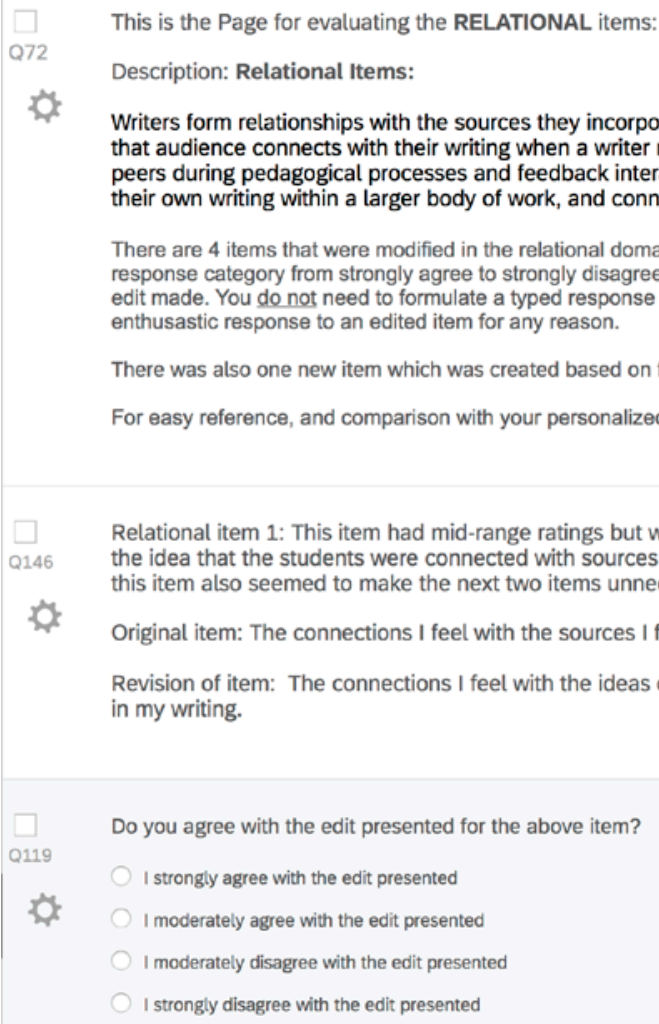
enthusastic response to an edited item for any reason. in my writing.

Do you agree with the edit presented for the above item?

There are 4 items that were modified in the relational domain. Please identify your level of agreement with these item revisions by selecting your preferred response category from strongly agree to strongly disagree. You will also be able to provide an open ended response about your level of agreement with the edit made. You do not need to formulate a typed response about each item but please do provide comments if you have an enthusiastic or less than

There was also one new item which was created based on feedback in this domain. Please rate and comment on that item as indicated.

For easy reference, and comparison with your personalized result summary, the original item numbers have been maintained for each item.

Relational item 1: This item had mid-range ratings but was preferred by nurses. The major stopping point for some panelists related to this item was the idea that the students were connected with sources rather than ideas. The edit presented below takes into account that perspective. Revision of this item also seemed to make the next two items unnecessary and contributed to the choice to delete them.

10. Original item: The connections I feel with the sources I find on my topic can motivate me to express my own ideas on that topic in writing.

Revision of item: The connections I feel with the ideas of other authors as I research my paper, can inspire me to express my own ideas on my topic

Relational item 4: This item rated high and was frequently chosen as a top three item. The supportive environment created by teachers was deemed very important to development of self-efficacy and self-regulatory help seeking. The primary concern with this item was the use of the word "freely" some participants felt it was too much of an English idiom and might be troublesome for English second language students.

Q

Original item: If I get stuck, I can freely contact a teacher or tutor to help me move forward with my writing ideas.

Revised item: If I get stuck, I can feel comfortable contacting a teacher or tutor to help me move forward with my writing ideas.

Do you agree with the edit presented for the above item?

I strongly agree with the edit presented

I moderately agree with the edit presented

I moderately disagree with the edit presented

I strongly disagree with the edit presented

Relational item 5: This item was highly rated and writing scholars were likely to choose it as a top three item. Adding the phrase "think about my audience" emphasized the conscious awareness of audience that writers should have when writing. Editing this item in this fashion made the item that followed it obsolete.

Original item: I can write so the audience I am writing for can clearly understand my meaning.

Revised item: When I write, I can think about my audience and write so they clearly understand my meaning.

Do you agree with the edit presented for the above item? 
Relational Item 7: This item rated quite high but not above $80 \%$ scores. It was also a common top three item selection. The original intention of this item was about staying on focus and not writing extraneous material into a paper. I'm not sure that meaning came through clearly based on some of the feedback provided. Some panelists bumped on the word "prioritize". These comments inspired the following edit:

家

Original item: I can prioritize writing what my audience needs to know over my needs for self-expression.

Revised item: I can focus my writing to what my audience needs to know over my needs for self-expression.

Do you agree with the edit presented for the above item?

I strongly agree with the edit presented

Q

I moderately agree with the edit presented

I moderately disagree with the edit presented

I strongly disagree with the edit presented

Do you have any additional comments to provide regarding the above four items. If you continue to disagree with the relevance of these items as part of this questionnaire or you disagree with an edit, please explain why.

穴

NEW ITEM Question 8 Relational -- please rate this item to its relevance to the relational domain and writing self-efficacy.

Q77

Q

*

When I receive
feedback from peers
or teachers, I can
decide when that
feedback should be
ignored or
incorporated into a
revision in my
writing.

Completely relevant

Please provide any comments, reactions, concerns or thoughts about this item. For example.

- Did you rate the item very high or very low? Provide your reasons for your choice of rating

- Does the item require editing in any way for grammar, clarity or meaning?

- Does the item fit within this domain (relational)?

- Would you recommend deleting this item? If so why? 
This is the Page for evaluating the CONTEXT items:

Q90

Description: Context Items:

Writers form relationships with the sources they incorporate through citation, inspiration, or interpretation. Writers write for an imagined audience and that audience connects with their writing when a writer reveals themselves in their work. Students also form relationships with their teachers and peers during pedagogical processes and feedback interactions. Ability to understand and relate to the sources read to inform their writing, position their own writing within a larger body of work, and connect with faculty and peers during the writing process will all affect student writing self-efficacy.

There are 3 items that were modified in the context domain. Please identify your level of agreement with these item revisions by selecting your preferred response category from strongly agree to strongly disagree. You will also be able to provide an open ended response about your level of agreement with the edit made. You do not need to formulate a typed response about each item but please do provide comments if you have an enthusiastic or less than enthusastic response to an edited item for any reason.

For easy reference, and comparison with your personalized result summary, the original item numbers have been maintained for each item.

Context item 1: This item demonstrated disciplinary rating differences. It was rated highly by writing scholars but mid-range by nurses. It was a common top three item by the panel. There was a suggested edit about not just considering style adjustments but also process adjustments. The item is intended to speak to the difficulty with writing transfer across courses. I also wanted to capture the broad context of writing with respect to the

o. ability to adjust (or transfer) writing ability, or figure out a process, no matter what the writing assignment asks or what the course content demands.

Original Item: With each new writing assignment, I can adjust my writing style to meet the needs of that assignment.

Revised item: With each new writing assignment, I can adjust my writing style and process to meet the needs of that assignment and/or course requirements.

Do you agree with the edit presented for the above item?

I strongly agree with the edit presented

Q I moderately agree with the edit presented

I moderately disagree with the edit presented

I strongly disagree with the edit presented

Context item 5: The panel gave this item high ratings. My goal with this item was to capture disciplinary comfort with language and values in writing. The part of the original item "in my own words" caused some domain related critiques (was it an identity item?). I edited the item to be generic to writing assignments.

Original item: I can comfortably express nursing concepts, language, and values in my own words.

Revised item: I can comfortably express nursing concepts, language, and values in my writing assignments.

Do you agree with the edit presented for the above item?

I strongly agree with the edit presented

Q $\bigcirc$ I moderately agree with the edit presented

I moderately disagree with the edit presented

I strongly disagree with the edit presented

Context item 8: This item had mid-range ratings and was rated much higher by nurses. What I was originally hoping to capture in this item was the context of the "scary" evaluator. Some teachers are rumoured to be hard markers. Some classes are perceived as more difficult than others. We experience this as academics as well. Some grant panels have lower chances of success. Some grad student advisors are difficult to please. It is the fear of the "red pen" or having our writing critiqued heavily. It could also be an issue of managing emotions. So that cross-applicability is there. It's managing that perception that I would like to hear about from students.

Original item: I can write effectively even when I know those evaluating my writing will be critical.

Revised item: I can write effectively even when the grader marking my work is known to be a strict or critical evaluator.

Do you agree with the edit presented for the above item? 
Do you have any additional comments to provide regarding the above three items. If you continue to disagree with the relevance of these items as part of this questionnaire or you disagree with an edit, please explain why.

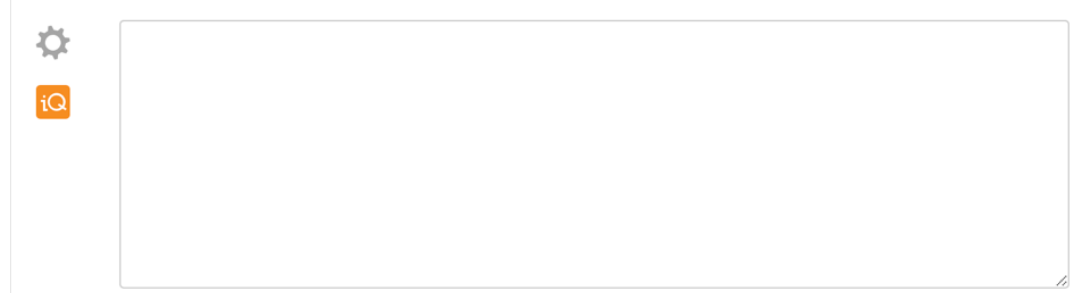

\section{INCLUDED ITEMS}

The following is a list of items that I decided to carry forward to this round without any modifications. This decision was usually made when the item was rated highly by the entire group. Sometimes the item was well liked, but the panel felt the item might be too difficult for undergraduates. Thus it was decided that the item would remain as is and edits as necessary would be deferred to cognitive interview testing with the undergraduate iC students. 10 items met this criteria.

Identity

6. I feel I can develop my own writing voice.

7. When I reflect on my writing, I can make my writing better.

Creativity

5. I feel I can give my writing a creative spark and still sound professional. (Quotation marks removed off the word spark)

6. I can visualize the connected parts of a paper I have written and see how it tells the complete story of my topic or argument.

7. I can choose a writing process that will best fit the writing I have been assigned.

Emotions

3. When I am excited about what I am writing, I can work with that excitement to write a better paper.

5. Even when the writing is hard, I can find ways to overcome my writing difficulties.

8. When I receive feedback on my writing, no matter how it makes me feel, I can use that feedback to improve my writing in the future.

Relational

NONE

Context

2. I can successfully use scholarly academic words and writing styles when writing in my courses.

7. When I get corrective feedback on the content of my writing, I can usually understand how I've strayed from the assignment guidelines.

If you have any additional comments on any of these items, please write them in the box below. 


\section{DELETED ITEMS}

The following is a list of items that feedback provided strong evidence for deletion of the item. These items were typically rated low by participants or were rarely chosen as a top three item in their domain. Items were typically deleted because they were too vague or general, because they contained too many unfounded assumptions about writing, or because an edit to another item made the item obsolete. 17 items are slated for deletion.

iQ Identity

3. No matter what it is I am asked to write, I can write it well

4hen I write, I can look past any negative experiences I may have had with writing assignments and get the job done.

5. When I am preparing for a writing assignment, I can often find myself thinking, at unusual times and places, about how to approach the writing

Creativity

1. When I choose a topic, I feel I can make more unique choices than most of my classmates.

Emotions

2. I can remain calm and in control through the writing process.

6. If I am frustrated with my writing, I can always identify what is causing the frustration.

7. I can communicate my frustration to others to help me solve my writing problems.

7. I can usually feel proud of my writing.

. When I write a first draft, I can complete the task without worrying if my grammar is correct or not.

11. can write without worrying that I will get the APA format requirements wrong.

Relational

2. I can understand the research sources I find to support my writing ideas.

3. I can correctly interpret the meaning of the sources I find for my writing assignments.

6. I can alwyas think about my audience when I write.

Context

3. I can consider the needs of nursing when I choose the topics I write about in my courses.

4. I can usually figure out the way a teacher wants me to write sol can get a good grade.

6. I can make an effort to write my best work regardless of the value of the assignment to my overall grade.

If you have any further comments about any item on this list, please type your response into the box below.

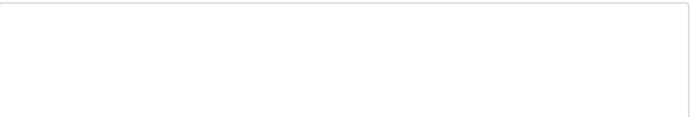

Do you have any additional feedback you would like to share about this survey process, the results summary you may have been sent, or any questions you would like to ask about the research. Please feel free to include your observations in the box below.

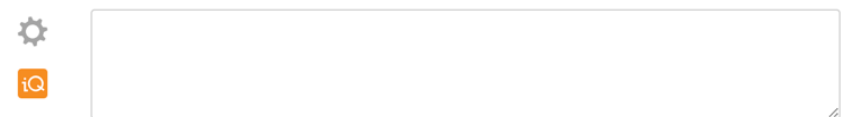

(1)

You have nearly completed this survey! Thank you so much for your time so far. I have been humbled and honoured by the high quality of the

Q110 feedback provided for my doctoral work by the members of this Delphi panel. I will be in touch in the next couple of weeks regarding the final results summary for this Delphi phase of the Writing self-efficacy instrument development.

ф.

Type your name in the box below. Your name is required in order to prepare your personalized response summary.

\%.

*

To ensure no one's mind has changed about having their name made public an any acknowledgement of this work, I must re-ask this question. Would you be willing to allow your name to appear in the acknowledgement section of Kim Mitchell's final thesis and in any future publications that may result from this project?

Q.

Yes

No

Thank you very much for your time in completing this survey. This is the end of Round 2 - which I expect to be the last round. You will receive a personalized summary of your results and (only if needed) the link to the next round of the survey when analysis is completed (approximately two weeks after the deadline for submitting survey responses). If you have any questions about your participation please feel free to email Kim Mitchell at kmmitch@myumanitoba.ca 


\section{Appendix H - Example of Summary of the Results Round 2}

The following table presents a summary of the agreement/disagreement with edit choices for each individual item by proportion within the entire sample $(\mathrm{N}=15)$, writing scholar sample $(\mathrm{n}=8)$, nurse scholar sample $(n=7)$. The final column represents your personal selected category or rating.

$\mathrm{S}$ = Sample; $\mathrm{W}=$ Writing; $\mathrm{N}=$ Nurse

SA = Strongly agree; $\mathrm{MA}=$ Moderately agree; $\mathrm{MD}=$ Moderately disagree; $\mathrm{SD}=$ Strongly disagree

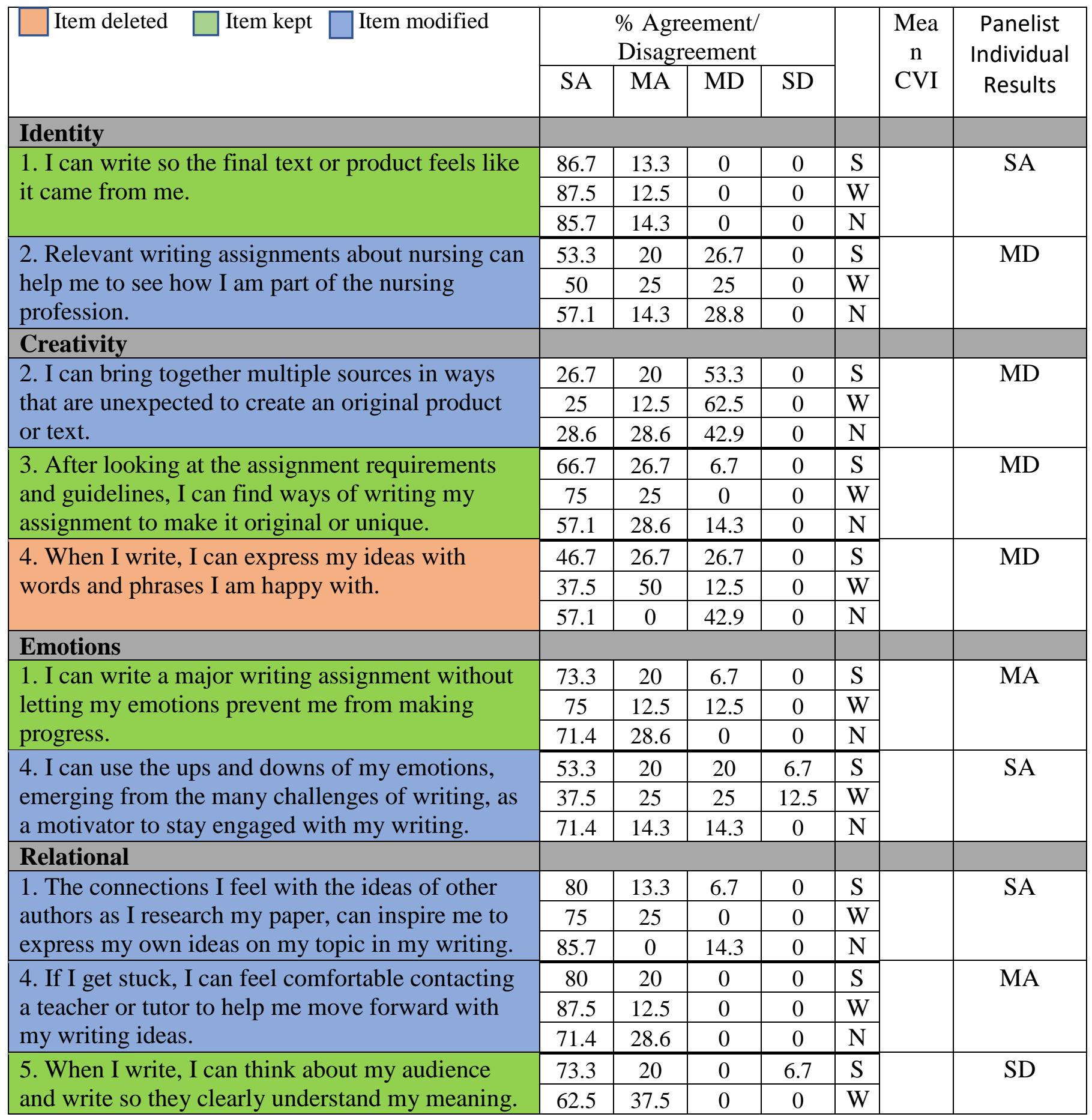




\begin{tabular}{|l|c|c|c|c|c|c|c|}
\hline & 85.7 & 0 & 0 & 14.3 & $\mathrm{~N}$ & & \\
\hline & & & & & \\
\end{tabular}

Thanks once again to this incredible panel for their time and commitment to being my expert reviewers on this project. Of the 15 items which were re-presented, or presented new, to the panel, the second round of the survey resulted in some additional edits to 7 items (in blue, above) which I will describe in more detail below. Seven other items I elected to leave as revised from the previous round (in green, above), including the new item (Relational \#8) that generally resulted in high scores across the panel (note: one nurse and one writer gave the new item a more moderate relevance score).

I elected to delete one item (Creativity \#4 in orange above). The primary reason for deletion was that many respondents were not happy with the edit to the item, disliked the "I am happy with" phrasing at the end of the item, and reminded me that words alone did not dictate creativity in writing. Also, one of the items kept from the previous round asked about one's ability to give their writing a creative spark. This already included item was likely capturing what I was also trying to capture with this item. It felt fair with this combined evidence to delete this item focusing on word choice, outright.

During this round, an item receiving a high agreement with edit score ( $>80 \%$ strongly or moderately agree combined), and, in one case, disagreement with edit score ( $>50 \%$ strongly or moderately disagreed combined) did not necessarily result in automatically keeping an item as is (see for example Relational items 1 and 4) or outright deleting the item (see Creative item 2). I would define much of the panel's qualitative feedback given during this phase as wordsmithing - tinkering with existing phrasing either grammatically, for word choice, or for simplification of the item due to multi-clause phrasing. I made the choice to weigh pros and cons of editing an item further now, versus deferring decision-making to the cognitive interview phase with the undergraduate students. There were a few interesting cases where the edit was for the large part accepted by the panel but there were one or two raters that disliked it for a multitude of reasons (for example, all of the context items). Those were tough decision-making circumstances, but if you were a minority dissenter to any edit, please know I did consider your feedback carefully, but more often than not, the decision was made to defer editing because I really wanted the student reaction on an item.

Your reflective commentary was also useful. Reading your stream-of-consciousness thoughts about some aspects of writing resulted in two additional revisions decisions that went beyond the 15 item presented in 
this second survey: 1) I returned one item from the previous round deletion list to the questionnaire; 2) I also wrote one new item to account for a gap that had been bugging one panelist - a diminishment in creativity that was bugging me too.

The item I chose to remove from the deletion list and include on the questionnaire again was the item related to worrying about APA format. One panelist mentioned being disappointed I removed it. I suspect this panelist was a nurse, but I can't say for sure. For the most part (both in this phase and the previous phase), I looked at the qualitative comments anonymously. There were other motivators that prompted me to put an APA related item back in the questionnaire. First, I just finished working with a group of students on a writing assignment and the number of anxiety-rooted APA questions I was asked were concerning - not just related to my own assignment but also for assignments in other courses - in my institution my name is on our APA summary so they see me as the expert. The second motivator emerged because I just got back from the Canadian Association for the Studies of Discourse and Writing conference and every time I revealed to someone at the conference that I was a nursing instructor, the response was, "I work with nursing students. They are always so concerned about APA" or, "Nurses really like their APA.” So, whether the item remains in the questionnaire or not, I feel I must ask the students about their APA-related self-efficacy. I did re-write the original question to read:

Emotions \#11: I can write without worrying about my ability to correctly apply the rules of the required style guideline (e.g. APA format).

Notice I am deliberately less concerned with their ability to implement APA correctly as I am with their worry about it. I also wrote the item so the style guide could easily be changed to any relevant style guide in the context of use.

I decided to develop a new creativity item because of a panelist comment about how every edit of the items seemed to diminish the creative elements of academic writing more and more. I agreed. As with the last survey, I did really feel a lot of dissent within the panel data about whether academic writing was creative or not. I strongly believe it is creative in its own way. I developed a really broad creativity question because I really feel I need to ask students in a direct and clear manner about their thoughts related to creativity in academic writing.

Creativity \#8: I can use creativity when writing an academic paper.

The following are the items that received additional modifications. The vast majority of these edits were made to eliminate wordiness or remove multiple clauses. A few item edits require some additional explanation because the edit came about from more than just semantic issues. You'll find that commentary after the related edit.

Identity \#2: Relevant writing assignments about nursing can help me to see how I am part of the nursing profession.

Revised: Writing assignments relevant to nursing can help me to feel part of the nursing profession.

Creativity \#2: I can bring together multiple sources in ways that are unexpected to create an original product or text.

Revised: I can bring together multiple sources to create an original product or text.

12/15 panellists indicated a dislike for the use of the word "unexpected." The unexpected nature of writing is a reader-based perception. A writer would have no way of knowing if their writing could be seen as unexpected by others. 
Emotions \#4: I can use the ups and downs of my emotions, emerging from the many challenges of writing, as a motivator to stay engaged with my writing.

Revised: I can use the positive and negative emotions of writing as a motivator to stay engaged with my writing.

Relational \#2: The connections I feel with the ideas of other authors as I research my paper, can inspire me to express my own ideas on my topic in my writing.

Revised: As I do research for my paper, the connections I feel with the ideas of other authors can inspire me to express my own ideas in my writing

Relational \#4: If I get stuck, I can feel comfortable contacting a teacher or tutor to help me move forward with my writing ideas.

Revised: If I get stuck, I can contact a teacher or tutor to help me move forward with my writing ideas.

Context \#1: With each new writing assignment, I can adjust my writing style and process to meet the needs of that assignment and/or course requirements.

Revised: With each new writing assignment, I can adjust my writing process to meet the needs of that assignment.

After I edited this item (a Context item), I went to the list of items that had been selected for inclusion based on the last survey and found there was an item that had already been included under Creativity that read: 1 can choose a writing process that will best fit the writing I have been assigned. It seemed, to me, these two items were asking the same or similar question. I chose to delete the item from Creativity and leave this newly edited item under Context.

Context \#8: I can write effectively even when the grader marking my work is known to be a strict or critical evaluator.

Revised: I can write effectively even when the grader marking my work is known to be strict or critical.

If you don't see a revision or word suggestion you might have given used in the above modifications, I assure you that all additional suggestions given in the feedback from this round (and the previous round) will be very important to the next phase of this study. The next phase will trial the remaining 25 items with a sample of undergraduate students in a face-to-face interview format. The students will be asked to read the items out loud and comment on how they would rate themselves on the item and tell any stories that might come to mind that contributed to their rating choices. They will also be asked to speak aloud any other thoughts they might have about the item in terms of its meaning, relevance, or emotional reaction stimulated. One of the issues I will be observing will be problems with any "I can" phrasing, which a few of you noted in places. I will also be able to prompt them for their understanding about certain concepts or elements of writing such as "voice" or if they think it is possible to not apply feedback suggested to them by a teacher (a concern brought up about the new Relational \#8 item). My intention is to create a very specific script for myself for prompting the students. I will go back through the qualitative feedback provided by this panel during the previous two rounds and make detailed notes about additional suggestions with respect to certain items including: alternative words and phrasings, suspicions about places undergraduates may get confused, and other issues related to item construction.

Thank you very much for your time dedicated to this project. If you have any questions or comments about this final summary of results, please do not hesitate to email me. As all of you requested updates on the future rounds of the project, I will also provide those as they become available. The questionnaire that will be tested in the next round will be presented as follows, with each item rated from "completely sure I cannot" to “completely sure I can” on a 0-100 scale:

1. I can write so the final text or product feels like it came from me. (I) 
2. I can bring together multiple sources to create an original product or text. (Cr)

3. I can write a major writing assignment without letting my emotions prevent me from making progress. (E)

4. As I do research for my paper, the connections I feel with the ideas of other authors can inspire me to express my own ideas in my writing. (R)

5. With each new writing assignment, I can adjust my writing process to meet the needs of that assignment. (Co)

6. Writing assignments relevant to nursing can help me to feel part of the nursing profession. (I)

7. After looking at the assignment requirements and guidelines, I can find ways of writing my assignment to make it original or unique. $(\mathrm{Cr})$

8. When I am excited about what I am writing, I can work with that excitement to write a better paper. (E)

9. If I get stuck, I can contact a teacher or tutor to help me move forward with my writing ideas. (R)

10. I can successfully use scholarly academic words and writing styles when writing in my courses. (Co)

11. I feel I can develop my own writing voice. (I)

12. I feel I can give my writing a creative spark and still sound professional. (Cr)

13. I can use the positive and negative emotions of writing as a motivator to stay engaged with my writing. (E)

14. When I write, I can think about my audience and write so they clearly understand my meaning. (R)

15. I can comfortably express nursing concepts, language, and values in my writing assignments. (Co)

16. When I reflect on my writing, I can make my writing better. (I)

17. I can visualize the connected parts of a paper I have written and see how it tells the complete story of my topic or argument. (Cr)

18. Even when the writing is hard, I can find ways to overcome my writing difficulties. (E)

19. I can focus my writing to what my audience needs to know over my needs for self-expression. (R)

20. When I get corrective feedback on the content of my writing, I can usually understand how I've strayed from the assignment guidelines. (Co)

21. I can use creativity when writing an academic paper. (Cr)

22. When I receive feedback on my writing, no matter how it makes me feel, I can use that feedback to improve my writing in the future. (E)

23. When I receive feedback from peers or teachers, I can decide when that feedback should be ignored, or incorporated into a revision in my writing. (R)

24. I can write effectively even when the grader marking my work is known to be strict or critical. (Co)

25. I can write without worrying about my ability to correctly apply the rules of the required style guideline (e.g. APA format). (E) 


\section{Rady Faculty of}

Health Sciences

College of Nursing

Helen Glass Centre for Nursing

Winnipeg, Manitoba

Canada

R3T 2N2

Telephone 204-474-9080

Fax 204-474-7682

\section{Appendix I - Informed Consent Cognitive Interviews}

Please take the time to carefully read the following informed consent form.

Research Project Title: A Mixed-Methods Validation of a New Measurement of Writing SelfEfficacy in the Nursing Context

Principal Investigator: $\quad$ Kim M. Mitchell

Doctoral Candidate

College of Nursing, Rady Faculty of Health Sciences

University of Manitoba

\section{Committee:}

Advisor - Dr. Diana E. McMillan - College of Nursing, Rady Faculty of Health Sciences Internal - Dr. Michelle M. Lobchuk - College of Nursing, Rady Faculty of Health Sciences External - Dr. Nathan C. Nickel - Department of Community Health Sciences, Rady Faculty of Health Sciences

This consent form is only part of the process of informed consent. It should give you the basic idea of what the research study is about and what your participation will involve. If you would like more detail about something mentioned here, or information not included here, you should feel free to ask. Please take the time to read this carefully and to understand any accompanying information.

\section{Research Purpose}

The purpose of this study is to validate an instrument to measure writing self-efficacy in a nursing education context. Writing self-efficacy is the personal beliefs you might have about your abilities as a student writer in nursing. To achieve this purpose, undergraduate students will be asked to participate in a videotaped interview where they read each item on the new questionnaire and think aloud about past writing experiences that may have contributed to how they would score themselves on each item. Your interview data will be used to:

1) make decisions to delete, retain, or edit any items on the questionnaire. Items may be deleted or edited if interviews with participants demonstrate the item is not clear or is not being interpreted the way that was intended; and 
2) to explore the kinds of writing experiences undergraduate nursing students describe as having an influence on their writing self-efficacy scores.

\section{What would I have to do if I agree to participate?}

If you agree to participate in this study you will be asked to complete a computerized survey while talking out loud about how you decided on your score for each item on the survey. The survey will be done on a computer and the items will require clicking and sliding on a circle on a line and dropping the circle at the point on the line that represents your score between 0 and 100 on a given item. The questionnaire will ask you questions about your thoughts and feeling about writing and writing assignments in your nursing program. The interview is expected to take 1 to 1.5 hours of your time. You will be videotaped during the survey completion process to capture your reaction to the individual items which may be apparent in your body language or your facial expressions. Alternatively, your interview can be audio recorded. You will be asked to read each item on the questionnaire out loud, decide on how you would score yourself, and to explain to the researcher the factors that might have influenced your score.

Part of thinking aloud while answering the questionnaire might include describing:

1. What in your own words is this question asking you?

2. Any emotional response you might have to the question.

3. Your understanding of specific words and phrases in the questions, because it will be very important that students responding to this questionnaire understand the words used.

4. Any stories prompted by the questions which may describe a past experience you might have had with a writing assignment at any time in your life.

5. Anything else that might come to mind - no matter what - even if you think it isn't important. This includes both positive and negative reactions you might have to the questions.

Because learning to think aloud might take some practice, at the start of the interview you will also be presented with a pretend academic writing assignment and be asked to describe the steps you might take to get started with that assignment.

You will also be asked some information about your personal characteristics such as your age, gender identity, ethnicity, your nursing program, your year of study, the grade you got on a recent writing assignment, your grade point average, any previous degrees you might have, if English is your first language, and if you consider yourself a person who likes or dislikes writing.

\section{Are there any risks if I take part?}

There are no risks to you if you choose to participate. Participation in the study involves a time commitment. Participating is completely voluntary and choosing to participate or not participate in this study will not affect your status in a course, your standing in your nursing program, or any course grades including any writing assignments you may be graded on this term. 
If taking a part in this interview or reflecting on your past writing experiences causes you any stress or anxiety, you may contact counselling services at your institution to discuss your feelings and experiences:

University of Manitoba - Rm. 474 University Center - 204-474-8592

Red River College -- Rm D101 - 204-632-3966

Brandon University - Rm 115-1, A. E. McKenzie Building - 204-727-9739

\section{What will be the benefits?}

If you choose to participate in this study there may or may not be a direct benefit to you. Some studies show that reflecting on assignments and learning experiences can enhance students' understanding. Also, by participating in the interview you will see an example of nursing research and qualitative data collection which could reinforce concepts you have learned or will learn in the nursing program.

\section{Will I receive any compensation for participating in this study?}

Students who participate in the interview will receive \$50 cash.

\section{Confidentiality}

Because the interview takes place fact to face with a researcher and is being videotaped, your responses will not be anonymous to the researcher or to the members of her doctoral committee who will be aware of your identity as a participant in this study. The research interview may also be transcribed by a transcriptionist hired specifically to type out the conversations that take place in the interviews. All researchers who view the videos and the transcriptionist will be required to sign an oath of confidentiality which will emphasize the importance of not sharing your identity with others outside the research study. The researcher and her committee will be the only individuals who may view the video recordings of your interview. Once the videos are transcribed and sent to the researcher, only the researcher and her committee, will have access to the transcribed interviews. The transcribed interviews will be anonymized by using a pseudonym instead of your name. You will be given the opportunity to review the transcript from your interview after transcription has occurred and given one week to respond with any changes you would like to make.

The findings of this study may be published in an academic journal and presentations may be given locally, nationally, and internationally. In any publications about the study findings, information you contributed to the researcher in the form of direct quotes may be used. These quotes will be used anonymously, names changed to pseudonyms, your nursing program affiliation not mentioned or mentioned generically as, for example, "Institution \#1", and any other potentially identifying information will be altered to protect your identity. The personal data collected from you will be presented in a summary format where only average scores or proportions for an entire group will be reported.

Your responses will also remain confidential. The electronic files containing the video recordings, spreadsheets of results for the demographic survey, and the typed transcripts of the interviews will be stored on a password protected laptop owned by Kim Mitchell for the duration of the study until publication of the results in a peer-reviewed journal (approximately 6 months to one year after the interview). The anonymized transcripts may be kept indefinitely by the 
researcher and used for educational purposes or in future research studies. The video recordings will be kept until after publication of the study and then permanently deleted from all computers. Any paper copies of the transcripts and other researcher notes will be kept in a locked filing cabinet during the active study period and the time following study completion in the home of Kim Mitchell.

\section{Will I find out about the results of the study?}

If you would like a brief summary of the research findings from these interviews, you can indicate your interest at the end of this consent form by checking the appropriate box and providing your email address. This results summary will be available in approximately January 2020.

\section{Can I withdraw from the study?}

Your participation in this research is completely voluntary. Even if you start the interview you can decide to end your participation at any time. If there are any questions you do not feel comfortable answering, you can decline to respond to that item. After you complete the interview and your interview is transcribed (approximately 2-3 months after your interview date), you will be sent a transcribed copy of your interview where you can make corrections, deletions, or clarifications to the statements you made during the interview. You will be given one week from the date you are sent this email to make these changes.

You can continue to withdraw your interview data after the interviews are completed and recorded. However, once the videos have been analyzed to assist with edits to the questionnaire and those edits have been made, you will not be able to withdraw your contribution from that portion of the study. For the analysis of the transcripts which will explore the stories you might tell about writing experiences that have affected your writing self-efficacy, you will be able to withdraw your interview up until the point that materials have been prepared for the final thesis, or publication in scholarly journals or presentations at academic conferences (approximately June 2020).

Who do I contact if I have questions?

If you have any questions about the study, you can contact Kim Mitchell by email at

or her advisor Dr. Diana McMillan at

\section{Additional Information}

Signing this consent form indicates that you have understood to your satisfaction the information regarding participation in the research project and agree to participate as a subject. In no way does this waive your legal rights nor release the researchers, sponsors, or involved institutions from their legal and professional responsibilities. You are free to withdraw from the study at any time, and /or refrain from answering any questions you prefer to omit, without prejudice or consequence. Your continued participation should be as informed as your initial consent, so you should feel free to ask for clarification or new information throughout your participation. 
The University of Manitoba may look at your research records to see that the research is being done in a safe and proper way.

This research has been approved by the Education/Nursing Ethical Review Board. If you have any concerns or complaints about this project you may contact any of the abovenamed persons or the Human Ethics Coordinator (HEC) at 474-7122 or at humanethics@umanitoba.ca

Participant's printed name:

Participant's signature:

Participant's email address (for sending copies of transcripts)

I would be interested in receiving a summary of the research results (approximately January 2020) (check box if yes).

Date:

Researcher's printed name:

Researcher’s signature:

Date: 


\section{Appendix J - Script for Cognitive Interviews}

I thank you for agreeing to participate and helping me gain an understanding about the effectiveness of this writing self-efficacy questionnaire. On the computer screen in front of you are the items for the questionnaire. We are going to start with a short warm up exercise then we will talk about the questionnaire.

\section{WARM UP EXERCISE}

Before we start, and as a bit of practice to help you understand what I mean when I say, "think aloud”, can you describe for me the steps you might take as soon as you get written instructions for an essay assignment? The guidelines for the assignment give you the following information: You are asked to write a 5-page paper that finds scholarly sources. You are required to use peer reviewed journals (about 3 articles minimum) as well as websites and books. The topic you are asked to write about says:

Nursing is one of many professions where the work does not conform to standard working hours. Working shifts requires nurses to be alert when their natural body rhythms would prefer sleep. Discuss 2-3 negative effects of shift work on a nurse's physical and/or mental health and overall performance and suggest solutions for counteracting these effects. Support your discussion with research literature.

What would be the first step you take to get started on this paper? How would you proceed after that first step?

\section{QUESTIONAIRE INTERVIEW}

Now we are ready to read the items on the questionnaire.

I'm going to ask you to read each item aloud and then, please, speak out loud all the thoughts you are having while you decide what score you would give yourself on that item. Please also tell me the score you would give yourself as a rating on the item you are reading and try and describe how you decided that this score represents what you feel are your abilities with respect to that item.

Part of thinking aloud while answering the questionnaire might include describing:

1. What in your own words is this question asking you?

2. Any emotional response you might have to the question.

3. If you don't understand what words mean, please tell me because it is very important that students responding to this questionnaire understand the words used.

4. If the question makes you think of a past experience you might have had with a writing assignment at any time in your life, please share those stories. 
5. Speak aloud anything that might come to mind - no matter what - even if you think it isn't important. This includes both positive and negative reactions you might have to the questions.

Please don't worry about what you think I might want to hear from you - just explain what you are thinking with your response to each item. While you are answering these questions, I may from time to time, interrupt you to get you to clarify something about your response. Do you have any questions about what I am asking you to do today? When you are ready we will get started. 


\section{Appendix K - Prescripted Prompts for Cognitive Interviews}

These prompts were inspired by prompts used/suggested in various other cognitive interview studies and theory papers reviewed for this protocol (Beatty \& Willis, 2007; Drennan, 2003; Fowler et al., 2016; Garcia, 2011; Willis, 2005)

1. Tell me in your own words what this question is asking you.

2. What does the word/phrase XXX mean to you? (e.g. what does the phrase "connect with your sources” mean?”

3. I see you gave yourself a high score on that item. What past experiences have you had that makes you confident you would be good at that task?

4. I see you gave yourself a low score on that item. What past experiences have made you feel less confident about that task?

5. Can you walk me through how you came to decide on that score?

6. I see you are having XXX reaction after reading that question. What is making you react that way? (e.g. laughing, frowning, groaning, eye rolling, sighing, head shaking etc.)

7. What made you think of that story about your writing?

8. We just recently edited this question because participants before you were having trouble with it, so I would like to ask you to paraphrase what this question is asking so we can check if we have the wording right.

9. In what way does this question apply (or not apply) to you?

10. How much thought have you given to your writing processes before this interview?

11. You seem uncertain about your response to this item; do you feel as if you are guessing at what rating you should give?

Beatty, P. C., \& Willis, G. B. (2007). Research synthesis: The practice of cognitive interviewing. Public Opinion Quarterly, 71(2), 287-311.

Drennan, J. (2003). Cognitive interviewing: Verbal data in the design and pretesting of questionnaires. Journal of Advanced Nursing, 42(1), 57-63.

Fowler, F. J., Lloyd, S. J., Cosenza, C. A., \& Wilson, I. B. (2016). Coding cognitive interviews: An approach to enhancing the value of cognitive testing for survey question evaluation. Field Methods, 28(1), 3-20.

García, A. A. (2011). Cognitive interviews to test and refine questionnaires. Public Health Nursing, 28(5), 444-450.

Willis, G. B. (2005). Cognitive interviewing: A tool for improving questionnaire design. Thousand Oaks, CA: Sage. 


\section{Appendix L - Demographic Form Cognitive Interviews}

1. What is the name of your university or college?

2. How many years/levels are there in your program in total?

1. 1

2. 2

3. 3

4. 4

5. Other

3. What year of your program are you currently in?

1. 1

2. 2

3. 3

4. 4

5. Other

4. What degree or qualifications will you have when you complete your program?

1. $\mathrm{BN}, \mathrm{BScN}, \mathrm{BSN}$

2. Post registration $\mathrm{BN}, \mathrm{BScN}, \mathrm{BSN}$

3. Associate degree

4. Midwifery

5. Psychiatric nursing

6. Other

5. What is your age in years and months?

6. What is your gender?

1. Female

2. Male

3. Other or non-binary

7. What is your race/ethnicity

8. What is your GPA?

9. What was the last grade you received on an academic paper at the university level?

10. Did you take university courses prior to entering nursing and/or do you have a previous degree or diploma? What discipline? 
11. When did you learn to speak English fluently?

1. Spoke only English from a young age (under 5 years of age).

2. Spoke English and another language (under 5 years of age).

3. Spoke another language (under 5 years of age) and learned English between the ages of 5 and 18.

4. Spoke another language (under 5 to age 18) and learned English as an adult.

12. When did you learn to write in English?

1. In elementary school (kindergarten to grade 4).

2. In middle school (grades 5-9).

3. In high school (grades $10-12$ or 13 as applicable).

4. After graduating high school.

(Start recorded interview here)

13. Would you consider yourself someone who:

1. Generally enjoys writing?

2. Generally does not enjoy writing?

3. Somewhere in between.

(We will discuss your response to this question more thoroughly during the recorded interview) 


\section{Appendix M - Invitation to Participants for the Cognitive Interview}

\section{Seeking Undergraduate Nursing Students for a Research Study about Writing.}

\section{Do you love writing? Do you hate writing? No two nursing students experience writing in the same way. What would you say if you were given the opportunity to talk about your writing experiences in your nursing program?}

Kim Mitchell, a doctoral student in the College of Nursing at the University of Manitoba, is conducting a research study exploring how students feel about their writing abilities. Your contribution to this research will explore the items on a new instrument designed to measure student writing self-efficacy. You will be asked to read through this measurement instrument and tell your stories of writing in nursing and how those stories have affected how you feel about your writing ability.

If you choose to participate in the study you will be offered $\$ 50$ as a thank you for your time and contribution.

The interview is expected to take between 1 and 1.5 hours of your time and will be video and/or audio recorded in order to capture your words, body language, and facial expressions, as you respond to the questions on the survey. No one other than the research team will see the videos of the interviews.

Kim is looking for all kinds of nursing students to participate in this research:

- Registered nursing students in any year of your nursing program.

- Students who like writing, students who dislike writing.

- Students who feel they are good writers, students who feel they are not good writers.

- Students who are happy with their writing grades and students who have been unhappy with their writing grades.

- Students whose first language is English and students whose speak multiple languages.

Your contribution to this research will help me revise this questionnaire and ensure all the items are clear and understandable, but it will also help me and other nursing instructors have a greater understanding of the kinds of writing experiences that are influencing how students feel about their writing assignments in nursing programs.

If you are interested in participating in this research, or would like more information, please email Kim Mitchell at $\quad$ You may also email Kim’s doctoral advisor Dr. Diana McMillan at

Kind Regards, Kim Mitchell, Doctoral Candidate Dr. Diana McMillan, Associate Professor

College of Nursing

Rady Faculty of Health Sciences

University of Manitoba 


\section{Appendix N - Email Request to Nursing Programs for Cognitive Interviews}

Dear nname and title of contact person $\}$

My name is Kim Mitchell and I am a doctoral candidate in the College of Nursing, Rady Faculty of Health Sciences at the University of Manitoba. I am emailing today to inform you about a study I am conducting titled: “A Mixed-Methods Validation of a New Measurement of Writing Self-Efficacy in the Nursing Context.” I am also seeking your permission and assistance to recruit the students from your nursing program for this study. The primary purpose of this study is to validate a new measurement instrument assessing writing self-efficacy in undergraduate nursing students. I am seeking to interview nursing students, using cognitive interviews, to help understand the clarity and interpretation of this new instrument. These interviews are Phase III of a four-phase instrument validation process and are expected to take between 1 and 1.5 hours of a student's time. I will also be re-contacting this nursing program about student recruitment for Phase IV in the next few months.

This study has received ethical approval from the Nursing Education Research Ethics Board at the University of Manitoba and approval from \{specific institutional approval or other ethics board as appropriate .

I am seeking to recruit nursing students from your program at \{institution\}. Below is a recruitment script I have written intended for students. I have also attached a recruitment poster which can be used electronically along with the recruitment script. The poster can also be directly emailed to students. I also have printed posters which can be, with faculty permission posted on site on your campus.

Please let me know if you are willing to forward these materials to your students. I thank you kindly for your support for my doctoral work.

Kind regards,

Kim Mitchell

Doctoral Candidate

College of Nursing, Rady Faculty of Health Sciences

University of Manitoba 
Appendix O - Recruitment Poster for Cognitive Interviews

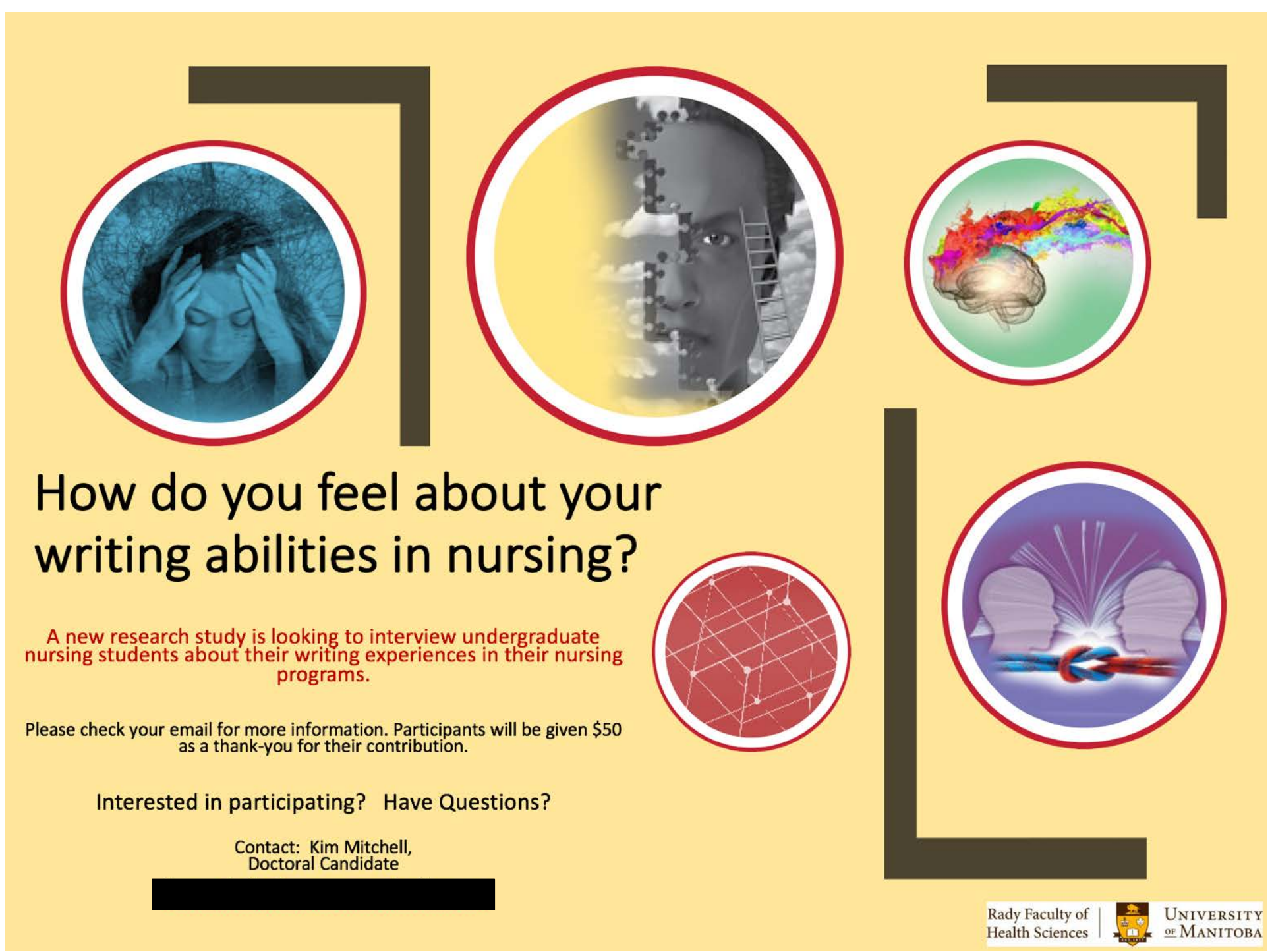




\section{Appendix P - Nursing Survey and Questionnaires Including Demographic Items}

\section{Writing Self-Efficacy Survey Phase IV Rady Faculty of Health Sciences

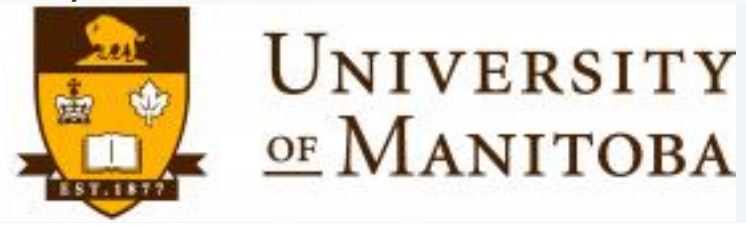

Consent form appears here.

\section{Page Break}

Q3

The purpose of this survey is to assess your writing experiences in nursing education and to gather information about the new writing self-efficacy instrument you will complete on the next page. The survey should take 10-15 minutes of your time.

As you respond to the questions on the pages to follow, please visualize the writing assignment and writing environment that you are experiencing in the current academic term.

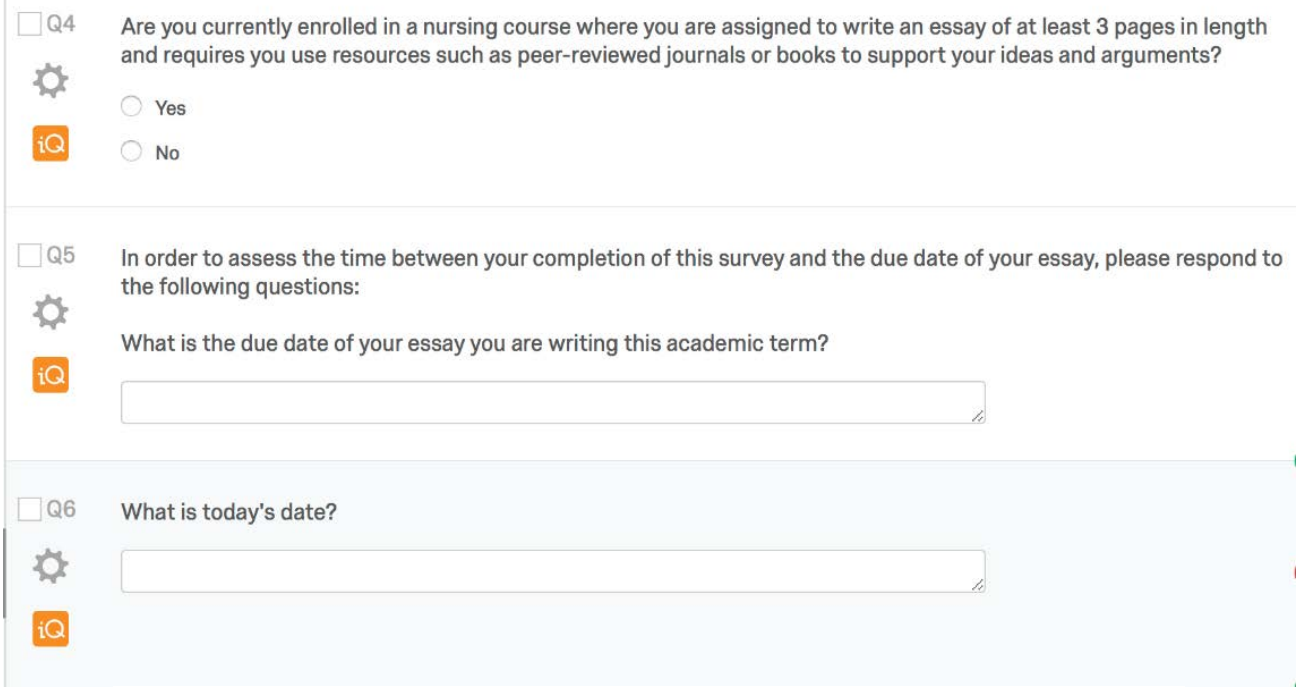

If you have been given a paper copy of the new writing self-efficacy questionnaire, please type in the number found on the front page of that paper copy here. If not leave the question blank. 


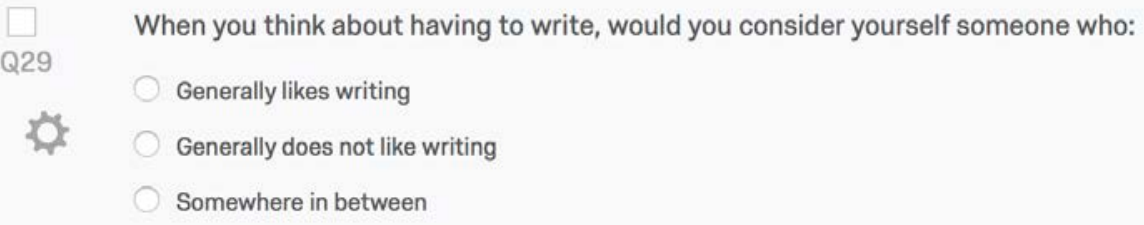

Q7

\section{Page Break}

Q7 Writing Self-Efficacy

2. Reminder: Visualize the writing assignment you are required to submit this academic term.

You must click on the circle on the line in order for the system to record a result (this is only important if you intend to give yourself a score of zero on an item). By sliding the circle along the line, rate your ability to successfully achieve each task presented in the question with a score of 0 meaning you are "completely sure you cannot" successfully perform that item and 100 meaning you are "completely sure you can" successfully perform the item.

Completely sure I Cannot

Completely sure I Can

\begin{tabular}{|} 
1. Even when the \\
writing is hard, I can \\
find ways to \\
overcome my \\
writing difficulties. \\
2. If I get stuck, I \\
can contact a \\
teacher or tutor to \\
help me move \\
forward with my \\
writing ideas. \\
3.I can successfully \\
use scholarly \\
academic words \\
and phrases when \\
writing in my \\
courses.
\end{tabular}

100 

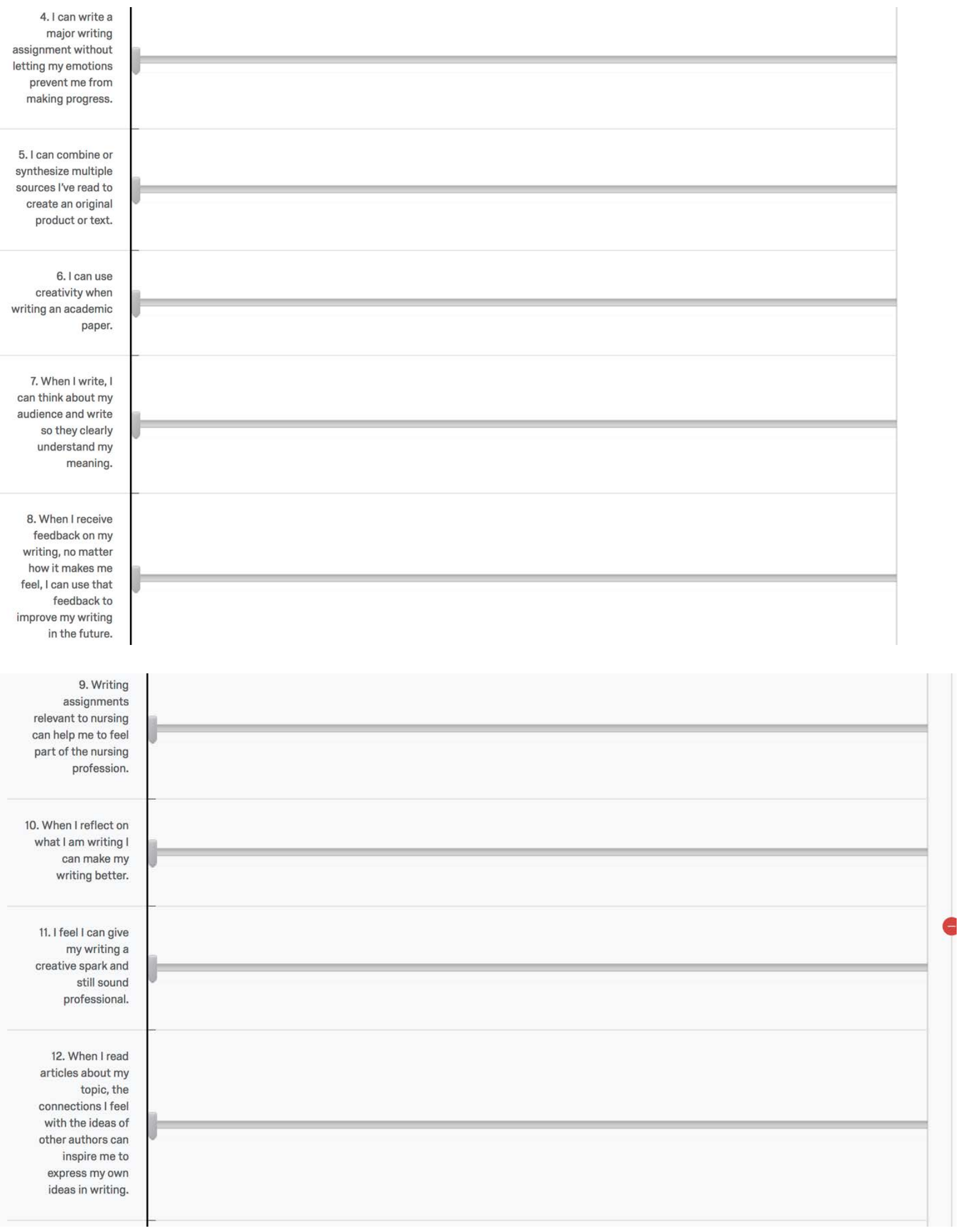


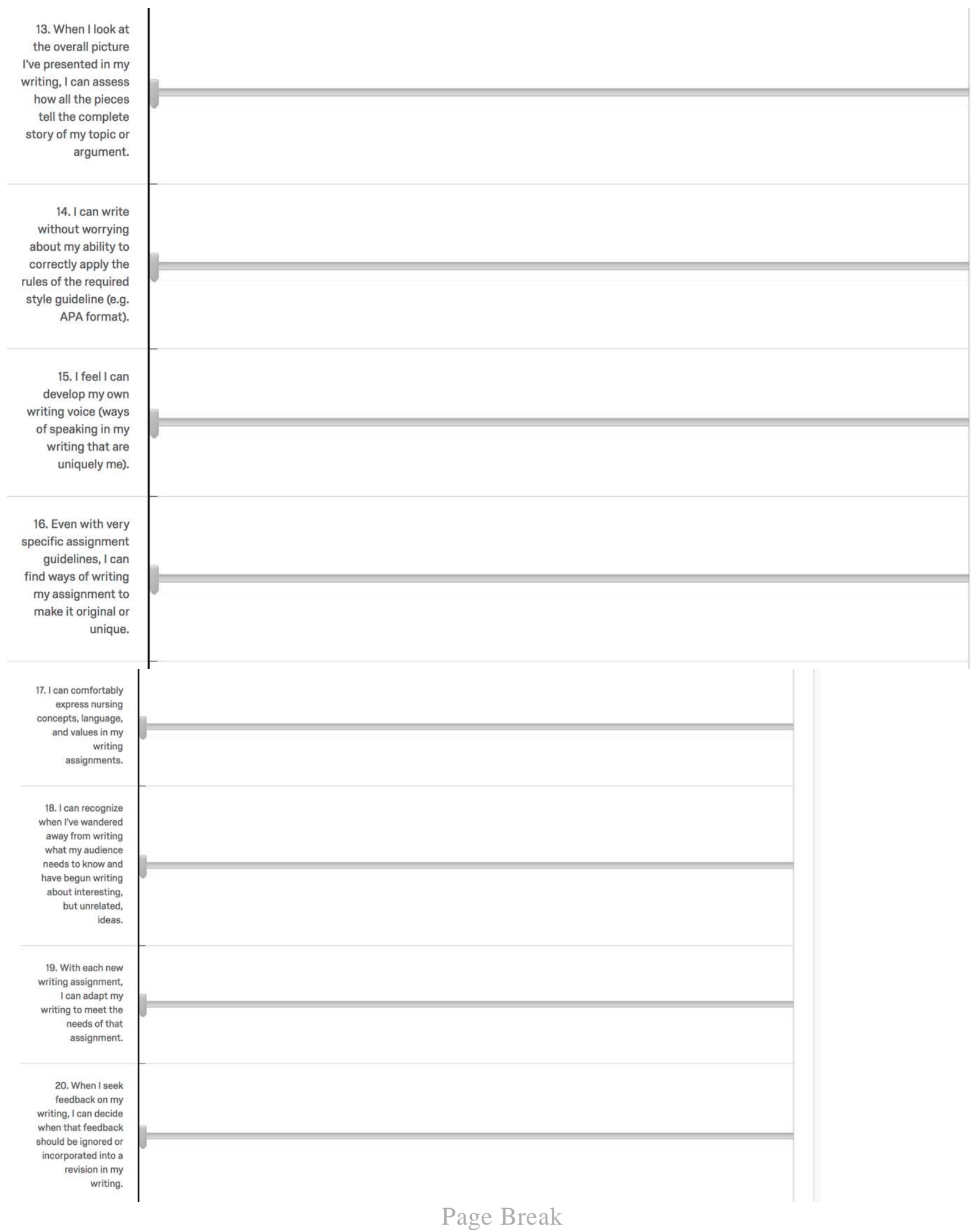

Q9

Reminder: Visualize the writing assignment you are required to submit this academic term. Read each statement below, which asks you about your ability to complete a specific writing task, activity, or manage an emotion about writing. Rate the degree to which you agree or disagree with the statement. 


\begin{tabular}{|c|c|c|c|c|}
\hline & \multicolumn{4}{|c|}{ Self-Efficacy Scale for Academic Writing } \\
\hline & Strongly Agree & Agree & Disagree & Strongly Disagree \\
\hline $\begin{array}{l}\text { I feel I have the skills to write a } \\
\text { scholarly paper. }\end{array}$ & 0 & 0 & 0 & 0 \\
\hline $\begin{array}{l}\text { Researching a topic comes } \\
\text { easily to me. }\end{array}$ & 0 & 0 & 0 & 0 \\
\hline $\begin{array}{l}\text { If I encounter a problem with } \\
\text { my chosen topic, I can find } \\
\text { strategies to overcome my } \\
\text { difficulties. }\end{array}$ & 0 & 0 & 0 & 0 \\
\hline $\begin{array}{l}\text { I am confident that I can write } \\
\text { clearly so that others will } \\
\text { understand my meaning. }\end{array}$ & 0 & 0 & 0 & 0 \\
\hline $\begin{array}{l}\text { I am confident in my ability to } \\
\text { understand the topic I've } \\
\text { chosen. }\end{array}$ & 0 & 0 & 0 & 0 \\
\hline $\begin{array}{l}\text { I have the skills to choose } \\
\text { appropriate research materials } \\
\text { to support my ideas on my } \\
\text { topic. }\end{array}$ & 0 & 0 & 0 & 0 \\
\hline $\begin{array}{l}\text { I am confident that I will } \\
\text { understand the content of the } \\
\text { research articles I find on my } \\
\text { topic. }\end{array}$ & 0 & 0 & 0 & 0 \\
\hline $\begin{array}{l}\text { With persistence, I can write } \\
\text { about anything asked of me. }\end{array}$ & 0 & 0 & 0 & 0 \\
\hline $\begin{array}{l}\text { I will remain calm and in control } \\
\text { through the writing process. }\end{array}$ & 0 & 0 & 0 & 0 \\
\hline
\end{tabular}

\section{Page Break}

Q11

Reminder: Visualize the writing assignment you are required to submit this academic term.

Please rate your ability to successfully achieve the following writing tasks on the scales below. You must click on the circle on the bar in order for the system to record a result. By sliding the bar along the line rate your ability to successfully achieve each task presented in the question with a score of 0 meaning you have "no chance" of being successful and 100 meaning you are "completely certain" you can be successful . 


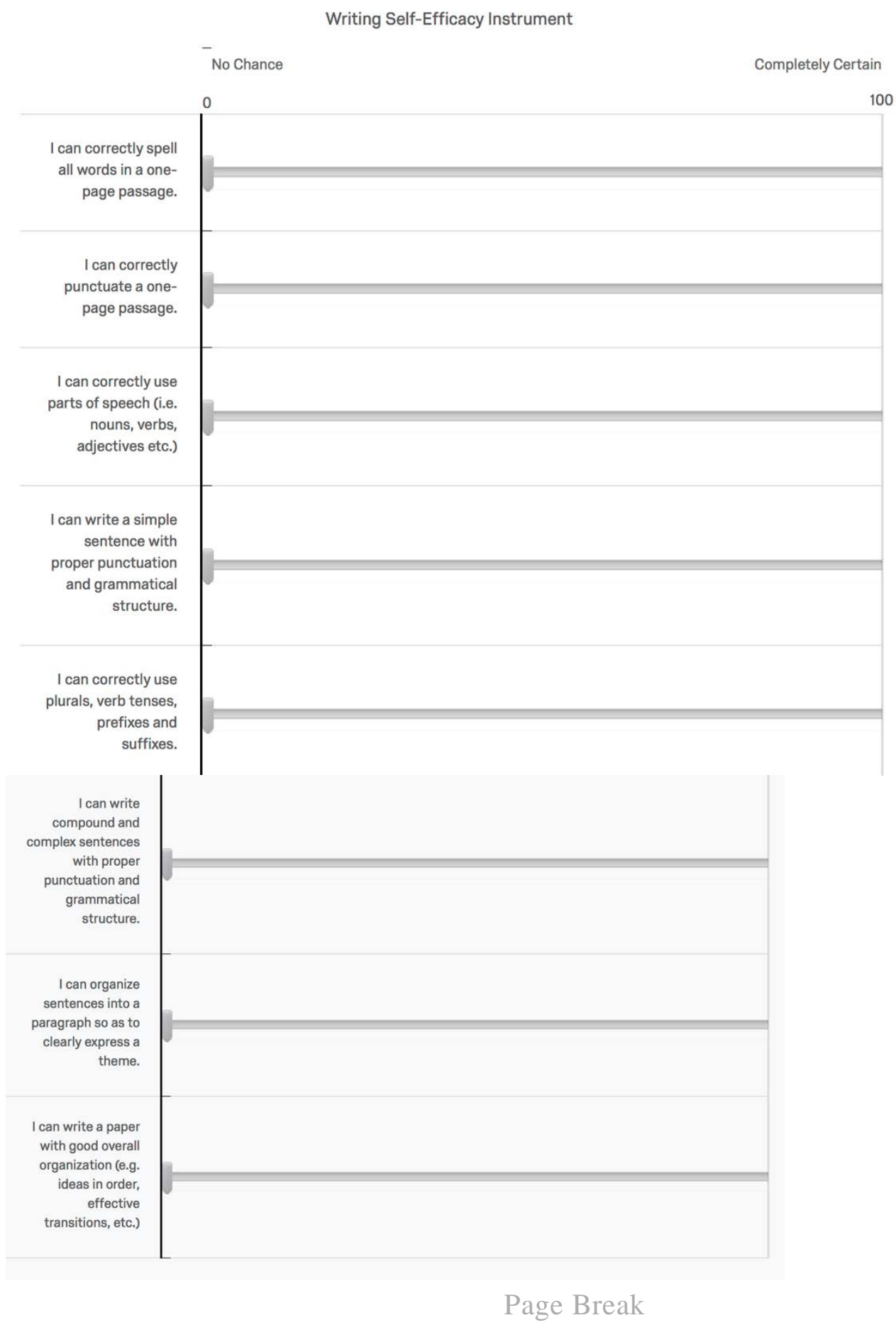

Q20

Reminder: Visualize the writing assignment you are required to submit this academic term.

Below are 20 statements that people sometimes make about themselves. Please indicate whether or not you believe each statement applies to you by marking the degree to which you agree or disagree with each statement. 


\begin{tabular}{|c|c|c|c|c|c|}
\hline & \multicolumn{5}{|c|}{ Writing Apprehension Test } \\
\hline & Strongly Agree & Agree & Neutral & Disagree & Strongly Disagree \\
\hline I avoid writing. & 0 & 0 & 0 & 0 & 0 \\
\hline $\begin{array}{l}\text { I have no fear of my writing } \\
\text { being evaluated. }\end{array}$ & 0 & O & 0 & $\bigcirc$ & 0 \\
\hline $\begin{array}{l}\text { I look forward to writing down } \\
\text { my ideas. }\end{array}$ & O & 0 & O & 0 & O \\
\hline $\begin{array}{l}\text { My mind seems to go blank } \\
\text { when I start to work on an } \\
\text { essay. }\end{array}$ & 0 & 0 & 0 & 0 & 0 \\
\hline $\begin{array}{l}\text { Expressing ideas through } \\
\text { writing seems to be a waste of } \\
\text { time. }\end{array}$ & 0 & 0 & O & O & 0 \\
\hline $\begin{array}{l}\text { I would enjoy submitting my } \\
\text { writing to magazines or journals } \\
\text { for evaluation and publication. }\end{array}$ & 0 & 0 & 0 & 0 & 0 \\
\hline I like to write my ideas down. & 0 & O & O & O & O \\
\hline $\begin{array}{l}\text { I feel confident in my ability to } \\
\text { clearly express my ideas in } \\
\text { writing. }\end{array}$ & 0 & 0 & 0 & 0 & 0 \\
\hline $\begin{array}{l}\text { I like to have my friends and/or } \\
\text { family read what I have written. }\end{array}$ & O & O & O & 0 & O \\
\hline I am nervous about writing. & 0 & 0 & 0 & 0 & 0 \\
\hline $\begin{array}{l}\text { People seem to enjoy what I } \\
\text { write. }\end{array}$ & O & O & O & 0 & O \\
\hline I enjoy writing. & 0 & 0 & 0 & 0 & 0 \\
\hline $\begin{array}{l}\text { Inever seem to be able to } \\
\text { clearly write down my ideas. }\end{array}$ & 0 & 0 & 0 & O & 0 \\
\hline Writing is a lot of fun. & 0 & 0 & 0 & 0 & 0 \\
\hline $\begin{array}{l}\text { I like seeing my thoughts on } \\
\text { paper. }\end{array}$ & 0 & 0 & 0 & 0 & 0 \\
\hline $\begin{array}{l}\text { Discussing my writing with } \\
\text { others is an enjoyable } \\
\text { experience. }\end{array}$ & 0 & 0 & 0 & O & O \\
\hline $\begin{array}{l}\text { It is easy for me to write } \\
\text { anything well. }\end{array}$ & 0 & 0 & 0 & 0 & 0 \\
\hline $\begin{array}{l}\text { I don't think I write as well as } \\
\text { most other people. }\end{array}$ & 0 & 0 & 0 & O & 0 \\
\hline $\begin{array}{l}\text { I don't like my writing to be } \\
\text { evaluated. }\end{array}$ & 0 & 0 & 0 & 0 & O \\
\hline I am no good at writing. & 0 & 0 & 0 & 0 & 0 \\
\hline
\end{tabular}

Page Break

Q21

Below are several statements that people sometimes feel about their choice to become a nurse. Please rate your level of agreement or disagreement with the following statements. 
Below are several statements that people sometimes feel about their choice to become a nurse. Please rate your level of agreement or disagreement with the following statements.

I feel like a member of the
nursing profession.
I feel I have strong ties with
members of the nursing
profession.
I am often ashamed to admit
that I am studying to be a
nurse.
I find myself making excuses for
belonging to the nursing
profession.
I am pleased to belong to the
nursing profession.
I can identify positively with
members of the nursing
profession.
Being a nurse is important to
me.
I feel I share characteristics
with other nurses.

Page Break

Q22

Reminder: Visualize the writing assignment you are required to submit this academic term.

The following items will explore various aspects of your writing environment and the impact of your writing assignment on you as a student and a nurse. You must click on the circle on the bar in order for the system to record a result. Rate each of the three items below on the 0-100 scales provided.

Q23 


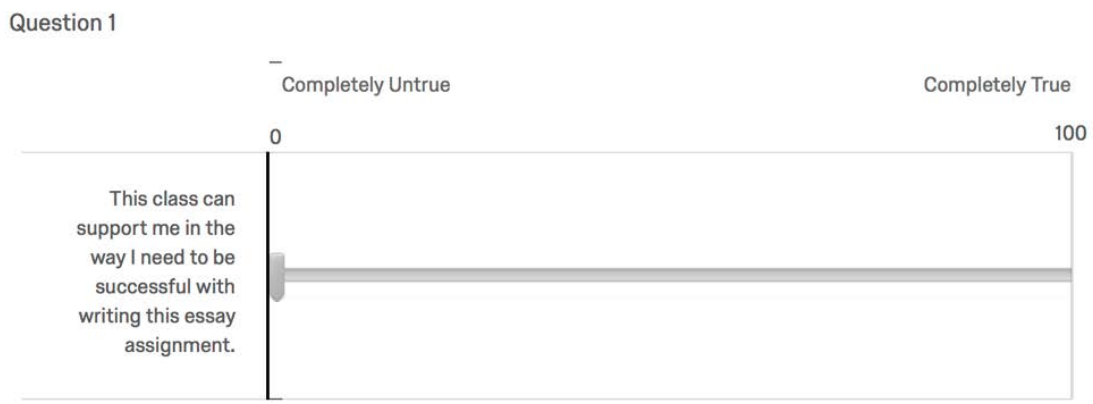

Question 2

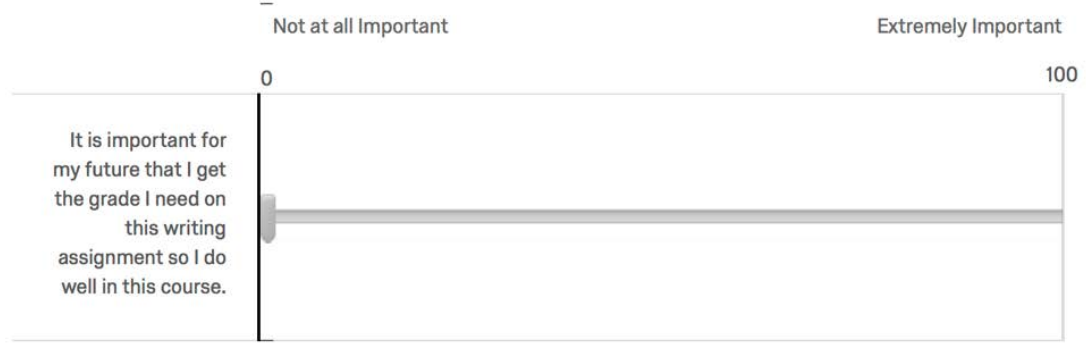

Question 3

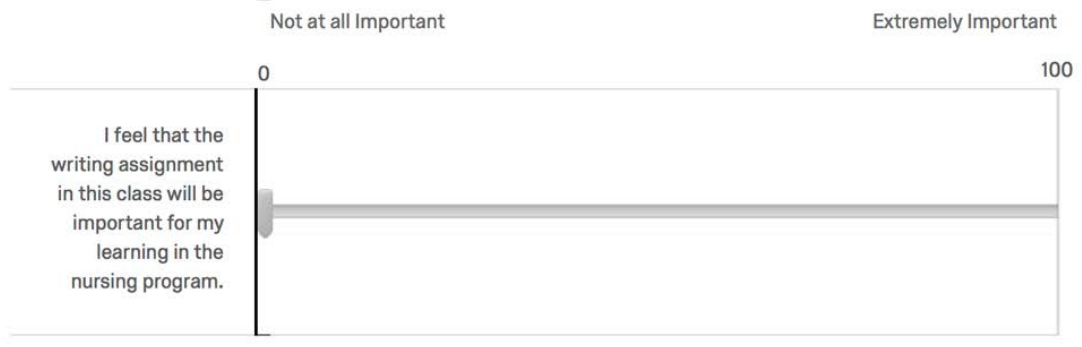

\section{Page Break}

Q26

You are almost finished! Thank you very much for your time so far. The remaining questions will ask you about your personal characteristics. These items will be used to identify patterns in your writing experiences and preferences as you've identified in the previous questions.

Q27 
The nursing program I attend is in the following country:

Canada

United States

Australia

Other (please identify country) "

What is the name of the university or college you attend?

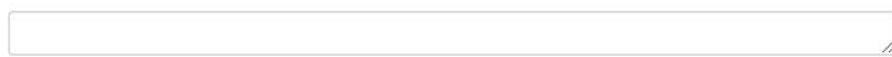

How many years/levels are there in your program in total?

It is a 1 year program.

It is a 2 year program.

It is a 3 year program.

It is a 4 year program.

Other ,

How many years/levels are there in your program in total?

It is a 1 year program.

It is a 2 year program.

It is a 3 year program.

It is a 4 year program.

Other

What year of your program are you currently in?

I am a first year student

I am a second year student

I am a third year student

I am a fourth year student

Other ",

What kind of degree or qualifications will you have when you graduate from your program?

$\mathrm{BN}, \mathrm{BScN}, \mathrm{BSN}$

Post registration $\mathrm{BN}, \mathrm{BScN}$, or $\mathrm{BSN}$

Associate Degree Nursing

Midwifery

Psychiatric Nursing

Other , 
What is your age in years and months? (e.g. 22 years, 3 months)

What is your gender identity?

Male

Female

Other or non-binary

What is your race/ethnicity?

When did you learn to speak English fluently?

I spoke only English from a young age (under 5 years of age).

I spoke English and another language (under 5 years of age).

I spoke another language (under 5 years of age) and learned English in school between the ages of 5 and 18 .

I spoke another language (under 5 to age 18) and learned English as an adult.

Other (please explain) "

Above is the OLD open-ended race/ethnicity and olde English language speaking items:

Below are the new versions.

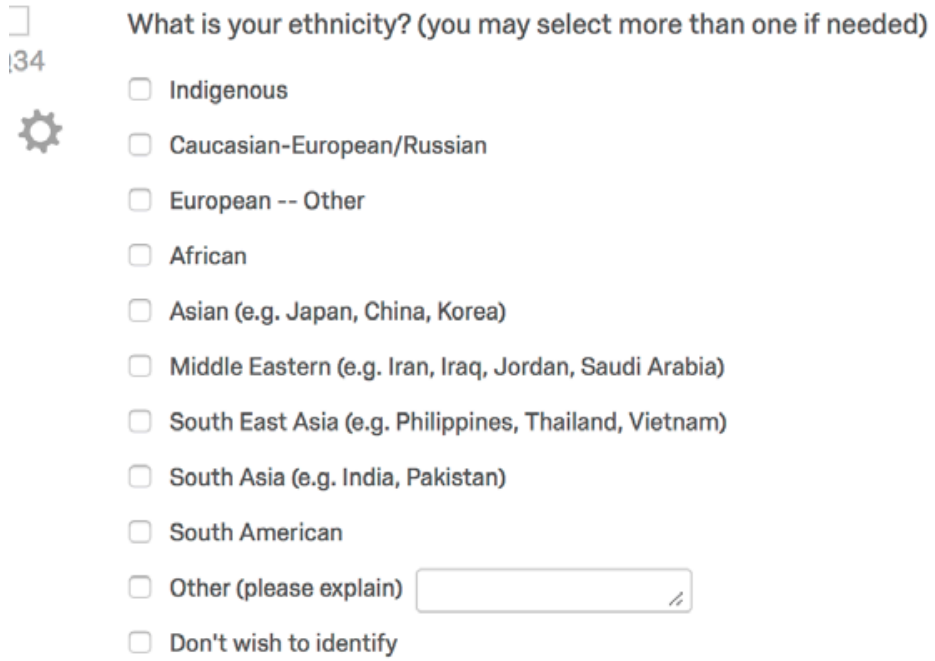


When did you learn to speak English fluently?

Q35

I spoke only English from a young age (under 5 years of age).

\&

I spoke English and another language (under 5 years of age).

I spoke another language (under 5 years of age) and learned English in school between the ages of 5 and 12 .

I spoke another language (under 12 years of age) and learned English in school between the ages of 13 and 18 .

I spoke another language (under 5 to age 18) and learned English as an adult.

Other (please explain)

When did you first learn to write in English?

In elementary school (kindergarten to grade 4)

In middle school (grades 5-9)

In high school (grades 10-12 or 13 as applicable).

After graduating from high school.

Other (please explain) 
College of Nursing

Helen Glass Centre for Nursing

Winnipeg, Manitoba

Canada

R3T 2N2

Telephone 204-474-9080

Fax 204-474-7682

\section{Appendix Q - Informed Consent for Nursing Survey}

Please take the time to carefully read the following informed consent form.

Research Project Title: A Mixed-Methods Validation of a New Measurement of Writing SelfEfficacy in the Nursing Context

Principal Investigator: $\quad$ Kim M. Mitchell

Doctoral Candidate

College of Nursing, Rady Faculty of Health Sciences

University of Manitoba

\section{Committee:}

Advisor - Dr. Diana E. McMillan - College of Nursing, Rady Faculty of Health Sciences Internal - Dr. Michelle M. Lobchuk - College of Nursing, Rady Faculty of Health Sciences

External - Dr. Nathan C. Nickel - Department of Community Health Sciences, Rady Faculty of Health

Sciences

This consent form is only part of the process of informed consent. It should give you the basic idea of what the research study is about and what your participation will involve. If you would like more detail about something mentioned here, or information not included here, you should feel free to ask. Please take the time to read this carefully and to understand any accompanying information. For your records, a copy of this consent form was attached to the email you received containing the link to the survey.

\section{Research Purpose}

The purpose of this study is to validate an instrument to measure writing self-efficacy in a nursing education context. Writing self-efficacy is the personal beliefs you might have about your abilities as a student writer in nursing. The study will also explore the relationship between writing self-efficacy, nursing identity, writing apprehension and your writing context.

\section{What would I have to do if I agree to participate?}

If you agree to participate in this study you will be asked to complete an online survey that will take you approximately 10-15 minutes to complete. The online survey will ask you questions about your thoughts and feeling about writing and writing assignments in your nursing program. 
It will also ask you questions about your identity as a student nurse. Some of the questions will ask you about some of your personal characteristics which may affect your writing experiences as a student, such as socio-demographic information, the type of nursing program you are enrolled in, what kind of degree you will obtain when you graduate, and if you've been speaking and writing in English since you were very young or if you learned English when you were older. Questions are in both open and closed response formats, and you can skip any question that you do not wish to answer, although the system will ask you if you wish to leave a question blank, just in case you missed a response by accident. You can complete the online survey in the allocated class time or outside of class, and you need access to a computer or smart phone to participate in the study. Some, but not all, students will be asked to complete a paper version of the new writing self-efficacy instrument. If this is the case, you will be asked to report the number on the paper questionnaire in the survey so that your paper questionnaire can be matched with your electronic survey responses.

\section{Are there any risks if I take part?}

There are no risks to you if you choose to participate. Participation in the study involves a time commitment. Participating in the study is completely voluntary and choosing to participate or not participate in this study will not affect your status in a course, your standing in your nursing program, or any course grades including any writing assignments you may be graded on this term.

\section{What will be the benefits?}

If you choose to participate in this study there may or may not be a direct benefit to you. Some studies show that reflecting on assignments and learning experiences can enhance students' understanding. Also, by completing the online survey you will see an example of nursing research and quantitative data collection which could reinforce concepts you have learned or will learn in the nursing program.

\section{Will I receive any compensation for participating in this study?}

At the end of the online survey, you can enter your name to win 1 of $5 \$ 100$ gift cards to Amazon. If you skip questions you can still enter the draw to win the gift card. If you wish to enter into this draw you will have to provide your name and email address but this information will be collected in a separate data collector which will not connect your survey responses to your identity. The winners will be contacted by the Manitoba Center for Nursing and Health Research once data collection for this study is completed.

\section{Will my responses be anonymous?}

Yes, your responses to the online survey will be anonymous. The research team members, course professors, and course teaching assistants will not know who participates in the study. When you complete the online survey, your name or student number will not be connected to your survey responses. Once the survey period has ended, your anonymous responses will be downloaded onto a password protected S: drive at the University of Manitoba. Only the researcher and her committee will have access to the study data. This data may be kept indefinitely by the researcher, and used, anonymously, for educational purposes or in future research studies. 
If you choose to enter your name for the gift card draw, an intermediary from the Manitoba Centre for Nursing and Health Research, will be the only person with access to this information. This individual will contact the winners and provide them with the prize.

The findings of this study may be published in an academic journal and presentations may be given both locally, nationally and internationally. In any publications about the study findings, the researchers will ensure that participants will not be individually identified. All the data will be presented in a summary format where only average scores for an entire group or sub group will be reported along with statistical results and findings.

Your responses will also remain confidential. The electronic files containing the spreadsheet of results for the survey will be stored in a password protected University of Manitoba network drive accessible only by the researchers and on the password protected laptop owned by Kim Mitchell, or her committee members, for the duration of the study and for an indefinite period of time after study completion. Any paper copies of the spreadsheet, your personalized result summaries, and other researcher notes will be kept in a locked filing cabinet during the active study period in the home of Kim Mitchell. After the study period (completion expected six months after end of data collection), the data will be kept indefinitely and used for educational purposes.

\section{Will I find out about the results of the study?}

If you would like, a brief summary of the research findings you can contact the researcher at any time if you would like more information about the study findings. Also, the results will be shared with the participating nursing programs and will be posted in a repository, on a website, or on social media in a format that can be viewed by any interested participating students.

\section{Can I withdraw from the study?}

At the end of the survey, you will be asked if you are willing to submit the information you provided for inclusion in the study. If you answer "Yes" to this question, your data will be used in the study. If you answer, "No," your data will be deleted from the spreadsheet and will not be included. If you complete the survey to the end and chose to, "Yes," submit your responses, it will not be possible to remove your data from the study at a later date as your identity will not be linked to your survey responses.

\section{Who do I contact if I have questions?}

If you have any questions about the study, the researcher (Kim Mitchell) or a research assistant will be present during one of your classes to answer your questions. You can also contact Kim Mitchell by email at or her advisor Dr. Diana McMillan at

\section{Additional Information}

If you proceed to take the online survey as a research participant, this indicates that you have understood to your satisfaction the information regarding participation in the research project and agree to participate as a subject. In no way does this waive your legal rights nor release the researchers, sponsors, or involved institutions from their legal and professional responsibilities. You are free to withdraw from the study at any time, and /or 
refrain from answering any questions you prefer to omit, without prejudice or consequence. Your continued participation should be as informed as your initial consent, so you should feel free to ask for clarification or new information throughout your participation.

The University of Manitoba may look at your research records to see that the research is being done in a safe and proper way.

This research has been approved by the Education/Nursing Ethical Review Board. If you have any concerns or complaints about this project you may contact any of the abovenamed persons or the Human Ethics Coordinator (HEC) at 474-7122 or at humanethics@umanitoba.ca

If you consent to participate in this project as outlined in the above consent form, please click on the "Next" button below, to be taken to the first page of the survey. 


\section{Appendix R - Email Request to Nursing Programs for Nursing Survey}

Dear name and title of contact person $\}$

My name is Kim Mitchell and I am a doctoral candidate in the College of Nursing, Rady Faculty of Health Sciences at the University of Manitoba. I few months ago I emailed you about recruiting students for interviews that were a part of Phase III of my study: "A Mixed-Methods Validation of a New Measurement of Writing Self-Efficacy in the Nursing Context.” That phase is now complete, and today I email you about Phase IV of this study which involves an online survey. The study will explore the relationship between writing self-efficacy, writing apprehension, nursing identity, and the writing context as part of the validation process for the instrument and should take approximately 10-15 minutes of a student's time.

This study has received ethical approval from the Nursing Education Research Ethics Board at the University of Manitoba and approval from \{specific institutional approval or other ethics board if applicable\} .

I am seeking to recruit nursing students from your program at \{institution\}. Below is an email I have directed toward your faculty. I would like to ask faculty who incorporate an academic writing assignment of at least 3 pages in length and asks students to use research materials such as peer reviewed journals to support their ideas and arguments, if they would consider inviting me to their classes to introduce the study to their students and possibly allow some time for completion of the survey during or immediately following class time.

Could you please forward the email below to your faculty in order to make this request? I thank you kindly for your support for my doctoral work.

Kind regards,

Kim Mitchell

Doctoral Candidate

College of Nursing, Rady Faculty of Health Sciences

University of Manitoba 


\title{
Appendix S - Email Invitation to Faculty to Attend Classes to Conduct Nursing Survey
}

\author{
Dear Faculty Member at $\{$ Institution $\}$
}

My name is Kim Mitchell and I am a doctoral candidate in the College of Nursing, Rady Faculty of Health Sciences at the University of Manitoba. I am emailing today to request your assistance with student recruitment for my doctoral thesis titled: “A Mixed-Methods Validation of a New Measurement of Writing Self-Efficacy in the Nursing Context.” The primary purpose of this study is to validate a new measurement instrument assessing writing self-efficacy in undergraduate nursing students. Using an online survey, the study will also explore the relationship between writing self-efficacy, writing apprehension, nursing identity, and the writing context as part of the validation process. This study has received ethical approval from the Nursing Education Research Ethics Board at the University of Manitoba and approval from \{specific institutional approval or other ethics board\}.

I am seeking the assistance of faculty who teach in nursing programs who are also assigning an academic writing assignment to their classes of at least 3 pages in length and requires the students seek out additional research sources (peer reviewed journals, books etc.) to support their ideas and arguments. If you offer such an assignment in your class, I would like the opportunity to attend your class and introduce your students to my research study.

What your assistance will involve:

- I anticipate the introduction of the study will require approximately 10 minutes of your class time.

- If you are also willing to allow class time for the students to complete the online survey, this may require an additional 15 minutes of class time.

- Prior to my attendance at your class, I will have [name of person at specific institution] send an email to the students in your class which contains the link to the survey.

Please feel free to contact me if you have any questions about this research or if you are uncertain if your assignment qualifies for inclusion. I have attached a copy of the informed consent form that will be presented to students which provides more details of the study expectations and purposes.

If you are willing to allow me to come to your class to introduce my research survey, please feel free to email me at $\quad$ or by telephone . You may also contact my advisor, Dr. Diana McMillan at _ $\quad$ if you have any questions.

Kind Regards,

Kim Mitchell

Doctoral Candidate

College of Nursing, Rady Faculty of Health Sciences

University of Manitoba 


\section{Appendix T - Email Invitation to Nursing Students to Request Participation}

\section{Would you like to participate in a research study?}

Dear Students in $\{$ Name of Course $\}$,

My name is Kim Mitchell and I am a doctoral candidate in nursing at the University of Manitoba. I have been invited to this class on \{date to introduce you to an online study survey for a study titled "A Mixed-Methods Validation of a New Measurement of Writing Self-Efficacy in the Nursing Context.” In this study, nursing students in all years of all programs will be invited to complete an online survey asking them questions about how they feel about their capabilities as nurse writers, how you think and feel about writing in general, and about your identity as a student nurse. Your participation in this survey is completely voluntary and will not affect your grades in your course or your status in the nursing program whether you choose to participate or not.

The link to this survey, if you choose to participate, can be found here: https://umnursing.ca1.qualtrics.com/jfe/form/SV_czFN0WfOFfR6IiV

The survey is expected to take approximately 10-15 minutes to complete, and we ask that you bring a laptop computer or smartphone to class to complete this activity. We have designed the study to ensure that your confidentiality is protected at all times - before, during, and after this study. The Manitoba Centre for Nursing and Health Research staff will manage the anonymous survey to ensure your privacy.

If you choose to participate in the study by submitting your online survey responses, you will be able to enter a draw to win one of five \$100-dollar gift cards.

Additional information about the study will be available on the online survey. I have also attached a copy of the informed consent letter to this email for your easy reference. The Education Nursing Research Ethics Board has approved this study. If you have any concerns about this project you may contact the Human Ethics Coordinator at 204.474.712 or at humanethics@umanitoba.ca. If you have questions about this study, please contact Kim Mitchell at $\quad$ or her advisor Dr. Diana McMillan at

Kind Regards,

Kim Mitchell, Doctoral Candidate

Dr. Diana McMillan, Associate Professor

College of Nursing

Rady Faculty of Health Sciences

University of Manitoba 


\section{Appendix U - Reminder Email to Nursing Students to Complete Survey}

Dear Student in $\{$ name of course ,

Last week, I attended your class on \{date and introduced you to my research study titled, “A Mixed-Methods Validation of a New Measurement of Writing Self-Efficacy in the Nursing Context.” If you have already completed this survey, I thank you very much for your time and contribution to this research study.

If you have not yet completed this survey and are still interested in participating, you may access the survey at the following link:

https://umnursing.ca1.qualtrics.com/jfe/form/SV_czFNOWfOFfR6IiV

The survey is expected to take approximately 10-15 minutes to complete. We have designed the study to ensure that your confidentiality is protected at all times - before, during, and after this study. The Manitoba Centre for Nursing and Health Research staff will manage the anonymous survey to ensure your privacy.

If you have questions about this study, please contact Kim Mitchell at or her advisor Dr. Diana McMillan at

Kind Regards,

Kim Mitchell, Doctoral Candidate

Dr. Diana McMillan, Associate Professor

College of Nursing

Rady Faculty of Health Sciences

University of Manitoba 


\section{Appendix V - Script to Introduce Study During Nursing Classes}

\section{What is the purpose of the study?}

- The purpose of this study is to validate an instrument to measure writing self-efficacy in a nursing education context.

- Writing self-efficacy is the personal beliefs you might have about your abilities as a student writer in nursing.

- The study will also explore the relationship between writing self-efficacy, nursing identity, writing apprehension and your writing context.

\section{What would I have to do if I agree to participate?}

- If you agree to participate in this study you will be asked to complete an online survey that will take you approximately 10-15 minutes to complete.

- The online survey will ask you questions about your thoughts and feeling about writing and writing assignments in your nursing program.

- It will also ask you questions about your identity as a student nurse.

- Some of the questions will ask you about some of your personal characteristics which may affect your writing experiences as a student, such as socio-demographic information, the type of nursing program you are enrolled in, what kind of degree you will obtain when you graduate, and if you've been speaking and writing in English since you were very young or if you learned English when you were older.

- Questions are in both open and closed response formats, and you can skip any question that you do not wish to answer, although the system will ask you if you wish to leave a question blank, just in case you missed a response by accident.

- You can complete the online survey in the allocated class time or outside of class, and you need access to a computer or smart phone to participate in the study.

- Some, but not all students will be asked to complete a paper version of the new writing selfefficacy instrument. If this is the case, you will be asked to report the number on the paper questionnaire in the survey so that your paper questionnaire can be matched with your electronic survey responses.

\section{Risks and Benefits to Participating}

- There are no risks to you if you choose to participate.

- Participation in the study involves a time commitment.

- Participating in the study is completely voluntary and choosing to participate or not participate in this study will not affect your status in a course, your standing in your nursing program, or any course grades including any writing assignments you may be graded on this term.

- If you choose to participate in this study there may or may not be a direct benefit to you. Some studies show that reflecting on assignments and learning experiences can enhance students' understanding.

- At the end of the online survey you can enter your name to win 1 of 5 \$100 gift cards to Amazon. The draw will take place by redirecting you to a second website not associated with the survey in order to keep your information separate from your survey responses. 


\section{Will my responses be anonymous?}

- Yes, your responses to the online survey will be anonymous. The research team members, course professors, and course teaching assistants will not know who participates in the study.

- Your name will not be associated with the data you submit in any way.

- The data may be kept indefinitely and used for additional research or educational purposes.

\section{Will I find out about the results of the study?}

- If you would like, a brief summary of the research findings you can contact the researcher at any time if you would like more information about the study findings.

- A copy of the informed consent with the researcher's contact information was attached to the email containing the link to the survey.

- Also, the results will be shared with the participating nursing programs and will be posted in a repository, on a website, or on social media in a format that can be viewed by any interested participating students.

\section{What if I decide I don't want to include my data?}

- You may withdraw from participation in this study at any time while completing the online survey by closing your internet web browser.

- At the end of the survey, you will be asked if you are willing to submit the information you provided for inclusion in the study. If you answer "Yes" to this question, your data will be used in the study. If you answer, "No," your data will be deleted from the spreadsheet and will not be included.

- If you complete the survey to the end and chose to, "Yes," submit your responses, it will not be possible to remove your data from the study at a later date as your identity will not be linked to your survey responses. 


\section{Appendix W - Interdisciplinary Survey Including Demographic Items}

Consent form appears here:

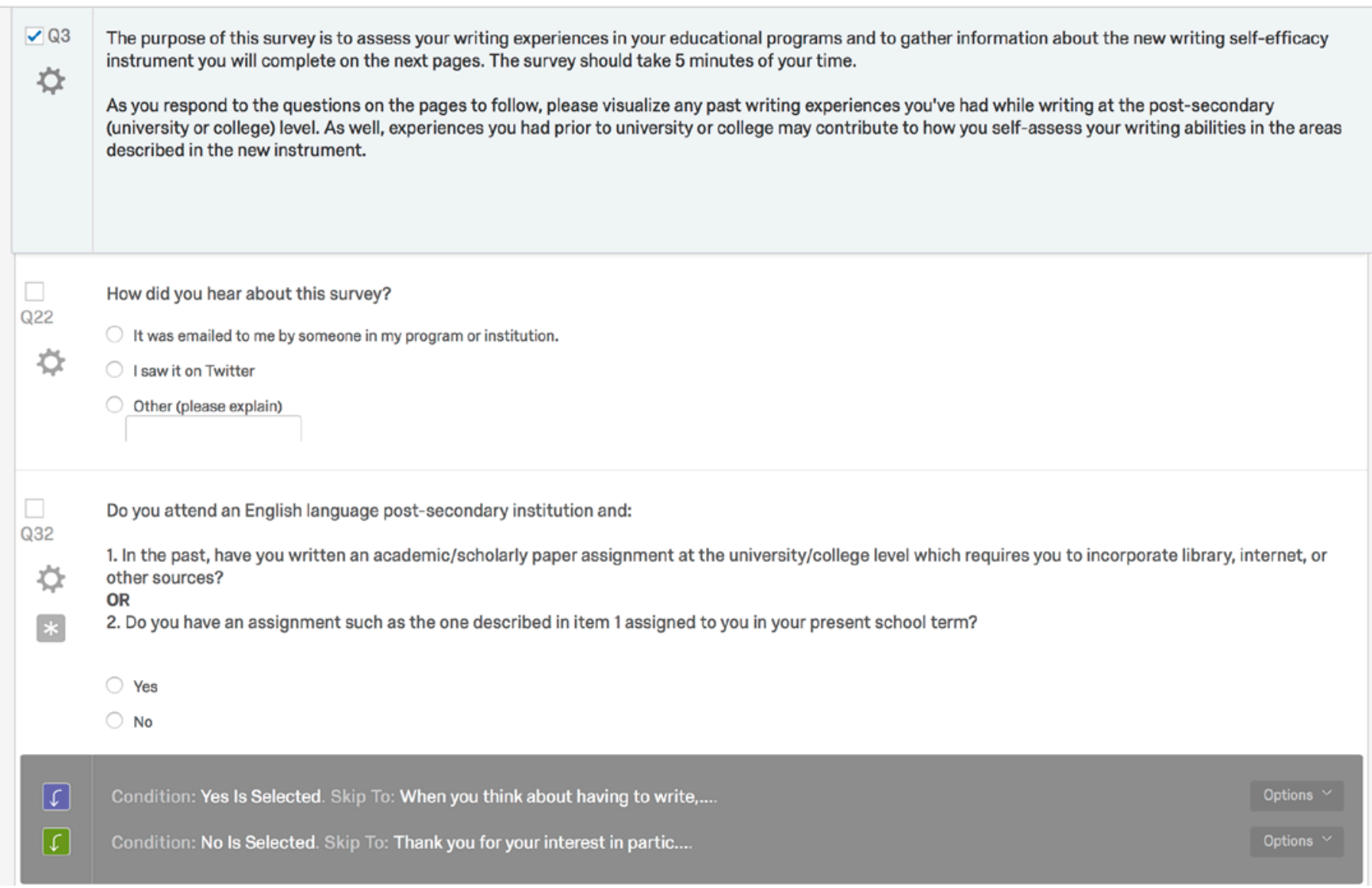

There is a response condition attached to Q32 if they respond No.. they will be taken to the following page:

\section{Display This Question:}

$\hookrightarrow$ If Do you attend an English language post-secondary institution and:\&nbsp;\&nbsp; 1. In the past, have you written an academic/scholarly paper assignment at the university/college level which requires ... No is Selected

Thank you for your interest in participating in this questionnaire validation study. Currently, your present writing experiences mean you do not qualify for this Q37 study.

If they respond YES to Q32 they will begin the survey. 
The second page asks:

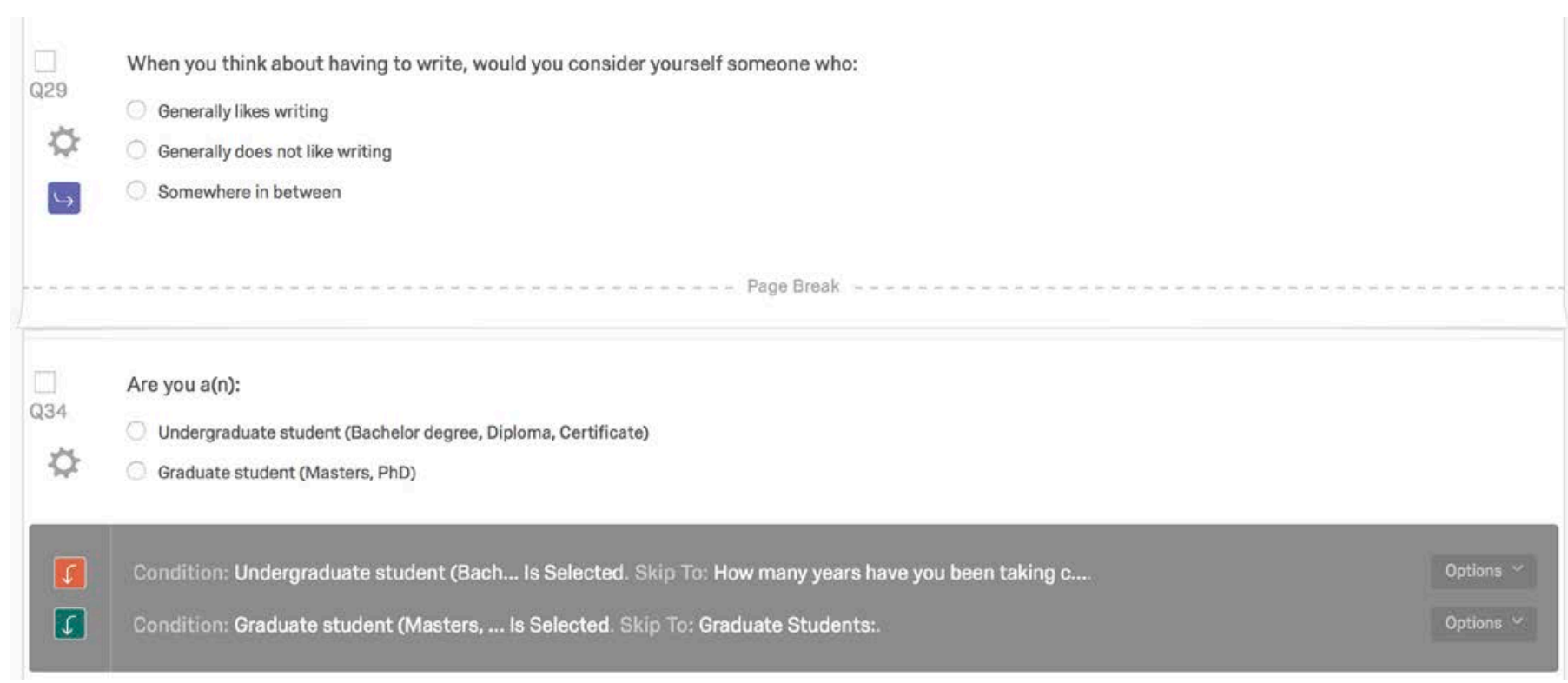

There are 2 pathways... one for undergraduate and another for graduate students.

\section{Undergraduate students view the following page:}

Display This Question:

If Are you a(n): Undergraduate student (Bachelor degree, Diploma, Certificate) Is Selected

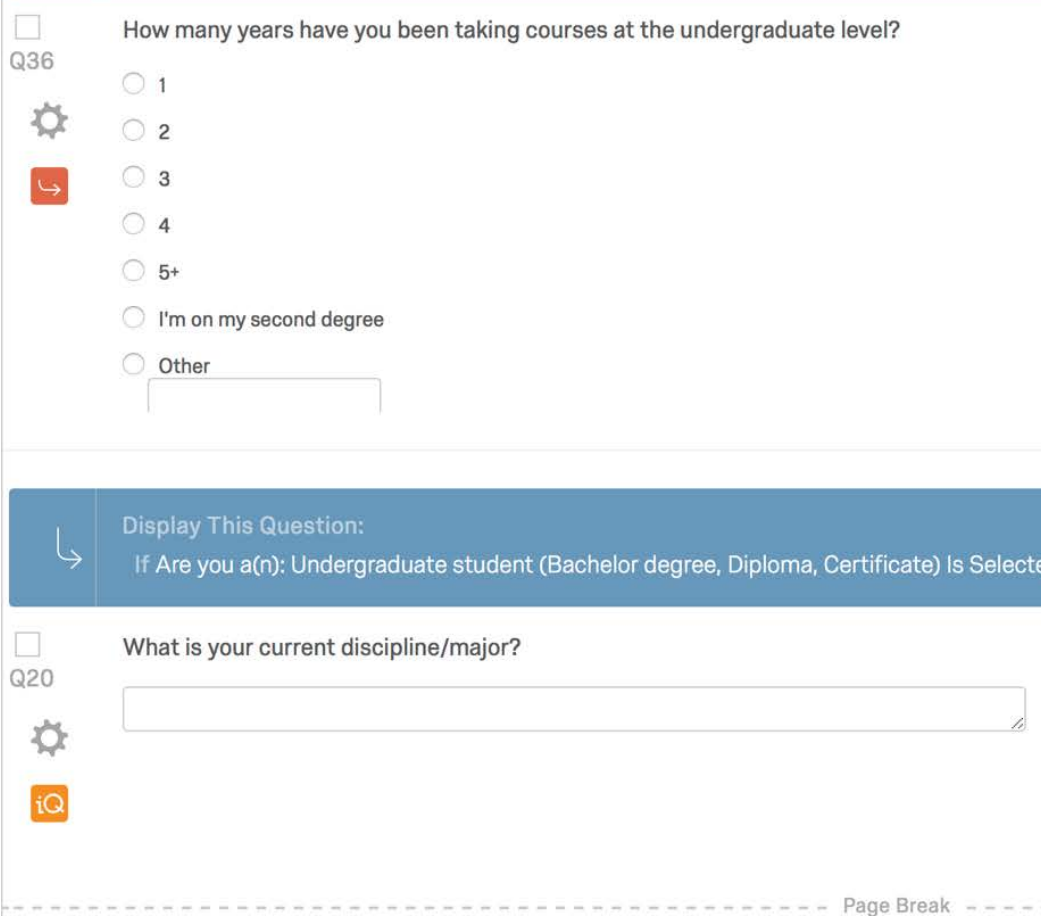


Graduate students view this page:

Display This Question:

If Are you a(n): Graduate student (Masters, PhD) is Selected

Q35 Graduate Students:
Masters degree presently taking coursework
Masters degree thesis or capstone stage
PhD presently taking coursework
PhD post-coursework, pre-candidacy
PhD candidate
PhD waiting for defence
Other

\section{Display This Question:}

If Are you a(n): Graduate student (Masters, PhD) is Selected

What is your current discipline/major?

Q21

$\not$

iQ

They are then taken to the 16 item Situated Academic Writing Self-Efficacy Scale:

Q7 Writing Self-Efficacy -- a measure of your self-assessed writing abilities.

1. By sliding the circle along the line, rate your ability to successfully achieve each task presented in the question with a score of 0 meaning you are "completely sure you cannot" successfully perform that item and 100 meaning you are "completely sure you can" successfully perform the item.

* You must click on the circle on the line in order for the system to record a result (this is only important if you intend to give yourself a score of zero on an You m
item).

\begin{tabular}{|c|}
$\begin{array}{r}\text { 1. Even when the } \\
\text { writing is hard, I can } \\
\text { find ways to } \\
\text { overcome my } \\
\text { writing difficulties. }\end{array}$ \\
\hline $\begin{array}{r}\text { 2.I can successfully } \\
\text { use scholarly } \\
\text { academic words } \\
\text { and phrases when } \\
\text { writing in my } \\
\text { courses/program. }\end{array}$ \\
$\begin{array}{r}3 . \text { I can combine or } \\
\text { synthesize multiple } \\
\text { sources I've read to } \\
\text { create an original } \\
\text { product or text. }\end{array}$ \\
\hline
\end{tabular}




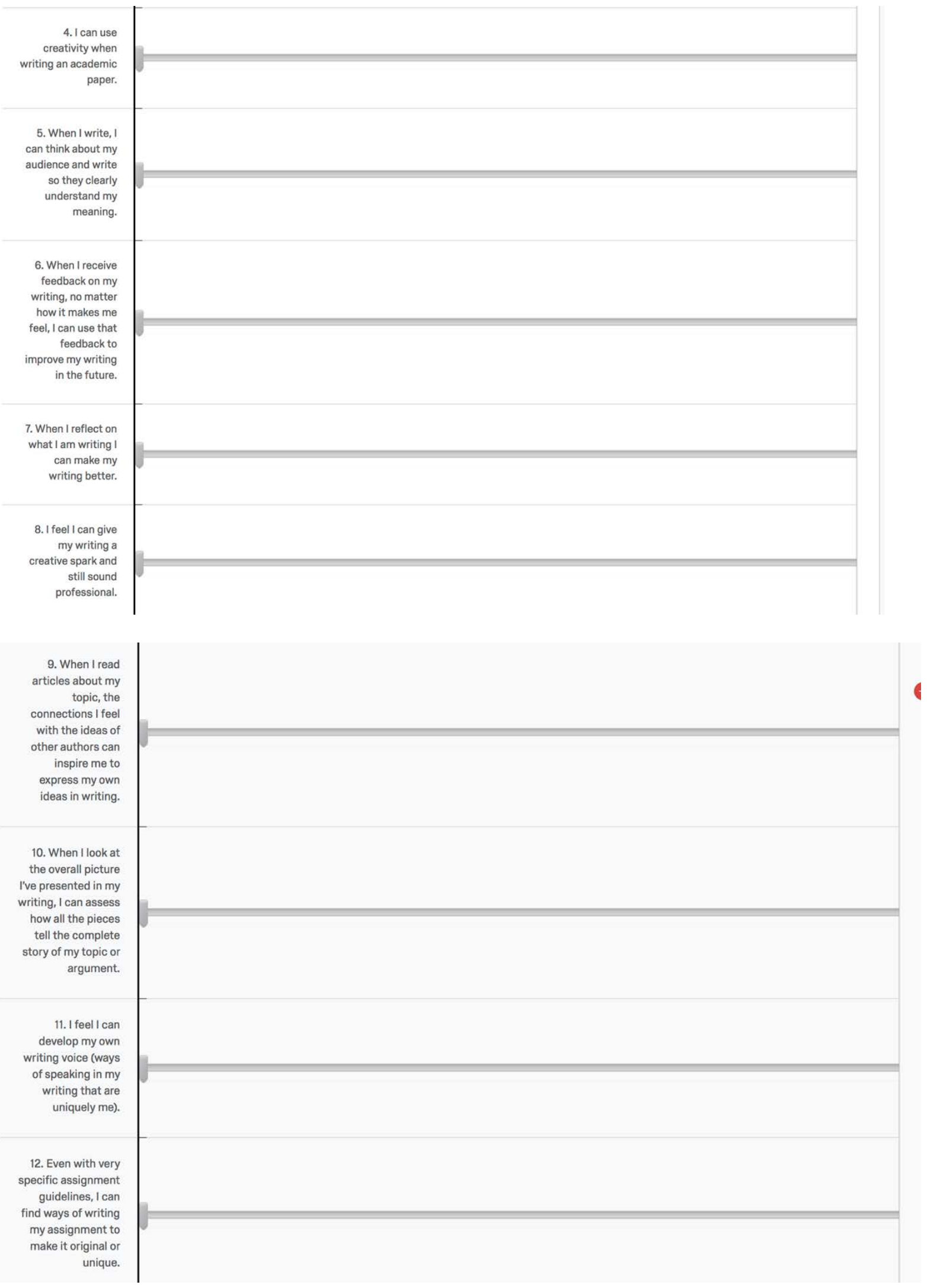




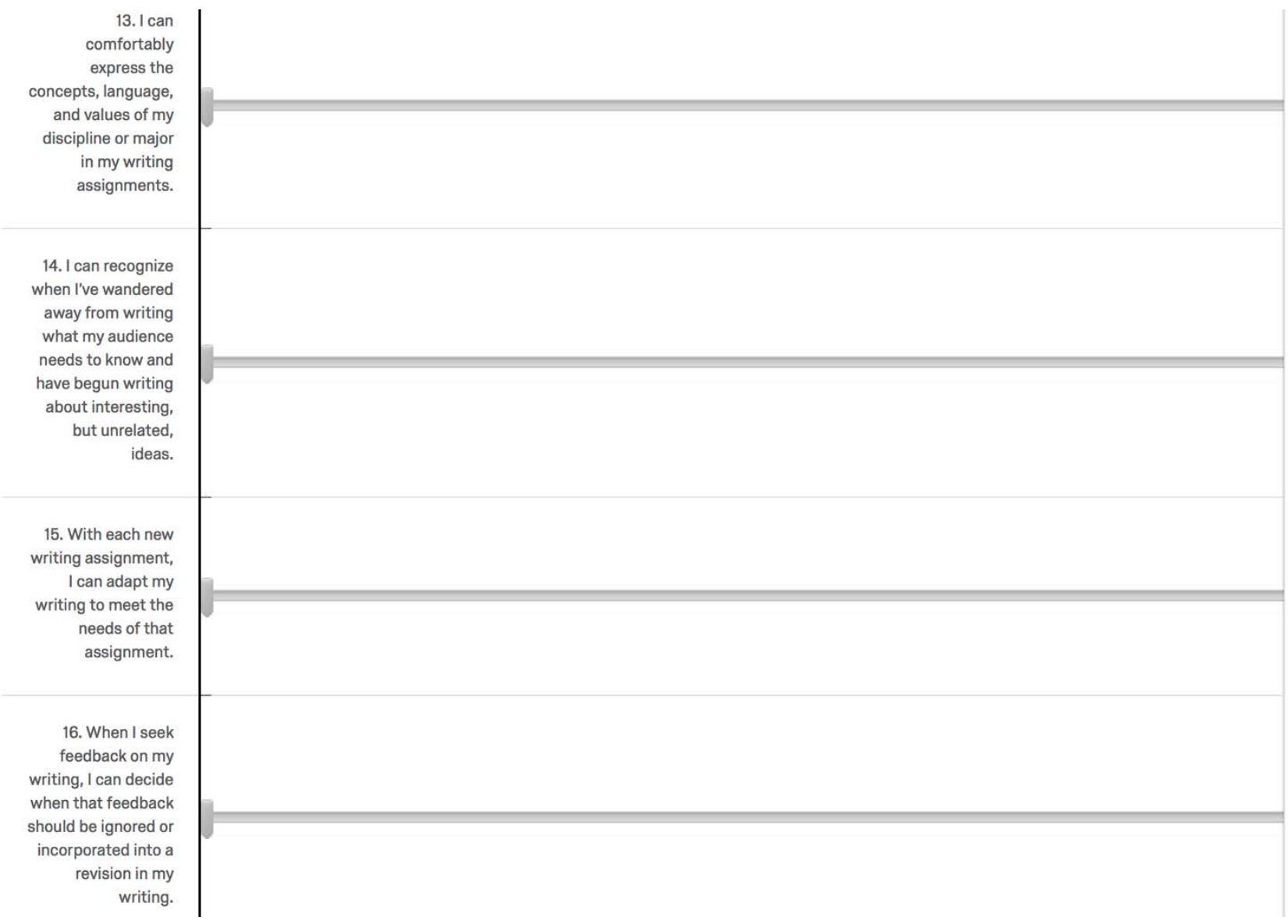

There is also an optional open ended response to indicate any issues they may have had with the items.

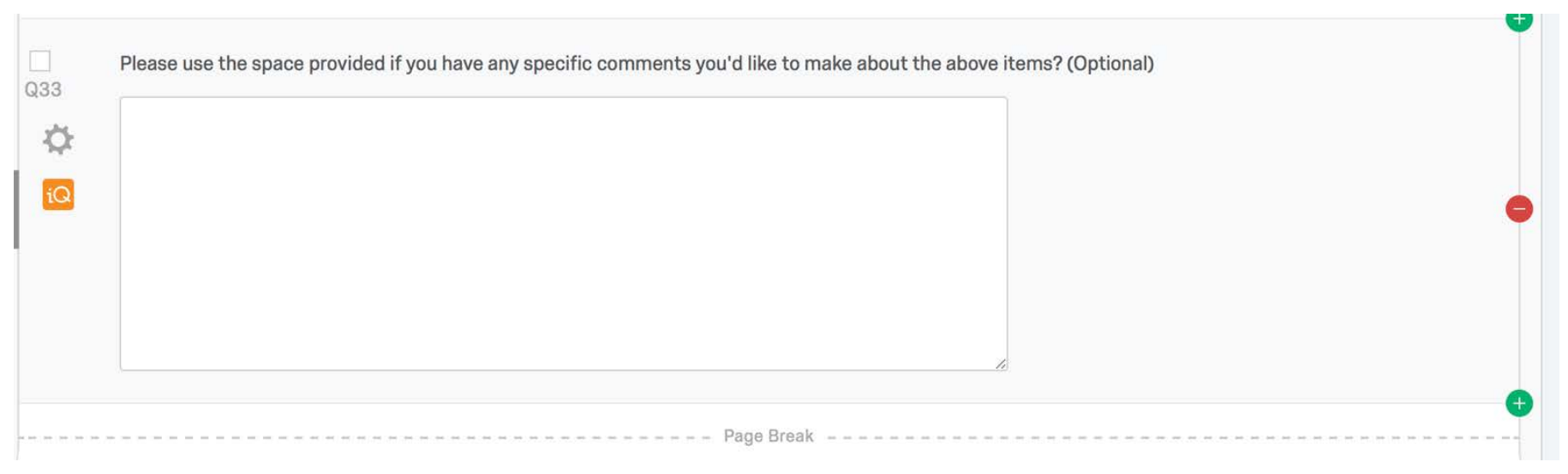

Finally, the last page contains the demographic questions which are similar to the original survey except for the removal of the ethnicity question and the institution/country questions have been made open-ended because of the social media recruitment. 
You are almost finished! Thank you very much for your time so far. The remaining questions will ask you about your personal characteristics. These items will be used to identify patterns in your writing experiences and preferences, as you've identified in the previous questions, as compared to your personal characteristics.

$\not \mathbf{p}$

The university/college program I attend is in the following country:

$\not \mathbf{q}$

iQ

What is the name of the university or college you attend?

Q28

iQ

What is your age in years and months? (e.g. 22 years, 3 months)

Q32

家

iQ

What is your gender identity?

Q. Male

Other or non-binary

When did you learn to speak English fluently?

I spoke only English from a young age (under 5 years of age).

I spoke English and another language (under 5 years of age).

I spoke another language (under 5 years of age) and learned English in school between the ages of 5 and 12 .

I spoke another language (under 12 years of age) and learned English in school between the ages of 13 and 18.

I spoke another language (under 5 to age 18) and learned English as an adult.

Other (please explain)

When did you first learn to write in English?

In elementary school (kindergarten to grade 4)

In middle school (grades 5-9)

In high school (grades 10-12 or 13 as applicable).

After graduating from high school.

Other (please explain)

The survey ends with the final thank you message on the next page. 


\section{Appendix X - Informed Consent for Interdisciplinary Survey}

\section{Rady Faculty of Health Sciences
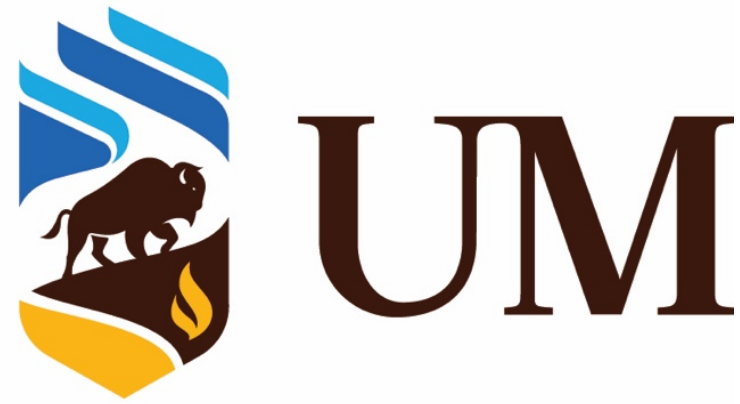

Please take the time to carefully read the following informed consent form.

Research Project Title: A Mixed-Methods Validation of a New Measurement of Writing Self-Efficacy

Principal Investigator: $\quad$ Kim M. Mitchell

Doctoral Candidate

College of Nursing, Rady Faculty of Health Sciences

University of Manitoba

\section{Committee:}

Advisor - Dr. Diana E. McMillan - College of Nursing, Rady Faculty of Health Sciences

Internal - Dr. Michelle M. Lobchuk - College of Nursing, Rady Faculty of Health Sciences

External - Dr. Nathan C. Nickel - Department of Community Health Sciences, Rady Faculty of Health

Sciences

This consent form is only part of the process of informed consent. It should give you the basic idea of what the research study is about and what your participation will involve. If you would like more detail about something mentioned here, or information not included here, you should feel free to ask. Please take the time to read this carefully and to understand any accompanying information.

\section{Research Purpose}

The purpose of this study is to validate an instrument to measure writing self-efficacy. Writing selfefficacy is the personal beliefs you might have about your abilities as a student writer. You qualify to complete this survey if you have written academic papers in English at the university/college level in the past or if you have been assigned an academic paper in your current term of study.

\section{What would I have to do if I agree to participate?}

If you agree to participate in this study you will be asked to complete an online survey that will take you 5-10 minutes to complete. The online survey will ask you questions about your thoughts and feeling about writing and writing assignments in your program of study. Some of the questions will ask you about some of your personal characteristics which may affect your writing experiences as a student, such as socio-demographic information, the type of program you are enrolled in, what kind of degree you will obtain when you graduate, and if you've been speaking and writing in English since you were very young or if you learned English when you were older. Questions are in both open and closed response formats, and you can skip any question that you do not wish to answer, although the system will ask you if you wish to leave a question blank, just in case you missed a response by accident. 


\section{Are there any risks if I take part?}

There are no risks to you if you choose to participate. Participation in the study involves a time commitment. Participating in the study is completely voluntary and choosing to participate or not participate in this study will not affect your status in a course, your standing in your program, or any course grades including any writing assignments you may be graded on this term.

\section{What will be the benefits?}

If you choose to participate in this study there may or may not be a direct benefit to you. Some studies show that reflecting on assignments and learning experiences can enhance students' understanding. Also, by completing the online survey you will see an example of research and quantitative data collection which could reinforce concepts you have learned or will learn in your program.

\section{Will I receive any compensation for participating in this study?}

There is no special compensation for participating in this research.

\section{Will my responses be anonymous?}

Your responses to the online survey will be kept in strict confidence and will not request directly identifying information. The research team members and any course instructors or professors who may share the survey will not know who participates in the study. When you complete the online survey, your name or student number will not be connected to your survey responses. Once the survey period has ended, your responses will be downloaded onto a password protected computer. Only the researcher and her committee will have access to the study data. This data may be kept indefinitely by the researcher, and used, anonymously, for educational purposes or in future research studies.

The findings of this study may be published in an academic journal and presentations may be given both locally, nationally and internationally. In any publications about the study findings, the researchers will ensure that participants will not be individually identified. All the data will be presented in a summary format where only average scores for an entire group or sub group will be reported along with statistical results and findings.

Your responses will also remain confidential. The electronic files containing the spreadsheet of results for the survey will be stored in a password protected laptop owned by Kim Mitchell, or her committee members, for the duration of the study and for an indefinite period of time after study completion. Any paper copies of the spreadsheet and other researcher notes will be kept in a locked filing cabinet during the active study period in the home or work office of Kim Mitchell. After the study period (completion expected six months after end of data collection), the data will be kept indefinitely and used for educational purposes.

\section{Will I find out about the results of the study?}

If you would like a brief summary of the research findings, you can contact the researcher at any time.

\section{Can I withdraw from the study?}

If you complete the survey to the end it will not be possible to remove your data from the study at a later date as your identity will not be linked to your survey responses.

\section{Who do I contact if I have questions?}

If you have any questions about the study you can contact Kim Mitchell by email at kmmitch@myumanitoba.ca or her advisor Dr. Diana McMillan at diana.mcmillan@umanitoba.ca 


\section{Additional Information}

If you proceed to take the online survey as a research participant, this indicates that you have understood to your satisfaction the information regarding participation in the research project and agree to participate as a subject. In no way does this waive your legal rights nor release the researchers, sponsors, or involved institutions from their legal and professional responsibilities. You are free to refrain from answering any questions you prefer to omit, without prejudice or consequence.

The University of Manitoba may look at your research records to see that the research is being done in a safe and proper way.

This research has been approved by the Education/Nursing Research Ethics Board, The Red River College Research Ethics Board, the Brandon University Research Ethics Committee. If you have any concerns or complaints about this project you may contact any of the above-named persons or the Human Ethics Coordinator (HEC) at the University of Manitoba at 1-204-474-7122 or at humanethics@umanitoba.ca

Notice Regarding Collection, Use, and Disclosure of Personal Information by the University Your personal information is being collected under the authority of The University of Manitoba Act. The information you provide will be used by the University for the purpose of this research project. Your personal information will not be used or disclosed for other purposes, unless permitted by The Freedom of Information and Protection of Privacy Act(FIPPA). If you have any questions about the collection of your personal information, contact the Access \& Privacy Office (tel. 204-474-9462), 233 Elizabeth Dafoe Library, University of Manitoba, Winnipeg, MB, R3T 2 N2.

If you consent to participate in this project as outlined in the above consent form, please click on the "Next" button below, to be taken to the first page of the survey. 


\section{Appendix Y - Email Invitation to Participants for Interdisciplinary Survey}

\section{What Defines You as a Student Writer? A)I like writing B) I hate writing C) It depends}

Kim Mitchell and I am a doctoral candidate in nursing at the University of Manitoba. I am currently conducting a study called "A Mixed-Methods Validation of a New Measurement of Writing SelfEfficacy.” In this study, students who have written for academic purposes in their undergraduate or graduate program, are invited to complete a short online survey asking them questions about how they feel about their capabilities as writers.

The link to this survey, if you choose to participate, can be found here:

https://umnursing.ca1.qualtrics.com/jfe/form/SV_7NBDbNPPA7k37Nj

The survey is expected to take approximately 5-10 minutes to complete and can be completed on a smart phone or computer. We have designed the study to ensure that your confidentiality is protected at all times - before, during, and after this study. The Manitoba Centre for Nursing and Health Research staff will manage the anonymous survey to ensure your privacy.

Your participation in this survey is completely voluntary. Your status in your educational program will not be affected in any way if you choose to participate or not.

Additional information about the study will be available on the online survey. The Education Nursing Research Ethics Board has approved this study. If you have any concerns about this project you may contact the Human Ethics Coordinator at 204.474.712 or at humanethics@umanitoba.ca. If you have questions about this study, please contact Kim Mitchell at or her advisor Dr. Diana McMillan at

Kind Regards,

Kim Mitchell, Doctoral Candidate

Dr. Diana McMillan, Associate Professor

College of Nursing

Rady Faculty of Health Sciences

University of Manitoba 


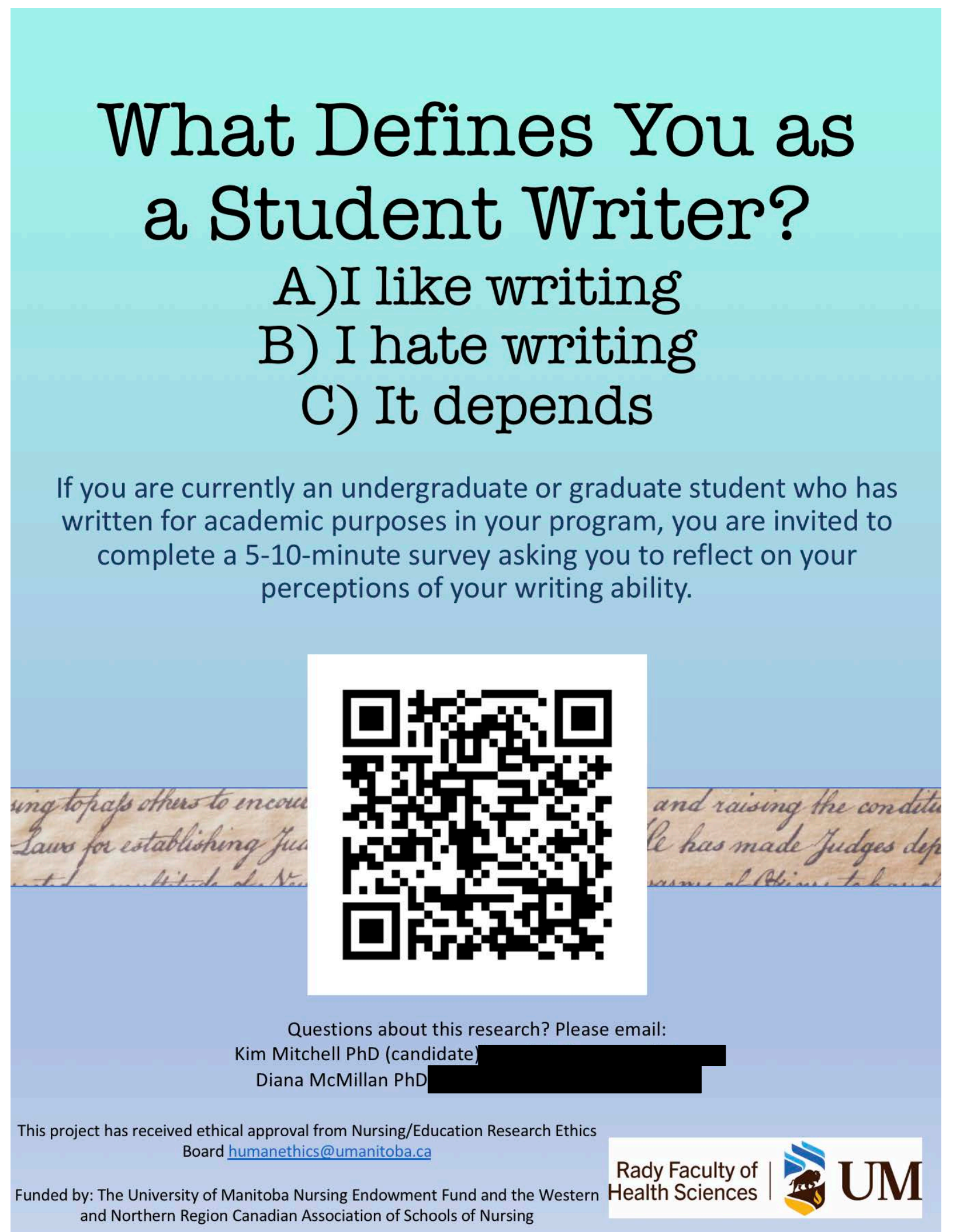

